\title{
LES CHARTES MÉDIÉVALES ENLUMINÉES DANS LES PAYS D'EUROPE CENTRALE
}

\author{
par \\ Martin ROLAND et Andreas ZAJIC
}

Toute étude sur les chartes décorées est confrontée à des limites empiriques $^{1}$ : Les archivistes et paléographes du $\mathrm{XIX}^{\mathrm{e}}$ et du début du $\mathrm{Xx}^{\mathrm{e}}$ siècle (comme leurs professeurs de diplomatique) ne s'intéressaient guère au décor des documents, de sorte que, dans les pays germanophones comme ailleurs $^{2}$, les inventaires, catalogues et éditions ne les mentionnent que rarement et de manière peu systématique. Il est donc impossible d'évaluer de manière fiable le nombre des chartes enluminées conservées dans les archives d'Europe.

L'étude qui suit, entre diplomatique et histoire de l'art, présente d'une part des objets singuliers et d'autre part des types diplomatiques auxquels l'enluminure a été appliquée en série. Commençons par quelques définitions, concernant les termes « charte », « enluminure », et nos bornes géographiques et chronologiques.

1. Les thèses principales de cet article ont été presentées à la journée d'études du 15 mai 2007 à Paris. Nous tenons à remercier Ghislain Brunel et Marc Smith de leur rigoureux travail éditorial, ainsi que Gustav Pfeifer (Südtiroler Landesarchiv/Archivio provinciale Bolzano), parmi d'autres collègues qui ont contribué à cet article par leur intérêt et leur critique. Nous préparons aussi une étude différente et plus ample, avec d'autres illustrations, « Illuminierte Urkunden des Mittelalters in Mitteleuropa », à paraître dans Archiv für Diplomatik, t. 59, 2013.

2. En France, les chartes ornées de la chancellerie royale ont attiré l'attention dès la première moitié du xix ${ }^{\mathrm{e}}$ siècle : Ghislain Brunel, « Le roi, le scribe et l'artiste : quelques réflexions sur les chartes décorées des Archives nationales », dans id., Images du pouvoir royal : les chartes décorées des Archives nationales. XIII ${ }_{-} X V^{e}$ siècle, Paris, 2005, p. 35-53, aux p. 35 et 38. Là aussi cependant on observe « un long désintérêt » à l'égard de l'enluminure des actes privés : Olivier Guyotjeannin, «Images en actes », ibid., p. 13-33, à la p. 13.

Martin Roland et Andreas Zajic, membres de l'Institut für österreichische Geschichtsforschung, collaborateurs de l'Österreichische Akademie der Wissenschaften, Institut für Mittelalterforschung, Wohllebengasse 12-14, A-1040 Wien. <Martin.Roland@oeaw.ac.at>, $<$ Andreas.Zajic@oeaw.ac.at> 
- La période étudiée est définie en amont par les plus anciens documents identifiés, en aval par une limite fixée pragmatiquement à 1500 (à quelques exceptions près) ${ }^{3}$.

- Les limites spatiales sont plus problématiques. L' « Europe centrale » est un terme certes récent et vague. Une référence historique au Saint Empire romain germanique ne conviendrait pas mieux : nous négligeons en effet (pour l'essentiel) ses parties italiennes, tandis que plusieurs pays retenus (comme la Hongrie) sont hors de ses frontières ${ }^{4}$; les Pays-Bas et la Confédération suisse, détachés de l'Empire au cours du Moyen Âge, ne seront pas non plus laissés hors du champ. Des critères de langue ou de style ne dessineraient pas des limites plus précises ni plus cohérentes. Par ailleurs, le critère géographique doit-il considérer l'auteur ou le destinataire des chartes? La question ne se pose que marginalement mais n'est pas indifférente dans le cas de diplômes impériaux pour des destinataires italiens ni surtout pour les documents curiaux ${ }^{5}$. Quant aux lettres d'indulgence, elles sont un phénomène paneuropéen, même si la plupart des originaux conservés proviennent d'Europe centrale.

- Selon une définition courante dans la diplomatique allemande, nous appelons chartes («Urkunden ») des textes de nature juridique composés en respectant certaines formes (différentes selon les dates, les lieux et les personnes). Nous nous occuperons seulement des chartes originales ${ }^{6}$, laissant de côté cartulaires et autres formes de tradition.

- Quant au terme « enluminé », les historiens de l'art l'appliquent aux manuscrits décorés, sans critère de qualité ou de richesse, du livre de luxe jusqu'au décor simplement dessiné et dépourvu de relation thématique au contenu du texte. En l'adaptant au domaine diplomatique, au sens le plus large, on prendra en compte tout élément dessiné ou peint extérieur à l'écriture du texte, portant donc sur l'écriture d'apparat, les divers symboles graphiques et signes de validation tels que le chrismon, les monogrammes ou les seings manuels ${ }^{7}$ : autant de sous-groupes particuliers peuvent ainsi

3. À bien des égards la fin du Moyen Âge marque la fin des actes enluminés, mais ils continuent plus ou moins longtemps notamment dans le cas des lettres d'armoiries et des lettres diffamatoires, dont l'apogée se situe au $\mathrm{XVI}^{\mathrm{e}}$ siècle. Même le simple dessin ornemental, ici laissé de côté, joue encore un rôle certain.

4. Par exemple les lettres d'armoiries de Hongrie ne se distinguent guère (à quelques caractéristiques près) de celles d'Autriche ou de Bohême.

5. $\mathrm{Au} \mathrm{xv}^{\mathrm{e}}$ siècle, l'enluminure des lettres d'indulgence des cardinaux et des suppliques au pape est italienne : elles sont donc omises. Âge.

6. Le support principal en est le parchemin, plus rarement le papier à la fin du Moyen

7. Graphische Symbole in mittelalterlichen Urkunden : Beiträge zur diplomatischen Semiotik, éd. Peter Rück, Sigmaringen, 1996; Peter-Johannes Schuler, Südwestdeutsche Notarszeichen, mit einer Einleitung über die Geschichte des deutschen Notarszeichen, Sigmaringen, 1976; Ellinor Reckenzaun, « Zur Kunstgeschichte des Notariatssignets in der Steiermark von 1344 bis zur Mitte des 16. Jahrhunderts », dans Mitteilungen des Steiermärkischen Landesarchivs, t. 52/53, 2004, p. 119-155, [en ligne :] www.verwaltung.steiermark.at (consulté déc. 
correspondre aux signes de validation, aux écritures d'apparat, aux initiales filigranées... Par souci d'efficacité terminologique, il faut néanmoins ajouter un second niveau, une définition plus stricte, limitée aux actes où la peinture ou le dessin jouent un rôle central, habituellement lié au contenu juridique, singularisant ainsi l'acte au sein de la production usuelle d'une chancellerie. Nous considérons donc comme chartes enluminées au sens le plus étroit les actes historiés, portant un décor relatif à leur contenu, à l'auteur, au destinataire ou au lecteur ${ }^{8}$; s'y ajoutent toutes les chartes dont le décor utilise ostensiblement une ou plusieurs couleurs. Cette définition exclut les éléments figuratifs purement ornementaux (animaux isolés, masques, etc.), dessinés à l'encre, appartenant au répertoire commun des ateliers et des chancelleries et dépourvus de signification particulière ${ }^{9}$. Inversement, elle inclut les décors peints ou dessinés non figuratifs mais d'un niveau d'exécution inhabituel ${ }^{10}$ : le caractère exceptionnel de l'acte est alors marqué par l'investissement artistique.

Il ne s'agit évidemment pas de dresser un recensement exhaustif, faute d'études préalables. Nous poursuivons cependant la compilation d'une base de données des chartes enluminées repérées, et toute indication supplémentaire sera bienvenue.

\section{Premiers exemples isolés.}

Dans une précédente publication, nous avons illustré les débuts de la production de chartes enluminées, avant la période gothique ${ }^{11}$. Le cas le

2011); Elfriede Kern, Notare und Notariatssignete vom Mittelalter bis zum Jahre 1600 aus den Beständen der staatlichen Archive Bayerns, Munich, 2008; sur les signes graphiques omis ici, Thomas Frenz, Verbale und nonverbale Kommunikation im europäischen Urkundenraum, [en ligne :] www.phil.uni-passau.de (consulté déc. 2011).

8. On désigne en effet comme « historié » un décor comportant des éléments figuratifs relatifs au contenu du texte, à l'auteur/scripteur ou au destinataire/lecteur : Christine JakobiMirwald, Buchmalerei : Terminologie in der Kunstgeschichte, $3^{\mathrm{e}}$ éd. rev., collab. M. Roland, Berlin, 2008, p. 56-57. Cette définition s'applique plus difficilement aux lettres d'armoiries, dont l'écu peut porter des figures ou de simples partitions et pièces.

9. Cette restriction pose des problèmes dans quelques cas, par exemple pour Louis de Bavière : seuls quatre originaux portent des initiales historiées. Le même enlumineur a pourtant ajouté à plusieurs pièces un décor ornemental, non historié. Il faut juger au cas par cas.

10. Exemple français : la charte de l'abbé de Chaalis (2 avril 1379, Chaalis) promettant des messes pour Charles V, somptueuse (gouache et or); Paris, Arch. nat., J 466, n ${ }^{\circ} 52$; O. Guyotjeannin, « Images... » [n. 2], p. 34 (ill.) et p. 50; G. Brunel, « Les Cisterciens et Charles V : un portrait du roi idéal dressé par les moines de Royaumont et de Chaalis », dans Annuaire-Bulletin de la Société de l'histoire de France, 2007, p. 67-92. Exemple allemand : la lettre d'indulgence de l'archevêque de Cologne de 1307 [n. 69], avec décor filigrané rouge, bleu et or.

11. A. H. Zajic, M. Roland, « Eine spätmittelalterliche Urkundenfälschung aus dem Augustiner-Chorherrenstift Dürnstein in Niederösterreich; zugleich ein Beitrag zu illuminierten Urkunden des Mittelalters », dans Archiv für Diplomatik, t. 51, 2005, p. 331-432, 
plus ancien reste la charte bien connue du 14 avril 972 , Rome, où l'empereur Otton II fixe la dot de son épouse Théophano, nièce du basileus byzantin $(i l l .1 b, 2)^{12}$. Cet acte ${ }^{13}$ au décor extraordinaire dut faire un effet considérable, dépassant à tous égards l' « horizon d'attente » des contemporains. On peut imaginer l'usage performatif de cet objet impressionnant, exhibé à Rome dans la pompe d'un mariage où se rencontrèrent les cultures occidentale et byzantine. Objet exceptionnel, la charte vise au premier chef à s'inscrire par son aspect dans la memoria, phénomène que nous retrouverons plus ou moins expressément dans tous les actes enluminés.

D'où est venue l'idée? Pour le rotulus de format large ${ }^{14}$, le fond de pour-

aux p. 394-396, [en ligne :] www.monasterium.net/Zajic_Roland.pdf (consulté déc. 2011) [ci-après : Zajic et Roland, « Urkundenfälschung »].

12. 14 avril 972, Rome; Wolfenbüttel, Niedersächsisches Staatsarchiv, 6 Urk. 11; Die Urkunden der Deutschen Könige und Kaiser, t. II/1 : Die Urkunden Otto II., Hanovre, 1888, $n^{\circ} 21$ (D O. II. 21). Étude déjà pleine de jugements pertinents (non signée) dans Die Heiratsurkunde der Kaiserin Theophanu, 972 April 14, Rom (expos., Niedersächs. Staatsarchiv), Göttingen, 1972; Dieter Matthes, Die Heiratsurkunde der Kaiserin Theophanu, 972 April 14 : Faksimile-Ausgabe..., Stuttgart, 1980; excellentes reproductions et état de la question : Kaiserin Theophanu : Begegnungen des Ostens und Westens um die Wende des ersten Jahrtausends, éd. Anton von Euw, Peter Schreiner, Cologne, 1991, 2 vol. (sur le décor, Wolfgang Georgi, «Ottonianum und Heiratsurkunde 962/972 », t. II, p. 135-160, aux p. 156-160, et ill. 2-5 aux p. 136-139; Anton von Euw, « Ikonologie der Heiratsurkunde der Kaiserin Theophanu », t. II, p. 175-191; Hiltrud Westermann-Angerhausen, « Spuren der Theophanu in der ottonischen Schatzkunst », t. II, p. 193-218, aux p. 193-201). Les auteurs se réfèrent largement à Hartmut Hoffmann, Buchkunst und Königtum im ottonischen und frühsalischen Reich, Stuttgart, 1986 (MGH, Schriften, 30), 2 vol., t. I, p. 106-122. Bon état de la question : Hans K. Schulze, Die Heiratsurkunde der Kaiserin Theophanu : die griechische Kaiserin und das römisch-deutsche Reich, 972-991, Hanovre, 2007. Informations solides sur Wikipédia, [en ligne :] de.wikipedia.org/wiki/Heiratsurkunde_der_Kaiserin_Theophanu (consulté août 2011).

13. Nous ne trancherons pas la question de savoir si la charte est un original ou, vraisemblablement, une copie de luxe ou ampliation; contre le caractère original au motif de l'absence de sceau, Carlrichard Brühl, « Purpururkunden », dans id., Aus Mittelalter und Diplomatik : gesammelte Aufsätze, Hildesheim-Munich-Zurich, 1989, t. II, p. 601-619, à la p. 616. On peut cependant penser à un scellement selon l'usage byzantin, sur des fils entourant la charte enroulée ou son étui : Otto Kresten, «Zur Chrysographie in den Auslandsschreiben der byzantinischen Kaiser », dans Römische historische Mitteilungen, t. 40, 1998, p. 139-186, aux p. 141 n. 8, et p. 179 n. 152; H. K. Schulze, Die Heiratsurkunde..., p. 39. La formule de corroboration (« manu propria roborari et anuli nostri impressione subter jussimus insigniri ») suit l'usage impérial alors que l'acte ne comporte ni signe autographe ni sceau plaqué. Mais un pareil écart entre formulaire et mode de scellement (différent ou manquant) se constate dans d'autres chartes royales et impériales.

14. Mesures selon H. K. Schulze, Heiratsurkunde..., p. 24 : 144,5 × 39,5 cm. La charte est donc plus large que les expéditions ottoniennes habituelles mais reste beaucoup plus petite que les trois lettres diplomatiques byzantines $d u$ XII $^{e}$ siècle conservées en original, longues de plus de $4 \mathrm{~m}$ : Herbert Hunger, «Schriftästhetik in den drei originalen kaiserlichen Auslandsschreiben der Komnenenzeit », dans Römische historische Mitteilungen, t. 40, 1998, p. 187-196, à la p. 190 . 
pre $^{15}$, l'encre d'or ${ }^{16}$ et l'encadrement, il y a dans l'Occident latin un modèle possible, l'acte dit Ottonianum (13 février 962, Rome; ill. 1a) ${ }^{17}$, par lequel Otton I ${ }^{\text {er }}$ confirma à l'Église romaine les privilèges concédés par Pépin en $756^{18}$ : diplôme qui à son tour (pour les caractères externes) avait au moins deux précédents, dont l'un dans l'environnement familial et politique des Ottoniens ${ }^{19}$, outre la fausse donation de Constantin ${ }^{20}$. L'écriture en or et le

15. C. Brühl, « Purpururkunden »..., p. 604-610. Contrairement aux modèles de l'Antiquité tardive et du haut Moyen Âge et aux lettres diplomatiques byzantines, la charte dotale n'est pas imprégnée de pourpre véritable mais peinte de deux couches de minium et de laque de garance.

16. Sur la chrysographie : Wilhelm Wattenbach, Das Schriftwesen im Mittelalter, 3e éd., Leipzig, 1896 (réimpr. Graz, 1958), p. 251-261; Vera Trost, Gold- und Silbertinten : technologische Untersuchungen zur abendländischen Chrysographie und Argyrographie von der Spätantike bis zum hohen Mittelalter, Wiesbaden, 1991; O. Kresten, « Zur Chrysographie... » [n. 13] (lettres diplomatiques byzantines). Sur les aspects techniques, Peter Schreiner, Doris Oltrogge, Byzantinische Tinten-, Tuschen- und Farbrezepte, Vienne, 2011, p. 50-74 (textes $\mathrm{n}^{\text {os }}$ 31-70) et p. 104-111 (commentaire); nous remercions P. Schreiner de nous avoir communiqué cette étude avant publication. L'écriture de la charte dotale est une minuscule livresque de la plus haute qualité. L'invocation et la suscription aux deux premières lignes, les deux lignes du signum et les noms de l'auteur et de son père ainsi que ceux de la destinataire et de son oncle sont en capitale « rustique » à la manière tardo-antique. H. Hoffmann, Buchkunst... [n. 12], p. 10-11, 176-177, attribue l'écriture au scriptorium de Fulda sans pouvoir identifier la main. L'utilisation d'écritures livresques pour un acte orné se retrouve ailleurs : outre les lettres d'indulgence avignonnaises en textualis formata (Alexander Seibold, Sammelindulgenzen : Ablaßurkunden des Spätmittelalters und der Frühneuzeit, Cologne-Weimar-Vienne, 2001, p. 59), voir la charte de fondation des chanoines réguliers de Dürnstein [n. 330].

17. 13 février 962, Rome; Arch. Vat., Arm. 1, Caps. III, $\mathrm{n}^{\circ} 1$; Die Urkunden der Deutschen Könige und Kaiser, t. I : Die Urkunden Konrad I. Heinrich I. und Otto I., Hanovre, 1879-1884, no 235 (D O. I. 235); W. Georgi, « Ottonianum... » [n. 12].

18. Horst Fuhrmann, « Konstantinische Schenkung und abendländisches Kaisertum », dans Deutsches Archiv für die Erforschung des Mittelalters, t. 22, 1966, p. 63-178, aux p. 126-127.

19. Lothaire, roi d'Italie, le premier mari d'Adélaïde, plus tard épouse d'Otton I'er, donna avec son père Hugues le 15 août (942), à Pavie, une charte établissant une fondation pieuse en faveur de Saint-Ambroise de Milan. L'original est perdu, mais une copie notariée du 7 juillet 1322 le décrit comme scellé d'une bulle d'or et écrit en or, probablement sur parchemin pourpre (« in corio pissis », sur peau de poisson!); W. Georgi, « Ottonianum... » [n. 12], p. 146; voir aussi Luigi Schiaparelli, I diplomi di Ugo e di Lothario, di Berengario II e di Adalberto, Rome, 1924, p. 189-193 (n 64); J. F. Böhmer, Regesta Imperii, I : Die Regesten des Kaiserreichs unter den Karolingern, 751-918 (926/962), Bd. 3 : Die Regesten des Regnum Italiae und der burgundischen Regna, Teil 3 : Das Regnum Italiae vom Regierungsantritt Hugos von Vienne bis zur Kaiserkrönung Ottos des Großen (926-962), éd. Herbert Zielinski, Vienne-Weimar-Cologne, 2006, no 1924 (bibliogr.). Cette occurrence n'est pas unique en Italie du Nord : le Liber pontificalis mentionne un acte de donation à l'encre d'or par le roi des Lombards Aripert en faveur du Saint-Siège (sous Jean VII, 705-707) : C. Brühl, « Purpururkunden »... [n. 13], p. 607-608; O. Kresten, « Zur Chrysographie... » [n. 13], p. 143 n. 10 (bibliogr.).

20. Dans les négociations sur les privilèges de l'Église romaine, comme on le rapporte en 1001 (Die Urkunden der Deutschen Könige und Kaiser, t. II/2 : Die Urkunden Otto des III., Hanovre, 1893, no 389 [D O. III. 389]), Jean XII aurait présenté une charte prétendue de 
parchemin pourpre étaient par ailleurs connus en Occident dans les manuscrits les plus solennels, en particulier dans des livres liturgiques.

Il est probable que les caractères externes des lettres diplomatiques byzantines ${ }^{21}$ influencèrent aussi l'acte dotal, le rapprochant symboliquement d'un véritable traité politique. Il faut seulement souligner que, de telles lettres byzantines, on ne conserve que trois originaux bien plus tardifs ${ }^{22}$.

Les ornements par lesquels la charte de $972(i l l .1 b)^{23}$ diffère de l'Ottonia-

Constantin, en réalité écrite par le cardinal-diacre Jean, « cognomento Digitorum mutilus », à l'encre d'or; Percy Ernst Schramm, Kaiser, Rom und Renovatio : Studien und Texte zur Geschichte des römischen Erneuerungsgedankens vom Ende des karolingischen Reiches bis zum Investiturstreit, Leipzig-Berlin, 1929, réimpr. Darmstadt, 1962, t. I, p. 161-00 et t. II, p. 65-00; H. Fuhrmann, « Konstantinische Schenkung... » [n. 18], p. 128-148; O. Kresten, « Zur Chrysographie... » [n. 13], p. 144 n.11; Kurt Zeillinger, « Otto III. und die Konstantinische Schenkung : ein Beitrag zur Interpretation des Diploms Kaiser Ottos III. für Papst Silvester II (D O. III. 389) », dans Fälschungen im Mittelalter : internationaler Kongreßs der Monumenta Germaniae Historica (München, 16.-19. September 1986), Hanovre, 1988 (MGH, Schriften, 33), t. II, p. 509-536, à la p. 525. Zeillinger suit l'opinion de Fuhrmann (p. 149-151) : le passage « preceptum aureis litteris scripsit » concernerait en réalité l'Ottonianum, ce qui n'est guère convaincant.

21. Voir le projet « Die Auslandsschreiben und Auslandsverträge der byzantinischen Kaiser » de l'Institut für Byzanzforschung der Österreichischen Akademie der Wissenschaften, [en ligne :] www.oeaw.ac.at/byzanz/aus.htm (consulté déc. 2011) et la litérature citée. Fondamental : O. Kresten, «Zur Chrysographie... » [n. 13]; plus récemment, voir la section « La lettre diplomatique », dans Byzance et le monde extérieur : contacts, relations, échanges, actes de trois séances du $X X^{e}$ Congrès international des études byzantines (Paris, 19-25 août 2001), dir. Michel Balard, Élisabeth Malamut, Jean-Michel Spieser, éd. Paule Pagès, Paris, 2005.

22. Juin 1139, avril 1141 et août 1146; Arch. Vat., Arch. Arcis, Arm. I-XVIII, nºs 402-404. Les documents sont caractérisés par le parchemin pourpre, l'écriture d'or et la forme en rouleau fermé par lacs de sceau enroulés, ne laissant aucune trace après l'ouverture, trois éléments que nous retrouvons dans l'Ottonianum et dans la charte dotale. À défaut d'originaux antérieurs, des actes perdus sont décrits dans l'historiographie : écriture à l'or en 938 ; fond de couleur (bleu ciel), écriture à l'or et sceau d'or en 947-949; pourpre, vraisemblablement, pour plusieurs lettres à partir de 1051-1052. Les originaux plus récents de l'époque comnène comportent en outre un décor dont les sources précédentes ne disent mot : Otto Kresten, « Correctiunculae zu Auslandschreiben byzantinischer Kaiser des 11. Jahrhunderts », dans Festschrift für Hermann Fillitz zum 70. Geburtstag, éd. Martina Pippal, Rudolf Preimesberger, Florentine Mütherich, Artur Rosenauer, Cologne, 1994, p. 143-162; O. Kresten, « Zur Chrysographie... » [n. 13], p. 157-177; H. Hunger, Schriftästhetik... [n. 14]. La lettre diplomatique de Saint-Denis (traditionnellement datée de 841 ou 843, mais peut-être de 827 selon Michael McCormick, « La lettre diplomatique byzantine du premier millénaire vue de l'Occident et l'énigme du papyrus de Paris », dans Byzance et le monde... [n. 21], p. 135-149), original le plus ancien, témoin de la forme tardo-antique, sur papyrus (O. Kresten, « Zur Chrysographie... », p. 153-155, 178), montre que pourpre et écriture d'or sont une innovation au temps de l'Ottonianum. La chancellerie byzantine se servait en revanche de pourpre et d'or dans les actes de nomination (kodikelloi) : le seul original décoré connu fut donné en 1109, mais la pourpre des kodikelloi est attestée dès 899 (ibid., p. 180-183). Les privilèges byzantins, dont l'Ottonianum et la charte de Théophano se rapprocheraient plus par le contenu, sont sans décor.

23. Le dictamen se rapproche de l'acte analogue délivré à Colombier le 12 décembre 
num ne s'expliquent cependant pas par ces antécédents. Les détails figuratifs de l'encadrement (bustes et animaux du bandeau supérieur) comme le décor du fond sont sans exemple dans la diplomatique médiévale. Il faut plutôt les comparer aux manuscrits de luxe et aux textiles : par exemple au poème de dédicace de la Bible de Vivien de 845 , œuvre du scriptorium de Tours ${ }^{24}$, semblable par le fond pourpre, les versets écrits à l'or et l'encadrement à médaillons.

Les médaillons aux animaux combattant arrangés par paires, qui remplissent le fond ${ }^{25}$ sont étroitement apparentés aux riches textiles byzantins ${ }^{26}$. Le combat d'animaux - griffon ou lion attaquant un quadrupède - est tout de même relativement peu fréquent dans ce domaine. Un lion mordant un onagre à la nuque est signalé dans une étoffe datant selon Anna Muthesius du viII ${ }^{\mathrm{e}}$ ou $\mathrm{IX}^{\mathrm{e}}$ siècle ${ }^{27}$; un griffon saisissant un taureau dans ses serres remplit le médaillon d'un tissu provenant de Sainte-Ursule de Cologne, qu'elle date au tournant des $\mathrm{IX}^{\mathrm{e}}$ et $\mathrm{x}^{\mathrm{e}}$ siècles ${ }^{28}$. Des reprises plus récentes (sauf de la morsure de la nuque) se trouvent aussi dans des textiles occidentaux ${ }^{29}$. Les motifs figuratifs en fond d'une page d'écriture sont exception-

937 pour Adélaïde, plus tard mère d'Otton II, par son premier époux Lothaire d'Italie avec son père Hugues : W. Georgi, « Ottonianum... » [n. 12], p. 148-149; J. F. Böhmer, Regesta Imperii..., I/3 [n. 19], no 1783. Sur le rapport avec Adélaïde, voir aussi n. 19.

24. Paris, Bibl. nat. Fr., ms. lat. 1; M. Roland, «Zierschriften und Miniaturen als Mittel der "Selbstdarstellung" von Stiftern », dans Régionalisme et internationalisme : problèmes de paléographie et de codicologie du Moyen Âge, actes du XVe colloque du Comité international de paléographie latine (Vienne, 13-17 septembre 2005), ed. Otto Kresten, Franz Lackner, Vienne, 2008, p. 203-225, aux p. 208-210. Die Heiratsurkunde... [n. 12], p. 15, et H. Hoffmann (Buchkunst... [n. 12], p. 103-116, spéc. p. 112 et 114) ont indiqué des modèles tourangeaux.

25. Quatorze médaillons plus deux demi-médaillons au bas emplissent le fond. Le texte se termine dans le tiers supérieur des derniers médaillons entiers. Sans doute a-t-on réservé en préparant le fond un espace d'écriture plus étendu que nécessaire, sans compter qu'on a pu prévoir un sceau plaqué, alternatif à la solution « byzantine » décrite ci-dessus.

26. Zajic et Roland, «Urkundenfälschung » [n. 11], p. 395, n. 90. Synthèse récente, Anna Muthesius, Byzantine silk weaving AD 400 to AD 1200, Vienne, 1997. Sur ces soieries comme cadeaux diplomatiques byzantins en Occident, ead., Studies in Byzantine and Islamic silk weaving, Londres, 1995, p. 165-172 (« Silken diplomacy »), p. 201-215 (« The role of Byzantine silks in the Ottonian Empire »), p. 235-238; Peter Schreiner, « Diplomatische Geschenke zwischen Byzanz und dem Westen ca. 800-1200 : eine Analyse der Texte, mit Quellenanhang », dans Dumbarton Oaks Papers, t. 58, 2004, p. 251-282.

27. Ibid., p. 174 (M 31, ill. 25a). Inspiration plus lointaine : le catalogue Die Heiratsurkunde... [n. 12], p. 49 et ill. p. 88, présente une coupe d'argent sassanide où les poses des animaux sont remarquablement semblables aux médaillons à lions de la charte.

28. A. Muthesius, Byzantine silk weaving..., p. 50-52, 179 (M 47, ill. 75b).

29. Autrefois à Saint-Géréon de Cologne, aujourd'hui partagés entre divers musées; bonne ill. sur Wikipédia : en.wikipedia.org/wiki/Cloth_of_St_Gereon (consulté déc. 2011); Ornamenta ecclesiae: Kunst und Künstler der Romanik in Köln (expos., Schnütgen-Museum), éd. Anton Legner, Cologne, 1985, t. II, p. 236 (E 29, par L. von Wilkens; Cologne, troisième quart du XI ${ }^{\mathrm{e}}$ siècle); A. Muthesius, Byzantine silk weaving..., p. 199-200 (M. 110). Sur l'origine occidentale, L. von Wilkens et A. Muthesius, Studies..., p. 207. Ici et dans Byzantine silk weaving..., p. 54, l'auteur étudie les relations avec la charte de Théophano. 
nels tant en Orient ${ }^{30}$ qu'en Occident ${ }^{31}$, et même le décor géométrique sur fond pourpre, qui contrarie évidemment la lecture du texte, est rare.

La combinaison d'éléments décoratifs propre à la charte de Théophano semble donc être une solution ad hoc pour un acte exceptionnel. (Hartmut Hoffmann a proposé d'identifier l'enlumineur avec le maître du Registrum Gregorii ${ }^{32}$, mais l'analyse stylistique contredit l'hypothèse.) La confrontation de deux sphères culturelles et politiques justifie le caractère exceptionnel du document. Une telle rencontre se produira à nouveau bien plus tard, aux origines d'un nouveau genre d'actes enluminés au XIV siècle.

La charte de Théophano resta longtemps un prototype sans suite. Les $\mathrm{XI}^{\mathrm{e}}$ et $\mathrm{XII}^{\mathrm{e}}$ siècles sont en Europe centrale - et au-delà, à notre connaissance - presque complètement vides de chartes enluminées ${ }^{33}$. Dans les territoires germanophones de l'Empire, on peut seulement citer une charte de fonda-

30. O. Kresten, «Zur Chrysographie... » [n. 13], p. 154 et n. 44, n'exclut pas une telle décoration des lettres diplomatiques byzantines contemporaines.

31. Die Heiratsurkunde... [n. 12], p. 47 (n 37) et ill. p. 87, cite (d'après F. Mütherich) un évangéliaire de Quedlinburg originaire de la Saxe du $\mathrm{x}^{\mathrm{e}}$ siècle (New York, Morgan Library \& Museum, M 755). Le fond pourpre de l'écriture à l'or est structuré assez sommairement par des ornements végétaux.

32. H. Hoffmann, Buchkunst... [n. 12], p. 103-116.

33. Citons en France la donation de l'abbé Raoul au chapitre cathédral de Clermont (octobre 1021), qui montre avant le texte un buste de l'auteur à la plume : Arch. dép. Puyde-Dôme, 3 G, armoire 18, sac A, cote 14; O. Guyotjeannin, « Images... » [n. 2], p. 13-33, aux p. 21-22 (ill.); id., «Penuria scriptorum : le mythe de l'anarchie documentaire dans la France du nord ( $\mathrm{x}^{\mathrm{e}}$-première moitié $\mathrm{du} \mathrm{xI}^{\mathrm{e}}$ siècle) 》, dans Bibliothèque de l'École des chartes, t. 155, 1997, p. 11-44, aux p. 24-26, 42-44 et ill. p. 4. En 1028, fut donné à Bari un acte de mariage, comportant au centre du texte une arcature peinte encadrant les époux : Bari, Arch. Capitolo metropolitano, perg. 14; reprod., Medioevo : la chiesa e il palazzo, atti del convegno internazionale di studi (Parma, 20-24 settembre 2005), éd. Arturo Carlo Quintavalle, Milan, 2007, p. 242. Le xiI ${ }^{\mathrm{e}}$ siècle livre une charte de Malcolm IV roi d'Écosse, de 1159-1160 (Elizabeth Danbury, « Décoration et enluminure des chartes royales anglaises au Moyen Âge », dans le présent fascicule), et le chirographe de Mathieu III, comte de Beaumont-sur-Oise, et de l'abbé Geoffroi de Saint-Martin de Pontoise, avec le crucifix pour devise, en 1177 (Paris, Arch. nat., J 168, no 2; Brigitte Miriam Bedos-Rezak, « Cutting edge : the economy of mediality in twelfth-century chirographic writing », dans Das Mittelalter : Perspektiven mediävistischer Forschung, t. 15, 2010, p. 134-161 [excessivement spéculatif]; Pierre Bureau, « Couper le corps du Christ en deux : un chirographe imagé du XII ${ }^{\mathrm{e}}$ siècle », dans Revue française d'héraldique et de sigillographie, t. 71-72, 2001-2002, p. 153-154), et l'acte de fondation de la confrérie de Saint-Martin du Canigou, 2 avril 1195, dont la partie supérieure est emplie de deux scènes : le Christ trônant entre les symboles des évangélistes, la Vierge et saint Martin, et une scène liturgique (Paris, Bibl. École nat. sup. des beaux-arts, ms. 38); Walter Cahn, Romanesque manuscripts : the twelfth century, Londres, 1996 (A survey of manuscripts illuminated in France), t. I, p. 66-67, et t. II, ill. 124; Patricia Stirnemann, « L'illustration du cartulaire de Saint-Martin-du-Canigou », dans Les cartulaires : actes de la table ronde organisée par l'École nationale des chartes et le GDR 121 du CNRS (Paris, 5-7 décembre 1991), ed. O. Guyotjeannin, Laurent Morelle, Michel Parisse, Paris, 1993, p. 171-178. Voir maintenant dans le présent fascicule l'article de Robert A. Maxwell, « Les chartes décorées à l'époque romane ». 
tion produite vers 1200 sous le nom du roi Dagobert I $^{\text {er }}$ par les moines de Saint-Pierre d'Erfurt, non enluminée mais conservée dans une enveloppe de parchemin montrant en grand l'auteur prétendu de l'acte et en plus petit, en buste, deux autres personnes participant à la fondation, le tout en dessin à la plume colorié ${ }^{34}$.

$\mathrm{Au} \mathrm{XIII}^{\mathrm{e}}$ siècle, on rencontre une charte de la confrérie Saint-Loup de Cologne, de 1246-1247 (ill. 3a) ${ }^{35}$. La communauté - fondée selon le message de l'image pour douze prébendiers par saint Cunibert, évêque de Cologne mort en 660 ou 663 - y précisait les services mémoriaux dus à l'occasion des funérailles des archevêques de Cologne, des capellarii (chefs de la chancellerie archiépiscopale) qui probablement étaient aussi magistri de la confrérie ${ }^{36}$, et des membres eux-mêmes. Il ne s'agit donc pas des statuts de la confrérie, mais seulement des obligations de la prière commémorative, appelée fraternitas. Ce règlement remplit le tiers central du parchemin en hauteur, et au-dessous sont placés deux blocs de texte nettement séparés (à gauche une liste des membres ${ }^{37}$, à droite la confirmation de l'archevêque ${ }^{38}$ ), manifestement de la même main ${ }^{39}$. La fraternitas est datée de novembre 1246, la confirmation de février suivant ${ }^{40}$.

Le dessin à la plume colorié placé en tête est encadré, le bandeau supérieur étant remplacé par six arcades trilobées évoquant un intérieur sacré. On voit dessous saint Cunibert sur un faldistoire, devant lui le (premier)

34. Magdeburg, Landeshauptarchiv Sachsen-Anhalt, Rep. U 15, Tit. IV, $\mathrm{n}^{0}$ 1a; Christine Sauer, Fundatio und Memoria : Stifter und Klostergründer im Bild, 1100 bis 1350, Göttingen, 1993, p. 169-170 et ill. 36.

35. Cologne, Historisches Archiv der Stadt Köln, U 3/184; Harald Brockmann, « Zwei kölnische miniierte Urkunden aus der Mitte des 13. Jahrhunderts », dans Wallraf-RichartzJahrbuch, t. 3-4, 1926-1927, p. 113-122; Hanns Swarzenski, Die lateinischen illuminierten Handschriften des XIII. Jahrhunderts in den Ländern an Rhein, Main und Donau, Berlin, 1936, 2 vol., Texte, p. 14 et 88 (n 4), et Planches, ill. 34; Richard Knipping (éd.), Die Regesten der Erzbischöfe von Köln im Mittelalter, t. III : 1205-1304, Bonn, 1909, p. 194-195 (n 1376); Benjamin Laqua, « Erzbischof, Bruderschaft und Hospital in Köln : die Lupusbrüder während des hohen Mittelalters », dans Mittelalterliche Bruderschaften in europäischen Städten : Funktionen, Formen Akteure = Medieval confraternities in European towns : functions, forms, protagonists, ed. Monika Escher-Apsner, Francfort, 2009, p. 110-141, aux p. 121-136.

36. B. Laqua, ibid., p. 125-126, considère le «magister » dont le texte fait mention comme une fonction particulière, mais comme il est nommé « dictus magister » juste après la mention du « capellarius », il doit s'agir de la même personne.

37. En tête de la liste des confrères, l'archevêque Conrad de Hochstaden et son chapelain Gérard de Müllenark; la liste fut mise à jour au moins jusqu’à la fin du XIII siècle.

38. De février 1247. Le sceau de l'archevêque fut appendu sur lacs de soie à la marge inférieure, sans repli.

39. Michael Matscha, Heinrich I. von Müllenark, Erzbischof von Köln (1225-1238), Siegburg, 1992, p. 531-532, attribue la charte au scribe et notaire archiépiscopal Magister Gottfried, nommé parmi les membres.

40. M. Matscha date à tort la charte (suivant H. Brockmann, « Zwei kölnische... » [n. 35], p. 114) de février 1248. 
maître de la confrérie (CAPELLARIUS) agenouillé. Il reçoit du saint un phylactère inscrit de deux hexamètres rimés : Que bene collegi, sua cuique stipendia dando, / ut decet, esto gregi pastor bonus, hoc tibi mando. Au-dessous, les douze confrères en buste, mains jointes en prière ${ }^{41}$. L'encadrement qui entoure le texte sous l'image établit un lien visuel entre la scène et le corps de la charte ${ }^{42}$.

Le style de dessin est celui de la transition du roman vers le gothique dans la région rhénane. Les plis pâteux et plats ressemblent fort à ses formes les plus anciennes (《Muldenfaltenstil »). Comme exemples voisins par la technique graphique et le milieu culturel, citons une scène de Barlaam et Josaphat, vraisemblablement d'Altenburg (vers 1220-1240) ${ }^{43}$ et la Bible de Bredelar (1238-1241) ${ }^{44}$; comme exemple plus récent, les fragments d'un antiphonaire au Victoria \& Albert Museum (vers $1250 ;$ ill. 3 b) ${ }^{45}$.

La représentation du saint évêque comme fondateur se réfère au passé illustre de ce siège, auquel les confrères de 1246 aussi bien que leurs successeurs pouvaient s'identifier. La charte enluminée visait plutôt à des fins identitaires, internes à un groupe d'élite ${ }^{46}$, qu'à la communication externe ${ }^{47}$.

41. Les douze bustes ne montrent, à part le « capellarius » agenouillé, ni tonsure ni vêtement liturgique.

42. Les actes avec encadrements ne sont pas complètement isolés. Outre les deux pièces ottoniennes [n. 17], citons un exemple anglais de 1291 (E. Danbury, « Décoration... » [n. 33], n. 13) et deux lettres d'indulgence de 1307 [n. 69] et 1314 [n. 71].

43. Düsseldorf, Landesbibl., Hs. B 67, fol. 41v; H. Swarzenski, Die lateinischen... [n. 35], Texte, p. 15, 88-89 ( $\mathrm{n}^{\circ}$ 6), et Planches, ill. 35; Universitäts- und Landesbibl. Düsseldorf, Kataloge der Handschriftenabteilung, t. I : Die mittelalterlichen Handschriften der Signaturengruppe B, $1^{\text {re }}$ partie : Eef Overgaauw, Joachim Ott, Gerhard Karpp, Ms. B 1 bis B 100, Wiesbaden, 2005, p. 219-227, à la p. 221 (probablement Altenburg, $1^{\text {er }}$ quart du XIII ${ }^{\mathrm{e}}$ siècle). L'acte et le manuscrit sont analysés comme produits d'un égal niveau stylistique par Judith H. Oliver, Gothic manuscript illumination in the diocese of Liege (c. 1250-c. 1330), Louvain, 1988, p. 135.

44. Darmstadt, Hessische Landes- und Hochschulbibl., Hss. 824, 825, 1993; H. Swarzenski, Die lateinischen..., Texte, p. 15, 96-98 (n 13), et Planches, ill. 163, 187; Die Handschriften der Hessischen Landes- und Hochschulbibliothek Darmstadt, t. IV : Kurt Hans Staub, Bibelhandschriften; Hermann Knaus, Ältere theologische Texte, Wiesbaden, 1979, p. 69-74.

45. Londres, Victoria \& Albert Museum, Prints, Drawings and Paintings Collection, $\mathrm{n}^{\text {os }} 1517$ et 1520; H. Swarzenski, Die lateinischen..., Texte, p. 29-30, 108 ( $\mathrm{n}^{\circ}$ 22), et Planches, ill. 253, [en ligne :] http://collections.vam.ac.uk/item/O122522/manuscript (consulté oct. 2011). L'appartenance à cet antiphonaire du no 1519 (omis par Swarzenski) est peu claire; le décor montre en tout cas deux mains différentes.

46. La confrérie recrutait dans un milieu limité : l'originelle communauté des (prébendiers) pauvres de l'hôpital de Saint-Loup devint une société de memoria étroitement liée à l'archevêque.

47. La charte fut adaptée, d'emblée ou après coup, pour être suspendue, que ce soit un mode de conservation ou (comme le pense B. Laqua, « Erzbischof... », [n. 35], p. 124) d'affichage public, dans l'hôpital ou dans la cathédrale. Des détails comparables, languettes ou œillets en haut du parchemin, restent à interpréter pour plusieurs lettres d'indulgence : l'usage de les suspendre dans les églises est invoqué par A. Seibold, Sammelindulgenzen... [n. 16], p. 113. 
Toujours au milieu du XIII ${ }^{\mathrm{e}}$ siècle, fut produite une feuille de parchemin presque carrée portant des notes sur l'acquisition de biens de la confrérie des Rois mages de Cologne, qui illustre l'éventail potentiel des styles. Il ne s'agit pas d'une charte enluminée au sens défini plus haut, mais d'un exceptionnel « cartulaire » miniature, qui consiste - du moins aujourd'hui - en une seule page, mais était visiblement destiné à être continué. Nous ne nous attarderons donc pas à cette pièce, malgré la brillante miniature centrale des Mages, peinte dans un style rhénan bien caractérisé («Zackenstil ») et accompagnée de huit textes à droite et au-dessous ${ }^{48}$.

La première moitié du XIv siècle est marquée par deux innovations diplomatiques qui comportent toutes deux une propagation des actes en masse : les lettres d'indulgence enluminées et les concessions d'armoiries. Commençons par le type qui apparaît le plus anciennement.

\section{LES LETTRES D'INDULGENCE.}

Dès le $\mathrm{XII}^{\mathrm{e}}$ siècle la contribution financière des fidèles aux dépenses de construction et d'aménagement des églises a été sollicitée par la délivrance d'indulgences. À partir de 1284 environ, cette tradition aboutit à un flot d'indulgences « collectives », accordées par un groupe de plusieurs évêques curiaux ${ }^{49}$. Le pénitent y gagnait habituellement, comme dans le cas des indulgences « simples », d'un auteur unique, une indulgence de quarante ou cent jours, à condition par exemple d'assister à la messe à certaines dates dans telle église. Cependant on inclut souvent une formule ambiguë multipliant le gain par le nombre des auteurs ${ }^{50}$ - de deux à trente et un! -, ce

48. Hambourg, Kestner-Museum, Hs. 3986; H. Brockmann, « Zwei kölnische... » [n. 35]; H. Swarzenski, Die lateinischen... [n. 35], Texte, p. 16 et 96, et Planches, ill. 157; Helmar Härtel, Handschriften des Kestner-Museums zu Hannover, Wiesbaden, 1999, p. 106-108, [en ligne :] www.manuscripta-mediaevalia.de/hs/katalogseiten/HSK0518_b106_jpg.htm (consulté déc. 2011); Heiliges Römisches Reich Deutscher Nation 962 bis 1806, von Otto dem Großen bis zum Ausgang des Mittelalters (expos., Magdebourg et Berlin), dir. Matthias Puhle, Claus-Peter Hasse, Dresde, 2006, t. II, p. 232-233 (no IV.40, par Wolfgang Schmid, et ill. coul.). Seule la première placée immédiatement sous la miniature commence par une invocation succincte, les autres textes par « Notum sit universis » ou « omnibus ».

49. Sur les indulgences, Nikolaus Paulus, Geschichte des Ablasses im Mittelalter, vom Ursprunge bis zur Mitte des 14. Jahrhunderts (Paderborn, 1922), 2e éd. augm. par Thomas Lentes, Darmstadt, 2000, 2 vol. (sur les constructions, t. II, p. 182-184); id., Geschichte des Ablasses am Ausgang des Mittelalters (Paderborn, 1923), 2e éd., Darmstadt, 2000 (sur la visite d'églises et les donations pieuses, p. 362-366, et sur le financement par les indulgences, p. 379-394).

50. Hippolyte Delehaye, « Les lettres d'indulgence collectives », dans Analecta Bollandiana, t. 44, 1926, p. 342-379, t. 45, 1927, p. 97-123, 323-344, et t. 46, 1928, p. 149-157, 287-343, au t. 45, p. 102; Otto Homburger, Christoph von Steiger, « Zwei illuminierte Ablassbriefe in Bern », dans Zeitschrift für schweizerische Archäologie und Kunstgeschichte, t. 17, 1957, p. 134-158 et pl. 39-50, à la p. 135 [ci-après : Homburger et Steiger, « Ablass- 
qui explique la popularité croissante des indulgences collectives ${ }^{51}$. Parmi les destinataires, on constate la prépondérance de l'Europe centrale ${ }^{52}$.

Alexander Seibold, auteur d'une étude diplomatique sur les indulgences collectives ${ }^{53}$, estime que furent délivrées entre 1281 et 1364 environ 4000 lettres d'indulgences collectives épiscopales, et entre 1404 et 1517 au moins 2000 lettres d'indulgences collectives de cardinaux, produits « de masse » issus du milieu curial ${ }^{54}$. Seibold n'étudie guère la proportion des exemplaires enluminés ni l'apparition (1322-1323) des initiales historiées, s'en rapportant pour cet aspect aux travaux antérieurs ${ }^{55}$.

Dès l'essor des concessions d'indulgence dans les années 1280, on trouve des chartes à décor graphique restreint, analogues à l'usage général de la diplomatique curiale ${ }^{56}$. L'initiale fourchue d'une concession d'indulgence pour Altenburg ${ }^{57}$ s'étend sur le double de la hauteur d'une ligne; la conces-

briefe »]; A. Seibold, Sammelindulgenzen... [n. 16], p. 41, 105, 190-191. Cette interprétation est confortée par les totaux parfois notés au dos par les destinataires, et par d'énormes totaux autrement inexplicables, par exemple en 1463 dans une inscription de l'église SaintSigismond de Bruck an der Mur (Styrie) : «Item su(m)ma des antlas pey dem / [g]egenburtigen gotzhaus pringt / [f] untczigtausent tag vnd ach/thundert tag Xx tag » (Somme des indulgences accordées à la présente église, 50820 jours); Karl Amon, « Die Ablaßinschrift von St. Ruprecht bei Bruck », dans Blätter für Heimatkunde, t. 42, 1968, p. 130-133 (reprod.; transcription fautive).

51. Liste provisoire chez H. Delehaye, « Les lettres d'indulgence... »; t. 45, p. 109-110 : en 1284, croissance rapide, à 16 actes contre 3 en 1283, puis environ 100 pièces par décennie (apogée en 1300, puis diminution).

52. Christopher R. Cheney, « Illuminated collective indulgences from Avignon », dans Palaeographica, diplomatica et archivistica : studi in onore di Giulio Battelli, Rome, 1979, t. II, p. 353-373 (trois lettres conservées en Angleterre); Patrick N. R. Zutshi, « Collective indulgences from Rome and Avignon in English collections », dans Medieval ecclesiastical studies in honour of Dorothy M. Owen, éd. Michael J. Franklin, Christopher HarperBill, Woodbridge, 1995, p. 281-293, à la p. 284. Voir aussi Joseph Rest, « Illummierte [sic] Ablaßurkunden aus Rom und Avignon aus der Zeit von 1282-1364 », dans Abhandlungen aus dem Gebiete der mittleren und neueren Geschichte und ihrer Hilfswissenschaften : eine Festgabe zum siebzigsten Geburtstag Geh. Rat Prof. Dr. Heinrich Finke gewidmet, Münster, 1925, p. 147-168, à la p. 149.

53. A. Seibold, Sammelindulgenzen... [n. 16] (bibliogr.). Exemplaire sur les formules, auteurs, destinataires et expédition, mais rapide sur l'enluminure (p. 70-87).

54. A. Seibold (ibid., p. 105) parle de « rasch hergestellte Massenware [...] von der Peripherie der Kurie »; H. Delehaye, « Les lettres d'indulgence... » [n. 50] compte environ 970 actes (originaux, copies ou autres).

55. Leo Santifaller, « Über illuminierte Urkunden », dans Kunstgeschichtliche Studien, Dagobert Frey zum 23. April 1943 von seinen Kollegen, Mitarbeitern und Schülern, éd. Hans Tintelnot, Breslau, 1943, p. 218-233, à la p. 221, et O. Guyotjeannin, « Images... » [n. 2], p. 24, citent la période 1322-1364. Les années 1323-1364 se trouvent dans A. Seibold, Sammelindulgenzen..., p. 195, qui suit J. Rest, « Illummierte Ablaßurkunden... » [n. 52].

56. Les exemples suivants sont tirés de la base de données monasterium.net, où beaucoup sont accompagnés d'un commentaire artistique.

57. 9 mars 1284, Orvieto; Altenburg, Stiftsarchiv. 
sion accordée à la chapelle de Gerolding, trois ans après ${ }^{58}$, double encore la hauteur de l'initiale sans en changer le décor. Trois ans après, le même peintre d'initiales, élargissant fortement l'initiale, produit pour la première fois un grand espace intérieur vide ${ }^{59}$. Peut-être s'inspirait-il d'un collègue qui en 1287 et 1288 dessina deux initiales entièrement ornées à l'intérieur ${ }^{60}$. Cette main est vraisemblablement aussi responsable d'une charte de l'abbaye bénédictine du Schottenkloster à Vienne (1296) ${ }^{61}$, où le répertoire ornemental est enrichi de masques de profil et d'animaux stylisés, et dont la première ligne entière est accompagnée de filigranes très délicats (ill. 4a). L'année suivante, une autre concession d'indulgence pour le Schottenkloster fut ornée par un autre dessinateur $(i l l .4 b)^{62}$. Dans les montants de l'initiale $U$ haute de quatre lignes sont tracés en réserve des rinceaux feuillus; l'intérieur est empli de filigranes rouges (« Knospenfleuronnée »), différents de ceux que nous venons de décrire et correspondant bien au développement du filigrane en Autriche sous influence française ou plus généralement occidentale. Il est difficile de dire si celui-ci fut comme ailleurs ajouté chez le destinataire ${ }^{63}$, parce que le reste du premier mot (UNIUERSIS) ne fut pas réalisé - autre innovation - de la même encre que le texte, mais en lettres d'apparat alternativement rouges et bleues (une autre initiale bleue se trouve dans le texte) : l'usage de couleurs, inhabituel dans une charte, était donc prévu d'emblée.

Ces exemples montrent d'une part une tendance à l'agrandissement des initiales et à leur enrichissement graphique, d'autre part une remarquable variété de formes et de mains. Cela vaut jusqu'à 1323, même si on peut former des groupes d'initiales homogènes ${ }^{64}$. À cette date, citons encore une indulgence collective accordée en 1323 par deux évêques, André de Bar et François de Ceneda, aux moniales du prieuré anglais de Maiden Bradley

58. 14 mars 1287, Rome; Vienne, Haus-, Hof- und Staatsarchiv, Allgemeine Urkundenreihe, sub dato.

59. 23 octobre 1290, Orvieto; Heiligenkreuz, Stiftsarchiv.

60. 1287 (sans jour), Rome; Altenburg, Stiftsarchiv; ou 1288 (sans jour), Rieti; Vienne, Schotten, Stiftsarchiv, 01.Urk 1288.1 (anc. : Scr. 66 Nr. 1). La deuxième charte comporte un décor de filigrane à spirales comparable à celui d'au moins une autre charte du pontificat de Nicolas IV (31 août 1288; Salzburg, Erzbischöfliches Archiv).

61. 1296 (sans jour), Rome; Vienne, Schotten, Stiftsarchiv, 01.Urk 1296 (anc. : Scr. 66 Nr. 4).

62. 1297 (sans jour), Rome; ibid., 01.Urk. 1297 (anc. : Scr. 66 Nr. 10).

63. Cf. la lettre d'indulgence accordée aux Dominicains de Clermont en 1288 [25 décembre]-1289 [22 février], présentant un espace vide pour l'initale $U$ qui ne fut pas exécutée (Arch. dép. Puy-de-Dôme, 27 H); Pierre-François Fournier, « Quelques nouvelles affiches d'indulgence des ХIII $^{\mathrm{e}}-\mathrm{XVI}^{\mathrm{e}}$ siècles », dans Bibliothèque de l'École des chartes, t. 104, 1943, p. 101-114, aux p. 104-106.

64. L'intérieur des initiales reste normalement vide; seule exception connue, l'indulgence pour les Cisterciens de Zwettl, avec initiale emplie de demi-palmettes symétriques : 1300 (sans jour), Rome; Zwettl, Stiftsarchiv. 
(Wiltshire) ${ }^{65}$. Les ornements en réserve dans les deux hastes de l'initiale et l'antenne caractéristique en haut à gauche, combinant trois rondelles avec deux lignes croisées, sont des éléments qui persisteront dans la phase suivante.

La première lettre d'indulgence proprement enluminée (historiée) date du 11 mai 1323 (Avignon), et fut accordé à la collégiale Saint-Martin de Picquigny (ill. 5) ${ }^{66}$. L'initiale $U$ contient une sainte Face (Vera Ikon) portant les cheveux et la barbe du type dit à trois mèches en pointe (« Dreizipfeltyp »). Ce type est représenté par bon nombre de lettres d'indulgence collectives jusqu'en 1327. Les montants de l'initiale s'écartent du schéma antérieur pour former deux tours crénelées de trois niveaux ${ }^{67}$.

D'où venait l'idée d'ajouter des motifs figurés à l'attrait visuel des lettres d'indulgence, qui auparavant s'imposaient surtout par leurs vastes dimensions ${ }^{68}$ ? Peut-être fut-elle inspirée par les larges espaces ainsi laissés vides? Il faut plutôt invoquer : $1^{\circ}$ les concessions d'indulgence accordées individuellement par des évêques de la région rhénane, semblablement décorées; $2^{\circ}$ le modèle de la Curie romaine, où se développa ce motif de la sainte Face.

Le 28 décembre 1307, l'archevêque de Cologne, Henri de Virneburg, accorda à l'évêque, au clergé, à la commune et au peuple de Florence une charte à l'occasion de la translation de deux reliques de crâne des Onze Mille Vierges, provenant de la collégiale Sainte-Ursule de Cologne (ill. 6 a $)^{69}$. Aux pénitents qui visiteraient l'église ou les églises destinées à abriter ces reliques

65. 17 mars 1323, Avignon; Londres, British Library, Harley charter 43.A.9; Carole Rawcliffe, Leprosy in medieval England, Woodbridge, 2006, p. 323 (ill. 34; le couvent est appelé par erreur « a leprosarium for female religious »); Robert N. Swanson, Indulgences in late medieval England: passports to Paradise?, Cambridge, 2007, p. 40 (ill. 1).

66. 11 mai 1323, Avignon; Arch. dép. Somme, 18 G SC 13, [en ligne :] http://archives. somme.fr/ark:/58483/a011308867883TV4Log (consulté juin 2011); Joseph Estienne, « Une affiche d'indulgence de 1323 », dans Bibliothèque de l'École des chartes, t. 84, 1923, p. 428-430 ( " tête du Christ entre deux portes fortifiées »); Homburger et Steiger, «Ablassbriefe » [n. 50], p. 146, n. 5; P.-F. Fournier, « Quelques nouvelles affiches... » [n. 63], p. 107. La charte montre apparement des traces de suspension (?). Selon l'exposé, l'impétrant serait le seigneur de Picquigny et avoué du couvent, Robert de Picquigny. Donc l'indulgence comprend aussi les fidèles qui prient pour Robert et sa famille ou qui visitent la sépulture de ses parents Jean de Picquigny, vidame d'Amiens (†1304), et Marguerite de Beaumetz.

67. L'ancienne collegiale était dans l'enceinte du château de Picquigny, mais on ne saurait en déduire la motivation du décor inhabituel. En tout cas cette innovation (contrairement à l'introduction de la sainte Face) resta isolée.

68. A. Seibold, Sammelindulgenzen... [n. 16], p. 57, estime que les lettres d'indulgence épiscopales d'avant 1323, sans décor, étaient déjà conçues pour frapper le public, fonction renforcée par l'image.

69. 28 décembre 1307, Cologne; Florence, Arch. di Stato, Diplomatico, S. Pier Maggiore, [en ligne :] www.archiviodistato.firenze.it/pergasfi/ (consulté mars 2013); Armand Grunzweig, « Une lettre d'indulgence enluminée d'Adolphe de La Mark évêque de Liège (1315) », dans Bulletin de l'Institut historique belge de Rome, t. 10, 1930, p. 141-153, à la p. 143; A. Seibold, Sammelindulgenzen..., p. 195-196; Wilhelm Kisky, Die Regesten der Erzbischöfe 
furent accordés quarante jours d'indulgence et une carène à diverses fêtes ${ }^{70}$. Un rôle décisif dans la translation revenait au marchand florentin Donato di Niccolò Biliotti, membre de la compagnie de commerce des Peruzzi ${ }^{71}$, auquel l'archevêque avait fait don des deux bustes reliquaires. Le parchemin, écrit en lettre de forme (textualis formata), présente une initiale filigranée bleu et or et un délicat encadrement en filigrane bleu et rouge, type de décor non figuratif omniprésent dans les livres : on peut établir un lien direct avec l'atelier de Cologne qui décora le graduel de Wettingen (ill. 6b) ${ }^{72}$.

Proche par la forme et le contenu, citons une lettre délivrée en 1315 par l'évêque de Liège, Adolphe (VIII) de La Marck (ill. 7, 8a-b), suffragant de Cologne, écrite en minuscule diplomatique mais munie d'une initiale historiée ${ }^{73}$. L'auteur y vidime un acte de son métropolitain Henri de Virneburg, du 30 septembre 1314 (Cologne), indiquant que l'archevêque avait de

von Köln im Mittelalter, t. IV : 1304-1332, Bonn, 1915, p. 485 (n 2032). Le sceau est perdu, les lacs de soie rouges et verts sont toujours dans le repli.

70. Clause de réserve usuelle : « dummodo diocesani consensus accedat ».

71. La désignation « dilectus noster Donatus Nicholai mercator noster de societate Peruciorum de Florentia » a suscité des spéculations sur l'existence d'une filiale des Peruzzi à Cologne, rejetées par Kurt Weissen, « Florentiner Kaufleute in Deutschland bis zum Ende des 14. Jahrhunderts », dans Zwischen Maas und Rhein : Beziehungen, Begegnungen und Konflikte in einem europäischen Kernraum von der Spätantike bis zum 19. Jahrhundert, Versuch einer Bilanz, éd. Franz Irsigler, Trèves, 2006, p. 363-401, à la p. 394. Dans une autre lettre d'indulgence de l'archevêque de Cologne, datée du 30 septembre 1314 (voir plus bas), Donato est nommé « servitor noster », sans doute comme une sorte de fournisseur. A. Grunzweig, « Une lettre... » [n. 69], p. 141, fait de lui « un des banquiers attitrés de l'archévêque » et le rattache par ses armes à la famille des Biliotti « da Vicchio » du popolo de Santa Croce (p. 146-148). Voir aussi id., « Note supplémentaire sur la lettre d'indulgence enluminée d'Adolphe de La Marck », dans Bulletin de l'Institut historique belge de Rome, t. 13, 1932, p. 295. Donato exécuta des paiements auprès de la curie d'Avignon en 1322 et 1328, donc (coïncidence?) au moment de la naissance des lettres d'indulgence curiales enluminées. Lui-même ou un homonyme, habitant de San Gimignano, y testa le 6 septembre 1340 : Anna Margherita Vallaro, «Considerans fragilitatem humanae naturae... » : testaments et pratique testamentaire à San Gimignano de 1299 à 1530, Berne, 2005, p. 118.

72. Aargau, Aargauer Kantonsbibl., MsWettFm 1-3, par exemple fol. 4v, 11, [en ligne :] www.e-codices (consulté sept. 2011); Charlotte Bretscher-Gisinger, Rudolf Gamper, Katalog der mittelalterlichen Handschriften des Klosters Wettingen : Katalog der mittelalterlichen Handschriften in Aarau, Laufenburg, Lenzburg, Rheinfelden und Zofingen, Dietikon-Zürich, 2009, p. 156-162; Marie Mollwo, Das Wettinger Graduale, eine geistliche Bilderfolge vom Meister des Kasseler Willehalmcodex und seinem Nachfolger, Berne-Bümplitz, 1944, aux p. xv, 11 et passim. Mentionnant la fête de la Trinité, le graduel ne saurait être antérieur à 1334; et le ms. du Willehalm à Cassel (Landesbibl., 20 Ms. poet. et roman. 1), de 1334, montre un décor filigrané de la même main. L'enluminure du premier volume du graduel et du Willehalm montre un maître formé vers 1300. Il faut supposer aussi un filigraneur dont le style ne varia guère entre 1307 et les années 1330. Mollwo estime que le dessinateur et l'enluminure sont le même, puisqu'ils apparaissent concurremment dans deux cas.

73. 23 mai 1315, Liège; Florence, Arch. di Stato, Diplomatico, S. Croce; A. Grunzweig, «Une lettre... » [n. 69]; W. Kisky, Die Regesten... [n. 69], p. 486-487 (n ${ }^{\text {os } 2036-2037) ;}$ P.-F. Fournier, « Quelques nouvelles affiches... » [n. 63], p. 106-107; Alain Marchandisse, La 
nouveau obtenu, à la demande de Donato Biliotti, une relique de crâne de la collégiale Sainte-Ursule pour la faire exposer à la vénération en un lieu lointain ${ }^{74}$, et accordait aux visiteurs d'une église encore indéterminée une indulgence de quarante jours à la date de l'arrivée de la relique et à la fête des Onze Mille Vierges (21 octobre). La concession nécessitant la confirmation par l'évêque diocésain, l'évêque de Liège y ajoute sa propre indulgence de quarante jours ${ }^{75}$, comme un nouveau maillon dans une chaîne collective de lettres d'indulgence ${ }^{76}$. L'évêque de Florence de même dut sans doute accorder une indulgence à cette occasion; un buste de sainte Ursule aujourd'hui conservé à Florence, dans l'église franciscaine de Santa Croce, contint peutêtre les reliques concernées ${ }^{77}$.

La charte de Liège porte une initiale à la gouache (ill. $8 \mathrm{a}$ ) donnant naissance à un décor encadrant. L'initiale $N$ abrite sous une structure architectonique l'évêque trônant. Dans les branches à feuilles trilobées pointues s'insère à droite, à mi-hauteur du texte, une niche à gable où l'impétrant à genoux exprime sa demande dans un phylactère $(i l l .8 b)^{78}$. Celui-ci, l'évêque et l'archevêque de Cologne (non présent en personne) sont identifiés par des écus suspendus aux branches. Les deux figures sont enveloppées dans des vêtements à plis ondulés, au relief soigneusement modelé mais soulignant peu les corps. Des éléments de style parisien (Maître Honoré) sont traduits en un dialecte artistique local de la France de l'est ou flamand; de même le décor des marges et les drôleries, centaures musiciens en haut et chasse aux lapins en bas. À titre de comparaison livresque, citons un cérémonial produit à Gand en $1322^{79}$ (ill. $8 c$ ), dont la première page est ornée d'une

fonction épiscopale à Liège aux XIII e et XIVe siècles : étude de politologie historique, Liège, 1998, p. 298-299.

74. Cette concession fut sans doute la contrepartie d'une fourniture. S. Pier Maggiore aussi bien que S. Croce se situent dans la sphère d'intérêt de Donato; A. Grunzweig, « Une lettre... », p. 147-148. Henri de Virneburg donna d'autres reliques à Florence, comme l'atteste une lettre d'indulgence de l'évêque de Florence pour S. Salvatore de Settimo, du 25 mars 1320 : Florence, Arch. di Stato, Diplomatico, S. Frediano in Cestello già S. Maria Maddalena, [en ligne :] www.archiviodistato.firenze.it/pergasfi/ (consulté mars 2013); A. Grunzweig, «Une lettre ... », p. 144.

75. Contrairement à l'opinion d'A. Grunzweig, ibid., p. 142.

76. A. Seibold, Sammelindulgenzen... [n. 16] ne traite pas de cette forme mais de combinaisons comparables (p. 187-190, 259-261). Il attribue un rôle important à l'addition des indulgences simples (d'un auteur) dans la genèse des indulgences collectives curiales au XIII $^{\mathrm{e}}$ siècle (p. 181, 186-187).

77. A. Grunzweig, « Une lettre... » [n. 69], p. 295.

78. Il tient un phylactère. L'inscription, peu lisible sur les reproductions, est transcrite par A. Grunzweig, ibid., p. 149 : «Supplicat Donatus a vobis, domine episcope Leodiensii » (sic); et par W. Kisky, Die Regesten... [n. 69], p. 487 : « ...eat Donatus ei... (?) domine episcope Leodii ».

79. Gand, Universiteitsbibl., ms. 233; Gent, duizend jaar kunst en cultuur : boekdrukkunst, boekbanden, bordurenkunst, edelsmeedkunst, miniatuurkunst (expos.), Gand, 1975, t. II, p. 347-348 (n ${ }^{\circ}$ 574, par Kerstin Carlvant) et ill. 81. 
initiale historiée contenant une figure frontale du Christ trônant, proche de notre évêque et d'antennes en bordure peuplées comme dans la charte d'oiseaux chanteurs.

D'autres indices incitent à placer l'origine des lettres d'indulgence enluminées au nord des Alpes et probablement dans la région rhénane :

$1^{\circ}$ Le trésor de la cathédrale de Halberstadt conserve une tablette de cuivre jaune provenant de l'église Notre-Dame («Liebfrauenkirche »), énumérant les indulgences qu'on pouvait y gagner (ill. $9 a)^{80}$. L'inscription encore visible en 1737 à l'extérieur de l'église fut plus tard transférée à l'intérieur. Elle est dominée par une Vierge à l'Enfant trônant, d'un style conforme à la date des indulgences mentionnées (après $1290 ;$ ill. 9b). Peu avant 1300 on eut donc l'idée de combiner un texte relatif aux indulgences avec la représentation d'une image vénérée dans la même église ${ }^{81}$. C'était comme une préfiguration des lettres d'indulgence enluminées; suivirent de près la lettre de Liège en 1315, puis en 1323 la première lettre collective curiale.

$2^{\circ}$ Les panneaux dits de Marienstatt (ill. 10), en 1324 ou peu après, adoptèrent une combinaison comparable ${ }^{82}$. Sur ces deux grands panneaux de bois habillés de feuilles de parchemin, le texte, placé à la partie inférieure ${ }^{83}$, évoque la fondation de l'abbaye cistercienne en 1215 puis son histoire jusqu'à la consécration de la nouvelle abbatiale, sur un nouvel emplacement, le 27 décembre 1324 (certainement l'occasion de l'exécution des tableaux). Le texte finit par l'énumération des indulgences accordées alors et autrefois aux visiteurs. La première feuille montre, comme un raccourci visuel de la translation, la Vierge trônant, tenant dans ses mains le buisson d'épines miraculeux et un modèle de l'église, flanquée à sa gauche de l'archevêque de Cologne, Henri de Virneburg (auteur de l'indulgence déjà citée de 1307, ill. $6 a$ ), et à sa droite de l'abbé Wigand de Greifenstein; plus loin à droite de celui-ci, une petite figure à genoux, sans doute Henri III, comte de Sayn, qui joua un rôle dans la confirmation épiscopale de la deuxième fondation. Au-dessous de la scène, vingt-six moines agenouillés; et dans les écoinçons, deux anges en adoration. Autour de l'image et du texte, un cadre contient les portraits des abbés en buste, jusqu'au XviI ${ }^{\mathrm{e}}$ siècle, et aux coins les symbo-

80. Halberstadt, Domschatz, inv. 32 : la tablette additionne diverses indulgences (la somme de 8 ans, 85 jours et 10 carènes diffère de dix jours du résultat attendu). L'indulgence

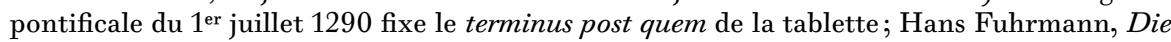
Inschriften des Doms zu Halberstadt, Wiesbaden, 2009, no 27 et ill. 40.

81. Évidemment la Vierge de Halberstadt, statue-reliquaire en bois; ibid., $\mathrm{n}^{\circ} 21$.

82. Bonn, Rheinisches Landesmuseum, inv. 790; Wilhelm Kisky, « Bemalte rheinische Urkunden », dans Rheinischer Verein für Denkmalpflege und Heimatschutz, t. 29, 1936, p. 146-156, aux p. 147-149 (ill.); Anja Sibylle Dollinger, « Farbiger sehen : Maßwerk in der Marienstätter Urkunde und am Kölner Dom », dans Architektur Geschichten : Festschrift für Günther Binding zum 60. Geburtstag, éd. Udo Mainzer, Petra Leser, Cologne, 1996, p. 63-72 (ill.).

83. Transcription (fautive) dans Ausstellung der kunstgewerblichen Alterthümer in Düsseldorf1880, Düsseldorf, 1880, p. 323-325. 
les des évangélistes. Le deuxième panneau est structuré de manière analogue et montre les Arma Christi : pourquoi ce choix ${ }^{84}$ ? L'association des indulgences avec la mise en valeur visuelle du nouvel édifice de Marienstatt peut être vue comme un prototype des panneaux d'indulgences peints au $\mathrm{XV}^{\mathrm{e}}$ siècle ${ }^{85}$. Ce cas s'apparente par ailleurs à celui d'images cultuelles ellesmêmes dotées d'indulgences, qui pouvaient porter des inscriptions invitant à ce titre à la vénération ${ }^{86}$.

84. Cette image précoce des Arma Christi comprend le sudarium ou Véronique, ce qui est inhabituel; de même, un peu plus tôt, dans le passionnaire de Cunégonde [n. 188]. Dans les deux cas le type diffère de celui à trois mèches pointues, caractéristique des indulgences.

85. Sur les panneaux d'indulgences peints (sur le bois ou sur parchemin), A. Seibold, Sammelindulgenzen... [n. 16], p. 12-13; Hartmut Boockmann, « Über Schrifttafeln in spätmittelalterlichen deutschen Kirchen », dans Deutsches Archiv für Erforschung des Mittelalters, t. 40/1, 1984, p. 210-224, aux p. 211, 216-219. Voir aussi deux panneaux richement peints de 1466 (diptyque) et 1513 (triptyque) au trésor de l'ordre Teutonique à Vienne, dérivant d'une compilation antérieure des indulgences accordées à l'ordre entier jusqu'à 1375; B[éla] Dudík, « Über Ablasstafeln », dans Sitzungsberichte der philosophisch-historischen Classe der kaiserlichen Akademie der Wissenschaften (zu Wien), t. 58, 1868, p. 155-180; plus succinct, [Wolfgang Krones], Die Schatzkammer des Deutschen Ordens : Führung durch die Ausstellungsräume des Museums, Sammlungs-Inventar, Vienne, [2000], p. 100-101 (inv. B 202 et 203). On peut attribuer la même fonction à un grand parchemin (après avril 1318) où sont copiées huit indulgences pour le monastère de Frauenberg, avec la somme sur un morceau de parchemin collé au bas; Joachim J. Halbekann, Gräflich von Bodmansches Archiv : Urkundenregesten 1277-1902, Stuttgart, 2001, p. 58-60, ill. 4, 5 et $\mathrm{n}^{\circ}$ 19. De même pour deux listes imprimées, dont une affiche des indulgences des Bénédictins de Königslutter imprimée à Magdebourg le 29 juin 1500, illustrée d'une gravure sur bois montrant l'église entre le pape et l'empereur; Falk Eisermann, Verzeichnis der typographischen Einblattdrucke des 15. Jahrhunderts im Heiligen Römischen Reich Deutscher Nation (VE 15), Wiesbaden, 2004, t. I, ill. 4, et t. II, p. 40-41 (A-79).

86. Un relief en pierre du Christ au Mont des Oliviers (détruit) attaché au nouvel ossuaire (chapelle de la Madeleine) dans le cimetière de la cathédrale (alors église paroissiale) SaintÉtienne à Vienne fut doté en 1343 d'une indulgence de 40 jours par une lettre collective épiscopale enluminée : 22 janvier 1343, Avignon, ill. 18b; Vienne, Diözesanarchiv, [en ligne :] monasterium.net; Dénes Radocsay, « Illuminierte Ablaßbriefe aus Avignon in Wien », dans Alte und moderne Kunst, t. 15, 1970, fasc. 112, p. 8-12, aux p. 11-12 [ill. 7] (indulgence attribuée à tort à la chapelle de la Madeleine). Le Christ à l'initiale permet d'observer l'influence des impétrants sur l'iconographie : il tient de la main gauche un phylactère avec les mots $\mathrm{du}$ Jardin des Oliviers « $\mathrm{P}($ ate)r si fieri $\mathrm{p}$ (otes) $\mathrm{t}$ (ra)nseat a me calix iste ». Au plus tard en 1474, semble-t-il, le relief reçut une inscription en allemand paraphrasant la lettre de 1343; Renate Kohn (éd.), Die Inschriften der Dom- und Metropolitankirche St. Stephan zu Wien, 1 : Bis 1520, à paraitre (Die Deutschen Inschriften, Wiener Reihe, 9/1). Un buste du Christ de Douleur à l'extérieur de l'église paroissiale de Langenlois en Basse-Autriche (1415) est accompagné d'un catalogue des reliques qu'il contenait; la sculpture était dotée d'une indulgence de 40 jours par l'évêque diocésain de Passau ( 8 décembre 1415, Vienne), ensuite renouvelée par l'évêque de Passau et son suffragant (23 septembre 1498); Langenlois, Stadtarchiv, Urk. 92 et 148; A. Zajic, éd., Die Inschriften des Poltitischen Bezirks Krems, Vienne, 2008 (Die Deutschen Inschriften, 72; Wiener Reihe, 3/3), nº 42. 
- Que la Curie romaine ait joué un rôle décisif dans le développement des indulgences collectives épiscopales, c'est ce que suggère l'histoire d'un motif visuel frappant mais dépourvu de référence à une église ou à un destinataire précis, la sainte Face à trois mèches pointues (ill. 5 et 11). En dépit de son aspect archaïque et stylisé, ce type ne paraît pas être très ancien ${ }^{87}$. Gerhard Wolf y voit une invention byzantine de l'époque des Paléologue (à partir de 1259) ${ }^{88}$, d'après une étude de la tradition des images ${ }^{89}$ : avant 1300 prédominait un type dérivant d'anciens modèles byzantins ${ }^{90}$, tandis

87. Archétypes : une image au Vatican, Lipsanoteca [autrefois Rome, San Silvestro]; Il volto di Cristo, éd. Giovanni Morello, Gerhard Wolf (expos., Rome, Palazzo delle Esposizioni), Milan, 2000, p. 91 (par Herbert L. Kessler) et ill. p. 78. Une autre à Gênes, San Bartolomeo degli Armeni; ibid., p. 79a, 91 (par H. L. Kessler, partiellement périmé); et Mandylion : intorno al Sacro Volto, da Bisanzio a Genova, éd. G. Wolf, Colette Dufour Bozzo, Anna Rosa Calderoni Masetti (expos., Gênes, Museo diocesano), Milan, 2004, passim. L'analyse technique indique une fabrication à Gênes au XIII ${ }^{\mathrm{e}}$ siècle (Mandylion..., p. 117-119, par Mario Milazzo); panneau de bois couvert de tissu, procédé ordinaire (ibid., p. 30, par Colette Dufour Bozzo). Une articulation originelle avec deux ailes plus anciennes (Sinaï, monastère de Sainte-Cathérine; Mandylion..., p. 82, ill.) parfois proposée, ne tient pas, le type du Christ du Sinaï est tout à fait différent. Sous l'image on a découvert le tracé préparatoire d'une face en forme de goutte, à barbe pointue (Mandylion..., p. 112-114, par Michele Lanza), dont la diffusion est mal connue. Des exemples tchèques (Il volto..., p. 139, ill., et p. 182, $\mathrm{n}^{\circ}$ IV.18, par Olga Pujmanova) pourraient aider à résoudre la question. Le cadre décoré des scènes de la légende d'Abgar [n. 89], comportant la sainte Face à trois pointes, date des Paléologue, sans doute du XIve siècle (Mandylion..., p. 119, par Mario Milazzo, et p. 161-163, par Paul Hetherington). L'objet, encore à Byzance, ne put servir de modèle ni à la lettre de « réclame » de 1300 [n. 91] ni aux lettres d'indulgence de 1323-1327 (supposition de Homburger et Steiger, « Ablassbriefe » [n. 50], p. 146). Le panneau fut acquis pour Gênes au plus tard en 1384. La copie romaine est d'origine inconnue, et conservée dans la Ville avec certitude seulement à partir du xvie siècle; H. L. Kessler a supposé qu'elle devait y être au plus tard en 1377 (Il volto..., p. 91). Le type à trois pointes était en tout cas connu à Rome dès 1300 , puisqu'on le voit sur la « lettre de Sylvestre » [n. 91].

88. Mandylion..., p. 22. Outre le tableau de Gênes et celui de Rome (s'il est byzantin) on ne connaît pas à Byzance d'autre cas du type à trois pointes.

89. Le texte est fondé sur deux légendes : celle d'Abgar est centrée sur une image du Christ non faite de main d'homme (acheiropoieton) qui guérit le roi Abgar V d'Édesse (H. L. Kessler, dans Il volto... [n. 87], p. 67-69; id., dans Mandylion... [n. 87], p. 62-65). La version concurrente de la Véronique (Vera Ikon), centrée sur Rome, évoque la guérison miraculeuse de l'empéreur Tibère (G. Wolf, dans Mandylion..., p. 104-105). Les images de la sainte Face souffrante, avec couronne d'épines et gouttes de sang, sont plus récentes. Deux images occupent une position intermédiaire : le fol. 10 du Passionnaire de Cunégonde (avant 1321) [n. 188] montre la tête du Christ selon le type classique (note suiv.), sans signe de souffrance, parmi les instruments de la Passion; de même les panneaux de Marienstatt (1324 ou peu après) [n. 82], dont les autres motifs cependant diffèrent clairement.

90. Cette formule différente du type à trois pointes montre au moins une petite partie du cou (Il volto..., p. 81-84 et p. 117-120 [ill.]) et fut adaptée non seulement pour la légende d'Abgar mais aussi pour celle de la Véronique. Il faut citer Paris, Bibl. nat. Fr., ms. lat. 2688 (dernier quart du XIII ${ }^{\text {e }}$ siècle), avec des illustrations de la légende d'Abgar suivant le type de la Vera Ikon bien que produites à Rome; Il volto..., p. 119 et 173 (par Alessandro Tomei), et surtout François Avril, Marie-Thérèse Gousset, Claudia Rabel, Manuscrits enluminés d'origine italienne, t. II, XIII esiècle, Paris, 1984, p. 133-135. 
que le type à trois pointes se répand à partir de l'an 1300, manifestement à partir de Rome ${ }^{91}$, donc comme un support de la « commercialisation » du jubilé $^{92}$. La formule iconographique de la vraie face du Christ s'adapte dès lors sans difficulté à de nouveaux usages. Un autre tournant a lieu en 13271328; le type à trois pointes, qui dominait depuis 1323, est supplanté par une nouvelle sainte Face. Il subsiste cependant dans les articles pour pèle-

91. Outre les deux archétypes [n. 87], citons d'abord le parchemin enluminé de la lettre dite de Sylvestre, datée de la Cathedra Petri (22 février) de l'année jubilaire 1300, Rome; Cortone, Bibl. del Comune e dell'Accademia etrusca, Cod. 101, fol. 6 (ill. 11). Les trois paragraphes montrent des initiales assez typiques de la Curie. Dans les marges supérieure et (la tête en bas) inférieure, une sainte Face à trois pointes entre les saints Pierre et Paul debout, de la même taille : Il volto..., p. 176-178 (par Elisabetta Mori et G. Wolf) et ill. 123; Eduardo et Elisabetta Mori, Un documento cortonese sul giubileo del 1300 : la lettera di Silvestro scriptor pontificio (carta 6 del codice 101), Cortona, 2000; G. Wolf, « La Veronica tra i santi Pietro e Paolo come timbro giubilare », ibid., p. 19-24. L'enluminure est sans doute de 1300 comme le texte (dont deux exemplaires non enluminés sont au Vatican). Quelle qu'ait été la fonction de l'expedition ornée, la formule n'eut guère d'écho. - Toujours à Rome : la matrice de sceau de Lorenzo dei Tiniosi (Tignosi), chanoine de Saint-Pierre; Rome, Museo nazionale del Palazzo di Venezia, coll. Corvisieri Romana, inv. 9529/97; Mandylion... [n. 87], p. 123 (ill.), 178-179 (par A. Tomei); Ruth Wolff, « Siegel-Bilder : Überlegungen zu Bildformularen und -ebenen am Beispiel italienischer Siegel um 1300 », dans Die Bildlichkeit korporativer Siegel im Mittelalter : Kunstgeschichte und Geschichte im Gespräch, éd. Markus Späth, Cologne-Weimar-Vienne, 2009, p. 149-166, aux p. 162-163. - Dans une peinture murale à Pruhonice (église de la Nativité de la Vierge), la Véronique est incluse dans les Arma Christi (sainte Face à trois pointes mais sans suaire); base de données « Real-online » de l'Institut für Realienkunde des Mittelalters und der Frühen Neuzeit, université de Salzbourg, Krems [en ligne :] http://tethys.imareal.oeaw.ac.at/realonline, image $\mathrm{n}^{\circ} 013290$ (consulté sept. 2011), avec datation de 1315-1325 sans doute trop précoce. - Un petit livre à miniatures christologiques (Allemagne, vers 1330-1350) montre la Résurrection en page de gauche et la « Véronique » en regard (type à trois pointes); Londres, Victoria \& Albert Museum, inv. 11-1872, [en ligne :] http://collections.vam.ac.uk/item/O92726/devotional-booklet-devotional-booklet (consulté août 2011). - Voir encore : un fragment de fresque (Ikonenmuseum Recklinghausen, inv. 448; Il volto..., p. 125, 179-180, par A. Tomei et G. Wolf); - le bréviaire du grand maître Leo de 1356 (sainte Face à trois pointes sur un linge porté par des anges); Prague, Národní knihovna, ms. XVIII F 6, fol. 1v; - enfin un groupe de panneaux peints pour l'empereur Charles IV, probablement autour de son voyage à Rome en 1368, dont certains étaient au trésor royal de Bohême; Il volto..., p. 128-131 (ill.) et p.181-184 (par Olga Pujmanová et Karin Gludovatz). Les deux études récentes plusieurs fois citées ne font aucune mention de la production considérable de lettres d'indulgence collectives à sainte Face entre 1323 et 1328 .

92. Mentions liées à l'année sainte : Dante, Paradiso, chant 31, v. 103-111 (Giuseppe Caciagli, La « Comedia », per la prima volta interpretata e commentata secondo la volontà e le intenzioni dell'Alighieri..., Pontedera, 2005-2006, p. 334); Giovanni Villani, Istorie fiorentine, Milan, 1834, liv. VIII, chap. 26, et Nuova cronica di Giovanni Villani, éd. Giovanni Porta, Parme, 1991, [en ligne :] www.classicitaliani.it/villani/cronica_11.htm, liv. IX, chap. 36 (capitulation différente); présentation chaque vendredi à Saint-Pierre; sans précision utile sur le type iconographique. 
rins ${ }^{93}$ et réapparaitra dans les suppliques au pape et les lettres d'indulgence collectives des cardinaux vers la fin du $\mathrm{Xv}^{\mathrm{e}}$ siècle ${ }^{94}$.

L'adoption de ce type romain dans le milieu de la Curie (installée à Avignon depuis 1309) est d'autant plus remarquable qu'il est absent d'une lettre d'indulgence délivrée le 30 mars 1338 à Rome même, par douze évêques italiens, en faveur de l'église paroissiale Saint-Martin de Klosterneuburg près de Vienne ${ }^{95}$ : celle-ci montre une initiale $U$ de quatre lignes à la manière d'avant 1300, avec une bande ornementale verticale à l'intérieur, analogue par exemple à celle de la lettre du scriptor pontifical Sylvestre écrite en 1300 à Cortone (ill. 11) ${ }^{96}$.

Dès 1957 Otto Homburger ${ }^{97}$ a groupé les chartes historiées d'Avignon selon des critères stylistiques assez satisfaisants. Avant de traiter de l'enluminure, quelques remarques s'imposent sur l'écriture, sur la relation entre les formules diplomatiques et l'image, et sur l'usage « médiatique » des actes. La plupart des concessions d'indulgence collectives avignonnaises que nous avons analysées sont écrites par un petit nombre de mains, dans une textualis formata d'exécution médiocre voire faible. De longs passages étaient écrits d'avance, les blancs étant ensuite complétés des données spécifiques ${ }^{98}$. Le dictamen reste inchangé malgré l'ajout de l'image; celle-ci avait donc bien la fonction d'un support publicitaire ${ }^{99}$. Les historiens avancent d'ailleurs souvent que ces lettres étaient exhibées, au moins aux jours d'indulgence,

93. Le type à trois mèches continua principalement à destination des pèlerins à Rome : Il volto... [n. 87], p. 124 (ill.) et p. 179 (par Giovanni Morello); voir les bases de données [en ligne :] www.baitwakil.de et www.kunera.nl (consultées août 2011). Sur ce terrain aussi le jubilé de 1300 marque une césure notable. Outre les « badges » de pèlerin il existe une transmission en masse de faces du Christ par les « pictores Veronicarum » (parfois plusieurs sur un seul parchemin ou papier); Il volto..., p. 124 (ill.) et p. 179 (par Jeffrey F. Hamburger).

94. Les plus anciens cas repérés sont une supplique ornée de Veit, Georg et Christoph von Niederthor au pape Innocent VIII (entre le 29 août 1484 et le 28 mars 1489; Franz Fabian, Prunkbittschriften an den Papst, Graz, 1931, p. 117 et pl. VI) et une lettre d'indulgence collective des cardinaux pour l'église paroissiale de Saint-Oswald et l'église filiale de Haslach du 28 mars 1494, dans les archives abbatiales de Schlägl ([en ligne :] monasterium.net), plaçant toutes deux la Véronique à trois mêches dans le médaillon central de la bordure supérieure. Si la sainte Face est un motif dominant à la fin $d u x^{e}$ siècle, le type à trois mêches est une variante parmi plusieurs; on ne peut non plus attribuer simplement les types à différents ateliers romains. Nous ne traiterons pas ici des suppliques ornées ni des lettres d'indulgence collectives des cardinaux.

95. Klosterneuburg, Stiftsarchiv, [en ligne :] monasterium.net.

96. Voir ci-dessus, n. 91.

97. Homburger et Steiger, « Ablassbriefe » [n. 50].

98. Voir J. Rest, « Illummierte Ablaßurkunden... » [n. 52], p. 158-160.

99. Le procédé de « réclame » est déjà souligné dans Pierre-François Fournier, « Affiches d'indulgence manuscrites et imprimées des $\mathrm{XIV}^{\mathrm{e}}, \mathrm{XV}^{\mathrm{e}}$ et $\mathrm{XVI}^{\mathrm{e}}$ siècles », dans Bibliothèque de l'École des chartes, t. 84, 1923, p. 116-160, à la p. 116; id., « Quelques nouvelles affiches ... » [n. 63], p. 102-103. 
comme des affiches ${ }^{100}$, mais ce n'est qu'une supposition d'après leur apparence $^{101}$, faute de témoignages.

Dans une première phase, de 1323 à 1328, la sainte Face est dessinée (ill. 5, $12 a-c)$. Il est clair que plusieurs dessinateurs sont alors à l'œuvre, mais les différences se manifestent plus dans l'ornementation de l'initiale que dans le dessin de la tête du Christ. Il est difficile de dire si le dessinateur de la lettre d'indulgence de Picquigny ${ }^{102}$ (ill. 5), la plus ancienne à décor figuratif, est encore responsable d'une des pièces suivantes. La charte pour les Cisterciennes de Maria Saal (Aula sancte Marie) à Staré Brno (ill. 12 a) ${ }^{103}$ est au contraire à l'origine d'un groupe assez homogène ${ }^{104}$, jusqu'à la lettre d'indulgence pour l'abbaye cistercienne de Heiligenkreuz ${ }^{105}$, dont l'intérieur de l'initiale est resté vide (ill. $12 d)^{106}$. La riche ornementation de l'initiale, les masques de profil (régulièrement placés contre le montant de gauche sous le trait horizontal; ill. $12 c, d$ ) et les antennes en forme de croix (ill. 12a, $c, d$ ) sont typiques de ce groupe. Au sein de celui-ci apparaît une autre nouveauté riche d'avenir : la charte pour l'église paroissiale de Rheydt ${ }^{107} \mathrm{du} 25$ avril 1326 est la plus ancienne repérée qui montre un discret coloriage, ouvrant la voie aux initiales de couleur proprement dites (voir aussi ill. 12c). Un autre dessinateur a exécuté une charte pour Reichersberg (ill. 12b) ${ }^{108}$.

En 1328 apparaissent les lettres d'indulgence du « principal atelier »

100. A. Seibold, Sammelindulgenzen... [n. 16], p. 55 et 113.

101. Il est incertain si les languettes d'étoffe au haut d'une charte pour Schildesche servaient à un procédé d'affichage ou de conservation (31 mai 1333, Avignon, ill. 16; Joseph Bernhard Nordhoff, « Illustrirte Urkunden aus Avignon », dans Archivalische Zeitschrift, t. 5, 1880, p. 142-148, aux p. 144-145; Homburger et Steiger, « Ablassbriefe » [n. 50], ill. 32 (languettes non visibles); Kunst und Kultur im Weserraum 800-1600 (expos., Corvey, 1966), Münster, 1967, 2 vol., t. II, no 223.

102. Voir ci-dessus, n. 66.

103. 8 décembre 1325, Avignon; Brno, Moravský zemský archiv, E 9 (Cisterciáčky Brno), sub dato, [en ligne :] monasterium.net.

104. Homburger et Steiger, « Ablassbriefe » [n. 50], ill. 19-21; ajoutons une lettre d'indulgence pour l'hôpital Onze-Liewe-Vrouw ter Potterie (N.-D. de la Poterie) à Bruges (26 avril 1326, Avignon; Brugge, Openbaar Centrum voor Maatschappelijk Welzijn [OCMW], archief, O.-L.-V. ter Potterie, KAP1; J. H. Oliver, « The Herkenrode indulgence, Avignon, and the pre-Eyckian painting of the mid-fourteenth-century Low Countries », dans Flanders in a European perspective : manuscript illumination around 1400 in Flanders and abroad, proceedings of the international colloquium, Leuven, 7-10 September 1993, éd. Maurits Smeyers, Bert Cardon, Louvain, 1995, p. 187-206, aux p. 191-198 et ill. p. 199). À ce groupe appartient sans doute, d'après le décor de l'initiale, la charte déjà citée pour Maiden Bradley [n. 65].

105. 10 avril 1328, Avignon; Heiligenkreuz, Stiftsarchiv, [en ligne :] monasterium.net.

106. Que cet inachèvement signale ou non la fin de l'activité (mort, départ) de l'artiste, le premier document de la phase postérieure est du mois suivant (voir plus bas).

107. 25 avril 1326, Avignon; Düsseldorf, Landesarchiv Nordrhein-Westfalen, Abteilung Rheinland, 1.2.5.10 (Geistliche Institute, Rheydt), Urk. 1; Homburger et Steiger, « Ablassbriefe » [n. 50], p. 145 et ill. 20.

108. 3 avril 1326, Avignon; Reichersberg, Stiftsarchiv, [en ligne :] monasterium.net. 
avignonnais, usant pour la première fois de couleurs opaques à la gouache. La plus ancienne connue à ce jour ${ }^{109}$ (ill. 13) est caractéristique de la transition : l'initiale combine des éléments de l'atelier précédent avec ceux des lettres filigranées d'Europe centrale : les rinceaux et la créature hybride tracés en réserve sur fond de couleurs, qui emplissent l'espace intérieur, correspondent à des motifs habituellement insérés dans les montants d'une initiale dont l'intérieur serait filigrané ${ }^{110}$ : disposition adoptée en effet un peu plus tard par le même atelier ${ }^{111}$. La sainte Face centrale, tradition de l'atelier précédent, devient un buste moins abstrait, inséré en médaillon dans le montant gauche (ill. 13) ${ }^{112}$. Même cette disposition n'est pas sans précédent : dans une charte accordée à la chapelle d'Otto Haimo («Ottenheimkapelle », aujourd'hui « Salvatorkapelle ») à Vienne (ill. 12c) ${ }^{113}$, variante rare ou unique, une tête dans cette position (mais inclinée d'un quart de tour) s'ajoutait déjà à la sainte Face centrale. Le décor des montants cite des éléments de l'atelier précédent. Le filigrane, tracé à la plume en rouge, se développe seulement sur le pourtour de l'initiale, mais intègre toujours le masque de profil, en haut à gauche (ill. $12 c, d$ et 13).

Entre 1328 et 1331 les têtes de Christ occupent l'intérieur de l'initiale $U$ (ill. $14 a, b)^{114}$. Ce nouveau type de la vraie face de Jésus adapte une image d'origine byzantine, en buste, déjà aperçue ci-dessus ${ }^{115}$. Un élément nouveau réside dans les mains levées, paumes visibles, la droite bénissant ${ }^{116}$. C'est apparemment une manière d'exhiber les stigmates, soulignés par la couleur rouge, bien que parfois celle-ci manque. Ce type ne correspond plus parfaitement à une image cultuelle romaine, mais semble amalgamer divers

109. 12 mai 1328, Avignon; Vienne, Schotten, Stiftsarchiv, 01.Urk 1328_05_12 (anc. : Scr. 24 A Nr. 1a), [en ligne :] monasterium.net (avec lien erroné au $1^{\mathrm{er}}$ novembre $13 \overline{3} 28$ ).

110. Feuillages et motifs zoomorphes en réserve apparaissent dans les initiales filigranées des livres dès 1310-1320 (la Rhénanie et l'Autriche étant à l'avant-garde). Sur le filigrane, dit en allemand « Fleuronné(e) », voir Wolfgang Augustyn, Christine Jakobi-Mirwald, M. Roland, C. Sauer, art. « Fleuronné », dans Reallexikon zur deutschen Kunstgeschichte, t. IX (fasc. 105/106), Munich, 1996-1997, col. 1113-1196, [en ligne :] http://rdk.zikg.net/gsdl/ cgi-bin/library.exe (consulté juill. 2011).

111. Que ce décor (fond bicolore et motifs en réserve) dérive des manuscrits rhénans est noté à juste titre dans Homburger et Steiger, « Ablassbriefe » [n. 50], p. 154. Sur la dérivation des figures, en revanche, Homburger était dans l'erreur.

112. Ce type de buste se trouve à Byzance comme en Occident, avec des variantes, jusqu'au XIII $^{\mathrm{e}}$ siècle : un exemple précoce dans $I l$ volto... [n. 87], p. 92 (n ${ }^{\circ}$ III.3; par H. L. Kessler) et p. 81-82 (ill.). Il y a des parallèles frappants en Angleterre au XIII ${ }^{\mathrm{e}}$ siècle : ibid., p. 116-118 (ill.) et p. 169-173 ( $\mathrm{n}^{\circ}$ IV.2-IV.4, par Peter K. Klein et Karin Gludowatz).

113. 30 septembre 1327, Avignon; Vienne, Stadt- und Landesarchiv, Hauptarchiv, Urk. 101, [en ligne :] monasterium.net; Homburger et Steiger, « Ablassbriefe » [n. 50], p. 145 et ill. 21; D. Radocsay, « Illuminierte Ablaßbriefe... » [n. 86], p. 8.

114. Homburger et Steiger, « Ablassbriefe », ill. 1, 3, 5-12, et bien d'autres exemples.

115. Voir ci-dessus, n. 87.

116. Plus ancien exemple repéré : lettre d'indulgence pour Saint-Léonard de Léau (Zoutleeuw), Bruxelles, Arch. gén. du Royaume, Arch. ecclésiastiques, nº 966/32 bis (7 juin 1328); Homburger et Steiger, « Ablassbriefe », p. 146 et ill. 5. 
motifs : la sainte Face byzantine, la Majestas Domini et le Juge du Jugement dernier. On ne saurait dire si l'atelier inventa cette figure ou adapta une image de dévotion antérieure. Une image comparable se trouve dans le livre de prières de la reine Élisabeth (ill. 14c) ${ }^{117}$ : un Christ en buste frontal, main droite levée. La miniature, qui omet l'autre main, donc le lien avec la Passion, fut exécutée à Ratisbonne vers la fin du XIII ${ }^{\mathrm{e}}$ siècle. Outre les probables influences du Nord, il faut prendre en compte la tradition locale (du Midi) : ainsi la Majestas Domini d'un missel ${ }^{118}$ (ill. 14d) montre un Christ aux mains levées, la droite bénissant, la gauche tenant l'orbe.

Par la suite, ce type apparaît encore à l'intérieur des initiales, mais entre autres motifs ${ }^{119}$. Ici encore on observe d'emblée la coopération de plusieurs mains, avec de grandes différences de qualité ${ }^{120}$. Dans les lettres en rouge et vert se trouvent souvent des feuillages en réserve, initialement parfois aussi des créatures hybrides ou des dragons (1328-1329) ${ }^{121}$; une charte de 1331 montre pour la première fois dans le montant droit l'impétrant agenouillé $^{122}$. À partir de 1328 on place les figures parfois hors de l'initiale : le premier exemple est encore la lettre d'indulgence pour Saint-Léonard à Léau/Zoutleeuw ${ }^{123}$. L'illustration encadrée, à gauche du texte, présente le saint patron et au-dessous l'impétrant à genoux, tous deux identifiés par écrit ${ }^{124}$. En 1329 Marie est pour la première fois placée comme sainte patronne dans l'initiale ${ }^{125}$. Les feuillages en réserve dans les montants

117. Vienne, Minoritenkonvent [Alser Straße], non coté, fol. 8, [en ligne :] Real-online [n. 91], no 003091 (consulté sept. 2011).

118. Voir ci-dessous, n. 129.

119. Nous connaissons plus de 20 exemples. Le Christ en buste est encore en 1345 sur une lettre d'indulgence pour la chapelle de Hopton Cangeford (18 décembre 1345; Chelmsford, Essex Record Office, D/DW, T 1/21); C. R. Cheney, « Illuminated collective indulgences... » [n. 52], p. 363-369. Dans les décors les plus riches, il est déplacé au centre de la bordure supérieure.

120. Un cas à part : la lettre pour Saint-Jacques à Neumarkt (30 avril 1331, Avignon); Arch. abbatiales de Waldhausen, [en ligne :] monasterium.net. Le Christ en buste correspond aux œuvres de l'atelier principal pour l'iconographie, mais les couleurs (tout en nuances de rouge) et la conception graphique sont tout autres.

121. Voir Homburger et Steiger, « Ablassbriefe » [n. 50], ill. 3, 5, 6.

122. Voir la charte pour Echternach, 25 janvier 1331, Avignon; Homburger et Steiger, « Ablassbriefe », ill. 11.

123. Voir ci-dessus, n. 116.

124. Dans la lettre d'indulgence pour le Großmünster de Zurich (1 ${ }^{\mathrm{er}}$ septembre 1332 , Avignon; Homburger et Steiger, « Ablassbriefe », ill. 16), cette position est occupée par l'évêque qui confirme l'indulgence; l'impétrant, identifié par son nom, est dans le montant droit de l'initiale (position attestée depuis 1331).

125. La lettre d'indulgence pour les Cisterciennes de Benninghausen (24 octobre 1329, Avignon; Münster, Landesarchiv Nordrhein-Westfalen, Abteilung Westfalen, 1.1.1.2 [Stifte und Klöster im Herzogtum Westfalen], Kloster Benninghausen, Urkunden, $\mathrm{n}^{\circ}$ 178) est ornée de la Vierge à l'Enfant trônant (patronne de l'église); J. B. Nordhoff, « Illustrirte Urkunden... » [n. 101], p. 144 (sans ill.). Le contour de l'initiale $U$ est caractéristique des chartes écrites dans (ou pour) l'atelier principal et non peintes. Le style rend quand même peu 
furent ensuite - à la demande des destinataires? - remplacés par des figures additionnelles de saints (Jean Baptiste, Marie et autres). Le premier exemple à trois figures (Marie à l'intérieur, le Baptiste et l'Évangéliste dans les montants) est une charte pour l'église paroissiale de Cembra (ill. 15; et cf. ill. 16) $)^{126}$.

La variante la plus complexe, développée dès 1332, au sommet de la hiérarchie décorative, comporte des ornements entourant le texte sur trois cotés (ill. 17, 18). Ce cadre inclut souvent en haut des médaillons avec des têtes ou des bustes du Christ ou de saints, et dans les marges gauche et droite deux champs l'un sur l'autre avec des figures debout ${ }^{127}$.

La lettre d'indulgence collective accordée en 1335 à la chapelle SaintPancrace du palais ducal (« Hofburg ») de Vienne, orné seulement d'une figure debout à l'intérieur de l'initiale $U$ et de quelques initiales dans le texte ${ }^{128}$, montre cependant sur trois cotés, près du texte, un encadrement

probable l'exécution en Rhénanie; reste à décider si elle pourrait être avignonnaise ou méridionale, en l'absence de matériau de comparaison concluant dans Francesca Manzari, $L a$ miniatura ad Avignone al tempo dei papi (1310-1410), Modène, 2007. - Le 12 novembre 1330, à Avignon, fut délivrée une lettre d'indulgence pour la chartreuse du Val-Royal à Gand (Gent, Rijksarchief, Fonds Sint-Baafs, Karthuizers Gent, $\mathbf{n}^{\circ} 18$ ), montrant dans l'initiale une crucifixion à trois figures; J. H. Oliver, « The Herkenrode indulgence... » [n. 104] ], p. 199; Gent, duizend jaar... [n. 79], p. 350 (no 576, par Antoine de Schryver) avec localisation de l'écriture et de l'enluminure à Gand. Dans ce cas et en ce qui concerne la charte pour Dinant (1 ${ }^{\text {er }}$ septembre 1330, Avignon; Namur, Arch. État, Arch. ecclésiastiques n. 311, chapitre Notre-Dame de Dinant, no 1 ; J. H. Oliver, « The Herkenrode indulgence... », p. 199; voir aussi Jean Bovesse, Françoise Ladrier, A travers l'histoire du Namurois : catalogue analytique et explicatif de l'exposition permanente de documents, VIII ${ }^{e}-X X^{e}$ siècle, Bruxelles, 1971, p. 263-265, no 138, pl. X; H. Delehaye, « Les lettres d'indulgence... » [n. 50], t. 44, p. 367-368, et t. 45, p. 334, avec une Vierge à l'intérieur), il reste à examiner si le décor est dû à l'atelier principal ou au destinataire. Ce dernier cas est manifeste dans une charte pour Notre-Dame de Fargues à Albi (26 février 1331, Avignon; Baltimore, Walters Art Gallery, W 742 Lf). Le premier décor indubitablement dû à l'atelier principal mais avec une iconographie relative au destinataire, le saint patron à l'intérieur de l'initiale, est une charte pour les Dominicaines de Saint-Laurent de Vienne (12 mai 1331, Avignon; Vienne, Haus-, Hof- und Staatsarchiv, Allgemeine Urkundenreihe, sub dato, [en ligne :] monasterium.net; D. Radocsay, « Illuminierte Ablaßbriefe... » [n. 86], p. 9-10 et ill. 1; Barbara Schedl, Klosterleben und Stadtkultur im mittelalterlichen Wien. Zur Architektur religiöser Frauenkommunitäten, Innsbruck, 2009, p. 220, $\left.\mathrm{n}^{\mathrm{0}} 13\right)$.

126. 15 septembre 1331, Avignon; Trente, Arch. di Stato, PAT, busta 4, no 1; L. Santifaller, « Über illuminierte Urkunden... » [n. 55], p. 227-228 et ill. 4. Nous remercions chaleureusement Mme Fiammetta Baldo (Soprintendenza per i beni librari e archivistici, Trento) de son aide importante.

127. Pour la première fois dans une lettre pour trois églises et chapelles à Lahnstein et à Lahneck (15 octobre 1332, Avignon) montrant à l'intérieur un trône de grâce, [en ligne :] www.bildindex.de (mots-clés : Lahneck, Ablaßbrief). Ensuite, deux lettres d'indulgence pour Niederlana (novembre 1332, Avignon) et Sterzing (19 décembre 1333, Avignon); Trecento : pittori gotici a Bolzano (expos., Bolzano, 2000), éd. Tiziana Franco, Andrea de Marchi, Silvia Spada Pintarelli, Trente, 2002, $\mathrm{n}^{\text {os }} 4 \mathrm{a}$ et $4 \mathrm{~b}$ (ill.).

128. 22 mars 1335, Avignon; Vienne, Schotten, Stiftsarchiv, 01.Urk 1335_03_22 (anc. : 
réglé de fines doubles lignes à la plume ou à la pointe sèche, et qui n'a pas été peint. Cette disposition était donc préparée comme une solution standard, mais l'impétrant pouvait décider de la richesse du décor.

Les très nombreuses indulgences postérieures comportent peu de nouveautés notables, et un niveau généralement modeste. On y voit des saints patrons locaux, mais les images du Christ (en buste, trônant ou crucifié) restent un décor générique. Quant aux éléments figuratifs, ils semblent issus de sources méridionales (ill. $14 a, b, d)$, dont le style est caractérisé, selon les termes de François Avril, par « le graphisme un peu sec et la forte stylisation des figures ${ }^{129}$. Au total, donc, les figures sont d'origine méridionale, l'ornement de style rhénan et l'idée de la peinture comme moyen de publicité semble aussi née en Rhénanie.

L'atelier est à son apogée dans les années 1330, et semble spécialisé exclusivement dans le décor des chartes («Diplommalwerkstätte » ${ }^{130}$ ). Il était évidemment lié à l'activité de la chancellerie ${ }^{131}$, comme le montre une observation d'A. Seibold : le notaire responsable notait quelquefois sur les chartes de brèves indications iconographiques pour l'enlumineur, dans les montants ou à l'intérieur de l'initiale, voire ailleurs ${ }^{132}$. Homburger a essayé d'identifier un membre de l'atelier ${ }^{133}$, mais les sources sont trop incertaines. Toutefois, nombre d'actes furent aussi décorés, tout ou partie, hors de l'atelier, à l'initiative du destinataire ${ }^{134}$.

L’atelier principal atteint son niveau le plus élevé dans deux chartes de

Scr. 24 A Nr. 1b), [en ligne :] monasterium.net. Autre charte très similaire : 15 mai 1337, Avignon; 01.Urk 1337_05_15 (anc. : Scr. 66 Nr. 13), [en ligne :] monasterium.net; et nombreux exemples de 1337-1339. Une lettre d'indulgence précoce de 1328 était destinée à la même chapelle (voir ill. 13).

129. À propos du ms. Lyon, Bibl. mun. 526, missel du diocèse de Vienne; Les fastes du gothique : le siècle de Charles V (expos., Paris, Grand Palais), Paris, 1981, p. 308-309 (ill.). Nous remercions de son aide à la bibliothèque $M$. Pierre Guinard.

130. D. Radocsay, « Illuminierte Ablaßbriefe... » [n. 86], p. 8.

131. Homburger et Steiger, « Ablassbriefe » [n. 50], p. 135-136.

132. A. Seibold, Sammelindulgenzen... [n. 16], p. 112-113 et n. 798-799, cite deux exemples : Munich, Bayerisches Hauptstaatsarchiv, Klosterurkunde Asbach [non Aldersbach] 37 (10 janvier 1336, Avignon; absent de monasterium.net), instruction « Hic ponatur sanctus Matheus in una parte et in alia parte ponatur ymago abbatis nigri »; Nuremberg, Stadtarchiv, Reichsstadt Nürnberg Urk. 533 (26 mai 1337, Avignon), indication « impetrator genibus ».

133. Homburger et Steiger, « Ablassbriefe »[n. 50], p. 155 (Galterius Alamannus, chanoine de Strasbourg, mentionné comme enlumineur dans des sources curiales).

134. Voir notes 160-161; aussi une charte du 20 mai 1333, Avignon, pour l'abbatiale et les autres églises et chapelles de l'abbaye de Saint-Gall : l'initiale de l'atelier principal a été partiellement repeinte et la marge supérieure a reçu un bandeau à trois bustes, le Christ entre les saints Gall et Othmar; Homburger et Steiger, « Ablassbriefe », p. 152 et ill. 15; Buchmalerei im Bodenseeraum, 13. bis 16. Jahrhundert, éd. Eva Moser, Friedrichshafen, 1997, p. 332 (nº BR 1, par Andreas Bräm, et ill. p. 156). 
1342, l'une pour Fröndenberg (ill. 18a) ${ }^{135}$, l'autre pour Maaseik ${ }^{136}$. On y retrouve l'encadrement en trois parties à figures debout et à médaillons ${ }^{137}$, les mêmes initiales (surtout lettrines de second rang), les fonds quadrillés et l'écriture en textualis formata ${ }^{138}$. Cependant les figures y sont plus picturales que graphiques, les plis subtilement modelés, et les chevelures et visages mieux différenciés.

Il est parfois difficile de séparer les produits les moins élaborés du nouveau style d'avec ceux de l'atelier principal, eux-mêmes inégaux ${ }^{139}$. Les innovations consistent en l'usage dominant de couleurs fortes (rouge, violet, vert olive), dans le décor additionnel des fonds et autres petites parties du parchemin et surtout dans les antennes courtes à feuillage : l'atelier principal emplissait habituellement d'ornements l'encadrement des exemplaires de prestige, et nous ne connaissons que trois exemples d'antennes florales sans encadrement, dans les lettres d'indulgence pour Cembra (ill. 15) ${ }^{140}$, pour les Cisterciennes de Burtscheid ${ }^{141}$ et pour les chanoinesses régulières d'Ahnaberg ${ }^{142}$. Le premier document connu du nouveau type est la lettre pour l'église de Notre-Dame de Nenkersdorf ${ }^{143}$, suivie d'une autre pour le relief du Christ au mont des Oliviers dans le cimetière de Saint-Étienne à

135. 2 janvier 1342, Avignon; Münster, Landesarchiv Nordrhein-Westfalen, Abteilung Westfalen, 1.4.1.2 [Preußisch Westfalen, Grafschaft Mark, Stifte und Klöster], Stift Fröndenberg, Urkunden, $\mathrm{n}^{\circ} 162$; Krone und Schleier : Kunst aus mittelalterlichen Frauenklöstern (expos., Essen, Ruhrlandmuseum; Bonn, Kunst- und Ausstellungshalle der BRD), Munich, 2005, p. 355 (n 236, par Susan Marti).

136. 22 mars 1342, Avignon; Maaseik, Museactron/Fonds Sint Catharinakerk, Kerkmuseum; P. Daniels, J. Gielen, C. Bamps, « Charte enluminée du XIve siècle », dans L'ancien pays de Looz, t. 4, 1899, p. 11; J. H. Oliver, « The Herkenrode indulgence... » [n. 104], p. 189 et 200 , ill. 2 .

137. Une bordure sur trois côtés orne aussi une lettre d'indulgence endommagée (5 juillet 1347, Avignon; coll. Huyskens, en dépôt au Kreisarchiv Viersen), vraisemblablement pour la paroisse Saint-Remi de Borken; nous remercions M. Gerhard Rehm, Viersen, de cette information importante. Elle est singulière par l'usage de feuille d'or à certains endroits et par une miniature à deux figures debout avec encadrement d'éléments d'architecture, à la place normale de l'initiale. Le mot « Universis », à la suite, commence par une simple initiale de second rang.

138. Parmi les changements principaux, la nouvelle main remplace l'a à double panse de forme rectangulaire (le « Kasten- $a$ » de la paléographie allemande) par un $a$ dont la crosse n'est pas entièrement fermée.

139. Problème évident dans les documents publiés par D. Radocsay, «Illuminierte Ablaßbriefe... »[n. 86], p. 11-12.

140. 15 septembre 1331, Avignon [n. 121].

141. 11 janvier 1335, Avignon; Düsseldorf, Landesarchiv Nordrhein-Westfalen, Abteilung Rheinland, Kloster Burtscheid, Urk. 170.

142. 15 septembre 1336, Avignon; Marburg, Hessisches Staatsarchiv, Kloster Ahnaberg, Urkunden, $\mathrm{n}^{\circ} 136$; ill. dans l'art. d'Otto Schmitt, «Ablaß », dans Reallexikon zur Deutschen Kunstgeschichte, t. I, 1933, col. 78-82, aux col. 79-80. À gauche du texte, les moniales destinataires.

143. 12 février 1342, Avignon; Priessnitz (comm. Frohburg, Landkreis Leipzig), Arch. de la paroisse. Le document n’a été publié - comme bon nombre de trouvailles - que dans la 
Vienne (ill. 18b) ${ }^{144}$. La combinaison d'éléments anciens et nouveaux laisse supposer un renouvellement progressif de l'équipe ${ }^{145}$.

De nombreux documents témoignent d'une qualité croissante avant $1350^{146}$. Le plus intéressant est peut-être la lettre accordée à la confrérie de flagellants ou « battuti » (fraternitas seu societas verberatorum) de Cividale, consacrée à la Mère de Dieu (ill. 19). La charte invite à participer aux processions et surtout à se joindre à la confrérie et à tester en sa faveur ${ }^{147}$. L'enfant Jésus sur les genoux de sa mère trônant (à l'intérieur de l'initiale) salue les sept flagellants qui viennent en procession au-dessus du texte et dont le premier, portant une croix, s'agenouille. Un ange thuriféraire à

presse régionale, [en ligne :] http://nachrichten.lvz-online.de/region/geithain/priessnitzerkirchenarchiv-enthaelt-manchen-schatz/r-geithain-a-62904.html.

144. 22 janvier 1343, Avignon; Vienne, Diözesanarchiv, [en ligne :] monasterium.net; D. Radocsay, « Illuminierte Ablaßbriefe... » [n. 86], p. 11-12.

145. Voir la lettre d'indulgence pour Ruppertsberg, donnée bien après les premiers exemples du style nouveau, et dont le décor donne l'impression d'un adieu final au style de l'atelier principal; 13 juillet 1342, Avignon; Koblenz, Landeshauptarchiv, A.2, Bestand 164 : Ruppertsberg; W. Kisky, « Bemalte rheinische Urkunden »... [n. 82], p. 150 (ill.).

146. Citons : 6 juin 1343, Avignon, pour Saint-Léonard de Bâle; Bâle, Staatsarchiv, Klosterarchiv St. Leonhard, Urk. 378; H. Delehaye, « Les lettres d'indulgence... » [n. 50], t. 45, p. 339; Konrad Escher, Miniaturen in den Basler Bibliotheken, Museen und Archiven, Bâle, 1917, p. 249, no 358); - 1343, Avignon, pour Bevagna (New York, Morgan Library \& Museum, M 697; Meta Harrsen, « Figural grisaille ornament on a historiated initial of about 1400, and the derivation of its style from the indulgences of Avignon », dans Bookmen's holiday : notes and studies written and gathered in tribute to Harry Miller Lydenberg, éd. Fulton Deoch, New York, 1943, p. 316-322, ill.; F. Manzari, La miniatura... [n. 125], p. 136; - 27 juin 1344, Avignon, pour Scheibbs; Vienne, Haus-, Hof- und Staatsarchiv, Allgemeine Urkundenreihe, sub dato, [en ligne :] monasterium.net; - 1344-1345, pour une église anglaise (fragment); Enid M. Donkin, « A collective letter of indulgence for an English beneficiary », dans Scriptorium, t. 17, 1963, p. 316-323 et pl. 31; -2 janvier 1345, pour la cathédrale de Płock; Płock, Archiwum Diecezjalne, Sygn. P. IV/54; Barbara Miodónska, Małopolskie malarstwo ksiażkowe 1320-1540, Varsovie, 1993, p. 119-120; - 30 juillet 1345, pour Sankt Georgen im Attergau; musée paroissial, [en ligne :] www.atterwiki.at/index. php?title=Pfarrmuseum_St._Georgen_im_Attergau ; - 22 août 1345, pour une chapelle de Notre-Dame et de Saint-Jean-Baptiste, dans un lieu inconnu (nom estropié par le clerc) du diocèse de Passau; Prague, Národní Archiv, Maltézští rytíri české velkopřevorství, Urk. 2186, [en ligne :] monasterium.net; - 12 janvier 1347, pour Hirsau (feuillage à bustes au dessus de l'écriture et figures debout dans les marges gauche et droite); Ochsenkopf und Meerjungfrau : Wasserzeichen des Mittelalters (expos. itinérante, Landesarchiv Baden-Württemberg, Hauptstaatsarchiv Stuttgart; Österr. Akad. d. Wiss., Komm. für Schrift- und Buchwesen des Mittelalters), dir. Peter Rückert, Stuttgart, 2006, p. 20 ( $\mathrm{n}^{\circ}$ III 2, par P. Rückert); - 3 mars 1348, pour l'église paroissiale Saint-Pierre de Naklo; Ljubljana, Nadškofija Ljubljana, Arhiv, Urk. 130, [en ligne :] monasterium.net.

147. 28 novembre 1345; Udine, Bibl. civica Vincenzo Joppi, Fondo principale, 1228/III, $\mathrm{n}^{\circ}$ 16; Laura Pani, « La lettera collettiva d'indulgenza per i Battuti di Cividale della Biblioteca civica "Vincenzo Joppi" di Udine », dans « Nulla historia sine fontibus » : Festschrift für Reinhard Härtel zum 65. Geburtstag, éd. Anja Thaller, Johannes Gießauf et Günther Bernhard, Graz, 2010, p. 348-357 (bibliogr.). Sur les flagellants en Frioul, [en ligne :] www. liceolefilandiere.it/tesine/ospedale_battuti/storia/ALICE.html\#_ftnref2. 
gauche et un ange bénissant à droite les encadrent ${ }^{148}$. Un sujet d'iconographie remarquable est Jésus élevant l'hostie, dans l'initiale d'une lettre d'indulgence pour la confrérie du Corpus Christi à Kazimierz (aujourd'hui quartier de Cracovie), du 15 avril $1347^{149}$.

Par la suite on voit se multiplier les lettres où les contours de l'initiale $U$ sont uniquement tracés d'un fort trait de plume ${ }^{150}$. On pouvait donc (comme pour les lettres collectives des cardinaux $\mathrm{du} \mathrm{xv}^{\mathrm{e}}$ siècle) recevoir, évidemment à moindre coût, une charte dont l'initiale simplement mise en place à Avignon restait à enluminer par un artiste local ${ }^{151}$. L'aspect

148. Le geste de l'Enfant le lie aux flagellants, confirmant que la procession fait partie de la conception d'origine. Des figures de style comparable (œuvres de miséricorde : soins et alimentation des malades) sont à la même place sur la lettre d'indulgence pour l'hôpital Onze-Lieve-Vrouw ter Potterie à Bruges. L'initiale $U$ est occupée par le Christ-Juge, la marge gauche par saint Michel et le dragon (18 février 1354, Avignon [n. 146]). Il reste à décider si le décor est dû au moins en partie au destinataire (par exemple le fond extraordinaire et la vrille montant de la queue du dragon).

149. Cracovie, Kanonicy Regularni Laterańscy, Archiwum, no 1126 ; H. Delehaye, « Les lettres d'indulgence... »[n. 50], t. 45, p. 339; Franciszek Piekosiński, Codex diplomaticus Poloniae Minoris, 1138-1386 = Kodeks dyplomatyczny Małopolski, 1138-1378, Cracovie, 1876, p. 264-267 ( $\mathrm{n}^{\circ}$ CCXXIII); B. Miodónska, Małopolskie malarstwo... [n. 141], p. 119-120 et ill. 48-49. Au dessus de l'initiale, un pape trônant (avec tiare et clé) et le confrère « Johannes cantor $[\ldots]$ confirmationis impetrator »; à droite sous l'écriture, à genoux : « Stanislaus Soffka confrater », non mentionné dans le texte (donc sans doute ajouté). Une indulgence fut aussi accordée aux fidèles priant pour les âmes de neuf confrères nommés dans le texte. De manière extraordinaire, l'indulgence fut confirmée et élargie non seulement par l'éveque contemporain Bodzatha de Cracovie, mais aussi par six de ses successeurs (et un évêque de Lubusz).

150. Ainsi : 25 janvier 1350, Avignon, pour l'église paroissiale de Rickenbach (SaintGall, Stiftsarchiv, J.2.A.1ß); 8 mai 1353, Avignon, pour l'hôpital des chanoines réguliers de Klosterneuburg (ibid.) ou 17 avril 1359, Avignon, pour Schlins (Bregenz, Vorarlberger Landesarchiv, Pfarrarchiv Schlins, Urk. 2956), [en ligne :] monasterium.net. L'initiale vide de cette dernière contient une note secondaire sur l'impétrant, non mentionné dans le texte (« Noverint universi quod Ulricus dictus Emet [Smet?] de Rons [Röns] procuravit istam litteram in curia Romana pure propter Deum et in remedium anime sue et omnium fidelium defunctorum »); «Der unbekannte Jagdberg » : das ehemalige Gericht bis zu seiner Auflösung 1808 (expos., Vorarlberger Landesarchiv), par Manfred Tschaikner, Bregenz, 2007, p. 20.

151. Sur cette possibilité, voir plus haut, et notamment la charte viennoise de 1297 [n. 62]. Dans la même période, citons : 25 mars 1350, Avignon, pour l'église Saint-Gall d'Ebringen (Saint-Gall, Stiftsarchiv, O.2.Cc.1, [en ligne :] monasterium.net). Le style rhénan laisse supposer que le décor fut commandé aussitôt après l'expédition. Dans l'initiale, crucifixion à trois figures : le cœur de la Vierge est percé d'une épée et la traverse de la croix est en branches à bourgeons et feuilles (lignum vitae). Les montants de l'initiale sont occupés par des dragons et créatures hybrides dérivés de la tradition des initiales filigranées, ainsi que deux dragons debout sur l'initiale. À gauche de l'initiale, saint Gall debout en évêque, plus bas l'impétrant agenouillé, «f(rate)r Johan(n)es » (selon le dispositif, « de Rocwil », Roggwil en Thurgau). La partie historiée est à la gouache, les motifs zoomorphes ou végétaux et ornementaux en dessin à la plume lavé. La crucifixion inhabituelle n’est pas justifiée par le texte. Bonne synthèse sur ce style régional : Buchmalerei im Bodenseeraum... [n. 134], ill. aux p. 59, 88, 103, 104, 158, 243. - 13 juin 1351, Avignon, pour l'église Sainte-Catherine et la 
extraordinaire de la lettre d'indulgence accordée le 6 septembre 1353 aux moniales de Saint-Laurent de Vienne (ill. 20a) s'explique probablement par là : l'initiale ne fut peinte que vers le milieu $d u x^{\mathrm{e}}$ siècle, par un remarquable enlumineur viennois ${ }^{152}$. L'intérieur de l'initiale est transformé en une petite chambre (presque une armoire, avec une porte dans le mur de droite), en perspective convaincante, où se tient debout le saint. Le style est étroitement lié à l'enluminure viennoise du second quart $\mathrm{du} \mathrm{Xv}^{\mathrm{e}}$ siècle ${ }^{153}$. La Bible historiale III $a$, datée de 1448 (ill. 20b) ${ }^{154}$ fut enluminée par le « Josefsmeister » puis par le « Mose-Meister » (nommés selon les passages bibliques qu'ils ornèrent). La fille de Pharaon (fol. 44v), Elkana et ses deux épouses (fol. 110) ou la reine de Saba (fol. 151v) montrent des analogies évidentes ${ }^{155}$.

Après la fin de la tradition d'atelier décrite plus haut, à côté des pièces ornées chez le destinataire et de celles laissées sans couleurs, se multiplient les enluminures avignonnaises, comme l'a montré Francesca Manzari : une charte de $1354{ }^{156}$ pour l'éphémère ermitage de Smithfield qui précéda la chartreuse de Londres, fut selon elle décorée par l'enlumineur d'un office de saint Martial (Bibliothèque nationale de France, ms. lat. 916), présent

chapelle du château de Hohenems (Bregenz, Vorarlberger Landesarchiv, Reichsgrafschaft Hohenems, [en ligne :] monasterium.net); 18 février 1354, Avignon, pour l'église hospitalière Onze-Lieve-Vrouw ter Potterie à Bruges (Bruges, OCMW-archief, O.-L.-V. ter Potterie, KAP2; J. H. Oliver, « The Herkenrode indulgence... » [n. 104], p. 190, 200 et ill. 3; parallèles stylistiques avec l'acte du 28 novembre 1345, Avignon [n. 147]); 15 juin 1360 pour Cavalese (Cavalese, Arch. parrocchiale, Perg. n. 1).

152. 6 septembre 1353, Avignon; Vienne, Haus-, Hof- und Staatsarchiv, Allgemeine Urkundenreihe, sub dato, [en ligne :] monasterium.net; B. Schedl, Klosterleben... [n. 125], p. 209-234, spéc. p. 222. Autre lettre d'indulgence enluminée pour le même monastère : 12 mai 1331 [n. 125]. B. Schedl (Klosterleben... p. 210, 226-127) constate une importante activité documentaire vers 1445-1455 lorsque ce couvent dominicain devint une communauté de chanoinesses regulières : c'est peut-être le contexte de l'ajout. Il est même possible, du point de vue paléographique, que la charte, sans sceau, soit une copie faite au milieu du Xve siècle d'un original perdu (non decoré).

153. Voir Mitteleuropäische Schulen V (ca. 1410-1450), Wien und Niederösterreich, éd. Katharina Hranitzky, Veronika Pirker-Aurenhammer, Susanne Rischpler, M. Roland, Michaela Schuller-Juckes, Christine Beier, Andreas Fingernagel et Alois Haidinger, Vienne, 2012 (Die illuminierten Handschriften und Inkunabeln der Österreichischen Nationalbibliothek, 14) : synthèse par $S$. Rischpler. La disposition en coin de la chambre se trouve de même chez Maître Michael, les plis brisés des vêtements sont typiques du cercle du Maître du Panneau votif de Saint-Lambert (St. Lambrecht). L'aspect coloré, les figures robustes et la spatialité expressive se rattachent à l'art du « Josefsmeister » (voir MeSch V, nº 167 : Vienne, ÖNB, Cod. 2774), maître probablement originaire de Bavière.

154. Voir ci-dessous, n. 153.

155. MeSch V, ill. couleur 37, ill. 597 et 611 . Nous laissons de côté la question de l'attribution de l'initiale au « Mose-Meister » en personne.

156. Londres (Kew), The National Archives, Exchequer, King's Remembrancer, Ecclesiastical documents, E 135/15/1; C. R. Cheney, « Illuminated collective indulgences... » [n. 52], p. 369-373 (ill. 2). 
dans la bibliothèque pontificale en $1409^{157}$. La lettre d'indulgence en faveur de Santa Maria da Alcáçova de Santarém, de $1356^{158}$, est du même atelier qu'un luxueux pontifical (bibliothèque Sainte-Geneviève, ms. 143) ${ }^{159}$, dont la datation est ainsi corrigée par $\mathrm{F}$. Manzari d'après celle de la lettre. Dans ces deux cas des éléments stylistiques du Nord de la France et d'Italie sont amalgamés, à la manière typique de l'enluminure du Midi et d'Avignon.

Citons enfin deux actes (de qualité très inégale) préparés par le destinataire. D'abord une lettre d'indulgence du 20 août 1360, à l'occasion de l'agrandissement du chœur de Saint-Wendelin. L'intérieur de l'initiale montre la figure debout du saint en berger flanqué de deux figures agenouillées (moine et berger?). Au dessous de l'initiale à droite, illustrant la légende, un porc qui découvre une cloche ${ }^{160}$. Le style des dragons et des chiens en réserve dans les montants et le dessin colorié mais graphique, aux contours soulignés, caractérisent une œuvre locale et modeste.

Le décor fastueux de la charte du 6 avril 1363 (Avignon) pour les Cisterciennes de Herkenrode illustre au contraire une qualité élevée à l'initiative de destinataires exigeants (ill. 21) ${ }^{161}$. L'intérieur de l'initiale $U$ est occupé par une église, vue du sud, aux détails spécifiques. Plutôt que d'une simple invention pittoresque, il s'agit d'un exemple précoce de « portrait d'architecture » au nord des Alpes ${ }^{162}$. Partant du montant droit, une procession de la Fête-Dieu avance au dessus du texte. Un homme tenant l'aspersoir et des laïcs portant bannières et torches marchent en tête; derrière eux, deux femmes laïques et des moniales, suivies de l'abbesse; à coté d'elle, presque complètement caché, marche un homme; viennent enfin deux cisterciens et le célébrant avec l'ostensoir, flanqué de deux autres clercs, tous trois en vêtements liturgiques, sous un dais porté par quatre hommes. La présence de moniales échappées de la clôture, dans cette procession à l'air libre, mérite d'être notée.

Le décor hétérogène de ces exemples tardifs apparaît en même temps que

157. F. Manzari, La miniatura.... [n. 125], p. 153 (ill. 69, 70).

158. 9 août 1356, Avignon; Lisbonne, Arquivo Nacional da Torre do Tombo, Colegiada de Santa Maria da Alcáçova de Santarém, M. 13, Doc. 250; Saul António Gomes, « Uma littera indulgentiarum avinionense de 1356 na colegiada de Santa Maria da Alcáçova de Santarém (Portugal) », dans Faventia, t. 25/2, 2003, p. 75-84.

159. F. Manzari, La miniatura ..., p. 156-159, ill. 71 et 74 (Lisbonne), $72-73$ (Paris).

160. 20 août 1360, Avignon; Sankt Wendel, Klosterarchiv; W. Kisky, « Bemalte rheinische Urkunden »... [n. 82], p. 150-151.

161. 6 avril 1363, Avignon; Sint-Truiden, Provinciaal Museum voor religieuze Kunst, inv. KPL/sd/251 (dépôt du Stedelijk Museum de Hasselt); J. H. Oliver, « The Herkenrode indulgence... » [n. 104], p. 191-198 (ill.); Krone und Schleier... [n. 130], p. 48 (ill. couleur 6), p. 34 et 50 (mentions).

162. J. H. Oliver, « The Herkenrode indulgence... », p. 191 l'identifie comme l'église de Herkenrode (qui a brûlé en 1826) et signale, p. 193, une peinture (vers 1600) et une gravure de 1744 (en réalité 1743). Lidentification est confortée par un des vitraux de Herkenrode, installés à partir de 1805-1806 dans la Lady Chapel de la cathédrale de Lichfield : [en ligne :] http://users.skynet.be/abdijherkenrode/index2.htm (consulté juill. 2011). 
de nouvelles mains dans l'écriture, qui s'éloignent nettement de la textualis formata en usage dans les indulgences avignonnaises. Une lettre non enluminée pour les chanoines réguliers de Saint-Thomas de Brno ${ }^{163}$ montre (à part le nom des auteurs, mis en valeur) une écriture qui mérite même d'être nommée cursive, malgré la récurrence des $a$ de textualis (à panse double). La première ligne de la lettre d'indulgence pour Herkenrode ne viole pas moins complètement les conventions, en sens inverse : c'est une textualis formata de qualité élevée, laissée en réserve sur fond de hachures brunrouge. Les lettres ressemblent aux lettres « textiles » (« Tüchleinbuchstaben ${ }^{164}$ ) connues dans les livres ou à la minuscule gothique correspondante, certes plus tardive, des inscriptions (« Bandminuskel »).

Après 1363, la tradition des lettres d'indulgence collectives épiscopales enluminées s'interrompt ${ }^{165}$.

\section{LES CONCESSIONS D'ARMOIRIES.}

Le second groupe de chartes ornées en série est celui des concessions d'armoiries ${ }^{166}$. Nous appelons ainsi les chartes par lesquelles l'auteur

163. 4 octobre 1357, Avignon; Moravský zemský archiv v Brně, Augustiniáni Brno, [en ligne :] monasterium.net.

164. Forme trop peu étudiée; quelques indications dans le compte rendu de M. Roland sur Das ABC-Lehrbuch für Kaiser Maximilian I. : vollständige Faksimile-Ausgabe des Codex 2368 der Österreichischen Nationalbibliotehk Wien, éd. Karl-Georg Pfändtner, Alois Haidinger, Graz, 2004, et sur Ludwig Boyer, Das Prunk ABC Buch für Maximilian I., Österreichs älteste Fibel (um 1466), eine pädagogisch-didaktische Studie, Vienne, 2004, dans Kunstchronik, 2006, p. 290-295, aux p. 292-293. Cet acte y est cité comme le premier exemple connu. On trouve déjà des lettres en réserve chez Léonard de Munich, dès 1337 [n. 290] (combinée avec une initiale historiée). Une lettre ornée du même pour Passau évoque déjà un tissu; 17 novembre 1345; Christa Wrede, Leonhard von München, der Meister der Prunkurkunden Kaiser Ludwigs des Bayern, Kallmünz, 1980, nº 23 (ill.).

165. Sur la distribution chronologique (actes décorés ou non), voir n. 51. H. Delehaye, « Les lettres d'indulgence... » [n. 50] compte environ 100 actes conservés par décennie; en 1343 commence la décrue : 77 actes des années 1340, 51 des années 1350, 38 des années 1360 . Les années 1363 (9) et 1364 (2) marquent une césure mais non la fin de ce type d'acte, dont on fait encore des expéditions sans décor. Ces chiffres contredisent l'explication fréquente par l'interdiction faite aux prélats étrangers de résider à la Curie (14 novembre 1364); voir par ex. A. Seibold, Sammelindulgenzen... [n. 16], p. 222.

166. Meilleure synthèse : Gustav Pfeifer, « Wappenbriefe », dans Höfe und Residenzen im spätmittelalterlichen Reich: Hof und Schrift, dir. Werner Paravicini, éd. Jan Hirschbiegel, Jörg Wettlaufer, Ostfildern, 2007, p. 645-673 et pl. couleur 11-14; voir aussi : id., « Erby a sociální vzestup : poznamky k zlistinění erbů a k stavovským povýšením v pozdním středověku », dans Genealogické a heraldické informace, 2007, p. 28-42; id., Wappen und Kleinod: Wappenbriefe in öffentlichen Archiven Südtirols, Bozen, 2001, p. 9-28; pour l'époque moderne, Jürgen Arndt, « Die Entwicklung der Wappenbriefe von 1350 bis 1806 unter besonderer Berücksichtigung der Palatinatswappenbriefe », dans id., Hofpfalzgrafen-Register, Neustadt an der Aisch, t. II, 1971, p. v-xxxvII; Erbové listiny = Patents of arms, éd. Milan Šišmiš, Martin, 2006; un essai concernant notamment les débuts, Petr Elbel, A. Zajic, « Wappenmarkt und 
(normalement le roi ou l'empereur ou un comte palatin comme son représentant) accorde des armoiries (ou un changement d'armes) ou le droit de porter des armoiries soit existantes soit nouvelles, ou la confirmation de tels droits. Le destinataire peut être une personne physique aussi bien qu'une collectivité : ville ou marché ${ }^{167}$, confrérie ou métier. Dès la naissance de ces actes, ils furent très souvent complétés d'armoiries peintes.

Comme les lettres d'infamie (« Schmähbriefe »), dont il sera question plus loin, et différemment de tous les autres genres diplomatiques ici présentés, les concessions d'armoiries comportent une image immédiatement liée au contenu juridique. Dans quelques exemples précoces la peinture héraldique est même constitutive de l'acte, puisque le dispositif s'y réfère au lieu de blasonner verbalement. Par ailleurs, on note dans ces chartes l'absence presque totale d'initiales décorées ${ }^{168}$.

1. Les concessions d'armoiries de type ancien. - Les armoiries concédées traduisent en termes visuels les liens entre l'auteur et le bénéficiaire, donc une relation politique, particulièrement dans le cas des corps de ville.

La plus ancienne lettre d'armoiries conservée en original ${ }^{169}$, extérieure à l'Empire, fut accordée le 11 mars 1316 par Bernard de Coucy (Bernardus de

Marktwappen : diplomatische und personengeschichtliche Überlegungen zum Wappenbrief König Sigismunds für Mohelno aus der Zeit des Konstanzer Konzils; mit einem Quellenanhang 》, dans Kaiser Sigismund : Zur Herrschaftspraxis eines europäischen Monarchen (1368-1437), éd. Karel Hruza et Alexandra Kaar, Vienne-Cologne-Weimar, 2012, p. 301-364. Â l'échelle suprarégionale : Dénes Radocsay sur le royaume de Hongrie [n. 220] (bibliogr.); voir aussi id., « Österreichische Wappenbriefe der Spätgotik und Renaissance in Budapest », dans Zeitschrift des deutschen Vereins für Kunstwissenschaft, t. 18, 1964, p. 91-106; id., « Über einige illuminierte Urkunden », dans Acta historiae artium Academiae scientiarum Hungaricae, t. 17, 1971, p. 31-61; id., « Über den Stil einiger Wiener Wappenbriefe der Spätgotik und Renaissance », dans Genealogica et heraldica : 10. Internationaler Kongreß für genealogische und heraldische Wissenschaften $=10^{e}$ Congrès international des sciences génealogiques et héraldiques (Wien 14.-19. September 1970), Kongressberichte, éd. Franz Gall, Hanns Jäger-Sunstenau, Vienne, 1972, t. II, p. 415-420; id., « Wiener Wappenbriefe und die letzten Miniatoren von Buda », dans Acta historiae artium Academiae scientiarum Hungaricae, t. 19, 1973, p. 61-73. L'étude d'Ernestine Zolda, « Die gotischen Wappenbriefe in Österreich : ihre Entwicklung, ihre Form und ihre Künstler, 1400-1519 », dans Adler, Zeitschrift für Genealogie und Heraldik, t. 18, 1995-1996, p. 97-131, 153-177, 241-275, 298-319, est rendu à peu près inutilisable par ses défauts historiques et diplomatiques. Sur les lettres de noblesse et de promotion dans la noblesse (hors décor), Walter Goldinger, « Die Standeserhöhungsdiplome unter König und Kaiser Sigismund », dans Mitteilungen des Instituts für österreichische Geschichtsforschung, t. 78, 1970, p. 323-337.

167. G. Pfeifer, Wappen und Kleinod... [n. 166], p. 15-16, les exclut des lettres d'armoiries au sens strict.

168. Ce qui frappe particulièrement dans la chancellerie de Louis de Bavière (ci-après, section IV) : Léonard de Munich, qui écrivit les seules lettres d'armoiries de Louis conservées en original, n'y ajouta aucun décor malgré sa prédilection pour l'ornement.

169. La lettre d'armoiries du roi Albert Ier pour le diocèse de Gurk (Carinthie) du 11 janvier 1305, conservée en copie (prétendument authentifiée) du xvI siècle, est généralement jugée fausse : Hanns Jäger-Sunstenau, « Der Wappenbrief für das Bistum Gurk 
Cucuiaco), vicaire général du pape en Tuscie, à la ville de Viterbe (ill. 22) ${ }^{170}$, en rétribution de son soutien dans la reconquête des territoires rebelles du Patrimonium Petri après le décès de Clément V ${ }^{171}$. La ville reçut le titre honorifique de gonfalonier de l'armée pontificale et augmenta ses anciennes armes, lion et palme, du gonfanon, porté par le lion. Elle obtenait en outre pour dix ans la seigneurie de Montefiascone. Les armoiries sont blasonnées dans le dispositif, qui en même temps se réfère à l'illustration. La miniature occupe le tiers supérieur du parchemin, non coupé au bas. Le fond de l'image est de bleu opaque, et délimité au bas par un bandeau d'or. Au centre, devant une palme de sinople fleurie de gueules, un lion couronné d'or, lampassé et armé de gueules, passant, regardant de face, tenant de sa patte dextre un gonfanon. Le dessin intérieur du lion, sommairement tracé en lignes noires, évoque des modèles bien plus anciens, notamment en sculpture. Le gonfanon à deux pointes est de gueules à la croix d'argent, cantonnée de quatre clés d'argent posées en pal, le panneton en haut. Les armes évoquaient une somme d'associations concrètes : le lion (en héraldique, un « léopard ») ${ }^{172}$ pouvait être lu comme un symbole guelfe, la palme

(1305) : eine Bestandsaufnahme », dans Carinthia I, Zeitschrift für geschichtliche Landeskunde von Kärnten, t. 161, 1971, p. 213-223.

170. 11 mars 1316, Viterbe; Viterbe, Bibl. comunale degli Ardenti, serie Pergamene sciolte, no 220, collocazione 364; Friedrich Bock, « Der älteste kaiserliche Wappenbrief », dans Archivalische Zeitschrift, t. 41, 1932, p. 48-55, à la p. 52; Donald Lindsay Galbreath, Geoffrey Briggs, Papal heraldry, 2e éd., Londres, 1972, p. 3; brève mention dans Christoph Friedrich Weber, Zeichen der Ordnung und des Aufruhrs : Heraldische Symbolik in italienischen Stadtkommunen des Mittelalters, Cologne-Weimar-Vienne, 2011, p. 32 (n. 88); voir aussi G. Pfeifer, Wappen und Kleinod... [n. 166], p. 17; ill. de couverture de Biblioteca e società, t. 54/3, 2006. Nous remercions chaleureusement M. Francesco Biganzoli de nous avoir fourni une photographie. L’acte fut expédié sous forme notariée par Nicolaus quondam Brancafolio de Viterbe, notaire de chambre de Bernard de Coucy. Un vidimus (8 janvier 1320, Viterbe; Francesco Orioli, « Florilegio viterbese, 3 : Ancora de' suggelli e delle insegne di Viterbo », dans Giornale arcadico di scienze, lettere ed arti, t. 136, juill-sept. 1854, p. 120-138, à la. p. 135-136; Ignazio Ciampi, Cronache e statuti della città di Viterbo, Florence, 1872, p. 381) précise que l'original était scellé de cire rouge (sceau du vicariat général du Patrimoine pontifical pour la Tuscie), sur lacs de soie rouge et verte; Feliciano Bussi, Istoria della città di Viterbo, Roma, 1742, réimpr., Bologne, s. d. [av. 1968], p. 418-419 (édition défectueuse); surtout F. Orioli, « Florilegio... », p. 129-138 (édition améliorée), et I. Ciampi, Cronache..., p. 377-381 (le meilleur texte); Giuseppe Oddi, « L'arma della città di Viterbo », dans Giornale araldico-genealogico-diplomatico, t. 11, 1883-1884, p. 288-291, aux p. 289-290. La charte devint elle-même (à une date incertaine avant 1742) le sujet d'une peinture murale avec une inscription (détruite) au palais communal de Viterbe; F. Bussi, Istoria..., p. 184-185.

171. La charte raconte comment, résidant en novembre 1315 à Montefiascone, Bernard de Coucy et les siens furent attaqués par des rebelles et secourus par Viterbe; mention dans la chronique de Viterbe de Nicola della Tuccia; I. Ciampi, Cronache... [n. 170], p. 33, 377-381.

172. Le savant cardinal Egidio Antonini de Viterbe (1469-1532) interpréta dans son Historia viginti seculorum per totidem psalmos conscripta les armoiries de la ville, sans doute à cause du lion, comme un souvenir du culte d'Hercule; F. Bussi, Istoria ... p. 40-42, 184-185, et G. Oddi, « L'arma... » [n. 170]. Bussi explique la couronne du lion par le « principato » antique de Viterbe sur les autres villes d'Étrurie. Sur d'autres interpretations d'armoiries 
figurait la victoire sur la ville voisine Ferenzia (Ferento), détruite en 1171$1172^{173}$, et le gonfanon de 1316 rappelait la fidélité au pape ${ }^{174}$. Comme dans nombre de concessions d'armoiries dues plus tard à l'empereur (voir plus bas), la charte ne comporte pas seulement comme souvent un ample préambule mais un exposé détaillé énumérant les rebelles et les mérites guerriers des bénéficiaires.

L'acte pour Viterbe, émanant de l'entourage du pape ${ }^{175}$, ne resta pas sans écho du côté impérial. Deux chartes (originaux multiples) de grand format, données le 17 novembre 1327 à Lucques ${ }^{176}$ par Louis de Bavière, élevèrent

communales en Italie à la fin du Moyen Âge, C. F. Weber, Zeichen... [n. 170], p. 448-449, 470-472. En réalité le lion apparaît en 1198 sur le sceau de Viterbe, tenant un arbre déraciné et effeuillé; en 1225 on trouve ajoutée la légende en vers Non metuens verbum leo sum qui signo Viterbum; F. Orioli, « Florilegio... », p. 127; I. Ciampi, Cronache..., p. 307-308; G. Oddi, « L'arma... », p. 289.

173. Ainsi au xve siècle dans la chronique de Nicola della Tuccia : I. Ciampi, Cronache..., p. 7 (« Per la qual vittoria Viterbesi aggiunsero al leone del comune la palma, che era l'arma de' Ferentesi ») et p. 306-308; F. Orioli, « Florilegio... », p. 122-123; G. Oddi, « L'arma... », p. 289.

174. Le gonfanon pontifical est présenté au $\mathrm{Xv}^{\mathrm{e}}$ siècle comme remplaçant une bannière impériale concédée à Viterbe par Frédéric I Ir Barberousse en 1167 ou 1170 et confirmée le 19 mars 1172 à Sienne par le légat impérial. En réalité l'acte de 1172 (Viterbe, Arch. comunale, Pergamene $\mathrm{n}^{\circ} 11$ ), qui porte bien une note dorsale du xve siècle l'identifiant comme confirmation du droit de porter la bannière impériale, confirmait seulement la possession des biens dont l'empereur avait investi la ville « per vexillum imperiale »; regeste, Mainzer Urkundenbuch, t. II : Die Urkunden seit dem Tode Erzbischof Adalberts I. (1137) bis zum Tode Erzbischof Konrads (1200), 1 ${ }^{\text {re }}$ partie : 1137-1175, éd. Peter Acht, Darmstadt, 1968, $\mathrm{n}^{\circ}$ 344; plus détaillé, J. F. Böhmer, Regesta Imperii, IV/2 : Die Regesten des Kaiserreiches unter Friedrich I., 1152 (1122)-1190, $3^{\mathrm{e}}$ fasc., 1168-1180, éd. Ferdinand Opll, Vienne-CologneWeimar, 2001, no 1971; voir maintenant C. F. Weber, Zeichen... [n. 170], p. 70-73, 173 et passim (résumé p. 507-521); notamment sur la valeur symbolique de l'héraldique communale italienne dans le contexte des changements d'alliances politiques (p. 84-88, 111, 170-173 et passim), et sur l'importance des lances à bannières dans diverses actions juridiques. Noter que Crémone, investie de ses biens par l'empereur Henri VI en 1195 par une bannière (de gueules à la croix d'argent!), ajouta avant 1292 celle-ci à ses armes : on ne saurait exclure que Viterbe ait fait de même, et que ses armes « anciennes » aient été déjà semblables en cela aux « nouvelles » de 1316, pontificales (à part les clés); C. F. Weber, Zeichen..., p. 88-112.

175. Le seul acte héraldique pontifical connu n'est pas décoré; 5 juin 1466, Rome (Paul II pour la ville de Plzeň en Bohême); Plzeň, Archiv města, inv. č. 19, sign. I 182; Listár královského mèsta Plzně a druhdy poddaných osad. Čast II. Od r. 1450-1526, éd. Josef Strnad, Plzeň, 1905, p. 138 ( $\mathrm{n}^{\circ}$ 153); Codex juris municipalis regni Bohemiae III : Privilegia regalium civitatum provincialium annorum 1420-1526, éd. Jaromír Čelakovský et Gustav Friedrich, Prague, 1948, p. 498-499 (n 287); Rostislav Nový, « Počátky znakủ českých měst », dans Sborník archivních prací, t. 26/2, 1976, p. 367-412, aux p. 385-386; Tomáš Krejčík, « K problematice rozšíření erbovních listin v českém státě v 15 . a na počátku 16 století », dans $Z$ pomocných věd historických XVI : «Inter laurum et olivam », Prague, 2007, p. 221-227, à la. p. 222.

176. Lucques, Arch. di Stato, Tarpea 1327 XI 17; MGH, Legum sectio 4: Constitutiones et acta publica imperatorum et regum 6/1, p. 269-271 (no 362); C. Wrede, Leonhard... [n. 164], p. 142-145 (n ${ }^{\text {os }}$ 26-27) et p. 101-103; Peter Acht, « Die Prunkurkunden Kaiser Ludwigs des Bayern », dans Wittelsbacher und Bayern, t. I/1 : Die Zeit der frühen Herzöge, von Otto I. zu 
Castruccio Castracani degli Antelminelli ${ }^{17 z}$ au rang de prince héréditaire du duché nouvellement créé de Lucques, lui conférant le titre de gonfalonier de l'Empire, avec une autorité semblable à celle d'un comte palatin ${ }^{178}$. La suscription est ornée de lettres d'apparat majuscules dorées, et l'initiale $L$ du nom de l'empereur est agrandie. Les lettres dorées à la feuille sont entourées de filigranes bleus, rouges et brun clair ${ }^{179}$.

L’augmentation d'armoiries qui accompagna cette élévation semble avoir donné lieu à une charte perdue mais mentionnée par Giovanni Villani dans sa chronique de Florence : en reconnaissance des mérites de Castruccio dans la préparation de la reconquête de Pisa, Louis de Bavière augmenta les armoiries du condottiere, issu d'une famille de marchands toscans, de celles de Bavière (fuselées en bande d'azur et d'argent) ${ }^{180}$. L'acte était vraisemblablement orné de majuscules d'or comme la charte du 17 novembre, plutôt que d'un écu. La concession par Louis des armes de Bavière à un château (virtuel) de l'ordre Teutonique en Lituanie, en 1337, sera examinée ci-après avec les actes de cet empereur ${ }^{181}$; mais elle ne contient pas encore, elle non plus, de miniature.

La première est de 1338, sur une charte (originale) accordée par Louis de Bavière aux frères Bonifatius et Egesius de Carbonensibus, comtes de San Giovanni in Persiceto ou Persesena (ill. 23) ${ }^{182}$. L'écu incliné est écartelé

Ludwig dem Bayern, Munich, 1980, p. 398-407, aux p. 398-399; Michael Nadler, « Ludwig der Bayer : Krönungszug nach Italien », dans Bayern und Italien : Kontinuität und Wandel ihrer traditionellen Bindungen, Vorträge der "Historischen Woche" der Katholischen Akademie in Bayern vom 17. bis 20. Februar 2010 in München, éd. Hans-Michael Körner et Florian Schuller, Lindenberg, 2010, p. 96-104.

177. Dès 1315 il fut nommé conseiller intime (secretarius), familier et vicaire impérial par le roi Frédéric le Beau; Regesta Habsburgica, 3. Abteilung : Die Regesten der Herzoge von Österreich sowie Friedrichs des Schönen als Deutschen Königs von 1314 bis 1330, éd. Lothar Groß, Innsbruck, 1922-1924, no 292 (5 août 1315, au camp devant Esslingen); Louis Green, Castruccio Castracani : a study on the origins and character of a fourteenth-century Italian despotism, Oxford, 1986. Castruccio est surtout célèbre grâce à sa vie composée par Machiavel (imprimée en 1532).

178. Julius Ficker, Forschungen zur Reichs- und Rechtsgeschichte Italiens, t. II, Innsbruck, 1869, p. 103-105, 112, 114; Gustav A. Seyler, Geschichte der Heraldik : Wappenwesen, Wappenkunst, Wappenwissenschaft, Nuremberg, 1885-1889 (1890), réimpr. Neustadt an der Aisch, 1970, p. 356.

179. Sur deux chartes semblables, C. Wrede, Leonhard... [n. 164], p. 141-142 (n 25).

180. G. Villani, Istorie fiorentine... [n. 92], p. 328 (lib. X, cap. 36), et éd. en ligne, lib. XI, cap. 36; Aldo Manucci, Le azioni di Castruccio Castracane degli Antelminelli, signore di Lucca..., 3 3e éd. corr. et augm., Lucques, 1843, p. 123; G. A. Seyler, Geschichte der Heraldik..., p. 318; G. Pfeifer, Wappen und Kleinod... [n. 166], p. 17; C. F. Weber, Zeichen... [n. 170], p. 32. Sur l'interprétation des armoiries de Florence par G. Villani, ibid., p. 443-452, 471.

181. Voir ci-dessous, n. 184.

182. 8 février 1338; Bologne, Bibl. comunale dell'Archiginnasio, manoscritti Gozzadini 74/a; F. Bock, « Der älteste... » [n. 170]; C. Wrede, Leonhard... [n. 164], p. 84-85; G. Pfeifer, Wappen und Kleinod..., p. 17; id., «Wappenbriefe (unter besonderer Berücksichtigung der Tiroler Verhältnisse) », dans Quellenkunde der Habsburgermonarchie (16.-18. Jahrhun- 
en sautoir : 1. et 4. fuselés en bande d'azur et d'argent (l'argent concrètement laissé en réserve; Bavière ou peut-être plus précisément Wittelsbach), 2. et 3 . d'or (peinture jaune) ${ }^{183}$ à l'aigle (impériale) de sable, montrant bien les bénéficiaires en partisans de l'auteur. Le scripteur a laissé en blanc au milieu du texte le rectangle destiné à la peinture. Désormais la chancellerie impériale adoptera presque toujours cette disposition. Le dispositif omet le blason (verbal) pour se référer à l'illustration : arma depicta presentibus et inserta.

Autre exemple soulignant les liens entre le souverain et son partisan (amicus noster carissimus) : la charte de Jean $\mathrm{I}^{\mathrm{er}}$ roi de Bohême du 9 août 1339 concédant des armoiries à son chancelier Nicolas de Brno, installé l'année précédente comme évêque de Trente contre la volonté du pape ${ }^{184}$. Selon l'exposé, il aurait demandé pour son diocèse, afin de s'en servir sur ses bannières à la guerre, les armoiries vacantes ${ }^{185} \mathrm{du}$ saint patron de Bohême Wenceslas. Le roi prend sous sa protection spéciale le diocèse de Trente, exposé aux attaques de ses ennemis (du côté du Tyrol) comme la cible à la flèche (hostium incursibus velut signum ad sagittam est exposita ${ }^{186}$ ), au titre

dert) : ein exemplarisches Handbuch, éd. Josef Pauser, Martin Scheutz, Thomas Winkelbauer, Vienne, 2004, p. 291-302, à la p. 293; id., « Erby... » [n. 166], p. 32-33; C. F. Weber, Zeichen..., p. 31-32.

183. Une photographie aimablement fournie par la Biblioteca comunale dell'Archiginnasio montre qu'il s'agit d'un dessin à la plume coloré : d'où le choix normal de figurer l'or à la gouache, l'argent par le parchemin laissé en réserve et le noir/sable à l'encre.

184. 9 août 1339, Wrocław; Trente, Arch. di Stato, Arch. principesco vescovile, sezione latina, cassa 39, $\mathrm{n}^{\circ} 7$ bis; Frumenzio Ghetta, L'aquila, stemma di Trento e del Trentino, Trente, 1973; Eines Fürsten Traum : Meinhard II, das Werden Tirols (expos., château de Tirol et abbaye de Stams, 1995), Tirol-Innsbruck, 1995, p. 53, 138 (ill.), 157 (no 4.29, par Josef Riedmann); G. Pfeifer, Wappen und Kleinod... [n. 166], p. 18 (bibliogr.), 182-184 (annexe 3); Franz-Heinz von Hye, Wappen in Tirol, Zeugen der Geschichte : Handbuch der Tiroler Heraldik, Innsbruck, 2004, p. 161 et ill. 515; Kunst in Tirol, éd. Lukas Madersbacher, Paul Naredi-Rainert, Bozen, 2007, t. I : Von den Anfängen bis zur Renaissance, p. 269 et 280 (n. 33, par M. Roland). Nicolas (1336-1347) fut un des plus importants évêques de Trente au XIV siècle. Nous remercions chaleureusement M. Paolo Giovannini (Arch. di Stato di Trento) de nous avoir adressé une photographie.

185. L'usage persista longtemps de concéder à nouveau les armoiries d'une famille éteinte (les armoiries étant liées dans la conception féodale aux fiefs). Ainsi Frédéric III, comme duc de Styrie, concéda aux chanoines réguliers de Vorau des armoiries intégrant celles, vacantes, des Praunpeck; 17 juin 1453, Graz; voir aussi G. Pfeifer, Wappen und Kleinod... [n. 166], p. 12-14, 35 (no 2; 20 janvier 1488, Innsbruck : Frédéric III concède les armoiries vacantes des Rottenbucher à Erasmus [Asam] Remer et Jörg Kurz); Wilfried Schöntag, Kommunale Siegel und Wappen in Südwestdeutschland : ihre Bildersprache vom 12. bis zum 20. Jahrhundert, Ostfildern, 2010, p. 8 et 10. Mais nous ne pensons pas que dans les lettres d'armoiries de Charles IV les armes vacantes l'aient emporté sur les créations, comme le soutient Tomáš Krejčík, « K listině Václava IV. pro rod Gonzagů z roku 1394 », dans « Ad vitam et honorem » : Profesoru Jaroslavu Mezníkovi prátelé a žáci $k$ pětasedmdesátým narozeninám, éd. Tomáš Borovský, Libor Jan, Martin Wihoda, Brno, 2003, p. 125-132, à la p. 128 (sans référence).

186. La formule « velut signum ad sagittam », paraphrase de Lam. 3, 12, est fréquente dans des préambules des chartes. 
de l'avouerie appartenant au prince de Carinthie et de Tyrol et eu égard aux armoiries concédées (tum racione advocacie tum eciam propter arma prelibata). L'image substituée au blason verbal (arma [...] in fine presentis nostri privilegii designata) suit immédiatement sous l'écriture ${ }^{187}$. Les armes, d'argent (fond de parchemin en réserve) à l'aigle de sable, membrée, becquée, liée et couronnée d'or, flamboyante de gueules, ce sont toujours celles du Trentin. On les voit peintes dans le passionnaire de Cunégonde ${ }^{188}$ comme armes de saint Wenceslas, ce qui confirme l'identification donnée dans la charte.

On peut citer des concessions d'armoiries (de type ancien) à connotation politique jusqu'au XIv ${ }^{\mathrm{e}}$ siècle, notamment d'armoiries communales. Un bon exemple : la charte pour Kaschau (Košice, actuelle Slovaquie), délivrée le 7 mai 1369 à Diósgyőr par Louis Ir le Grand, roi angevin de Hongrie (13421382) ${ }^{189}$. Le dispositif décrit l'écu comme une adaptation des armes royales : fascé de gueules et d'argent de huit pièces (Hongrie), au chef d'armes d'azur, chargé de trois fleurs de lys d'or (Anjou). L'acte, sous forme de lettres patentes scellées du sceau du secret ${ }^{190}$, n'est pas orné; mais la confirmation par Sigismond en $1423^{191}$ et d'autres ont un décor de la plus haute qualité.

Presque à la même date, la lettre d'armoiries de Charles V de France pour Abbeville montre mieux encore sa dimension politique. Par lettres patentes du 19 juin 1369 (Vincennes), le roi récompense la fidélité de la ville, revenue le 29 avril de l'occupation anglaise dans l'obédience française, en augmentant ses armoiries (dérivées du comté de Ponthieu : d'or, à trois bandes d'azur à la bordure de gueules) du « chef d'armes de France, c'est assavoir d'asur semé de fleurs de liz d'or », armes qui pourront être portées « soit en leur bannieres et autres enseignes et es seaulx de ladicte ville et en paintures ou autrement $\gg 192$.

187. T. Krejčík, « K listině... », p. 129, explique à tort cette position par l'oubli de laisser en blanc un champ dans le texte, mise en page considérée comme déjà normale. On peut penser que la première lettre d'armoiries de la chancellerie de Bohême fut préparée avec soin. La position au centre du parchemin est attestée seulement un an auparavant (1338) dans la première lettre d'armoiries enluminée, par Louis de Bavière. Surtout, le texte mentionne expressément l'écu peint à la fin de l'acte.

188. Prague, Univerzitní knihovna, XIV A 17, fol. 1; Emma Urbánková, Karel Stejskal, Pasionál Přemyslovny Kunhuty = Passionale abbatissae Cunegundis, Prague, 1975, ill. 1 b. L'abbesse Cunégonde mourut à Prague le 27 novembre 1321, terminus ante quem de l'achèvement du manuscrit.

189. Voir Ladislav Vrtel', Osem storoči slovenskej heraldiky = Eight centuries of Slovak heraldry, Bratislava, 2003, p. 94-95 (ill.); Jozef Novák, « Armálesy na Slovensku », dans Erbové listiny... [n. 166], p. 9-16, aux p. 9-10.

190. La possibilité d'une expédition plus solennelle est mentionnée (selon l'usage de la chancellerie hongroise) dans la corroboration : « ... harum sub nostro sigillo secreto testimonio litterarum, quas in forma nostri privilegii sub magno nostro sigillo pro ipsis civibus redigi faciemus, dum nobis fuerint reportate. »

191. Voir ci-dessous, n. 256.

192. Texte enregistré (Paris, Arch. nat, JJ 100, p. 517), éd. dans Ordonnances des roys 
En 1437 encore, un rapport politique, mais fort différent, s'exprimait dans le changement des armes de Tábor en Bohême, lorsque la commune devint ville royale avec les droits de la vielle ville de Prague. Les nouvelles armoiries destinées au sceau de la ville n'étaient pas une marque d'honneur mais le signe de la soumission finale des Taborites autrefois hussites radicaux sous l'empereur Sigismond ${ }^{193}:$ d'or à une porte de ville dans un mur d'enceinte d'argent entre deux tours à deux étages d'argent, aux toits d'azur, derrière une aigle bicéphale de sable, nimbée d'or, portant sur la poitrine l'écu de Luxembourg. Le piètre état de conservation nécessiterait un examen technique poussé : fond d'or usé, argent métallique gravement oxydé et craquelé ${ }^{194}$. Les parties vides entre l'écu et le cadre rectangulaire sont d'un bleu opaque, sans la fine ornementation végétale qu'on attendrait. Il pourrait s'agir soit de la trace des difficultés politiques préalables soit de modifications secondaires.

Malgré leur appartenance à ce groupe nous présenterons d'autres concessions d'armoiries communales à leur place chronologique dans la section suivante.

2. Les concessions d'armoiries de type nouveau. - Au-delà des concessions d'armoiries de type ancien exprimant les relations directes entre auteur et bénéficiaire, d'autres chartes, de type « nouveau », présentent des armes sans allusion particulière (honorifique) à l'auteur.

Le plus ancien exemple, prototype d'un genre diplomatique nourri, est issu de la chancellerie de l'empereur Charles IV de Luxembourg (13461378). Le 25 mai 1355, il accorda une charte ${ }^{195}$ en faveur de Giacomo

de France de la troisième race... t. V (1367-1373), éd Denis-François Secousse, Paris, 1736, p. 196; Répertoire universel et raisonné de jurisprudence... éd. Joseph-Nicolas Guyot, nouv. éd. corr. et augm., t. I, Paris, 1784, p. 607.

193. 25 janvier 1437, Prague; Tábor, Archiv města, A I, č. 1 et 2 (deux expéditions, l’une à sceau de majesté, l'autre à bulle d'or); Codex juris municipalis regni Bohemiae, t. III : Privilegia regalium civitatum provincialium annorum 1420-1526, éd. Jaromír Čelakovský, Gustav Friedrich, Prague, 1948, p. 167-174 ( $\left.n^{\circ} 102\right)$; František Šmahel, « Vom apokalyptischen Drachen zum Städtegründer : Sigismund und Tábor », dans Sigismund von Luxemburg, Kaiser und König in Mitteleuropa, 1387-1437 : Beiträge zur Herrschaft Kaiser Sigismunds und der europäischen Geschichte um 1400, Vorträge der internationalen Tagung in Budapest vom 8.-11. Juli 1987..., éd. Josef Macek†, Ernő Marosi et Ferdinand Seibt, Warendorf, 1994, p. 144-155, à la p. 154; Alexander Patschovsky, «Der taboritische Chiliasmus : seine Idee, sein Bild bei den Zeitgenossen und die Interpretation der Geschichtswissenschaft », dans Häresie und vorzeitige Reformation im Spätmittelalter, éd. František Šmahel, collab. Elisabeth Müller-Lucknet, Munich, 1998, p. 169-195, à la p. 169. M. Petr Elbel (Brno/Vienne) nous a fourni des photographies, dont nous le remercions.

194. La surface devenue presque noire, le dessin de la porte, des fenêtres et du mur en lignes noires est à peine visible; de même l'écu de Luxembourg sur la poitrine de l'aigle.

195. 25 mai 1355, Pise; Venise, Fondazione Giorgio Cini, inv. 2042; Pietro Toesca et Giuseppe Fiocco, Miniature italiane della Fondazione Giorgio Cini, dal Medioevo al Rinascimento, Venise, 1968, p. 19 ( $\mathrm{n}^{\circ}$ 11); Percy Ernst Schramm, Hermann Fillitz, Florentine 
Santacroce, juriste et patricien padouan ${ }^{196}$ (ill. 24). Le destinataire était nommé son conseiller et familier, promu à la noblesse héréditaire ${ }^{197}$ et recevait des armes ${ }^{198}$, qui étaient à la fois blasonnées et peintes (signum armature designate sive depicte in clipeo infraposito). Le texte comporte un préambule solennel ${ }^{199}$, un blasonnement allégorique ${ }^{200}$ et une liste extraordinairement longue de témoins, tous proches de l'empereur. La charte était à l'origine scellée de la bulle d'or de Charles IV (perdue) ${ }^{201}$.

La rédaction raffinée est sans doute due à Jean de Neumarkt (Jan ze Středy) ${ }^{202}$, qui avait reçu un enseignement « proto-humanistique » et

Mütherich, Denkmale der deutschen Könige und Kaiser, t. II, Ein Beitrag zur Herrschergeschichte von Rudolf I. bis Maximilian I. 1273-1519, Munich, 1978, p. 62 (n 44); Die Parler und der Schöne Stil, 1350-1400 : europäische Kunst unter den Luxemburgern (expos., Cologne, Schnütgen-Museum), éd. Anton Legner, Cologne, 1978-1980, t. I, p. 36 (ill.; par Manfred Wundram), et Resultatband, pl. 2-3; Heiliges Römisches Reich... [n. 48], p. 385-387 (nº V.13, par Ulrike Bauer-Eberhardt); G. Pfeifer, « Erby... » [n. 166], p. 33; Robert Novotný, « Od veřejné prezentace $\mathrm{k}$ zlistinění, od rituálu $\mathrm{k}$ formalizaci : úvahy nad proměnami nejstarší nobilitační praxe », dans Nobilitace ve světle písemných pramenů, éd. Jiří Brňovják et al., Ostrava, 2009, p. 75-83, à la p. 81 (ill. intervertie avec la page suivante); C. F. Weber, Zeichen... [n. 170], p. 34 .

196. Le 30 mai 1363, à Prague, il reçut avec son fils Francesco, toujours de Charles IV, la dignité héréditaire de comte palatin; Elda Martellozzo Forin, « Conti palatini e lauree conferite per privilegio : l'esempio padovano del sec. xv », dans Annali di storia delle università italiane, t. 3, 1999, p. 79-119, passim (éd. d'après la copie Padoue, Arch. di Stato, Notarile 3394, fol. 181v-183). Le destinataire est mal connu. Il pourrait avoir été destinataire des lettres sous le titre Imperator scribit cuidam doctori in Padua et pro privilegiis quibuslibet de gracia fiendis chez Jean de Neumarkt, Summa cancellariae (cancellaria Caroli I.) : Formulár král. kanceláre české XIV. století, éd. Ferdinand Tadra, Prague, 1895, p. 42 (n ${ }^{\circ}$ LXVII); la $2^{\mathrm{e}}$ partie du préambule («Suavis tue fame... ») est reprise pour la formule « [Familiaritas] Pro doctoribus », dans Collectarius perpetuarum formarum Johannis de Geylnhusen, éd. Hans Kaiser, Innsbruck, 1900, p. 15 (no 20).

197. Sur la concession d'armoiries comme étape de l'ascension sociale, G. Pfeifer, « Erby... » [n. 166], et P. Elbel, A. Zajic, « Wappenmarkt... » [n. 166].

198. D'argent à la divise d'or au lion de gueules couronné d'or. Contrairement à l'amélioration d'armoiries accordée par Charles IV à Bartolo da Sassoferrato (perdue) [n. 210], le lion de Santacroce ne semble pas se référer au lion de gueules de Luxembourg.

199. Incipit : Humane condicionis circumspecta sagacitas. Suivent des réflexions répétées dans beaucoup de lettres d'armoiries plus tardives : le trône impérial augmente sa gloire en récompensant ses fidèles... Non moins nouvelle et importante pour l'avenir, l'amende de 100 marcs d'or, payable moitié au fischus impérial et moitié au destinataire ou à ses héritiers.

200. Le champ blanc (argent) symbolise la pureté et l'innocence des bonnes œuvres du bénéficiaire, qui, avec la férocité du lion et ceint de la probité exprimée par la divise jaune (or), se dresse pour écraser les mauvais et leur perfidie. Des interpretations comparables se trouvent parfois dans des actes plus tardifs.

201. La marge inférieure (avec le repli) et les marges gauche et droite semblent avoir être coupées. Indice d'originalité : la souscription du chancelier impérial Jean de Neumarkt, faisant la recognition au lieu de l'archevêque de Mayence, archichancelier de l'Empire per Germaniam, est d'une autre main que le texte.

202. Sur l'homme, Jean Lulvès, Die «Summa cancellariae » des Johann von Neumarkt: eine Handschriftenuntersuchung über die Formularbücher aus der Kanzlei Kaiser Karls IV., 
qui souscrivit l'acte comme chancelier de Charles IV. En effet, le texte se retrouve, à de minimes variantes près, et y compris le blason, dans la Summa cancellariae (ou mieux Summa cancellarii) ${ }^{203}$ composée par Jean de Neumarkt vers 1360 , sous le titre Imperator recipit quendam in familiarem et consiliarium, nobilitat eum et donat sibi arma; et un peu plus tard dans le Collectarius perpetuarum formarum, rédigé par Jean de Gelnhausen après 1379 sous l'influence de cette même Summa (formule Imperator nobilitat et dat arma) ${ }^{204}$.

L'importance de l'acte se mesure aussi à la qualité de l'enluminure ${ }^{205}$. Les lignes 19 à 28 sont interrompues par deux champs ${ }^{206}$. Celui de droite contient le monogramme impérial - anomalie parmi les concessions d'armoiries - et celui de gauche, en forme de $M$ oncial, accueille une double image $^{207}$ : à droite l'empereur trônant, à gauche le destinataire, vêtu de rouge comme juriste, agenouillé et levant un écu monumental que l'empereur touche en signe de confirmation : heureuse synthèse entre la repré-

Berlin, 1891, p. 4-19; Peter Moraw, « Über den Hof Kaiser Karls IV. », dans Deutscher Königshof, Hoftag und Reichstag im späteren Mittelalter, éd. id., Stuttgart, 2002, p. 77-103, aux p. 87-88; Jana Nechutová, Die lateinische Literatur des Mittelalters in Böhmen, CologneWeimar-Vienne, 2007, p. 176-183.

203. Voir Summa cancellariae... [n. 202], p. 53-55 (n ${ }^{\circ}$ LXXXI). La Summa contient d'autres formules pour lettres d'armoiries et actes similaires : « Imperator dat cuidam arma etc. » (p. 21, $\mathrm{n}^{\circ}$ XXIX), « Imperator facit quendam militem et recipit eum in consiliarium » (p. 52, $\left.\mathrm{n}^{\circ} \mathrm{LXXX}\right)$, « Imperator nobilitat quendam et facit eum comitem palatinum » (p. 56-58, $\mathrm{n}^{\circ}$ LXXXIV). Aucune ne figure dans le formulaire de la chancellerie de Jean de Bohême, probablement de 1336-1345 : Summa Gerhardi : ein Formelbuch aus der Zeit des Königs Johann von Böhmen (c. 1336-45), éd. F. Tadra, Vienne, 1882.

204. Voir Collectarius... [n. 196], p. 37-38 (no 41). Sur la relation entre les deux formulaires, Summa cancellariae..., p. xx et séq.; J. Nechutová, Lateinische Literatur..., p. 187-189. Autres formules de lettres d'armoiries dans le Collectarius, p. 38-40 ( $\left.{ }^{\circ} 42\right)$ : « Concessio armorum et nobilitacio militum »; voir aussi G. Pfeifer, Wappen und Kleinod... [n. 166], p. 23-24; id., « Wappenbriefe... » [n. 166], p. 656. La formule « Abilitacio ut possit feuda recipere » (Collectarius..., p. 32-33, $\mathrm{n}^{\circ} 35$ ) combine - comme les lettres d'armoiries modernes - le privilège héraldique proprement dit avec le Lehenartikel (« article de fief »), concédant à un bénéficiaire non noble le droit de détenir des fiefs.

205. Le décor est-il dû au destinataire (comme on le supposerait) ou à Jean de Neumarkt? Celui-ci, qui dirigea de manière très inventive la rédaction des actes, fut aussi un des principaux mécènes de l'enluminure des livres en Bohême sous Charles IV; Gerhard Schmidt, « Malerei bis 1450 : Tafelmalerei, Wandmalerei, Buchmalerei », dans Gotik in Böhmen, éd. Karl Maria Swoboda, Munich, 1969, p. 167-321, 423-444, aux p. 179-182.

206. La contradiction entre la position de la miniature héraldique dans le texte et le mode de présentation annoncé (« signum armature designate sive depicte in clipeo infraposito ») pourrait s'expliquer par une rédaction en minute prévoyant un décor semblable à la lettre d'armoiries de Jean de Bohême de 1339.

207. Le fait que l'écriture enveloppe au plus près le contour de la miniature témoigne d'un dessin préparatoire avant l'écriture. Mais le peintre intervient ensuite, et les couleurs couvrent parfois certains fins traits d'écriture. Cela permet de préciser la supposition d'U. Bauer-Eberhardt [n. 195], « que l'enlumineur et le scribe collaboraient étroitement dans la confection de la charte, voire que la miniature précédait l'écriture ». 
sentation de l'acte juridique (cf. ill. 39a) et l'illustration des armes. Ulrike Bauer-Eberhardt a localisé le style de l'enluminure dans la région natale du destinataire (Padoue), bien que la charte soit délivrée à Pise ${ }^{208}$. Elle en a comparé le style à juste titre avec celui d'un manuscrit de l'Historia destructionis Troiae de Guido de Columnis $(i l l .25 a, b)^{209}$, qui contient des indications pour le peintre en dialecte vénitien (et que la charte permet de dater plus tôt qu'on ne pensait). L'acte de 1355 marquait une faveur particulière au destinataire, dans une période où par ailleurs une grande quantité de lettrés et d'autres personnages, en quelques mois, furent faits familiers de l'empereur ${ }^{210}$. En 1356, un autre acte au texte très semblable, à quelques variations près, reçut un décor limité à l'écu ${ }^{211}$.

Dans d'autres régions aussi, certaines chartes reçurent des armoiries peintes. Ainsi en Angleterre, celle par laquelle Édouard III concéda en 1362 à son fils aîné Édouard (le Prince Noir) les duchés nouvellement créés d'Aquitaine et de Gascogne : un écu figure à l'intérieur de l'initiale ${ }^{212}$. En France, citons le contrat de mariage entre Jean duc de Berry et Jeanne de Boulogne de $1389^{213}$ : les mariés forment la lettre et les champs intérieurs de l' $A$ sont occupés par leurs armoiries, mises en couleur contrairement aux

208. U. Bauer-Eberhardt, ibid., p. 385 (excellentes ill.).

209. Cologny, Fondation Martin Bodmer, cod. Bodmer 78, [en ligne :] www.e-codices. unifr.ch/fr/description/cb/0078 (catalogue) et www.e-codices.unifr.ch/fr/cb/0078 (notice); consultés juill. 2011.

210. J. Ficker, Forschungen... [n. 178], t. II, p. 110-111, décèle de même dans les privilèges accordés par Charles IV au célèbre juriste Bartole (Bartolo da Sassoferrato) en 1355 une représentation sociale différenciée. On connait en copie les lettres faisant de Bartole un conseiller et familier de l'empereur et lui concédant des competences semblables à celles d'un comte palatin dans le domaine de l'université de Pérouse (ibid., p. 537 et 588). L'amélioration d'armoiries par ajout du lion de gueules de Luxembourg est connue par le traité de Bartole De insigniis et armis : C. F. Weber, Zeichen... [n. 170], p. 32-34; A grammar of signs : Bartolo da Sassoferrato's tract on insignia and coats of arms, éd. Osvaldo Cavallar, Susanne Degenring, Julius Kirshner, Berkeley, 1994, p. 109. Cette édition, peu satisfaisante dans l'ensemble et notamment pour l'héraldique, se méprend sur la teneur de la charte et en fait à tort une invention de Bartole (p. 1, 8-12, 18, 22, 24). Bartole témoigne de la fréquence des lettres d'armoiries de Charles IV, notamment sans doute pour des Italiens : ibid., p. 109.

211. 5 décembre 1356, Metz; Namur, Arch. État, Familles particuliers, Michelnbach, M 24; Dokumente zur Geschichte des Deutschen Reiches und seiner Verfassung, 1354-1356, éd. Wolfgang D. Fritz, Weimar, 1978-1992 (MGH, Constitutiones, 11), p. 471 (nº 844); Albert Huart, « Un anobli du xive siècle », dans Annales de la Société archéologique de Namur, t. 38, 1928, p. 217-229; P. Elbel, A. Zajic, « Wappenmarkt... » [n. 166]. Le bénéficiaire n'était manifestement pas lié à l'auteur mais à Jean comte de Nassau, son ancien suzerain, nommé comme intermédiaire. Le blason correspond aussi en grande partie à celui de 1355 .

212. 19 juillet 1362; Londres, National Archives, E30/1105; Henry Charles Maxwell Lyte, Catalogue of manuscripts and other objects in the Museum of the Public Record Office, with brief descriptive and historical notes, 15e ed., Londres, 1938, p. 86; Richard Barber, Edward, prince of Wales and Aquitaine : a biography of the Black Prince, Londres, 1978, p. 177-178, pl. 4.

213. 5 juin 1389, Paris; Paris, Arch. nat., J 1105, no 8 (AE II 411); Zajic et Roland, « Urkundenfälschung » [n. 11], p. 408; à la bibliogr. citée, ajouter Léopold Delisle, compte 
usages de la chancellerie de France. Ces images héraldiques ne sont cependant pas un élément juridique de l'acte comme à la chancellerie impériale.

Le fils de Charles, le roi Wenceslas, suivit son père dans les concessions d'armoiries (ill. 26), mais on manque d'études sur le volume de sa production ${ }^{214}$. Une pièce remarquable est l'acte qu'il délivra en 1394 comme roi des Romains et roi de Bohême en faveur de son vicaire général à Mantoue, François (I $\left.{ }^{\text {er }}\right)$ Gonzague (ill. 27) ${ }^{215}$. En récompense des services rendus par sa maison et pour la plus grande gloire de celle-ci, le destinataire recevait le droit de porter les armes des rois de Bohême (modifiées). Or au milieu du parchemin se trouve non pas un écu, mais - comme le souligne le texte une lance avec son gonfanon (signum armature designate seu picte in banderio infrascripto), dont la hampe s'étend vers le bas jusqu'au repli. Une charte non moins remarquable mais plus tardive (1416), en faveur d'une ville, sera présentée ci-après ${ }^{216}$.

La production de concessions d'armoiries sous le roi Robert (Ruprecht) du Palatinat (1400-1410) est connue au moins par les registres impériaux ${ }^{217}$. Elle se place après les premières armoiries accordées par Sigismond de Luxembourg comme roi de Hongrie (voir plus bas) et après une lettre d'armoiries donnée le 22 août 1407 à Milan par Jean-Marie Visconti,

rendu de Jules Chavanon, Initiales artistiques extraites de chartes du Maine (Mamers, 1898), dans Journal des savants, 1899, p. 51-63, à la p. 53; G. Brunel, Images..., [n. 2], p. 236 (ill. 1).

214. G. Pfeifer, Wappen und Kleinod... [n. 166], p. 19, connaît 3 originaux et 13 copies. Voir aussi Ivan Hlaváček, Das Urkunden- und Kanzleiwesen des böhmischen und römischen Königs Wenzel (IV.) 1376-1419. Ein Beitrag zur spätmittelalterlichen Diplomatik, Stuttgart, 1970 (Schriften der MGH, 23) p. 63 (n. 27, 6 actes). Nous connaissons 4 originaux : $-1^{\circ} 14$ fevrier 1392, Žebrák; Karlsruhe, Landesarchiv Baden-Württemberg, Generallandesarchiv Karlsruhe, D 426; Friedrich von Weech, « Wappenbrief König Wenzels für die Brüder Hans und Claus Conczmann von Staffurt in der Markgrafschaft Baden, 1392 Februar 14 », dans Anzeiger für Kunde der deutschen Vorzeit, t. 29, 1882, col. 164-165; Heinrich von Sybel, Theodor Sickel, Kaiserurkunden in Abbildungen, Berlin, 1891, p. 142, et fasc. VI, pl. 22, [en ligne :] http://geschichte.digitale-sammlungen.de/kaiserurkunden/online/angebot (consulté août 2011), une des premières lettres d'armoiries en allemand (ill. 26); $2^{\circ}$ la charte pour les Gonzague de 1394 [n. 215] (ill. 27); 3 l'amélioration d'armoiries pour Jacques de Stubenberg, 19 décembre 1410; Graz, Steiermärkisches Landesarchiv, Dipl. 0; $4^{\circ}$ une lettre d'armoiries de 1416 , ci-après.

215. 2 décembre 1394, Prague; Mantoue, Arch. di Stato, Arch. Gonzaga, busta 384; T. Krejčík, « K listině... » [n. 185]; éd. citée de Bartolo da Sassoferrato, A grammar... [n. 210], p. 10 note 31. La charte fut apparemment expédiée non scellée (repli sans trous), malgré l'annonce habituelle du sceau de majesté. Le lion du blason (de gueules au lion d'argent, armé et couronné d'or, lampassé de gueules) porte comme altération (du lion de Bohême) ou brisure un collier d'or (« circulus coloris aurei a superiori parte pectoris versus tergum se protendens »).

216. Voir ci-dessous, n. 251.

217. Alfred Anthony von Siegenfeld, «Die Wappenbriefe und Standeserhebungen des Römischen Königs Ruprecht von der Pfalz, mitgetheilt aus den Reichs-Registratursbüchern im k. u. k. Haus-, Hof- und Staats-Archive zu Wien », dans Jahrbuch der k. k. heraldischen Gesellschaft Adler, n. s., t. 5-6, 1895, p. 395-430. 
duc de Milan 218 : celle-ci élevait les frères Cavazzi della Somaglia au rang de comtes et barons de Somaglia et augmentait les vieilles armoiries de la famille d'un chef se référant à l'auteur par trois guivres, et par le nom abrégé du duc en majuscules gothiques, IO(annes) / MA(ria $)^{219}$. Le texte, dans les deux tiers inférieurs du parchemin, fait place à l'écu gouaché. L'initiale, pour la première fois mais non la dernière, est ornée.

Nous y voyons plus clair dans la chancellerie du frère cadet de Wenceslas, Sigismond. Il fut roi de Hongrie en 1387, roi des Romains en 1411, roi de Bohême en 1419 et enfin couronné empereur en 1433. Sous son règne les concessions d'armoiries deviennent un phénomène diplomatique de masse, en Hongrie aussi bien que dans l'Empire, y compris ses parties italiennes. Les savants se sont intéressés avant tout aux actes pour des impétrants hongrois ${ }^{220}$. Zsombor Jékely cite comme les plus anciens deux documents de 1398 et 1401, encore sans armes peintes ${ }^{221}$. Une charte de 1405 est la

218. Giulia Bologna, « Le pergamene miniate conservate nell'Archivio storico civico di Milano », dans Arte lombarda, t. 16, 1971, p. 187-200, aux p. 187-188; sur une lettre d'armoiries de Philippe-Marie Visconti en 1414 en faveur de Francesco Bussone, voir n. 231.

219. L'auteur, concédant « aliqua insignia seu arma [...] in ea forma, in qua in presenti pagina sunt depicta... », permet que « in signum celebritatis et fame comitatus [...] supra dicta insignia vipere nostre signum in tribus locis debeat more solito figurari [...] ut semper et omni tempore esse valeat manifestum a nobis et domo nostra serenissima ducali Vicecomitum hujusmodi comitatus et dignitatis titulum procesisse [sic] ». Apparemment la famille reçut une altération d'armoiries en 1452 de François Sforza, remplaçant le nom IO(annes) MA(ria) par FR(anciscus) SF(orza).

220. Monumenta Hungariae heraldica / Magyar czimeres emlékek, t. I, éd. László Fejérpataky, Budapest, 1901; t. II, éd. id., Budapest, 1902; t. III, éd. Antal Áldásy, Budapest, 1926. Les documents ont été catalogués, autant que possible en groupes stylistiques, par Dénes Radocsay, « Gótikus magyar címereslevelek » [Les lettres d'armoiries gothiques en Hongrie], dans Müvészettörténeti Értesítő, t. 6, 1957, col. 271-294 (1405-1489); id., « Gotische Wappenbilder auf ungarischen Adelsbriefen » (I), dans Acta historiae artium Academiae scientiarum Hungaricae, t. 5, 1958, p. 317-358 (1405-1489); id., « Renaissance letters patent granting armorial bearings in Hungary », ibid., t. 11, 1965, p. 241-264 (texte) et t. 12, 1966, p. 71-92 (catalogue, 1490-1540). Sur les lettres d'armoiries du royaume de Hongrie : id., « Gotische Wappenbilder auf ungarischen Adelsbriefen, II », ibid., t. 10, 1964, p. 57-68; L. Vrtel', Osem storoči... [n. 189], p. 119-122. Sur les lettres d'armoiries pour les villes de Hongrie supérieure (actuelle Slovaquie) : Zsombor Jékely, « Die Rolle der Kunst in der Repräsentation der ungarischen Aristokratie unter Sigismund von Luxemburg », dans Sigismundus rex et imperator: Kunst und Kultur zur Zeit Sigismunds von Luxemburg, 1387-1437 (expos.), dir. Imre Takács, Mayence, 2006, p. 298-310, aux p. 298-300; Iván Bertényi, « Simon von Barrwys Wappenbrief aus dem Jahre 1417 », ibid., p. 220-226; Dušan Buran, « Medzi dvorom a radnicou, mezi radnicou a kapitulou : umeleckohistorické poznámky k výzdobe erbových listin hornouhorských miest v 15. storoči », dans Erbové listiny... [n. 166], p. 63-80. Sur les lettres d'armoiries hongroises sous Sigismond, deux articles à paraître dans les actes du colloque « Sigismund of Luxemburg and his time » (Oradea, 6-9 décembre 2007) : György Feiszt, « The heraldic charters of King Sigismund », et Szidonia Weisz, « The price of fidelity : donations of coats of arms for nobles from Transylvania during the reign of Sigismund of Luxemburg ».

221. Z. Jékely, « Die Rolle... », p. 298. Tomáš Krejčík, « Diplomatika erbovních listin 
première enluminée, selon l'usage, au milieu du parchemin ${ }^{222}$. Le décor est de qualité assez modeste, et peut-être inachevé comme le suggère l'espace vide entre l'écu et l'encadrement. Le concile de Constance démultiplia enfin la demande dans toute l'Europe ${ }^{223}$. Le décor reste alors normalement restreint aux armoiries. Dans de rares cas, on trouve des feuillages, dérivés de l'enluminure des livres; en Hongrie, la miniature d'armes est par ailleurs presque toujours insérée au début du texte, dans la position d'une initiale livresque.

Un décor inhabituel figure dans deux chartes pour le beau-frère de Sigismond, Nicolas II Garaï (Mikuláš II Gorjansky z Gorje), palatin de Hongrie, délivrées le 26 mars 1416 à Paris, l'une par Sigismond, l'autre par le roi de France Charles VI (ill. 29 et $30 a-b)^{224}$. Le style situe le peintre dans le milieu parisien $^{225}$. L'exposé, détaillant les mérites du destinataire, est semblable aux concessions d'armoiries accordées par Sigismond en Hongrie, mais les armoiries sont peintes au centre du texte selon la coutume de la chancellerie impériale. Autre anomalie : les armes sont représentées deux fois, sur deux écus inclinés et inclinés vers le centre, différents seulement par leurs cimiers. Entre les écus, les insignes ou devises entrelacés de deux ordres équestres : l'ordre hongrois du Dragon et l'ordre tchèque du Foulard (en allemand « Tuchorden » : l'objet, tissu torsadé en forme d'anneau, est peutêtre dérivé d'un lacs d'amour) ${ }^{226}$.

vydaných českou panovnickou kanceláŕí 14.-18. století », dans Erbové listiny..., p. 132-144, à la p. 134, décrit une lettre d'armoiries hongroise de 1398 (sans référence) comme premier exemple de charte plaçant la peinture héraldique au début. Z. Jékely, s'intéressant à la noblesse, omet la charte pour Kaschau/Košice [n. 189].

222. 15 avril 1405, Buda, pour Péter et András Tétényi et pour leurs parents de la famille Haraszti (ill. 28); Budapest, Magyar Országos Levéltár, DL 64.122; D. Radocsay, « Gotische Wappenbilder... » (I), p. 318, 320, 351; id., « Über einige illuminierte Urkunden »... [n. 166], p. 31 (identifiant le lieu d'expédition); Z. Jékely, « Die Rolle... », p. 298-299 (ill.).

223. Avant le concile de Constance, D. Radocsay, « Gotische Wappenbilder... » (I), p. 351-352., cite seulement 3 actes; Z. Jékely, « Die Rolle... », p. 298-299, en compte 54 pour des Hongrois de septembre 1414 au début de 1419 (période où Sigismond résida principalement à Constance); voir aussi P. Elbel, A. Zajic, « Wappenmarkt... » [n. 166].

224. D. Radocsay, « Gotische Wappenbilder... » (I), p. 322 et 353; Gotika : Katalog výstavy (expos. Slovenská Národná Galéria), éd. Dušan Buran, Bratislava, 2003, p. 798-799 (nº 6.2.14, par Radoslav Ragač et D. Buran) et p. 174 (ill. 132); L. Vrtel', Osem storočí... [n. 189], p. 116-117 (ill.); J. Novák, « Armálesy... » [n. 189], p. 12 (date erronée); Attila Pandula, « Faleristické východiská jednotlivých armálesov », dans Erbové listiny... [n. 166], p. 194-202, aux p. 194-196; les deux exemplaires (Bratislava, Slovenský Národný Archív, Archív rodu Zay z Uhrovca, fasc. C, $\mathrm{n}^{\text {os }}$ 7-8) sont étudiés par Marta Melníková et Zsombor Jékely dans Sigismundus... [n. 220], p. 406-408 (ill. couleur).

225. Les légères différences d'exécution ne justifient pas l'attribution à deux peintres différents (proposée dans Sigismundus..., p. 408).

226. Voir aussi Igor Graus, « Armálesy z hladiska faleristiky », dans Erbové listiny... [n. 166], p. 181-193, aux p. 182-183 (ill. couleur). Garai, membre « fondateur » de l'ordre du Dragon, fut apparemment un collectionneur passionné d'insignes des ordres de chevalerie, qu'il fit mettre en image. En décembre 1415 il reçut l'insigne de l'ordre aragonais de l'Étole 
Dénes Radocsay a repéré à Constance quatre peintres d'armoiries chargés des privilèges héraldiques de Sigismond pour des Hongrois (armes au début du texte) ${ }^{227}$. Comme on pouvait s'y attendre, ils travaillaient en même temps pour d'autres destinataires dans l'Empire (armes au centre). L'exemple suivant illustre un parfait mélange des deux formes : au début de 1418 Sigismond accorda une charte aux frères Ermanno et Francesco de' Claricini, de Cividale, qui aurait dû suivre la coutume de la chancellerie impériale (ill. 31) ${ }^{228}$. Les impétrants ${ }^{229}$ virent leurs armoiries anciennes remplacées par celles de la famille Dornpacher qu'ils avaient héritées (hic depicta arma seu nobilitatis insignia in signum alterius armature antique alia arma hereditario nomine domus de Dornpacher). Le texte ne les blasonne pas. La miniature centrale fut exécuté apparemment par le « troisième peintre d'armoiries » de Radocsay : on reconnaît de lui l'encadrement doré à la feuille et contenant des quatre-feuilles, les parties filigranées en or à petites fleurs de couleur entre le quatre-feuilles et le cadre, enfin les lambrequins stylisés en forme d'acanthe qui emplissent le champ central. Une lettre d'armoiries pour la famille Suki, aussi de 1418, montre des formes presque identiques (ill. $32 a)^{230}$. En principe les concessions d'armoiries typiques de la chancellerie impériale n'offrent guère la liberté d'expansion dans les marges propre aux chartes hongroises. Cependant, celle des Claricini invente une solution : le scribe, en écrivant le texte, a laissé en blanc (outre la place de l'écriture d'apparat) une surface dans le coin gauche supérieur pour le $S$ de

et de la Jarre : Waltraud Winkelbauer, « Concedimus ordinis nostri inisgnia : die Ordensverleihungsurkunden des Georg von Volkersdorf im Niederösterreichischen Landesarchiv », dans Mensch und Archivar : Anton Eggendorfer zum 70. Geburtstag, Sankt Pölten, 2010, p. 385-442, aux p. 402-403 (n. 69, bibliogr. sur Garai).

227. D. Radocsay, « Gotische Wappenbilder... » (I) [n. 220], p. 321-330.

228. 28 janvier 1418, Constance; Brno, Moravská Galerie, inv. č. 20272; Tomáš Krejčík, « Erbovní listina z roku 1418 », dans Bulletin Moravské Galerie v Brně, t. 25, 1977, p. 23-24 (ill.). Sur le repli, souscription de chancellerie nommant l'évêque de Trogir, Simon. Nous remercions amicalement M. Petr Elbel (Brno/Vienne) qui nous a communiqué des photographies.

229. « ... nobilibus Hermanno et Francisco fratribus carnalibus de Claricinis de Civitate Austrie patrie Forijulii ». Ermanno de Claricini servait au plus tard en 1420 et probablement encore en 1476 comme l'un des deux provéditeurs de la ville : Giuseppe Vale (éd.), Itinerario di Paolo Santonino in Carintia, Stiria e Carniola negli anni 1485-1487 (codice Vaticano latino 3795), Cité du Vatican, 1943 (Studi e testi, 103). En 1368 Charles IV avait concédé aux frères Nicolò et Paolo de' Claricini le droit de recevoir et de concéder des fiefs (d'Empire); J. F. Böhmer, Regesta Imperii, VIII : Die Regesten des Kaiserreichs unter Karl IV. (1346-1378), erstes Ergänzungsheft, éd. Alfons Huber, Innsbruck, 1889, n$^{\circ} 7272$ (1 ${ }^{\mathrm{er}}$ mai 1368, Udine). Le 18 mai 1572, à Vienne, l'empereur Maximilien II accorda à la famille une amélioration d'armoiries, et la charte inclut le texte de l'acte de 1418; Vienne, Haus-, Hof- und Staatsarchiv, Reichsregister Maximilian II. 17, fol. 152v-155v.

230. 29 mars 1418, Constance; Cluj, Archiva Istorica a Filialei Din Cluj a Academici RR; D. Radocsay, « Gotische Wappenbilder... » (I) [n. 220], p. 327 (ill.) et 353; ill. couleur dans Z. Jékely, « Die Rolle... » [n. 220], p. 300. 
Sigismundus ${ }^{231}$. L'initiale a été tracée sur fond d'or sans encadrement, avec de fins rinceaux à gauche de l'écriture; des feuillages identiques mais indépendants se trouvent à droite. La marge supérieure fut laissée libre pour la suscription en écriture d'apparat à lettres allongées. En outre les espaces libres entre ces grandes lettres d'apparat sont emplis d'un très léger filigrane. L'écriture décorative, le décor filigrané et les bordures forment un luxueux cadre sur trois cotés.

La divergence de style entre les feuillages en marge et les lambrequins des armoiries (malgré des couleurs identiques) suggère que le décor d'origine fut complété plus tard. S'y ajoute l'argument de l'absence d'enluminures comparables de la deuxième décennie $\mathrm{du} \mathrm{xv}^{\mathrm{e}}$ siècle à Constance, alors qu'on trouve des parallèles significatifs vers 1435/1445 - époque du concile de Bâle. Il faut citer en particulier la seule initiale peinte du ms. Vienne, Österr. Nationalbibl., Cod. 1544 (ill. 32b). Les filigranes sur d'autres pages de ce livre montrent qu'il fut décoré à Vienne vers $1440{ }^{232}$, mais l'initiale est stylistiquement isolée, apparemment due à un enlumineur formé ailleurs; et l'initiale de la charte Claricini offre pour la première fois un parallèle stylistique satisfaisant ${ }^{233}$.

231. Il est douteux que seules les lettres d'armoiries hongroises aient servi de modèle. Le 11 novembre 1414, Philippe-Marie Visconti accorda à Francesco Bussone (da Carmagnola), qui l'avait préservé d'un attentat, des armoiries (outre une promotion et un fief); «Gentium memoriam archiva » : il tesoro degli archivi, Rome, 1996, p. 170, ill. 79 et pl. couleur V; T. Krejčík, « Diplomatika... » [n. 221], p. 133. Nous remercions le professeur Horst Enzensberger de ses informations importantes sur ce document. Outre l'écu central à la guivre des Visconti, la charte est ornée d'une initiale peinte, enrichie de motifs zoomorphes, et d'une bordure armoriée sur trois côtés. Des actes lombards de cette sorte auraient pu être connus des Claricini, Frioulans. Nous avons présenté [n. 218] un acte plus simplement orné montrant pour la première fois (à notre connaissance) la combinaison des armoiries avec une bordure (délivrée en 1407 par Jean-Marie Visconti, frère de l'auteur de celle de 1414). Les deux actes sont caractéristiques du type ancien. Citons aussi des exemples français postérieurs, de René d'Anjou, avec initiale peinte aux armes de l'auteur en haut à gauche et écu du destinataire en bas à droite: Splendeur de l'enluminure : le roi René et les livres [expos., Angers, 2009], dir. Marc-Édouard Gautier, [Angers et Paris], 2009, p. 253-257, $\mathrm{n}^{\text {os }}$ 15-17 (ill.; par Laurent Hablot) : 27 mars 1464, 22 mars 1475 et 25 juin 1475; cette dernière déjà décrite dans O. Guyotjeannin, «Images... » [n. 2], p. 30-31 et ill. 12 (millésime inexact).

232. Mitteleuropäische Schulen V... [n. 153], no 143 (par M. Roland).

233. Voir l'initiale $S$ sur fond d'or non encadré, la vrille fine tendant à former de petites spirales avec une petite fleur au centre, et la façon d'intégrer l'or et les motifs graphiques. À la recherche d'œuvres comparables on rencontre l'enlumineur des mss. Vienne, Österr. Nationalbibl., Cod. 5089, fol. 1, et Munich, Bayer. Staatsbibl., Clm 18.225, fol. 1, comportant chacun une seule initiale peinte. Le ms. de Munich a dû être produit autour de 1437-1438 (selon les filigranes), vraisemblablement pour Johannes Keck. Le ms. de Vienne, exécuté après 1443, fut probablement orné à la demande de Petrus Knorr. Les deux destinataires étaient des esprits ouverts, voyageurs, familiers des universités d'Italie du Nord et du conciliarisme, en même temps attachés à leurs racines bavaroises. Ce milieu, et peut-être plus précisément le concile de Bâle, pourrait avoir joué un rôle déterminant pour les actes enluminés ici cités. La description détaillée de Vienne, Österr. Nationalbibl., Cod. 5089, sera publiée dans Mitteleuropäische Schulen VI (ca. 1410-1450) : Österreich mit Ausnahme von 
3. Les comtes palatins, auteurs de lettres d'armoiries. - Outre le roi ou l'empereur, les comtes palatins qu'il nomme délivrent de plus en plus de concessions d'armoiries à partir du $\mathrm{xv}^{\mathrm{e}}$ siècle ${ }^{234}$. Nous connaissons déjà des précédents sous Louis de Bavière ${ }^{235}$, et un cas comparable se présente sous Charles IV : le 8 mai 1355, il éleva Francesco Castracani degli Antelminelli et ses successeurs mâles au rang de sacri palatii comites, avec droit de nommer juges et notaires et de légitimer les enfants illégitimes; il leur conféra le vicariat (vicariam) de Coreglia et transforma ce fief impérial, avec ses dépendances, en comté (comitatum) ${ }^{236}$. Les privilèges du palatinat furent assez fréquemment sollicités au XIv ${ }^{\mathrm{e}}$ siècle, surtout par des Italiens ${ }^{237}$, mais aucun ne comportait encore le droit de concéder des armoiries.

Un exemple intéressant de ce développement tardif date du concile de Bâle ${ }^{238}$. Sigismond avait déjà élevé son conseiller Giovan Francesco Capodilista au rang de chevalier par un acte du 6 avril 1434 (à Bâle), il l'avait intégré à son Conseil et l'avait encore, avec ses fils, nommé comte palatin avec des prérogatives très étendues; il l'avait même intégré à ses familiers et à la domesticité impériale, avec amélioration d'armoiries ${ }^{239}$. Le

Wien und Niederösterreich, Deutschland, Schweiz, Vienne, en préparation (Die illuminierten Handschriften und Inkunabeln der Österreichischen Nationalbibliothek, 15).

234. Sur le développement du palatinat, bref aperçu chez G. A. Seyler, Geschichte der Heraldik... [n. 178], p. 353-369; J. Arndt, Hofpfalzgrafen-Register [n. 166], t. I, 1964, p. v-xxiv (sur la fonction de comte palatin, de 1355 à 1806); t. II, 1971, p. v-xxxvir (sur les lettres d'armoiries et le palatinat, 1350-1806); t. III (Neustadt an der Aisch, 1988) p. vII-Xx (sur le droit de nomination des notaires); art. « Pfalzgraf », dans Deutsches Rechtswörterbuch : Wörterbuch der älteren deutschen Rechtssprache, t. 10, 1997-2001, col. 664-666 [en ligne : http://drw-www. adw.uni-heidelberg.de/drw/]. Sur les origines italiennes du palatinat avant le règne de Charles IV, voir encore l'indispensable J. Ficker, Forschungen... [n. 178], t. II, p. 66-118, à la p. 67; sur le palatinat en Italie, E. Martellozzo Forin, « Conti palatini... » [n. 196]. On a cru auparavant que les comtes palatins ont commencé à donner des lettres d'armoiries en 1438 (G. Pfeifer, Wappen und Kleinod... [n. 166], p. 19), ce que contredit l'acte de 1435 étudié ci-après.

235. Voir la charte pour Castruccio Castracani, 1327 [n. 176].

236. 8 mai 1355, Pise; Arch.di Stato, Armario 3, $\mathrm{n}^{\mathrm{o}} 17$; éd. (fautive) dans Le azioni di Castruccio Castracane... [n. 180], p. 237-240 (nº 25); J. Ficker, Forschungen... [n. 178], t. II, p. 109 et 115; La « Libertas Lucensis » del 1369 : Carlo IV e la fine della dominazione pisana, Lucques, 1970, p. 106-108.

237. Quelque cinq formules pour les privilèges palatinsse trouvet dans la Summa cancellariae... [n. 196], p. 54-59, $\mathrm{n}^{\text {os }}$ LXXXII-LXXXV, et p. 86-87, $\mathrm{n}^{\circ}$ CXXIV. Trois sont dans le Collectarius... [n. 196], p. 23-32 (n $\left.{ }^{\text {s }} 32-34\right)$. Les bénéfices revenaient à la chancellerie impériale : J. Ficker, Forschungen..., t. II, p. 110.

238. Ce qui témoigne du rôle que joua ce concile comme marché d'actes, de même que celui de Constance auparavant.

239. Venise, Bibl. naz. Marciana, Cod. Marc. lat. V 59 (2438), copie enluminée par le notaire Sébastien Cavazzoni de Padoue, 1542; J. F. Böhmer, Regesta Imperii, XI, 1-2 : Die Urkunden Kaiser Sigmunds (1410-1437), éd. Wilhelm Altmann, Innsbruck, 1896-1900, $\mathrm{n}^{\text {os }} 10218$ et 12316aa; éd. in extenso dans E. Martellozzo Forin, « Conti palatini... » [n. 196], d'après une copie à Padoue, Arch. di Stato, Notarile 3342, fol. 60-62v (l'original était scellé de la bulle d'or et signé sur le repli par le chancelier Kaspar Schlick). Selon l'usage, le palatinat devait passer à la descendance mâle. L'exposé rapporte l'activité de Capodilista comme représentant de 
bénéficiaire était un noble juriste qui avait longtemps enseigné in utroque à Padoue et participait au concile comme orator de Venise ${ }^{240}$. En sus de ses compétences antérieures (légitimation d'enfants, nomination de notaires, de dix docteurs ${ }^{241}$ et de dix chevaliers), il fut habilité par un deuxième acte de Sigismond ${ }^{242}$ à anoblir, dans une ville quelconque de l'Empire, trois personnes, dont Manfredo Dal Cortivo, et à conférer à celui-ci, au nom de l'empereur, des armoiries. De fait, il donna dès le 19 juillet 1435, à Bâle, une lettre de noblesse et d'armoiries en faveur dudit Manfredo ${ }^{243}$,

Venise au concile de Bâle. L'amélioration d'armoiries consista à modifier la position du cerf de gueules (non plus au pas mais cabré), avec une violette dans la gueule sur champ doré (armes d'origine), et à ajouter un nouveau champ, symbole de la dignité palatine (« pro comitatu ») : d'or au lion d'azur coiffé d'une couronne d'or, de gueules, collier d'or, sur mantelet de vair (« mantelina varii »), dessus une aigle.

240. Giovan Francesco consacra à la mémoire des Capodilista, dans les années 1430, un livre écrit de sa main et richement enluminé; voir Karl Schrauf, Familienbuch der Capodilista in Padua vom Jahre 1435, Vienne, 1881 (vieilli); et surtout le fac-similé De viris illustribus familiae Transelgardorum Forzatè et Capitis Listae, codice BP 954 della Biblioteca civica di Padova, $150^{\circ}$ anniversario della Cassa di risparmio di Padova e Rovigo, introd. Mario Salmi, éd., trad. et comm. Mirella Blason Berton, Rome, 1972; brièvement, Andrea von HülsenEsch, Gelehrte im Bild: Repräsentation, Darstellung und Wahrnehmung einer sozialen Gruppe im Mittelalter, Göttingen, 2006, p. 272-278; Sigismundus... [n. 220], p. 344-345 (nº 4.45, par Zsombor Jekely, Margret Scott). Le ms. raconte comment Charlemagne aurait conféré aux chevaliers Carlotus, Johannes et Transelgardus un titre comtal et à Transelgardus, en sus, les armoiries d'un chevalier sarde fait prisonnier. Voir aussi J. F. Böhmer, Regesta Imperii, I : Die Regesten des Kaiserreichs unter den Karolingern, 751-918, Bd. 1, éd. Engelbert Mühlbacher et Johann Lechner, Innsbruck, 1908; 2e éd., avant-propos Leo Santifaller, introd., concordances et compléments par Carlrichard Brühl et Hans H. Kaminsky, Hildesheim, 1966, nº 501. La légende de l'image de Giovan Francesco Capodilista à cheval (fol. 32) rapporte que, fait chevalier par Sigismond au concile de Bâle, admis au Conseil et parmi les familiers de l'empereur, il aurait été doté d'armoiries (fol. $35 \mathrm{v}$, description de son sceau comme comte palatin; fol. 36, ill. couleur). Son privilège palatin aurait été scellé d'une bulle d'or. L'empereur l'aurait autorisé à porter, outre sa propre devise, celles des ordres d'Angleterre et d'Aragon, et le roi de Chypre lui aurait aussi conféré son ordre. De fait, l'image le montre portant l'ordre du Dragon, l'ordre aragonais de la Jarre et le collier en $S$ de Lancastre (mais non l'ordre chypriote de l'Épée). Le manteau d'azur de son cheval et le lambrequin de l'écu (fol. 36) sont semés d'éperons, sans doute doute insigne de la dignité de chevalier aux éperons d'or (« eques auratus »). Le document très soigné, qui ne parvint peut-être pas au destinataire, s'inscrit dans ce contexte honorifique. Sur Capodilista, voir, outre l'édition citée (p. 40-45) : Annalisa Belloni, Professori giuristi a Padova nel secolo XV : profili bio-bibliografici e cattedre, Francfort, 1986; Paul F. Grendler, The universities of the Italian Renaissance, Baltimore, 2002, p. 24, 26, 184-185; Mirella Tocci, « Capodilista, Giovan Francesco », dans Dizionario biografico degli Italiani, t. 18, Rome, 1975, p. 638-640. Kristina Odenweller (université de Freiburg) prépare une thèse de doctorat sur le personnage. Nous remercions cordialement $\mathbf{M}^{\mathrm{me}}$ Odenweller de ses nombreux précieux renseignements.

241. Sur les nominations de docteurs par Capodilista, E. Martellozzo Forin, « Conti palatini... » [n. 196] (Annexe).

242. Le 7 juin 1435, Trnava (inséré dans la copie mentionnée n. 239). Le chancelier Kaspar Schlick a écrit la souscription. Analyse (insuffisante) dans Regesta imperii, t. XI/1-2 [n. 229], $\mathrm{n}^{\mathrm{o}} 11112$.

243. La note au milieu de la marge inférieure, du $\mathrm{xv}^{\mathrm{e}}$ siècle « In Hoff : id est a Curtivo » 
originaire de Padoue, et de ses fils, sous la forme d'un acte notarié enluminé $^{244}$ (ill. $33 a$ ). On concédait donc des armoiries à des demandeurs dont l'ascendance patricienne et d'ancienne noblesse était attestée; les armes de la famille recevaient deux améliorations, établissant encore une fois le lien avec l'empereur et avec le comte palatin. À l'ancien lion-de-mer en champ d'azur (leonem rubeum medium cum cauda galli in campo lazuro) fut surajoutée une couronne d'or; à l'écu, un chef qualifié d'impérial (analogue au capo dell'Impero comme marque d'appartenance au parti gibelin), d'or à l'aigle de sable mais monocéphale (cum aquila desuper imperiali nigra in campo aureo). L'auteur allait plus loin en conférant au bénéficiaire le cimier «très ancien » de sa propre famille des Transelgardi, Capodilista et Forzatè : un guerrier turc barbu et armé d'un cimeterre, tenant une horloge (rologium) ${ }^{245}$ où se lit l'inscription Memento quod cito labitur. Comme de coutume, l'image était annoncée et peinte au milieu du texte. La charte nomme notaire Giovanni, bachelier en décret, déjà attesté comme écrivain et notaire du concile depuis 1432 et actif autour de 1450 à la Curie; trois prélats d'Italie, les évêques de Lesina et d'Osimo et l'abbé de San Fermo à Vérone, souscrivirent comme témoins après le notaire ${ }^{246}$ et Capodilista.

La qualité de l'exécution invite à mieux cerner l'artiste. Le cimier se prête

donne un indice sur les bénéficiaires, peut-être la branche padouane (nommée en italien) de la famille patricienne Imhoff de Nuremberg, liée par le commerce à l'Italie, et dont les armoiries (de gueules au lion de mer d'or), attestées depuis environ 1400, ne diffèrent que par les couleurs; Johann Siebmachers Wappenbuch von 1605, éd. Horst Appuhn, 2e éd., Dortmund, 1989, t. II, pl. 206; Wilhelm von Imhoff, Genealogisches Handbuch der zur Zeit lebenden ratsund gerichtsfähigen Familien der vormaligen Reichsstadt Nuremberg, $8 \mathrm{e}$ livraison, Nuremberg, 1890, p. 109-110, et pl. entre les p. 108 et 109; Walter von Hueck, Adelslexikon, t. V : Has-I, Limburg an der Lahn, 1984, p. 447-450; Christoph von Imhoff, « Die Imhoff, Handelsherren und Kunstliebhaber : Überblick über eine 750 Jahre alte Nürnberger Ratsfamilie », dans Mitteilungen des Vereins für Geschichte der Stadt Nürnberg, t. 62, 1975, p. 1-42. Un Manfredo a Cortivo et ses descendants sont par ailleurs inhumés dès 1367 à Padoue dans Santa Maria del Carmine, [en ligne :] www.maldura.unipd.it/ddlcs/cem/catalogazione\%20corpus.pdf. Mais l'identification reste incertaine.

244. Le 19 juillet 1435, Bâle; Padoue, Bibl. civica, BP 1641/III; Il gotico nelle Alpi, 1350-1450 (expos., Castello del Buonconsiglio, Museo diocesano tridentino), éd. Enrico Castelnuovo, Francesca de Gramatica, Trente, 2002, p. 540-543 (no 54, par Gilda P. Mantovani, bonne ill., attribution à un enlumineur padouan); De viris... [n. 240], p. 46. Le sceau de l'auteur comme comte palatin est annoncé, mais la charte semble avoir été rognée au bas et ne conserve même plus de trou de scellement. Le Codex Capodilista contient au fol. 1v une paraphrase (ibid., p. 50).

245. La première charte où soit figurée une horloge est celle de l'abbé Robert de SaintSauve, Montreuil-sur-Mer, 1377, dont le contenu est en rapport (Paris, Arch. nat., K 522a, $\mathrm{n}^{\mathbf{0}} 2$ ter). Comme ici, c'est une horloge sans cadran, dont on voit les rouages et la sonnerie. Zajic et Roland, « Urkundenfälschung » [n. 11], p. 405-406 (ajouter à la bibliogr. : L. Delisle, compte rendu de Chavanon [n. 213], p. 53-54).

246. Dont la note de rédaction précise que, devant ces témoins, Rolando dal Cortivo fut constitué per anulum représentant de sa famille dans ses nouveaux droits. Présent dans l'entourage de Capodilista au concile, il est témoin à une nomination de notaire le 17 février 1435 : De viris..., p. 49-50 et fac-similé (fol. 1v). 
à une comparaison immédiate avec la chronique familiale des Capodilista $(\text { ill. } 33 b)^{247}$ : non seulement les moindres motifs correspondent, mais les lambrequins présentent le même fin modelé en hachures; parfaite identité également dans l'étonnant dessin du guerrier turc. Il est plus difficile de définir l'empreinte stylistique. Zsombor Jékely et Margret Scott attribuent la charte et le manuscrit Capodilista à un artiste de Bâle ${ }^{248}$ : sans doute à juste titre, mais ils soulèvent ainsi le problème de l'empreinte régionale sur le milieu international du concile, sans aller au-delà ${ }^{249}$. Il pourrait s'agir du style d'un enlumineur du nord de l'Italie, plus à l'aise dans les parties ornementales (comparer la queue des chevaux), peinant à représenter des figures dans un cadre spatial : en dépit du fin modelé, ses personnages manquent de présence corporelle. On trouve des figures de ce genre d'abord dans le domaine du portrait bourgeois, plus généralement dans les chroniques enluminées ${ }^{250}$.

Dans les concessions d'armoiries l'image a une fonction utilitaire : ni la valeur artistique ni la performance « médiatique » ne sont en général au premier plan. Mais outre la fonction juridique, les concessions d'armoiries remplissent aussi, et c'est une raison de bien les enluminer, une fonction identitaire dans la sphère sociale du bénéficiaire. On conserve ainsi un nombre d'exemples d'excellente qualité artistique, notamment en faveur de villes : sans doute l'effet d'un plus large cercle de bénéficiaires et donc d'un plus grand souci de publicité.

C'est le cas tout d'abord de la lettre d'armoiries (et de sceaux) donnée par Venceslas IV comme roi de Bohême, en 1416, pour une ville de Moravie, Austerlitz (Slavkov u Brna) ${ }^{251}$. Les armoiries sont combinées avec celles de

247. Padoue, Bibl. civica, BP 954 [n. 240], fol. 2. La chronique contient 26 peintures en pleine page de chevaliers, sans bordures, 2 p. avec 12 bustes dans un cadre architectural (fol. 33, 34), 3 p. d'armoiries (fol. 2, 3, 36) et un dessin à la plume d'amateur (fol. 37). L'unique lettre champie, fol. 32v, est d'un style français ou flamand alors courant à Bâle; M. Roland, « Basler Buchmalerei um 1430/40 : zwei Neuzuschreibungen aus dem Bestand der Österreichischen Nationalbibliothek », dans Scriptorium und Offizin : Festgabe für Martin Steinmann zum 70. Geburtstag = Basler Zeitschrift für Geschichte und Altertumskunde, t. 110, 2010, p. 81-105, aux p. 87-90.

248. Sigismundus... [n. 220], p. 344-345 (n $\left.{ }^{\circ} 4.45\right)$.

249. Ils suivent ainsi Mario Salmi, qui a proposé Bâle en 1972. D'après le style il indiquait « un artista di educazione austriaca, operoso a Basilea » (introd. citée [n. 240], p. 24-25) : supposition démentie par la connaissance de l'art autrichien acquise depuis.

250. Par ex. : Parme, Bibl. Palatina, ms. 1194, Antonio Baldana, De magno schismate; voir Paola Guerrini, « Iconografie di liturgie nella cronistica europea del xv secolo », dans Rivista di storia della miniatura, t. 11, 2007, p. 203-212; ead., Propaganda politica e profezie figurate nel tardo medioevo, Naples, 1997, p. 47-64, ill. 72-96. La chronique s'arrête en 1419, copie et enluminure sont de peu postérieures.

251. Prague, 1er juillet 1416; Vyškov, Státní okresní archiv, Archiv města Slavkov u Brna, inv. č. 1; P. Elbel, A. Zajic, « Wappenmarkt... » [n. 166], p. 309-310. Les armoiries représentées (en couleur) sont destinées selon le dispositif au sceau municipal (stat insigele); Vladimír Jan Sedlák, « Über den Ursprung der Städtewappen » dans Genealogica et heraldica, 10 
l'Empire (d'or à une aigle de sable à langue de gueules) et du margrave de Moravie (d'azur à un lion d'argent armé d'or) sur un écu parti. Les figures sur les trois armoiries sont à chaque fois partiellement représentées, et de telle manière qu'elles composent un corps hybride (mi-aigle, mi-lion) ${ }^{252}$. Le dispositif ne blasonne pas mais renvoie à l'illustration ${ }^{253}$. De ce point de vue, mais aussi par le rapport héraldique avec les armes de l'auteur, la pièce suit l'ancien modèle.

En 1369, le roi Louis le Grand de Hongrie avait déjà concédé à la ville de Kaschau (Košice) un sceau armorié ${ }^{254}$. La charte ne contient pas d'illustration, mais le blason, par le rapport avec le roi Louis, la rattache au groupe ancien. La lettre d'armoiries ${ }^{255}$ de Sigismond en faveur de Kaschau en 1423 représente, elle, l'écu (ill. 34) ${ }^{256}$. Le champ réservé à l'image au début du texte (lequel texte ne contient pas de blason), est dans un cadre doré aux coins ornés de feuilles d'acanthe. Ce cadre est accompagné, dedans et dehors, d'un « frémissement de filigrane » du plus haut raffinement; le champ est ainsi ancré sur le parchemin comme les armoiries sont ancrées dans le champ. Un ange à mi-corps sert de tenant ${ }^{257}$, importante inno-

[n. 166], t. II, p. 427-432, à la p. 429, ne reconnaît donc pas, dans cet acte et dans la charte de 1369 pour Kaschau/Košice [n. 189], des lettres d'armoiries au sens strict.

252. C'est une forme de mi-parti : Claus D. Bleisteiner, « Der Doppeladler von Kaiser und Reich im Mittelalter », dans Mitteilungen des Instituts für Österreichische Geschichtsforschung, t. 109, 2001, p. 4-52, à la p. 14. J. Sedlák, « Über den Ursprung... », p. 429, identifie l'aigle à deux têtes sur fond d'or du premier champ avec celle des armoiries silesiennes.

253. «Derselben wappen, als sie hyrynne mit pilden, farben, strichen und figuren eigentlich geczyret und gemalet sind » (« Lesdites armoiries, telles qu'elles sont ici proprement dessinées et peintes en images, couleurs, traits et figures »).

254. Voir ci-dessus, n. 189.

255. Les armoiries, selon le dispositif (faisant suite à la charte de 1369) étaient destinées aux sceaux et à la bannière (« sigillo secreto et missili ac vexillo »).

256. 31 janvier 1423, Presbourg; Košice, Archiv mesta, Insignia, $\mathbf{n}^{\circ} 2$; D. Radocsay, « Gótikus magyar címereslevelek »... [n. 220], p. 271-294; id., « Gotische Wappenbilder... » (I) [n. 220], p. 331-333; Gotika... [n. 224], p. 799-800, par Radoslav Ragač et Dušan Buran (ill.); Alžbëta Güntherova, Ján Misianik, Illuminierte Handschriften aus der Slowakei, Prague, 1962, p. 26 ( $\mathrm{n}^{\circ}$ 21) et ill. 81; Magyarországi müvészet 1300-1470 kôrûl, éd. Ernő Marosi, Budapest, 1987, p. 630-631, ill. 1442 ; L. Vrtel', Osem storocí... [n. 189], p. 96 et 130 (ill.), Sigismundus... [n. 220], p. 620-621 (no 7.61, par Zsombor Jekely); D. Buran, « Medzi dvorom a radnicou... » [n. 220], p. 63-68 (ill. couleur); Martin Javor, Heraldika na východnom Slovensku, Prešov, 2004, p. 35-36, [en ligne :] wwwmcpo.sk/downloads/Publikacie/SpolPred/SPDEJ200502.pdf (consulté juill. 2011).

257. Les anges tenants se retrouvent ensuite dans les lettres d'armoiries des villes : D. Radocsay, « Gotische Wappenbilder... » (I), p. 346-347; L. Vrtel', Osem storocí..., p. 130 ; D. Buran, « Medzi dvorom a radnicou... », p. 66-69. Auparavant, citons celles pour Kaschau/ Košice, 5 juin 1453, Vienne, par Ladislas le Posthume; puis 1502, Buda, par Ladislas II; D. Radocsay, « Gotische Wappenbilder... » (1958), p. 356; id., « Renaissance letters... » (1966) [n. 220], p. 73-74; Gotika..., p. 524 (ill. 474); L. Vrtel', Osem storocí... p. 132 (ill.); D. Buran, « Medzi dvorom a radnicou... », p. 68. Lettres d'armoiries comparables pour des Hongrois : $1^{\circ}$ (avec privilège du sceau de cire rouge) du roi Ladislaus Postumus pour la ville de Bardejov, 5 juin 1453, Vienne; D. Radocsay, « Gotische Wappenbilder... » (I), p. 356-357; id., « Gotische 
vation. L'enlumineur a pu être identifié par Gerhard Schmidt et Milada Studničková comme un artiste alors actif auprès de l'évêque de Cracovie Zbigniew Oleśnicki ${ }^{258}$, et dont le style est basé sur celui de l'atelier des martyrologes de Prague. À l'extrême droite, au-dessous du texte, se trouve un autre champ plus petit et cependant crucial, également bordé d'or et contenant des armoiries, dont la légende désigne Johannes Hebenstreyt comme titulaire ${ }^{259}$. Celui-ci a parfois été pris pour l'enlumineur, alors qu'il fut des années durant juge de Kaschau : donc non le peintre mais bien l'impétrant de la charte. Il faut ensuite mentionner les deux concessions d'armoiries en faveur de Presbourg (Bratislava) en $1436^{260}$. Le champ encadré contenant les armoiries se trouve au début. L'image d'un sceau (sigillum in forma circulari seu rotunda) est insérée (en couleurs) dans le dispositif, la légende transcrite en majuscules gothiques (+ SIGILLUM • CIVITATIS • POSONIE $[n]$ sIs),

Wappenbilder... » (1964), p. 92 (ill. 1); Gotika... p. 513 (ill. 462) et p. 802 (n 6.12.19, par Radoslav Ragač); L. Vrtel', Osem storocí... p. 131-132 (ill.); D. Buran, « Medzi dvorom a radnicou... », p. 63-64, 68; Vladimír Rabik, « Výsady miest a mestečiek o používaní farby pečatného vosku », dans Erbové listiny... [n. 166], p. 95-120, à la p. 97; - 2º pour István Császári Császár et Petneházy (1462); D. Radocsay, « Gotische Wappenbilder... » (I), p. 347-348 (ill.), 357; $-3^{\circ}$ (avec privilège du sceau de cire rouge), de Matthias Corvin pour la ville de Kežmarok, 13 juin 1463; D. Radocsay, « Gotische Wappenbilder... » (I), p. 357; Gotika... p. 514 (ill. 463) et 803 ( $\mathrm{n}^{\circ}$ 6.2.21, par R. Ragac et D. Buran); L. Vrtel', Osem storocí... p. 131 (ill.); D. Buran, « Medzi dvorom a radnicou... », p. 63 et 68 (ill. couleur). Ces trois actes sont en une planche dans Magyarországi müvészet... [n. 256], ill. 1834-1836. L’enluminure pour Kežmarok est d'une qualité remarquable, liée à l'art de Vienne ou de Basse-Autriche; Božena Malovcova, « Erbová listina král’a Mateja Korvína pre mesto Kežmarok z roku 1463 », dans Erbové listiny..., p. 58-62 (ill.), l'attribue à un artiste de la cour de Matthias Corvin. Anges tenants hors de Hongrie : lettre d'armoiries pour Weissenburg [n. 283], par Ulrich Schreier (1481), proche de la charte de 1423.

258. Gerhard Schmidt, Malerei der Gotik : Fixpunkte und Ausblicke, éd. M. Roland, Graz, 2005, t. I, p. 336 et 444; Milada Studníčkova, « Böhmische Orientierung in der Miniaturmalerei : der Kreis der Meister von Gerona », dans Sigismundus... [n. 220], p. 529-535, aux p. $532-533$.

259. Sur Hebenstreyt, voir surtout Mária Tischlerova (Maria Tischler), « Stredoveký richtár Hanns Hebenstreyt v Košiciach », dans Historica : zborník Filozofickej fakulty Univerzity Komenského, t. 26, 1975, p. 51-75; ead., « Das Kaschauer Stadtsiegel von 1404 und die städtische Wappenbildung unter König Sigismund in Ungarn : der wappenhaltende Engel in der Slowakei », dans Genealogica et heraldica: 19. Internationaler Kongreß für genealogische und heraldische Wissenschaften (Keszthely, 2.-6. 10. 1990), Kongreßberichte, éd. Iván Bertenyi, Laszló Czoma, Keszthely, 1992, p. 61-84; ead., « Hebenstreyt, Hans », dans Verfasserlexikon, t. 11, 2004, col. 594-598; voir aussi le projet d'édition de la même : http://dtm.bbaw.de/E_ Bericht/E_Tischler.html (consulté août 2011).

260. Bratislava, Archív mesta, Sign. 1435 et 1436 (double original), 8 et 9 juillet 1436 : D. Radocsay, « Gotische Wappenbilder... » (I) [n. 220], p. 339-341; A. Güntherova, J. Misianik, Handschriften... [n. 256], p. 27-28 ( ${ }^{\text {os }}$ 28-29), ill. 102-103; Magyarországi mǘvészet... [n. 256], p. 631-632, ill. 1447; L. Vrtel', Osem storoč́... [n. 189], p. 133-135 (ill.); Zajic et Roland, « Urkundenfälschung » [n. 11], p. 411; Gotika... [n. 224], p. 175 (ill.), 801-802 (n n $^{\circ} .12 .18$, par D. Buran); Erbové listiny... [n. 166], ill. couleur en couverture; Sigismundus... [n. 220], p. 313-315 (n ${ }^{\text {os }} 4.5 \mathrm{a}-\mathrm{b}$, par D. Buran); Susanne Rischpler, Der Illuminator Michael, Purkersdorf, 2009, p. 67-69 (n $\left.{ }^{\text {os }} 21-22\right)$ et ill. 165-166. 
et les armes blasonnées en détail. L'enlumineur viennois Michael a décoré les deux pièces (ill. 35). Les rinceaux d'acanthe ${ }^{261}$ issus de l'enluminure et développés à gauche et au-dessus du texte sont remarquables, et d'autant plus qu'ils sont rares dans les chartes enluminées : leur style les rattache avec certitude au même peintre ${ }^{262}$.

Suit, par ordre chronologique, une curiosité héraldique et diplomatique. D'après l'exemple de l'empereur d'Occident, Jean VIII Paléologue, empereur byzantin, fit au moins deux concessions d'armoiries en août 1439 lors de sa venue au concile de Florence. Les deux demandeurs, bourgeois florentins nommés Giacomo di Giovanni Paolo de Morelli(s) et Pancrazio Michele Fedini, avaient manifestement exploité l'occasion pour, en l'absence d'un empereur d'Occident, obtenir des armoiries impériales avec la dignité palatine ${ }^{263}$. Les demandeurs étaient élevés au statut de familiers de l'empereur et habilités à porter les symboles impériaux sur leurs bannières. L'exemplaire de Morelli montre à gauche sous le texte grec, lequel est suivi d'une traduction latine, un écu comportant les armes impériales, assorti dans la marge supérieure de chapiteaux de lys. Les deux chartes sont de toute évidence des solutions ad hoc inspirées des modèles occidentaux; le formulaire n'a rien de byzantin; bien plus, il est souvent nécessaire d'authentifier tout au long du $\mathrm{Xv}^{\mathrm{e}}$ siècle, dans les concessions d'armoiries pour des Italiens, la nomination, liée à la dotation en armoiries, du demandeur comme comte palatin (ко̀ $\mu \eta \tau \alpha \pi \alpha \lambda \alpha \tau$ ivov) pourvu du droit de nommer des notaires et de légitimer les enfants. Ce n'est pas un hasard si la famille Morelli prend ses précautions aussi peu de temps après en obtenant d'un roi occidental, Frédéric III, une concession équivalente de noblesse et d'armoiries, à Zurich en $14,42^{264}$.

L’apogée du développement artistique est atteint dans les concessions

261. Hors du champ, les rinceaux apparaissent, à un niveau plus modeste, chez les deux armoristes nommés de Buda : 2 juillet 1437, Buda (lettre de Sigismond pour Mihály Patrohi); Budapest, Magyar Országos Levéltár, DL 50.529; et 25 janvier 1443, Buda (lettre du roi Ladislas/Ulászlós I ${ }^{e r}$ de Hongrie pour Balás Kulpi), ibid., DL 13.702; D. Radocsay, « Gotische Wappenbilder... » (I), p. 339; Sigismundus..., p. 416, par Z.Jékely.

262. Sur Maître Michael, S. Rischpler, Der Illuminator...

263. La charte pour Fedini n'est connue qu'en copie; celle pour Morelli en original : Paris, Bibl. nat. Fr., suppl. grec 821; Regesten der Kaiserurkunden des oströmischen Reiches von 565-1453, 5. Teil, Schluß : Regesten von 1341-1453, éd. Franz Dölger, collab. Peter Wirth, Munich-Berlin, 1965, p. 127 (n ${ }^{\text {os }}$ 3489-3490); Franz Dölger, Johannes Karayannopulos, Byzantinische Urkundenlehre, 1. Abschnitt : Die Kaiserurkunden, Munich, 1968, p. 31 (où l'écu est jugé postérieur), 114-115, 168-170 ( $n^{\circ}$ 64) et pl. 64; O. Kresten, « Zur Chrysographie »... [n. 13], p. 181, n. 158; Nicholas Oikonomides, « The Byzantine overlord of Genoese possessions in Romania », dans Porphyrogenita : essays and literature of Byzantium and the Latin East in honour of Julian Chrysostomides, éd. Charalamos Dendrinos, Jonathan Harris, Eirene Harvalla-Crook, Judith Herrin, Aldershot, 2003, p. 235-238, aux p. 236-237.

264. 24 septembre 1442, Zurich; Joseph Chmel, Regesta chronologico-diplomatica Friderici IV Romanorum regis (imperatoris III) : Auszug aus den im k.k. geheimen Haus-, Hof-und Staats-Archive zu Wien sich befindenden Reichsregistraturbüchern vom Jahre 1440-1493, nebst 
d'armoiries du « Maitre de la Handregistratur », qui produisit en 1446 son chef-d'œuvre, le registre éponyme, pour Frédéric III ${ }^{265}$. Il parvient à tirer de la lumière un effet de réalité tactile, comme si les objets étaient réellement posés sur la page, révélant un rapport direct avec les développements les plus récents de la peinture néerlandaise. On connaissait déjà de cet artiste une lettre d'armoiries pour la collégiale de Wiener Neustadt ${ }^{266}$ (aussi de 1446), et deux autres pour les comtes Jean, Georges et Sigismond de Sankt Georgen et de Bösing (zo Sv. Jura a Pezinka) en 1459 ${ }^{267}$, outre le décor de la « Handregistratur » (ill. 36 a-d $)$. Dans ce vide entre 1446 et 1459 s'insère une découverte nouvelle : le 26 mai 1453, le roi Ladislas le Posthume, en tant que duc d'Autriche, concéda à la ville de Krems une amélioration des armoiries qu'elle portait depuis la seconde moitié du XIII ${ }^{\mathrm{e}}$ siècle, en forme de sceau, un arbre entre les écus de Nouvelle-Autriche (« Neuösterreich ») et de Styrie. On supprima l'arbre, et les deux écus d'or furent surélevés et placés côte à côte ${ }^{268}(i l l .36$ b). Le champ réservé aux armoiries est bordé

Auszügen aus Original-Urkunden, Manuskripten und Büchern, 1. Abteilung : Vom Jahre 1440 bis März 1452, Vienne, 1838, réimpr. Hildesheim, 1962, nº 1144.

265. Vienne, Haus-, Hof- und Staatsarchiv, Hs. Weiß 10 (Böhm 19); Michaela Krieger, « Der Buchschmuck der "Handregistratur" Friedrichs III. im Haus-, Hof- und Staatsarchiv », dans Wiener Jahrbuch für Kunstgeschichte, t. 47, 1993-1994 (Festschrift Gerhard Schmidt), p. 313-329, 455-457; voir aussi Geschichte der Bildenden Kunst in Österreich, t. III : Spätmittelalter und Renaissance, éd. Artur Rosenauer, réd. Anna Mader, Werner Telesko, Munich-Berlin-Londres-New York-Vienne, 2003, p. 540-541 (nº 281, par M. Roland) et p. 157 (pl. couleur); Christian Lackner, « Die sogenannte Handregistratur Friedrichs III. », dans König und Kanzlist, Kaiser und Papst : Friedrich III. und Enea Silvio Piccolomini in Wiener Neustadt, éd. Franz Fuchs, Paul-Joachim Heinig, Martin Wagendorfer, Vienne-CologneWeimar, 2013, p. 267-279 : nous remercions l'auteur qui nous a communiqué son manuscrit.

266. 15 février 1446, Vienne; Vienne, Haus-, Hof- und Staatsarchiv, Allgemeine Urkundenreihe, sub dato; H. v. Sybel, T. Sickel, Kaiserurkunden... [n. 214], p. 493-494, et t. XI, pl. 14; D. Radocsay, « Wiener Wappenbriefe... » [n. 166], p. 62 (ill. 2); M. Krieger, « Der Buchschmuck... », p. 319-320 et ill. 1. Le lendemain, Frédéric conféra à l'abbaye cistercienne de Neukloster, fondée par lui à Wiener Neustadt, des armoiries (en usage aujourd'hui); l'acte, perdu, put être confié au même peintre; [en ligne :] monasterium.net (mots-clés : 1446, Dreifaltigkeit, Wappen).

267. 9 juin 1459, Vienne; Budapest, Magyar Országos Levéltár, DL 24.832 et 15.371; D. Radocsay, « Gótikus magyar címereslevelek »... [n. 220], p. 282, 292-293; id., « Gotische Wappenbilder... » (I) [n. 220], p. 342-344, 346, 357; Gotika... [n. 224] ] p. 802-803 (nº 6.2.20, par R. Ragač); L. Vrtel', Osem storoč́... [n. 189], p. 122-123 (ill.); I. Graus, « Armálesy... » [n. 226], p. 183-184 (ill. couleur.). L'attribution par M. Krieger, « Der Buchschmuck... », p. 327-328 (et ill. 10-11) à deux artistes différents, le Maître de la Handregistratur et le « Lehrbüchermeister », n'est pas convaincante quant au style; elle suit Karl-Georg Pfändtner, Die Handschriften des Lehrbüchermeisters, Purkersdorf, 2011, p. 20-21, 147-148. Les couronnes, objet de l'augmentation d'armoiries, se réfèrent à la couronne cintrée de Frédéric III ; conception analogue dans la lettre d'armoiries pour la vieille ville de Prague [n. 276]. La partie supérieure du champ d'armoiries de DL 24832 contient de part et d'autre du cimier les devises de l'ordre aragonais de la Jarre.

268. 26 mai 1453, Vienne; Krems an der Donau, Stadtarchiv, Urk. 313; Die Rechtsquellen der Städte Krems und Stein, éd. Otto Brunner, Graz-Cologne, 1953, nº 179, [en ligne :] 
d'un cadre en grès chanfreiné, les angles ornés d'une pierre précieuse entourée de perles. L'incidence cohérente de la lumière, avec une ombre portée, et ses effets sur les différents matériaux ne laissent aucun doute quant à l'attribution.

La période de création du Maître de la Handregistratur peut même être encore allongée grâce à une autre œuvre : dix ans après Ladislas, l'empereur Frédéric III conféra à son tour à la ville de Krems de nouvelles armoiries, que leur sens politique rapproche de l'ancien modèle des concessions d'armoiries (ill. 37a) ${ }^{269}$. Dans sa lutte contre son frère Albert VI, l'empereur avait reçu en 1461 le soutien de Vienne ${ }^{270}$ et avait récompensé la ville par une amélioration d'armoiries; l'aigle d'or eut désormais deux têtes nimbées et la couronne impériale ${ }^{271}(\mathrm{ill}$. 37b). Cependant, les alliances changent : en octobre-novembre 1462, l'empereur, l'impératrice et le jeune archiduc Maximilien sont assiégés dans la Wiener Burg par les troupes de l'archiduc Albert soutenues par les Viennois, comme le rappelle la lettre d'armoiries pour Krems. Krems vole alors au secours de Frédéric; en reconnaissance, il prive dès 1463 Vienne de ses armoiries au bénéfice de Krems ${ }^{272}$. Par compa-

monasterium.net. Le plus ancien sceau de Krems est attaché à une charte de 1250 (Munich, Bayerisches Hauptstaatsarchiv, Passau Hochstift, Urk. 94, [en ligne :] monasterium.net). Il montre, dans un goût encore pré-héraldique dans la moitié de gauche, une aigle dont l'aile gauche est recouverte dans la moitié de droite par un lion rampant tourné vers la droite, la queue dressée, donnant à tort l'impression d'une demi-aigle dans des armes mi-parties. En 1264 (Klosterneuburg, Stiftsarchiv, Urk. 1264 VI 26, Krems, [en ligne :] monasterium.net), l'image du sceau apparaît dans la forme décrite ci-dessus : sur le motif « aux trois collines » se trouve un arbre (chêne), flanqué des écus de Styrie et de Nouvelle-Autriche. À partir de 1282 au plus tard (11 mars 1282, Vienne; Munich, Bayerisches Hauptstaatsarchiv, Hochstift Passau, Urk. 197, [en ligne :] monasterium.net), les feuilles de chêne deviennent feuilles de tilleul et l'écu de Styrie est remplacé par le panneau supérieur, tourné vers la gauche, de l'écu de Nouvelle-Autriche. Au plus tard en 1293 (10 août 1293, Krems; Herzogenburg, Stiftsarchiv, Fonds Herzogenburg [en ligne :] monasterium.net), le sceau retrouva sa forme initiale. L'arbre, assez semblable à celui des armes de Biberach (W. Schöntag, Siegel... [n. 178], p. 66 et 76), semble revenir à la conception pré-héraldique du mi-parti. Le plus ancien sceau de Krems ne montre pas encore les écus de Styrie et de Nouvelle-Autriche, et G. A. Seyler, Geschichte der Heraldik... [n. 178], p. 267, avait sans doute tort de l'associer au projet de 1245-1246 d'ériger l'Autriche et la Styrie en royaume.

269. $1^{\text {er }}$ avril 1463, Wiener Neustadt; Krems an der Donau, Stadtarchiv, Urk. 395; Die Rechtsquellen..., n 203.

270. Hanns Jäger-Sunstenau, « 500 Jahre Wappenbrief für die Stadt Wien », dans Jahrbuch des Vereins für Geschichte der Stadt Wien, t. 17/18, 1961/1962, p. 53-85, aux p. 59-60. Sur les chartes enluminées d'Albert VI, voir ci-après, section VII.

271. 26 septembre 1461, Leoben; Vienne, Stadt- und Landesarchiv, Hauptarchiv $\mathbf{n}^{\circ} 4002$ (Privil. no 46); H. Jäger-Sunstenau, « 500 Jahre... »; D. Radocsay, « Wiener Wappenbriefe... » [n. 166], p. 63-64 (ill. 4), Peter Csendes, Wolfgang Mayer, Wappen und Siegel der Stadt Wien, Vienne, 1986, p. 4-5, 7, [en ligne :] monasterium.net (mots-clés : Friedrich, Wien, Wappen, 1461). Les armes sont de sable, à une aigle à deux têtes et à langue de gueules, entre les deux têtes une couronne à mitre d'or avec infules (couronne impériale).

272. Il donne aussi à la ville, comme à Vienne auparavant, le droit de sceller en cire rouge, qu'elle avait déjà obtenu en 1453 de Ladislas; Alois Niederstätter, «"Rotwachsfreiheiten" im 
raison avec l'acte de 1461 pour Vienne, celui de 1463 montre des différences évidentes et pour ainsi dire palpables. Au lieu d'un simple encadrement d'un trait (1461), le Maître de la Handregistratur peint un cadre bordé de cordons dorés et tors, serti de pierres précieuses et de perles, le tout modelé par la lumière et souligné d'ombres portées. L'image des armoiries joue sur un contraste calculé avec ce cadre, qui place l'aigle, avec sa couronne sertie de joyaux, dans un autre plan du réel.

En 1464, Frédéric III remercia la ville de Trieste (sous la domination des ducs d'Autriche depuis 1382) de sa fidélité et de sa résistance militaire face à Venise par une amélioration d'armoiries d'un particulier poids symbolique $^{273}$. Les anciennes armoiries de la ville, figurant la lance de son patron saint Serge, furent modifiées pour souligner le lien avec l'Empire de Frédéric $^{274}$, mais par des moyens étonnamment simples et discrets. L'enlumineur se sert bien de gouache ainsi que de feuille d'or pour le fer de la lance, mais le champ de l'aigle à deux têtes est simplement peint en ocre clair, tandis que la couronne, insérée avec difficulté dans l'espace vide, se limite à un dessin en couleur, et l'encadrement est abandonné. L'acte, probablement réalisé à l'initiative de l'évêque de Trieste Antonio Goppo, porte le sceau de Frédéric en archiduc d'Autriche, gravé en $14599^{275}$.

Un autre acte à la suite du siège de 1462 est d'un niveau artistique bien plus élevé. Il fut concédé en 1475 par Frédéric III, en témoignage tardif de reconnaissance, à la vieille ville de Prague qui l'avait alors aussi soutenu ${ }^{276}$ (ill. 38a). Ce qui est inhabituel, c'est l'invention clairement inspirée par le texte qui, parmi les possibilités d'usage des armoiries, prévoit nommé-

Spätmittelalter », dans Mensch und Archivar... [n. 226], p. 291-308 (où manque la charte pour Krems de 1463); sur les privilèges bourgeois de cire rouge, voir aussi V. Rabik, « Výsady... » [n. 257].

273. 22 février 1464, Wiener Neustadt; Trieste, Arch. Diplomatico, $\beta$ B6; Daniel Luger, Kaiser Friedrich III. und Triest : Beiträge zur Kulturgeschichte der Verwaltung im Spätmittelalter, Vienne, 2010 (thèse de diplôme) p. 33-34.

274. « ... arma [...] et insignia ipsius civitatis publica utriusque tam imperialis majestatis quam illustrissime ducalis domus nostre insigniis [...] amplianda [...] laminam lancee sancti Sergii martiris ejusdem civitatis ac populi inter ceteros patrini ac defensoris... » L'écu est partagé : en haut, l'Empire (d'or à une aigle à deux têtes de sable à couronne d'or), en bas la Nouvelle-Autriche (« Neuösterreich » : de gueules à une solive d'argent), sous un fer de lance d'or ressemblant à une sorte de corsèque; une couronne de cimier orne la partie supérieure de l'écu; l'aigle est explicitement impériale (« Imperii sacri Romani victricem ac bicipitem aquilam »). L'augmentation consista dans l'or du fer de lance, auparavant au naturel.

275. Die Siegel der Deutschen Kaiser und Könige von 751 bis 1806, t. II : 1347-1493, éd. Otto Posse, Dresde, 1910, p. 13 et pl. 27, no 2; et t. V : Das Siegelwesen der Deutschen Kaiser und Könige von 751 bis 1913, Dresde, 1913, p. $52-53$ (no 24).

276. 5 juin 1475, au camp devant Neuss; Prague, Archiv hlavního města Prahy, Sbírka pergamenových listin I, č 22; Codex juris municipalis regni Bohemiae t. I : Privilegia civitatum Pragensium, éd. Jaromír Čelakovský, Prague, 1886, p. 273-277 (nº 174); R. Nový, « Počátky... » [n. 175], p. 388. L'augmentation, accordée sur demande de la ville, consiste en l'ajout de la couronne d'or impériale (à nouveau d'après la couronne à mitre de Frédéric) sur le heaume ainsi que des lions. 
ment les bannières de guerre (« streitpanyren »). Le champ rectangulaire dans un cadre doré est presque entièrement occupé par un drapeau, porté par une lance dont la hampe entre par le bas et le fer perce le haut. De l'arrière-plan bleu, chargé de rinceaux d'or, on ne voit qu'une bande étroite. Sur le drapeau de gueules, or et argent (blanc), auquel est suspendu au coin supérieur gauche un long tissu rouge à plis multiples, l'écu fait figure d'insigne militaire, sous un heaume de tournoi à lambrequins de gueules, or et argent, de front et flanqué de deux lions tournés vers l'intérieur. La mise en œuvre peut être attribuée à un enlumineur célèbre, le Maitre du Bréviaire de Frédéric III (« Friedrichsbrevier ») ${ }^{277}$, dont la carrière, commencée et achevée en Moravie, fut interrompue par une période (14751481 environ) au service de la cour de Frédéric III : notre acte, clairement peint en rapport avec la chancellerie, fournirait un repère pour le début de cette phase. Cependant, l'attribution s'appuie sur peu de chose : les plis du lambrequin et les filigranes.

L'attribution d'une autre œuvre repose sur des éléments plus larges. Elle est antérieure de deux ans et montre que l'artiste était encore dans sa patrie. Le roi Ladislas II de Bohême accorda alors aux drapiers de Laun (Louny) des armoiries, blasonnées et peintes au milieu du parchemin (quemadmodum pictura his nostris literis manu artificis inserta id clarius demonstrat), et destinées aux enseignes, bannières et sceau du métier ${ }^{278}$ (ill. 38b). Dans le beau filigrane en bordure et le remarquable saint Georges, on reconnaît immédiatement le Maître du Bréviaire de Frédéric III (nommé d'après un manuscrit datable vers $1475-1480^{279}$, au début de sa période autrichienne). Le filigrane et surtout les visages correspondent nettement. Gerhard Schmidt a pu prouver que le peintre avait souvent copié les gravures sur cuivre du maître E. S. ${ }^{280}$, et cela vaut aussi pour cet acte ${ }^{281}$ (ill. $38 d$ ).

Sur l'acte donné en 1476 par Frédéric III en faveur de Dürnstein ${ }^{282}$

277. M. Roland, « Buchmalerei », dans Geschichte der bildenden Kunst ..., t. III [n. 265], p. 154-162, 521-546, aux p. 527, 537, 541-542 (no 283; ill. du diptyque mentionné n. 268).

278. 7 juillet, 1473, Hrádek (nad Nisou?); Vienne, Haus-, Hof- und Staatsarchiv, Allgemeine Urkundenreihe, sub dato; d'abord publié par D. Radocsay, « Wiener Wappenbriefe... » [n. 166], p. 72 et ill. 15.

279. Munich, Bayer. Staatsbibl., cgm 68, fol. 1v-2, diptyque; M. Roland, « Buchmalerei »..., p. 541-542. (ill.).

280. Gerhard Schmidt, «Die zwei Stile des "Meisters des Friedrichsbreviers" : ein spätgotischer Buchmaler kopiert Stiche des Meisters E. S. », dans Tributes in honor of James H. Marrow : studies in painting and manuscript illumination of the late Middle Ages and northern Renaissance, éd. Jeffrey F. Hamburger, Anne S. Korteweg, Londres etc., 2006, p. 441-452.

281. Source : Max Lehrs, Geschichte und kritischer Katalog des deutschen, niederländischen und französischen Kupferstichs im 15. Jahrhundert, t. II : Meister E. S., Text- und Tafelband, Vienne, 1910, n 146; reprod. facile d'accès : Horst Appuhn, Meister E. S., alle 320 Kupferstiche, Dortmund, 1989, ill. 148.

282. 26 avril 1476, Wiener Neustadt; Dürnstein, Stadtarchiv, Sign. 1/6; A. Zajic, « Der Wappenbrief der Stadt Dürnstein aus dem Jahr 1476 », dans Burg Stadt Kloster : Dürnstein im Mittelalter, Dürnstein, 2005, p. 335-338 (sur CD-Rom); id., « Von der Marienkapelle zum 
figurent des armoiries qui ne respectent aucune règle héraldique, mais aussi une vue topographique étonnamment précise de la petite ville depuis la rive opposée du Danube. On y voit tous les bâtiments profanes comme sacrés, dominés par le château princier. Les vues topographiques étaient encore rares. La motivation précise des bourgeois de Dürnstein ou de l'engagiste de la seigneurie, Étienne d'Eitzing, dans le choix de cette représentation, certes propre à frapper le spectateur comme à nourrir une identité de groupe, reste à élucider.

Une lettre d'armoiries de Frédéric III en faveur de Weissenburg en Bavière, du 21 septembre 1481283, fut ornée par l'enlumineur salzbourgeois Ulrich Schreier, à qui on attribue une œuvre foisonnante ${ }^{284}$ (ill. 38c). L'ange tenant correspond d'assez près à celui de la lettre d'armoiries pour Kaschau de 1423 étudiée plus haut, comme aussi à d'autres ${ }^{285}$; la reprise est peut-être voulue, mais le motif est fréquent bien au-delà des concessions d'armoiries.

Terminons par deux chartes du $x^{\mathrm{e}}$ siècle, qui, sans être des concessions d'armoiries, témoignent de l'usage, pour des groupes sociaux, de signes visuels dans une disposition analogue (une image dans un champ rectangulaire au milieu du texte). En 1471, une charte de Frédéric III accordant aux couteliers du marché de Wendelstein (Moyenne-Franconie) une marque de provenance pour faire valoir la qualité de leurs produits ${ }^{286}$ : fonction économique, donc, plutôt que sociale. Et en 1485, en faveur des membres d'un cercle patricien, la société de la Trinité de Lubeck (« die geselschafft der heiligen trivaltickeit zu Lübecke, die man nennet die zirckelbruder ») ${ }^{287}$, la confirmation de leurs symboles existants, complétée par l'autorisation d'alterner ceux-ci avec des plumes de queue d'aigle pour en faire une devise ou un collier (« in einer geselschafft oder halßpanndt weise ») : symbole

Chorherrenkloster : ein Umweg durch vier Jahrzehnte », dans Stift Dürnstein : 600 Jahre Kloster und Kultur in der Wachau, éd. Helga Penz, A. Zajic, Horn-Waidhofen an der Thaya, 2010, p. 12-23, à la p. 15 (ill. 5).

283. Weissenburg, Reichsstadtmuseum; Michaela Schuller, Ulrich Schreier und seine Werkstatt : Buchmalerei und Einbandkunst in Salzburg, Wien und Bratislava im späten Mittelalter, Vienne, 2009 (thèse de doctorat), p. 62, 211-212; sur les chartes, voir Klaus Raab, « Siegel und Wappen der Stadt Weißenburg », dans Wizinburc-Weißenburg 867-1967 : Beiträge zur Stadtgeschichte, Weissenburg, 1967, p. 42-56.

284. M. Schuller, Ulrich Schreier...; plus brièvement, M. Roland, « Buchmalerei »... [n. 277], p. 159 (pl. couleur), 529, 542-543 (no 284).

285. Sur les anges tenants, voir ci-dessus, n. 257.

286. 24 juillet 1471; Nuremberg, German. Nationalmuseum, Archiv, Pergamenturkunde, sub dato; J. Chmel, Regesta... [n. 264], no 6338; Heinrich Schlüpfinger, Wendelstein : Geschichte eines Marktes mit altem Gewerbe und moderner Industrie, Nuremberg, 1970, p. 124 et 268.

287. 6 janvier 1485, Linz; Lübeck, Archiv der Hansestadt Lübeck, Urkunden, Auswärtige Beziehungen [Externa], Caesarea 218; Sonja Dünnebeil, Die Lübecker Zirkel-Gesellschaft : Formen der Selbstdarstellung einer städtischen Oberschicht, Lubeck, 1996, p. $19-20$ (ill. 4), éd. aux p. 204-206. Nous remercions chaleureusement S. Dünnebeil de ses renseignements. 
social d'appartenance, donc, tout à fait comparable à ceux des ordres de chevalerie dans la société nobiliaire.

\section{LA CHANCELLERIE DE L'EMPEREUR LOUIS DE BAVIÈre.}

Revenons maintenant au siècle précédent et à la chancellerie impériale sous Louis de Bavière (1314-1347), où eut lieu un développement étonnant de l'appareil décoratif. Christa Wrede en a fourni un bilan fondamental ${ }^{288}$, identifiant un des responsables en Léonard de Munich (Leonhard von München) ${ }^{289}$.

Examinons en premier lieu une charte de grand format datée du 15 novembre 1337 (Munich) (ill. $39 a)^{290}$, et la remarquable représentation que contient son initiale $L$, à savoir la remise d'une bannière aux losanges de Bavière, véritable scène d'inféodation. Par cet acte, Louis donne en francalleu à l'ordre Teutonique et à son grand maître Dietrich von Altenburg le pays des Lituaniens (terram Lythwinorum), qui restait à conquérir et à christianiser; il confirme aussi l'autorisation déjà accordée par le duc Henri XIV de Basse-Bavière de nommer la ville principale du duché héréditaire « Bavière », d'user des armoiries de Bavière, de porter la bannière à ces armes en tête de toute expédition contre les Lituaniens, enfin le droit de nommer « Bavière » l'archevêché qui pourrait être établi dans leur pays. Il s'agit de la première de quatre chartes de Louis de Bavière comportant un décor historié de forme livresque, qui ont attiré depuis longtemps l'atten-

288. C. Wrede, Leonhard... [n. 164]. On observe alors dans les chartes royales françaises la présence croissante d'éléments ornementaux et zoomorphes (G. Brunel, Images... [n. 2], p. 60-91, 39-67), mais non encore d'initiales historiées. En Angleterre, les chartes royales enluminées et historiées se sont multipliées dès le XIII ${ }^{\mathrm{e}}$ siècle (E. Danbury, « Décoration... » [n. 33]), mais les différences formelles semblent exclure qu'il y ait là un lien.

289. Sur sa biographie, C. Wrede, Leonhard..., p. 15-18. Voir également Helmut Bansa, Studien zur Kanzlei Kaiser Ludwigs des Bayern vom Tag der Wahl bis zur Rückkehr aus Italien (1314-1329), Munich, 1968, p. 191-200; Peter Moser, Das Kanzleipersonal Kaiser Ludwigs des Bayern in den Jahren 1330-1347, Munich, 1985, p. 6, 12-33.

290. 15 novembre 1337, Munich; Berlin, Geheimes Staatsarchiv, Preussischer Kulturbesitz, Staatsarchiv Königsberg, Schieblade 20, n⿳0 29; Wilhelm Arndt, Michael Tangl, Schrifttafeln zur Erlernung der lateinischen Palaeographie, t. III, Berlin, 1903, réimpr. Hildesheim, 1976, pl. 94 et p. 54; Albert Werminghoff, « Die Urkunden Ludwigs des Bayern für den Hochmeister des Deutschen Ordens vom Jahre 1337 », dans Archiv für Urkundenforschung, t. 5, 1914, p. 21-22; Preußisches Urkundenbuch. Politische Abteilung 3/1 : 1335-1341, éd. Max Hein, Königsberg, 1944, réimpr. Aalen, 1961, p. 96 (n 134); G. A. Seyler, Geschichte der Heraldik... [n. 178], p. 318-319; P. Acht, « Die Prunkurkunden... » [n. 176], p. 401; C. Wrede, Leonhard... [n. 164] , p. 59-61, 119-121 (n ${ }^{\circ} 10$; fondamental); Zajic et Roland, «Urkundenfälschung... » [n. 11], p. 400-402 (style); Robert Suckale, Die Hofkunst Kaiser Ludwigs des Bayern, Munich, 1993, p. 36-39, 219 (no 14); Heiliges Römisches Reich... [n. 48], t. I, p. 377-378 ( $\mathrm{n}^{\circ}$ V.7, par R. Suckale); R. Novotný, « Od veřejné prezentace... » [n. 195], p. 82-83 (ill. intervertie avec celle de la p. 81). 
tion $^{291}$. Datées de 1332 et 1339, elles montrent chacune l'action juridique sous forme d'une rencontre de l'empereur et du bénéficiaire, constituant des éléments de l'initiale $L$. La couleur, limitée principalement à des nuances de brun, est appliquée au pinceau, ajoutant au dessin à la plume un subtil dégradé dans les mêmes tons. Les armoiries jouent un rôle dans deux de ces actes; les losanges de Bavière emplissent le champ de la bannière mentionnée plus haut, et la croix (de gueules sur argent) de Trèves, la bannière tenue par l'archevêque Baudouin ${ }^{292}$. Malgré la configuration tout à fait semblable des bannières, l'acte juridique est différent : dans le cas de Baudouin, la charte confirme des privilèges de l'archevêché et concède le droit de Francfort à plusieurs villes du diocèse.

Quant à la figure de l'archevêque, elle est présentée presque à égalité avec celle de l'empereur : pareillement debout, presque de la même taille et portant comme lui des insignes de pouvoir (la mitre en pendant de la couronne). Ils se tendent la main et leurs robes sont symétriques. Il s'agissait clairement d'honorer ce prélat issu de la maison de Luxembourg, politiquement très actif et ayant aidé tant Henri VII que Louis à monter sur le trône. Les bénéficiaires des autres chartes - les représentants de Dortmund qui sollicitent la confirmation de leurs droits ${ }^{293}$, le grand maître des chevaliers Teutoniques comme les ducs de Poméranie-Stettin (élevés au rang de princes d'Empire ${ }^{294}$ ), sont tous à genoux. Quant aux modèles possibles de telles initiales à personnages, on peut signaler deux ensembles de dessins, le plus récent datable autour de 1330 (Oxford, Harvard et Washington) (ill. 39b). Les avis sont très partagés sur leur provenance, mais elle nous semble plus probablement française qu'allemande ${ }^{295}$.

Ces quatre actes s'inscrivent dans une production bien plus large, à partir de 1330, contenant des chartes à décors de personnages ${ }^{296}$, zoo-

291. Toutes quatre reproduites par R. Suckale, Die Hofkunst..., p. 37.

292. 10 mars 1339, Breslau; Koblenz, Landeshauptarchiv, Abt. 1a, no 4983; C. Wrede,

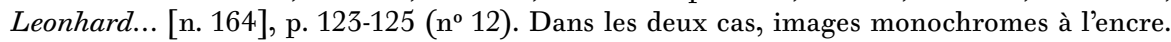
Dans le contrat de mariage de Jean duc de Berry, 5 juin 1389 [n. 213], les deux écus sont en couleur.

293. 25 août 1332, Nuremberg; autrefois Dortmund, Stadtarchiv, détruit en 1945; C. Wrede, Leonhard..., p. 116-118 ( $\mathrm{n}^{\circ}$ 8). Les deux demandeurs (le premier incliné jusqu'aux pieds de Louis) sont nommés « Her(man) Clipping » et « Ber(tram) Suderman ». Les noms sont aussi sous le repli (ibid., p. 117), et Suderman désigné comme « clericus civitatis ».

294. 14 août 1338, Francfort; Greifswald, Landesarchiv, Repositur 2, no 59a; C. Wrede, Leonhard..., p. 121-123 ( $\left.{ }^{\circ} 11\right)$.

295. Zajic et Roland, « Urkundenfälschung » [n. 11], p. 402 (ill. 24-25).

296. C. Wrede, Leonhard... [n. 164], p. 53-70, en traite en détail, selon une typologie discutable. La plupart des exemples sont décoratifs (Anhang 1 [1330], Kat., $\mathrm{n}^{\text {os }} 2$, 3, 5; Anhang $8, \mathrm{n}^{\mathrm{os}} 11$ [1331], 12, 14, 15 [1335], 20 [1336], 21 [1343]). On y trouve des motifs très variés, en particulier des bustes en médaillon. Un cas remarquable (p. 145-146, no 28 ) : deux petites figures (nues?) à la première ligne d'un acte notarié du 28 octobre 1336, les instructions de Louis à ses ambassadeurs auprès du pape Benoît XII. Les autres aspects (filigranes, écriture) permettent d'attribuer à Léonard au moins une part d'initiative. C. Wrede (p. 70) 
morphes ${ }^{297}$ ou à initiales purement ornementales. Outre les bannières héraldiques, on y trouve des écus plus traditionnels. La première de ces chartes, concédée pendant le retour d'Italie ( $1^{\text {er }}$ janvier 1330 , Trente) élevait le comte Berthold VII de Henneberg-Schleusingen au rang de prince d'Empire (ill. 40) ${ }^{298}$; elle arbore sur le montant du $L$ les armes de l'Empire (doublées) et de Bavière, et dans l'empattement triangulaire du pied, celles des comtes de Henneberg ${ }^{299}$.

Huit ans plus tard, Léonard de Munich est chargé de la première lettre d'armoiries impériale ${ }^{300}$, et le décor héraldique d'un acte important pour l'hôpital du Saint-Esprit auprès de Saint-Sebald de Nuremberg (ill. 41) fait directement référence à son contexte politique ${ }^{301}$. L'initiale est formée sur un combat entre l'aigle et le lion ${ }^{302}$; au-dessus de la première ligne d'écriture se trouve, au centre, un écu triangulaire à l'aigle impériale, vers lequel sont inclinés ceux de Bavière et du Palatinat; près de ce dernier se trouve encore la panthère de Basse-Bavière (dont Louis avait recueilli en 1340 le gouvernement de tutelle). L'œuvre n'est pas née ex nihilo, et nous avons mentionné des modèles possibles de lettrines à personnages. Léonard semble avoir été plus particulièrement lié à un scribe $(\mathrm{H} 33)$ actif lors du voyage en Italie de 1327-1328 : trois originaux de cette main ont reçu une initiale filigranée suivie de lettres à la feuille d'or ${ }^{303}$.

considère ces figures comme des anges, sûrement à tort. Un autre acte du 17 novembre 1345 pour Passau ( $\mathrm{n}^{\circ}$ 23), avec une tête couronnée en médaillon au centre de l'initiale et des armoiries (Empire, Palatinat, Bavière) présente un cas unique de propagande impériale.

297. Les motifs zoomorphes s'ajoutent après 1320 aux initiales filigranées : leur présence chez Léonard de Munich, fortement marqué par la tradition des initiales filigranées, n'est donc pas surprenante. Une exception, où l'aspect politique l'emporte sur l'ornement : le couple aigle-lion qui singularise cinq diplômes de Louis; C. Wrede, Leonhard..., n ${ }^{\text {os }}$ 9, 13, 16, 17, 24 (1336-1347).

298. $1^{\text {er }}$ janvier 1330, Trente; Meiningen, Thüringisches Staatsarchiv, Gemeinschaftliches Hennebergisches Archiv, Urk. 220; MGH, Legum sectio IV : Constitutiones et acta publica imperatorum et regum : Dokumente zur Geschichte des Deutschen Reiches und seiner Verfassung, 1331-1336, t. 6/1, éd. Ruth Bork, Hanovre, 1988, p. 566-568 ( $\mathrm{n}^{\circ}$ 671); Regesta Imperii : Regesten Kaiser Ludwigs des Bayern (1314-1347), éd. Michael Menzel, fasc. 8 : Die Urkunden aus den Archiven und Bibliotheken Österreichs, éd. Johannes Wetzel, CologneWeimar-Vienne, 2008, no 156; C. Wrede, Leonhard..., p. 83-88, 107-108 (nº 1). Berthold avait déjà reçu plusieurs privilèges, entre autres des compétences égales à celles d'un comte palatin (15 mars 1327, Trente; $M G H$ Legum sectio $I V . . .$, t. 6/1, p. 170-171, no 263).

299. Citons par ailleurs une charte pour le Liebfrauenstift (monastère Notre-Dame) de Francfort (10 novembre 1340), avec un écu triangulaire portant l'aigle impériale et un heaume à cimier dans le champ de l'initiale W(ir); C. Wrede, Leonhard... [n. 164], p. 126-127 [n $\left.n^{\circ} 14\right], 85-86$; aussi un acte par un autre scripteur pour l'évêché d'Eichstätt (3 avril 1344, Nuremberg), avec une aigle impériale dans la bordure filigranée.

300. C. Wrede, Leonhard..., p. 84-85; voir ci-dessus n. 182.

301. 24 février 1341; ibid., p. 86-87, 129-131 (n 17).

302. Sur ce motif chez Léonard de Munich, voir ci-dessous, n. 305.

303. H. Bansa, Studien... [n. 289], p. 175-177; C. Wrede, Leonhard..., p. 40-41, 101-103, 141-145. 
Nombre de pistes de recherche restent à parcourir. Une charte est-elle confiée à un artiste ou plus? Sur cet aspect, la distinction par la critique stylistique peut devenir (surtout en l'absence de comparaison avec les sources artistiques) une hypercritique sans issue ${ }^{304}$. Plus intéressant : pourquoi pareil essor des chartes enluminées dans la chancellerie de Louis de Bavière? On ne saurait ni l'attribuer aux bénéficiaires, trop disparates, ni l'associer à un type d'acte. Demeure l'hypothèse d'une initiative personnelle de l'empereur ou de quelque notaire de sa chancellerie, dont le goût aurait rencontré les intérêts de la propagande impériale. La symbolique animale fait bien une place notable à l'empereur : Louis est ainsi l'aigle qui triomphe du lion. Mentionnons la suggestion de Robert Suckale, aussi difficile à prouver que séduisante, qui voit dans les chartes enluminées impériales une réponse aux lettres d'indulgence avignonnaises ${ }^{305}$. Il reste surtout à chercher si Louis s'est inspiré de la pratique de la chancellerie royale française, comme pourraient le suggérer les initiales à personnages aussi bien que l'emploi restreint des couleurs - à moins que l'exemple impérial, au contraire, ait stimulé au temps de Charles $\mathrm{V}$ le développement des chartes historiées françaises ${ }^{306}$.

\section{EXEMPLES ISOLÉS DANS LES CHARTES PRIVÉES (DONT UN ACTE HÉBRAÏQUE).}

À la différence de l'Angleterre et de la France, où les chartes enluminées sont surtout issues de la chancellerie royale, une large part revient aussi dans l'Empire aux chartes privées : d'où nombre de pièces uniques, où l'on chercherait en vain des catégories ou des tendances générales. Voici quelques exemples saillants.

Deux chartes de Nuremberg en langue vernaculaire empruntant aux indulgences leurs personnages latéraux, illustrent l'influence formelle de celles-ci au milieu du XIv ${ }^{e}$ siècle (ill. 42). Il s'agit des contre-lettres données en 1362 par les deux grands couvents de Nuremberg au sujet des obits fondés par Konrad Waldstromer ( «Waltstromeyr »), issu de la famille patricienne nurembergeoise des Stromeyer ou Stromer et grand maître des forêts impériales aux alentours de la ville ${ }^{307}$. Les obligations des deux maisons sont identiques et la rédaction diffère à peine, mais le style pictural est moins

304. C. Wrede, ibid., p. 103-104, attribue le décor d'un acte pour l'évêché d'Eichstätt au scribe K 22, mais il correspond en détail à un autre du 22 avril 1343 (ibid., $\mathbf{n}^{\circ}$ 21). R. Suckale distingue plusieurs mains, sans aborder les sources stylistiques (Die Hofkunst... [n. 290], p. 36), et voudrait dissocier le scribe Léonard de Munich et le décor, alors que les deux aspects, comme l'a montré $\mathrm{C}$. Wrede, sont étroitement liés.

305. Il faut aussi prendre en considération dans ce contexte l'apparition des lettres d'armoiries, liée de près à la querelle pour la suprématie en Italie.

306. Quant aux chartes de Richard II d'Angleterre, elles s'inspirent plus probablement de celles de Louis de Bavière que d'exemples français.

307. Zajic et Roland, «Urkundenfälschung » [n. 11], p. 407-408. 
homogène ${ }^{308}$. Les personnages sur la charte du couvent des Clarisses sont inspirés du style d'un atelier de peinture sur bois qui avait déjà travaillé pour elles. La charte du monastère Sainte-Catherine, en revanche, appartient à un style suprarégional marqué par des personnages enserrés dans des vêtements presque cylindriques.

Un instrument de 1360 rédigé à Bâle par le notaire de la cour épiscopale Johannes de Cespite adopte le même style répandu que la charte du monastère de Sainte-Catherine ${ }^{309}$ (ill. 43). Le contenu est assez complexe ${ }^{310}$ : le 14 octobre 1359, Pierre, originaire de Ratisbonne, recteur de SaintSylvestre au Trastevere, remit à Rome diverses reliques, dont la plus importante était une dent de saint Paul, à Ulrich Conradi von Tuttwil, citoyen de Rome originaire du diocèse de Bâle. Celui-ci agissait pour le compte des premières destinataires apparentes, les Clarisses de Gnadental à Bâle ${ }^{311}$. Il joua peut-être double jeu; en tout cas les reliques, tout ou partie, aboutirent au chapitre cathédral de Bâle. Le récit en images, tracé à la plume dans le coin supérieur gauche ${ }^{312}$, dans des tons où dominent le vert et le rouge,

308. 28 août 1362; Nuremberg, Staatsarchiv, Reichsstadt Nürnberg, Urk. 1118 (Munich, Bayerisches Hauptstaatsarchiv, Reichsstadt Nürnberg, Faszikel 154); Krone und Schleier... [n. 135], p. 514-515. (no 460, par R. Suckale; ill. couleur). À gauche, sainte Claire, à droite, saint François. Riche décor : dais et encadrement autour des personnages et du texte, initiale filigranée de qualité et initiales de mots cadelées à la première ligne.

309. 25 avril 1360 [d'après la fête; mais 24 d'après les calendes]; Bâle, Staatsarchiv des Kantons Basel Stadt, Klosterarchiv Domstift, Urk. 119; Denkmäler zur Basler Geschichte, éd. Ernst Alfred Stückelberg, Bâle, 1907, pl. 17; K. Escher, Miniaturen... [n. 146], p. 249 ( $n^{\circ}$ 359). Le seing du notaire est aussi figuratif (buste couronné) : c'est sans doute une coïncidence, mais elle invite à étendre aux signes d'authentification, dans de rares cas, l'histoire de l'art. Deux lettres d'indulgence sont attachées à l'acte (transfixes) : l'une de l'évêque de Bâle, Johannes Senn von Münsingen (23 mai 1360, initiale $N$ à sarments évidés en rose et vert), et l'autre des deux évêques de Gurk, Johannes von Platzheim-Lenzburg, et de Chur, Peter Jelito (19 janvier 1361, espace de l'initiale $U$ resté en blanc).

310. S'insère dans l'instrument un acte par le bourgeois romain et notaire impérial Sabbas magistri Petri (14 octobre 1359, Rome), qui documente la remise d'un reliquaire à Ulrich Conradi. Pour authentifier les reliques, le donateur aurait prêté serment sur les Évangiles à genoux, ut moris est Romanis. Ce sont encore des clercs romains en partie originaires des Alpes du Nord qui servirent de témoins : le ministre des Mineurs, frère Jean de Bâle, le recteur de Saint-Jean della Malva au Trastevere, Gérard, et le recteur de Saint-Justin in porticu Sancti Petri, Georges d'Autriche.

311. La communauté avait quitté entre 1279 et 1282 son lieu d'origine à Gnadent(h)al dans le canton d'Argovie pour s'établir à Bâle, et en 1289 avait été affiliée aux Clarisses (il ne faut pas la confondre avec le couvent féminin du même nom, dans la même région d'origine, affilié à partir de 1394-1396 à l'ordre de Cîteaux); Brigitte Degler-Spengler, « Klarissenkloster Gnadental in Basel », dans Helvetia sacra, t. V/1, Berne, 1978, p. 545-551; Alfred Ehrensperger, Der Gottesdienst in Stadt und Landschaft Basel im 16. und 17. Jahrhundert, Zurich, 2010, p. 32-34.

312. La scène semble à première vue se jouer dans le cadre d'un $A$ « pseudo-oncial », mais le trait enluminé en rouge, avec deux dragons sans couleur, aux têtes entrelacées (motif courant dans les initiales filigranées; semblable dans les lettres d'indulgence de Sankt Wendel) est en réalité un $I$, et le cadre est formé de sarments étendus vers la gauche. 
interprète cette translation de façon originale : à gauche se tient Paul, qui s'incline vers l'évêque de Bâle Johann Senn von Münsingen et lui remet une dent d'une dimension assez effrayante. L'évêque la reçoit avec une certaine nonchalance, derrière son dos, son attention étant concentrée sur la Vierge à l'Enfant, patronne de l'évêché, devant qui il est agenouillé : Marie et Jésus, main tendue, reçoivent de lui, à leur tour, une monstrance contenant la dent réduite à une grandeur plus raisonnable ${ }^{313}$.

Autre acte helvétique : la « deuxième lettre jurée » («zweiter geschworener Brief») de la ville de Zurich, de 1373, qui redéfinit, à l'occasion d'une réorganisation des corps de métier, les modalités d'élection du conseil et la composition des instances politiques ${ }^{314}$. On y voit une jeune femme couronnée, chevelure dénouée, élégamment vêtue, avec un décolleté profond, personnage difficile à identifier précisément. Elle ne ressemble certainement ni à la Vierge Marie ni à une abbesse comme celle du couvent féminin zurichois, Beatrix von Wolhusen, dame nominale de la ville (« Stadtherrin de jure »), qui scelle la charte ${ }^{315}$.

Une remarquable liasse contient une grande charte du duc Amédée VI de Savoie, de 1382, donnant quatre cents florins pour une messe quotidienne dans la chapelle Notre-Dame de la cathédrale de Lausanne ${ }^{316}$ (ill. 44). $\mathrm{Au}$-dessus du texte, le parchemin découpé en triangle isocèle contient, dessinée à la plume, une Vierge d'humilité ${ }^{317}$, à gauche les armoiries complètes des ducs de Savoie et à droite l'emblème de l'ordre du Collier (ou de la Très Sainte Annonciade) constitué en 1362-1364 par Amédée VI, où est inscrite la devise « Fert/Savoye » 318 . À défaut d'étude stylistique et iconographique, seule l'initiale filigranée peut être attribuée à la tradition des Alpes du Nord.

313. Un reliquaire étonnamment proche, contenant une dent de saint Jean Baptiste : Vienne, Kunsthistorisches Museum, Weltliche Schatzkammer, inv.SK_WS_XIII_27. Il a été daté du dernier tiers du $\mathrm{XIV}^{\mathrm{e}}$ siècle et localisé près de Prague : http://bilddatenbank.khm.at/ viewArtefact?id=100452 (consulté août 2011).

314. 3 décembre 1373, Zurich; Zurich, Staatsarchiv, C I, no 536; Quellen zur Zürcher Zunftgeschichte, 13. Jahrhundert bis 1798, éd. Werner Schnyder, collab. Hans Nabholz, t. I : 13. Jahrhundert bis 1604, Zurich, 1936, p. $8-25$ ( $\mathrm{n}^{\circ}$ 34); Zajic et Roland, « Urkundenfälschung » [n. 11], p. 408; Otto Sigg, « Die Zunftrevolution 1336 : die Handwerke als Säulen des Staates », dans Kleine Zürcher Verfassungsgeschichte, 1218-2000, éd. Meinrad Suter, Zurich, 2000 p. 19-21, à la p. 20 (ill., et initiale reprod. en couverture); voir aussi [en ligne :] http:// de.wikipedia.org/wiki/Brunsche_Zunftverfassung (ill.; consulté août 2011).

315. D'autres hypothèses proposées (la Justice ou sainte Regula, patronne de Zurich) sont incompatibles avec les attributs.

316. 29 janvier 1382, Vevey; Turin, Arch. di Stato, Corte, Materie ecclesiastiche, Arcivescovadi e vescovadi stranieri, Vescovado di Losanna, mazzo 1, fasc. 5 ; Il gotico nelle Alpi... [n. 244], p. 480-483 (par Isabella Massabò Ricci et Simonetta Castronovo).

317. Type développé au XIv ${ }^{\mathrm{e}}$ siècle de Vierge à l'Enfant assise au sol et souvent allaitant (Maria lactans); Beth Williamson, The Madonna of Humility : development, dissemination and reception, c. 1340-1400, Woodbridge, 2009 : un rôle important dans sa genèse reviendrait aux enlumineurs de Metz.

318. Sur l'ordre du Collier de Savoie, D’Arcy Jonathan Dacre Boulton, The Knights of the 
L'immense diversité des chartes privées enluminées apparaît aussi dans l'exemple suivant (ill. 45). Il s'agit d'une kétouba, acte de mariage d'un couple de juifs, datée de l'année hébraïque 5152 (1391-1392) ${ }^{319}$, autrefois de grande dimension mais conservée sous forme de quatre fragments ${ }^{320}$. On peut très probablement l'attribuer à la communauté juive de Krems. Le texte hébreu, assez protocolaire ${ }^{321}$, est encadré par une bordure peinte à la gouache, où s'insèrent, en haut de part et d'autre, les figures des mariés. Le style est caractéristique de ce XIV ${ }^{\mathrm{e}}$ siècle, où l'Autriche se montrait si ouverte aux nouveaux développements de la peinture en Bohême ${ }^{322}$. La composition florale des bordures est plus difficile à situer, et emprunte sans doute au domaine de la peinture murale décorative. Cet acte de mariage enluminé est le quatrième que nous connaissons, après ceux de Théophano (972), de Bari (1028) et de Jean duc de Berry (1389) ${ }^{323}$.

Les exemples suivants, aussi de Bâle, nous mènent autour de 1400. En cette année, l'évêque Humbert (Humbrecht) de Neuenburg et son chapitre vendent à la ville de Bâle les châteaux et villes de Waldenburg, Homburg

Crown : the monarchical orders of knighthood in later medieval Europe, 1325-1520, Woodbridge-New York, 2000, p. 249-270. Cette charte est à ajouter aux documents (p. 254) sur les emblèmes de l'ordre, ou plutôt de son fondateur. Elle dément l'opinion que l'ajout de la devise « Fert » serait postérieur à 1400 (Malte Prietzel, « Hosenband und Halbmond, Schwan und Hermelin : zur Ikonographie weltlicher Ritterorden im späten Mittelalter », dans HeroldJahrbuch, n. s., t. 4, 1999, p. 119-134, à la p. 132, n. 35). Voir aussi la brève mais bonne étude de Michel Pastoureau, « L'emblématique princière à la fin du Moyen Âge : essai de lexique et de typologie », dans Héraldique et emblématique de la Maison de Savoie (XI ${ }^{e}-X V I^{e}$ s.), éd. Bernard Andermatten, Agostino Paravicini Bagliani, Annick Vadon, Lausanne, 1994, p. 19-43, aux p. 21, 30-32.

319. Vienne, Österr. Nationalbibl., Cod. Hebr. 218; Arthur Zacharias Schwarz, Die hebräischen Handschriften der Nationalbibliothek in Wien, Vienne-Prag-Leipzig, 1925, p. 237 (no 202), [en ligne :] www.manuscripta-mediaevalia.de/hs/kataloge/HSK0780.htm (consulté août 2011); Karl-Georg Pfändtner, « Wien, Österreichische Nationalbibliothek, Cod. Hebr. 218 (Ketubbah) », dans Europas Juden im Mittelalter (expos., Spire, Historisches Museum der Pfalz), Ostfildern-Ruit, 2004, p. 196-197; Martha Keil, « Gemeinde und Kultur : die mittelalterlichen Grundlagen jüdischen Lebens in Österreich », dans Geschichte der Juden in Österreich, éd. Eveline Brugger, M. Keil, Albert Lichtblau, Christoph Lind, Barbara Staudinger, Vienne, 2006 (Österreichische Geschichte, éd. Herwig Wolfram, 15), p. 15-122, 573-596 (notes), aux p. 37-38 (ill. couleur).

320. Vienne, Österr. Nationalbibl., Cod. 4600. Le manuscrit, qui appartint au célèbre maître de l'université de Vienne Thomas Ebendorfer, fut écrit en 1434 pendant le concile de Bâle; Mitteleuropäische Schulen V... [n. 153], nº 97 (par V. Pirker-Aurenhammer).

321. Nous remercions de son aide précieuse Mme Martha Keil, directrice de l'Institut für jüdische Geschichte Österreichs, à Sankt Pölten.

322. Voir pour comparaison la première phase du Rationale Duranti des ducs d'Autriche (Vienne, Österr. Nationalbibl., Cod. 2765, fol. 1), où figures et décor montrent l'influence de la Bohême; Mitteleuropäische Schulen II (ca. 1350-1410) : Österreich, Deutschland, Schweiz, éd. A. Fingernagel, K. Hranitzky, V. Pirker-Aurenhammer et al., Vienne, 2002 (Die illuminierten Handschriften der Österreichischen Nationalbibliothek, 11), n 31 (par A. Fingernagel), ill. 19 et 139 .

323. Ci-dessus, respectivement n. 12, 33, 213. 
et Liestal ${ }^{324}$ (ill. $\left.46 a-b\right)$. Deux des chartes, en allemand, commencent par un $W$; mais la lettre est dans les deux cas presque méconnaissable dans le dessin à la plume qui le recompose en figures, en sorte qu'un petit $W$ plus lisible est ajouté à gauche. Dans l'acte de Bâle, la scène représente le martyre de sainte Catherine; dans celui de Liestal, la Chute, dans un vallon herbeux. Le rapport iconographique avec l'action juridique étant assez générique, on hésitera à dire ces deux actes « historiés » au sens strict. Le style correspond à l'atelier de Rüdiger Schopf, actif à Bâle. Les vêtements des personnages dans l'acte de Bâle ressemblent à certaines que portent les évangélistes Jean et Luc, en 1392-1393, chez le « Johannesmeister » ${ }^{325}$.

Avec la grande lettre de la confrérie des « maîtres du marché au poisson frais » (《 Herren vom Grünen Fischmarkt ») de Cologne en 1402 326 , nous retournons dans le milieu des confréries. Différemment des exemples de Bâle deux ans plus tôt, l'illustration est en rapport étroit avec le contenu : sainte Catherine, dont la légende est racontée dans les scènes au-dessus du texte, est la patronne de la confrérie des poissonniers qui fixe ici son règlement. On la voit d'abord debout avec son attribut habituel, la roue; puis vient une narration en trois parties : l'échec du martyre par la roue, la décollation et l'étrange ensevelissement par des anges ${ }^{327}$. Dans le tiers inférieur de la feuille se trouvent, comme dans la charte de la confrérie Saint-Loup de Cologne, les noms des quinze premiers frères, liste qui fut ensuite régulièrement mise à jour. La pièce, en écriture livresque (textualis formata),

324. On connaît cinq exemplaires de deux chartes concédées le 26 juillet 1400 : $1^{\circ}$ l'évêque de Bâle, Humbrecht von Neuenburg, fait le serment de dégager les villes et châteaux de Waldenbourg, Hombourg et Liestal du comte Rudolf von Hachberg pour 22000 florins et de les vendre à la ville de Bâle pour le même montant (Liestal, Staatsarchiv Basel-Landschaft, Altes Archiv, Urk. 178, exemplaires $a$ et $b$, ce dernier avec initiale à visage); texte édité par Heinrich Boos, Urkundenbuch der Landschaft Basel, t. II, 1371-1512, Bâle, 1883, p. 589-592 ( $\mathrm{n}^{\circ}$ 525); - 2o acte de la vente : $a$, Liestal, Staatsarchiv Basel-Landschaft, Altes Archiv, Urk. 179, initiale représentant la Chute; $b$, ibid., Sisgau 1 (décor incertain); $c$ : Bâle, Staatsarchiv Basel Stadt, Städtische Urkunde 788a (K. Escher, Miniaturen... [n. 141], p. 249, $\mathrm{n}^{\mathrm{o}}$ 361), initiale avec sainte Catherine : texte édité d'après $2 a$ par H. Boos, Urkundenbuch..., p. 592-597 (n n $\left.^{\circ} 26\right)$.

325. Bâle, Universitätsbibl., A II 11, fol. 1 et 93v; étude fondamentale, Lieselotte Esther Stamm, Die Rüdiger Schopf-Handschriften : die Meister einer Freiburger Werkstatt des 14. Jahrhunderts und ihre Arbeitsweise, Aarau-Francfort-Salzbourg, 1981, ill. 18-19.

326. 4 juillet 1402; Cologne, Historisches Archiv der Stadt Köln, Zunftakten 271 (apparemment perdus en 1971); W. Kisky, « Bemalte rheinische Urkunden »... [n. 82], p. 150-151 (ill.); Heinrich Jerchel, « Die niederrheinische Buchmalerei der Spätgotik (1380-1470) », dans Westdeutsches Jahrbuch für Kunstgeschichte : Wallraf-Richartz-Jahrbuch, t. 10, 1938, p. 65-90, aux p. 66, 69-71 (ill. 37); Klaus Militzer, Quellen zur Geschichte der Kölner Laienbruderschaften vom 12. Jahrhundert bis 1562/63, Düsseldorf, 1997, t. II, p. 1357-1358 (nº 122).

327. Peter Schill, Ikonographie und Kult der Heiligen Katharina von Alexandrien im Mittelalter : Studien zu den szenischen Darstellungen aus der Katharinenlegende (thèse, Munich, 2005), annexe A, p. 152-153 (no XCI), p. 184-185, 202, 204, 262, 266, 270 n. 176 , avec état de la question, [en ligne :] http://edoc.ub.uni-muenchen.de/4091/1/Schill_Peter. pdf (consulté août 2011). 
constitue par son style une œuvre éminente dans l'enluminure florissante à Cologne au début du $\mathrm{Xv}^{\mathrm{e}}$ siècle ${ }^{328}$. Surtout, elle a donné lieu en Angleterre, durant les $\mathrm{Xv}^{\mathrm{e}}$ et $\mathrm{XvI}^{\mathrm{e}}$ siècles, à une tradition vivante de lettres (de fondation) royales en faveur de différents corps sociaux ${ }^{329}$.

Il y a plusieurs années, notre recherche sur les chartes enluminées a été amorcée par une liasse de quatre pièces provenant de Dürnstein ${ }^{330}$, petite ville de Basse-Autriche, sise sur le Danube près de Krems, lieu d'origine probable de la kétouba déjà mentionnée. La transformation progressive d'une ancienne chapelle mariale en une communauté de chanoines réguliers de Saint-Augustin est évoquée en peinture dès 1395; mais l'acte principal est la lettre de fondation du 17 février $1410^{331}$ (ill. 47). L'initiale $I$ devient ici quatre carrés superposés à gauche du texte, contenant de haut en bas : au $1^{\mathrm{er}}$, la première fondatrice agenouillée devant la Vierge à l'Enfant; aux $2^{\mathrm{e}}$ et $3^{\mathrm{e}}$, d'autres membres de la famille y compris l'auteur de la charte; au $4^{\mathrm{e}}$ les Augustins. De cette initiale sortent des rinceaux d'acanthe habités de personnages ${ }^{332}$. Le style est de toute évidence celui du principal atelier viennois de la première décennie $\mathrm{du} \mathrm{Xv}^{\mathrm{e}}$ siècle. La charte de fondation fut confirmée la même année par l'évêque de Passau, Georg von Hohenlohe. La quatrième charte de la liasse, enfin, est formellement un faux établi d'après la précédente, et date de 1415; les droits du nouveau monastère y sont augmentés, mais la qualité artistique du décor repris à l'identique est bien inférieure.

\section{LetTres Diffamatoires (《 SCHMÄHBRIEFE 》) ET IMAGES INFAMANTES (《 SCHANDBILDER »).}

Les lettres diffamatoires peintes d'images infamantes sont bien plus rares que les lettres d'armoiries, mais elles constituent de même un genre propre à l'Empire ${ }^{333}$. Il s'agit généralement de documents sur papier rédigés en forme de charte, parfois même scellés d'un ou plusieurs sceaux, qui - après une menace de publication sous des conditions plus ou moins strictes $^{334}$

328. On peut nommer le Mont du Calvaire (Köln, Wallraf-Richartz-Museum), une Crucifixion (Washington, National Gallery of Art, Kress Collection, anc. collection Schnitzler) et les deux personnages ailés de la Vierge aux Fleurs de pois de senteur (Munich, Alte Pinakothek); Alfred Stange, Deutsche Malerei der Gotik, t. III : Norddeutschland in der Zeit von 1400 bis 1450, Berlin, 1938, p. 53, 57-60, et ill. 61, 63, 64, 68 .

329. Voir E. Danbury, « Décoration... » [n. 33].

330. Zajic et Roland, «Urkundenfälschung » [n. 11], p. 331-391; A. Zajic, « Von der Marienkapelle... » [n. 282], p. 14 (ill. 4), 21-22 (ill. 10); M. Roland, « Der Dürnsteiner Stiftbrief : Multimedia im Mittelalter », dans Stift Dürnstein... [n. 282], p. 24-31 et ill.

331. Zajic et Roland, « Urkundenfälschung », p. 342-349, 361-367, 382-389.

332. Description précise ibid., p. 382-385.

333. Fondamental : Matthias Lentz, Konflikt, Ehre, Ordnung : Untersuchungen zu den Schmähbriefen und Schandbildern des späten Mittelalters und der frühen Neuzeit (ca. 1350 bis 1600), Hanovre, 2004.

334. Ibid., p. 42-54. 
- s'adressent au public ou à des destinataires spécifiés. Ces lettres étaient affichées en un lieu bien visible, de manière à défier l'adversaire, et le texte pouvait être renforcé par une image infamante ${ }^{335}$. Leur but était de forcer un débiteur à respecter ses engagements après des réclamations répétées ${ }^{336}$, les étapes du litige étant souvent récapitulées en détail dans la narration. C'est une procédure légitime, observant des formes rituelles de publicité 337 pour attaquer l'adversaire sur son honneur ${ }^{338}$. Si ces documents sont au fond bien différents des actes examinés jusqu'ici, il nous semble qu'ils méritent d'être examinés concurremment parce que le rôle de l'image y est très semblable et que la publicité y recourt à un moyen analogue : la focalisation du regard sur des signes peu nombreux et récurrents ${ }^{339}$.

La plus ancienne lettre à image infamante repérée date de 1420 ou environ $(i l l .48)^{340}$. Le comte Jean III de Nassau-Dillenbourg avait reçu du duc Jean de Bavière, comte de Hollande, par une charte du 21 mars 1418, l'assurance du versement d'une solde; or le duc n'avait ni payé ni livré les vingtquatre otages prévus en ce cas. L'image infamante sous le texte représente le parjure imprimant son sceau, fort agrandi pour rendre lisibles les armes des Wittelsbach, sur le postérieur d'une truie ${ }^{341}$. Un autre motif fréquent était la pendaison de l'opposant et/ou de ses armoiries ${ }^{342}$ (ill. 49). Une troisième

335. M. Lentz a catalogué 200 lettres diffamatoires dont 70 avant 1500 . Seules 20 , dont 16 originaux conservés, portent ou portaient une image. Lentz ne distingue pas assez entre les images infamantes et les lettres diffamatoires enluminées qui seules nous intéressent ici. Dans deux litiges en 1403-1404 (ibid., p. 174-175, n. 19-20), il s'agit de la menace de publier une image infamante. Dans deux autres cas (ibid., p. 52), nous avons bien des lettres diffamatoires enluminées : les livres de comptes du marchand colonais Johann van Nuyss et de Dietmar Bungart (vers 1427-1434) notent comme un fait banal le prix pour faire écrire, enluminer, diffuser et afficher des « kaex- » et « upslainbreven »; une chronique de Francfort, en mai 1469, rapportant un procès, mentionne un paiement semblable : «Item den molern die boßwichtzbrieffe zu machen kosten $1 \frac{1}{2} 2$ gulden » (« Item aux peintres pour faire les lettres diffamatoires, qui coûtent un florin et demi »); voir aussi p. 204-205 (nº 57).

336. Ibid., p. 150.

337. Sur la publicité, ibid., p. 154-156 (mais sans considération pour l'image comme médium). La publicité était la condition indispensable pour que l'image infamante, le cas échéant, puisse produire son effet; la simple menace devait souvent suffire à faire céder l'adversaire.

338. Lentz relève tout à la fin de son étude (p. 162) les vices invoqués dans les lettres. Ils correspondent peu au message de l'image.

339. Lentz ne se soucie guère du mode opératoire des images infamantes et n'en étudie ni les thèmes ni la forme, mais dresse une liste (problématique) du contenu des représentations; ibid., p. 357-358.

340. Wiesbaden, Hessisches Hauptstaatsarchiv, Abt. 170, no 1026 ; M. Lentz, Konflikt..., p. $177-178, \mathrm{n}^{\circ} 23$ (ill.).

341. Le contact déshonorant entre un sceau ou des armoiries et l'arrière-train d'un animal (principalement truie ou ânesse) est un motif assez courant dans les images infamantes; plusieurs exemples avant 1500 dans M. Lentz, Konflikt..., $\mathrm{n}^{\text {os }}$ 23, 55, 59 (pendu tête en bas), 64 .

342. Le premier exemple conservé en original est une lettre du chevalier Jean de Löwenstein contre le landgrave Louis I ${ }^{\text {er }}$ de Hesse, du 2 septembre 1438 (ill. 49); Francfort, Institut für Stadtgeschichte (Stadtarchiv), Reichssachen I, no 3605, [en ligne :] www.stadtgeschichte- 
formule le mettait en scène, énergiquement maltraité, sur le lieu des exécutions publiques ${ }^{343}$. D'autres, moins fréquentes, jusque vers 1500 , faisaient intervenir la Mort ${ }^{344}$. Il existe enfin des solutions tout à fait inhabituelles.

Le chevalier Werner von Elben, originaire de Hesse, s'efforçait de recouvrer au nom de sa sœur une dette de l'évêque Jean II de Wurtzbourg, cautionnée par divers dignitaires religieux et par trois villes. On conserve (séparément) sa lettre diffamatoire ou de supplication du 10 août 1458 et une image infamante. Le dessin réalisé à la plume et enluminé montre, d'une part, les débiteurs et leurs garants (accompagnés d'injures en rime), en cinq champs superposés; d'autre part, une potence avec un pendu et une truie, empruntés aux modèles plus courants. La situation est décrite en quelques mots au-dessous des illustrations, certaines étant assorties en outre d'un paragraphe de malédictions qui réduit d'autant la dimension de l'image ${ }^{345}$.

Le comte Bernard de Moers (Meurs) nous offre une véritable bande dessinée de son destin, exécutée à la plume et enluminée (ill. 50) : Charles d'Egmond (1467-1538), duc de Gueldre, avait été fait prisonnier après le siège de Béthune par les Français (1487). En 1492, Bernard se proposa en échange comme garant pour le restant de sa rançon ${ }^{346}$. Le duc ne l'ayant pas acquittée, le comte, le 20 novembre 1493, envoya de sa prison à Péronne une lettre monitoire ${ }^{347}$. Cependant il s'agissait dans ce cas de souligner son propre honneur - on voit Bernard voyageant en armure, et ses armoiries à droite et à gauche du texte -, non d'insulter le débiteur.

L' « impact publicitaire » des images infamantes est enfin à considérer

ffm.de/artikel/landgraf.html (consulté juill. 2011); M. Lentz, Konflikt..., p. 184-185, n 34 (ill.) : le landgrave y est pendu la tête en bas à une potence avec ses armoiries, deux corbeaux sur les pieds. Huit cas avant 1500 (avec figure, armes, ou les deux) sont cités ibid., nos 24, 34, 37, 38, 46, 51, 59 (avec sceau au derrière d'une truie), 66. Pour les nobles, le renversement des armoiries fait partie du rituel déshonorant qui précède une exécution capitale : Sir Ralph Grey, avant sa décapitation par jugement royal le 10 juillet 1465, fut condamné à porter ses armes renversées (puis gracié de cette partie de la peine); John Warkworth, A chronicle of the first thirteen years of the reign of King Edward the Fourth, éd. James Orchard Halliwell, Londres, 1839, p. 39.

343. Lettre de Bernhard von Wauer de Cologne contre l'ancien bourgmestre Johann Breyde (11 avril 1464); Cologne, Historisches Archiv, Haupturkundenarchiv, Nachträge (HUANA) 2/126a, [en ligne :] www.giselmut.de/strafen.htm (consulté août 2011); M. Lentz, Konflikt..., p. 200-201 (n. 52, ill.); représentations semblables jusqu'en 1500, ibid. $\mathrm{n}^{\text {os }} 49,63,65$.

344. Ibid., $\mathrm{n}^{\text {os }} 48,62$.

345. Bibl. Vat., Vat. lat. 11144, fol. 1; la lettre de supplication correspondante est conservée à Wurtzbourg, Stadtarchiv, Ratsakt no 4018, fol. 3; M. Lentz, Konflikt..., p. 195-197 (ill.).

346. Thomas P. Becker, « Moers im Zeitalter der Reformation (1500-1600) », dans Moers : die Geschichte der Stadt von der Frühzeit bis zur Gegenwart, éd. Margret Wensky, Cologne, 2000, t. I, p. 159-269, aux p. 159-160.

347. Zutphen, Regionaal Archif Zutphen, Municipal archif Zutphen, inv. 2386; M. Lentz, Konflikt..., p. 219-221 (ill.); avec bonne reproduction, description détaillée et transcription, [en ligne :] www.regionaalarchiefzutphen.nl/ (consulté sept. 2011). Il paraît peu probable que le prisonnier ait pu composer la lettre en prison, encore moins y employer un artiste. Le document avait-il une fonction rétrospective, de souvenir? En tout cas il est exceptionnel. 
dans le contexte des débuts de l'imprimerie et de l'estampe. Une feuille volante imprimée en 1461 montre un certain Nicolas d'Abensberg pendu à l'envers à une potence avec ses armoiries renversées ${ }^{348}$ (ill. 51a) ${ }^{349}$. Le plaignant, Bénigne de Tanndorf, fait savoir « allen und yeden fursten, graven, freiherrn, herrn, rittern und knechten ${ }^{350}$, que Nicolas, abusant sa confiance, a volé chez lui des bijoux. Le texte, manuscrit, se termine par deux vers en guise de légende : « Je m’appelle Nicolas seigneur d'Abensberg, ma méchanceté me rend très célèbre ${ }^{351}$. Une lettre diffamatoire de Paul Nawber d'Ingolstadt, vers 1490, représente le cas inverse ${ }^{352}$, une légende pré-imprimée ${ }^{353}$ jointe à un dessin à la plume enluminé - une vache déféquant sur le sceau armorial de Heinz von Gut(t)enberg, attaché à sa queue (ill. 51b). Ces deux exemples montrent assez combien le potentiel de l'imprimerie répondait au besoin de publicité de tels documents.

\section{QuelQues CAS PARTICULIERs.}

La décision d'intégrer de l'enluminure dans les chartes était souvent associée à la fondation ou à l'aménagement d'une église. C'est le cas de deux actes notariés datés du 19 mars 1411, concernant une fondation en faveur de la chapelle (rebâtie à partir de 1380) des saints Antoine et Corneille à Sankt Tönis près de Krefeld ${ }^{354}$. Les deux saints y figurent dans un champ à côté de l'initiale $I$; à gauche se trouvent, plus petits, les fondateurs, un homme et une femme agenouillés, et les membres de la petite communauté conduits sous une banderole (Sancti Dei, orate pro nostra omniumque salute, amen) par le rector de l'église, Guillaume in Agro.

348. Wilhelm Ludwig Schreiber, Handbuch der Holz- und Metallschnitte des XV. Jahrhunderts, t. IV, Holzschnitte darstellend religiös-mystische Allegorien, Lebensalter, Glücksrad..., Leipzig, 1927, p. 113 (no 1975); M. Lentz, Konflikt..., p. 198-200, no 51 (ill.).

349. Lieu de conservation inconnu : dans les années 1920 l'œuvre était à Vienne (coll. princes de Liechtenstein). Nous ignorons si, comme d'autres parties de la bibliothèque, elle fut vendue à $H$. P. Kraus (New York) après la seconde guerre mondiale.

350. D'après W. L. Schreiber, Handbuch..., t. IV, p. 113 (texte intégral).

351. « Nicklaus herre zcu Abensperg ben ich genannt / Miem posheit macht mich weid bokant. » On peut lire ces deux lignes dans M. Lentz, Konflikt..., p. 199, ill.

352. Nuremberg, Germanisches Nationalmuseum, Kupferstichkabinett, HB 2527, Kaps. 1382; M. Lentz, Konflikt..., p. 211-212, nº 64 (ill.).

353. Ingolstadt, imprimeur du Lescherius, après le 22 février 1487 (vers 1490); F. Eisermann, Verzeichnis... [n. 85], t. III, p. 231 (N-1); Gesamtkatalog der Wiegendrucke, [en ligne :] www.gesamtkatalogderwiegendrucke.de (consulté sept. 2011), no M25882; M. Lentz, Konflikt..., p. 211-212, no 63 (ill.). Une autre lettre diffamatoire imprimée, illustrée d'une simple xylographie, peut être datée après 1500 ; F. Eisermann, Verzeichnis..., t. II, p. 373 [D-1]; M. Lentz, Konflikt..., p. 221-223 (n ${ }^{\circ}$ 71).

354. 19 mars 1411; Tönisvorst, Pfarrarchiv Sankt Cornelius, no 3a (en rouleau); W. Kisky, « Bemalte rheinische Urkunden »... [n. 82], p. 151-152 (ill.); copie du répertoire par W. Kisky (1933) du Pfarrarchiv St. Tönis, Kreisarchiv Viersen, 1 (n⿳⺈ 3a); Paul Wietzorek, St. Tönis : aus der Geschichte einer niederrheinischen Gemeinde, 1188-1969, Horb am Neckar, 1991, p. 252-254. Nous remercions chaleureusement M. Gerhard Rehm (Kreisarchiv Viersen). 
On a vu que les chartes enluminées étaient apparues en rapport avec le financement des édifices religieux, et cette tradition est poursuivie dans deux lettres de Benoît Siebenhirter, évêque in partibus de Tibériade et évêque de la cour de Frédéric III, pour la consécration d'églises à Lienz en $1457^{355}$. L'acte pour l'église Saint-Jean montre à l'intérieur d'une grande initiale $I$ le buste de saint Jean Baptiste avec l'Agneau, à la plume. En revanche l'initiale pour l'église paroissiale Saint-André (St. Andrä) a reçu un buste du Christ en médaillon à la gouache; cette charte se distingue encore par ses capitales proto-humanistiques et par l'écriture mêlée, ornée à la gouache et à l'or, de la première ligne. En dépit des différences d'écriture et de technique, l'artiste est manifestement le même.

On ne connaissait pas jusqu'ici de chartes enluminées de la chancellerie du duc (archiduc) d'Autriche Albert VI (ill. 52) ${ }^{356}$. Entre la mort de Ladislas le Posthume (1457) et la sienne en 1463, il donna au moins quatre confirmations de privilèges en faveur d'institutions ecclésiastiques en Haute-Autriche et en Bavière, comportant un décor. La plus ancienne, du 18 décembre 14.58, pour les Bénédictins de Lambach ${ }^{357}$, montre des feuilles et des fleurs jaillissant d'une branche pour composer l'initiale $W^{358}$. L'artiste trace le feuillage à la plume avant de le modeler soigneusement à l'encre, sans autre couleur. On retrouve la même composition pour les Prémontrés de Schlägl ${ }^{359}$. Les deux confirmations suivantes, sans être enluminées au sens strict, représentent des saints patrons dans l'initiale; elles furent données respectivement pour le chapitre cathédral de Passau ${ }^{360}$ et pour l'église Saint-Gilles (St. Gilgen) de Vöcklabruck, affectée aux chanoines réguliers de Saint-

355. 7 octobre 1457; Lienz, Pfarrarchiv St. Andrä, XX.33; Benedikt Siebenhirter consacre l'église Saint-Jean de Lienz et accorde une indulgence de 40 jours; Meinrad Pizzinini, « Die Kirche zu St. Johannes dem Täufer in Lienz », dans Robert Büchner, Bauen zum Lobe Gottes und zum Heil der Seele : der Neubau der St. Johanneskirche zu Lienz im 15. Jahrhundert (mit einer Edition des Rechnungsbuches 1467-1491), Krems, 2006, p. 151-183, aux p. 155 et 170 (ill. 5-6) : 9 octobre 1457; Lienz, Pfarrarchiv St. Andrä, Urkunden 97; B. Siebenhirter consacre l'église paroissiale Saint-André de Lienz et accorde une indulgence de 50 jours; voir Circa 1500 : Leonhard und Paola, ein ungleiches Paar; De ludo globi, Vom Spiel der Welt; An der Grenze des Reiches (expos., Innsbruck, Tiroler Landesmuseum Ferdinandeum), Milan, 2000, p. 113 (no 1-4-10, par M. Pizzinini) et ill. 54.

356. Sur les lettres d'armoiries de son frère l'empereur Frédéric III, en cette période de querelle fratricide, voir plus haut, section III. Sur la chancellerie d'Albert : Erwin M. Auer, Studien zur Geschichte der Kanzlei Albrecht VI. von Österreich, mémoire inédit, Institut für Österreichische Geschichtsforschung, Vienne, 1948.

357. 18 décembre 1458; Linz; Lambach, Stiftsarchiv, [en ligne :] monasterium.net.

358. Le $E$ du titre Erzherzog est aussi une composition florale.

359. 14 mai 1459, Linz; Schlägl, Stiftsarchiv, [en ligne :] monasterium.net.

360. 21 janvier 1459, Linz; Munich, Bayerisches Hauptstaatsarchiv, Klosterurkunden Domkapitel Passau, Urk. 1047, [en ligne :] monasterium.net : saint Étienne agenouillé de face et quatre hommes agités qui ramassent des pierres et les lui lancent. L'acte inclut le texte d'une charte du roi Ladislas du 21 août 1456 (Vienne), insérant à son tour une charte analogue du roi Rodolphe I ${ }^{\text {er }}$ du 28 avril 1281 (Vienne); voir ibid., Urk. 84. 
Florian $^{361}$. La technique identique et la similitude des motifs floraux montrent qu'un même remarquable artiste fut chargé des quatre actes. Les motifs végétaux pourraient dériver de modèles imprimés ${ }^{362}$.

Un cas troublant, restant à résoudre, est celui d'une lettre de confrérie donnée en 1469 par le prieur provincial austro-bavarois des Augustins (ermites), Paul de Munich, pour Éléonore d'Écosse, épouse du duc Sigismond de Tyrol ${ }^{363}$ : les figures du donateur et de la bénéficiaire, à côté du texte, pourraient être un ajout du XVIII ${ }^{\mathrm{e}}$ ou du $\mathrm{XIX}^{\mathrm{e}}$ siècle $^{364}$.

Un cas exceptionnel par la forme de tradition de l'acte est celui d'un acte enluminé du notaire Raoul Goullette ou Houllette, du diocèse de Lisieux, acte non daté mais contenant la copie d'une charte donnée le 11 juin 1465 à Wiener Neustadt, par laquelle Frédéric III éleva Gérard du Champ, Liégeois, au rang de comte palatin avec le droit de créer des notaires et de légitimer des enfants (ill. 53) ${ }^{365}$. Gerhard Schmidt en a reproduit des détails agrandis ${ }^{366}$. Au-dessus du texte, dans un cadre cintré, une gouache représente l'empereur sur son trône remettant au bénéficiaire agenouillé sa lettre palatine. Sous le texte, une autre miniature montre le nouveau comte palatin en fonction : il tend un bâton (?) à un demandeur agenouillé à sa droite, caractérisé comme clerc et identifié par la légende Peto notariari; en face se tient un laïc à qui le notaire tend une charte, avec la légende : Peto legitimari. Les armoiries, fixées en double au dossier du siège, correspondent à celles décrites dans l'acte. On peut douter que la lettre palatine origi-

361. 2 février 1460, Linz; Sankt Florian, Stiftsarchiv, [en ligne :] monasterium.net. L'initiale est mal conservée : on reconnaît à peine saint Gilles en abbé, assis au pied d'un rinceau, et la biche appuyée contre sa cuisse. Contrairement à la légende, c'est l'animal, non le saint, qui est représenté atteint d'une flèche.

362. Voir encore la gravure du Maître E. S., dans M. Lehrs, Geschichte... [n. 281], t. II,

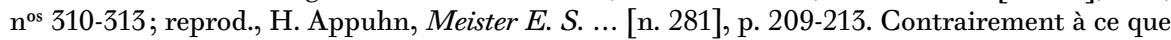
l'on voit chez le Maître du Bréviaire de Frédéric [n. 277 et 279] on ne peut établir ici qu'une parenté assez générique, qui demanderait une étude plus approfondie.

363. 25 janvier 1469; Vienne, Haus-, Hof- und Staatsarchiv, Familienurkunden, no 716 ; Österreich-Tirol, 1363-1963, Innsbruck, 1963, p. 55 ( $\mathrm{n}^{\circ}$ 62); Der Herzog und sein Taler : Erzherzog Sigmund der Münzreiche, Politik, Münzwesen, Kunst (expos., Burg Hasegg, Hall in Tirol), Innsbruck, 1986, p. 12 (ill.).

364. Considérant la largeur des marges, surtout en haut, une décoration a pu être prévue.

365. Paris, Bibl. nat. Fr., ms. Clairambault 1052, fol. 20. Le 7 juin 1465, Gérard du Champ avait déjà reçu une lettre d'armoiries de Frédéric III à Wiener Neustadt : J. Chmel,

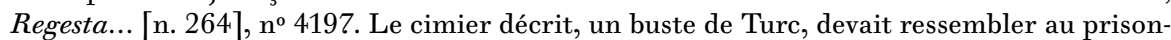
nier turc offert par Matthias Corvin au Liégeois. Son inscription « Servire Deo regnare est » se rapporte à l'engagement de Gérard du Champ dans une societas de Jesu (il participa à une expédition hongroise contre les Ottomans). L'Ottoman devait être avec lui à la cour de Wiener Neustadt. Chmel (no 4208) situe l'événement le 20 juin 1465 : il faut tenir compte de l'écart entre la date de la charte et son enregistrement. Une formule intitulée « Creacio publici notarii a comite palatino » figurait dans le Collectarius de Jean de Gelnhausen [n. 196], p. 22-23 ( $\left.n^{\circ} 31\right)$.

366. Gerhard Schmidt, « Porträt oder Typus : zur Frage der Ähnlichkeit in den Darstellungen Kaiser Friedrichs III. », dans Jahrbuch des kunsthistorischen Museums Wien, t. 8-9, 2006-2007, p. 10-59, aux p. 34-36. 
nale ait été enluminée, et on peut imaginer que le bénéficiaire aurait fait exécuter cette copie précisément pour pouvoir mieux illustrer sa dignité.

Parmi les exemples de la fin du $\mathrm{xv}^{\mathrm{e}}$ siècle, le premier rang par la qualité revient à la lettre de fondation que Gaspard de Roggendorf, petit noble promu à la cour de Frédéric III, donna le 11 novembre 1494 pour l'église paroissiale de Pöggstall dont il était le patron (ill. 54) ${ }^{367}$. L'initiale $I$ étirée sur toute la hauteur se compose de fines branches au naturel qui suivent ses contours et se prolongent en amples rinceaux puis en longues feuilles à nervures longitudinales, découpées et s'enroulant en griffes aux extrémités. Le corps de la lettre, sur fond d'or, abrite trois personnages debout : à gauche sainte Anne (patronne de l'église), qui accepte l'enfant Jésus des mains de sa fille Marie placée au centre, et à droite saint Gilles, patron de la chapelle du château de Pöggstall rebâtie par l'auteur de la charte. Au bas, agenouillé sur une feuille au centre de grands rinceaux, Gaspard de Roggendorf entre son écu et son heaume à cimier suspendus aux branches.

Le style caractéristique de ce temps pourrait être rapproché de divers artistes autrichiens, notamment du Maître du Missel de Wolfgang de 14921493 (« Meister des Wolfgang-Missales ») ${ }^{368}$ ou des œuvres de Berthold Furtmeyr à Ratisbonne. Gerhard Schmidt nous à indiqué le retable du maître-autel dans l'église paroissiale de Maria Laach de Jauerling, non loin de Pöggstall ${ }^{369}$, similaire en effet par le style des personnages, les plis froissés et les amples mouvements. Une charte pour la collégiale d'Ardagger, récemment passée en vente, a par ailleurs été située dans le milieu du Maître du Missel de Wolfgang ${ }^{370}$.

367. $1^{\mathrm{er}}$ novembre 1494, Vienne; Sankt Pölten, Diözesanarchiv, Pergamenturkunde, sub dato; M. Roland, « Buchmalerei »... [n. 266], p. 533-534 (ill. 22); A. Zajic, « Kaspar von Roggendorf (gest. 1506), Karrierist und Kunstliebhaber », dans Waldviertler Biographien 2, éd. Harald Hitz et al., Horn-Waidhofen a. d. Thaya, 2004, p. 9-32, aux p. 9 (ill. 1), $26-27$ et pl. I, [en ligne :] monasterium.net.

368. Voir Hinrich Sieveking, Der Meister des Wolfgang-Missale von Rein : zur österreichischen Buchmalerei zwischen Spätgotik und Renaissance, Munich, 1986. Les grands rinceaux, dans leur agencement, sont semblables à ceux d'un missel sans doute réalisé pour Saint-Lambrecht en Styrie (Graz, Universitätsbibl., Cod. 115); H. Sieveking, Der Meister..., ill. 75-76; Christine Beier, Die illuminierten Handschriften und Inkunabeln der Universitätsbibliothek Graz : die illuminierten Handschriften, 1400 bis 1550, t. I, Vienne, 2010, p. 256-258 (n $n^{\circ}$ 79), et t. II, ill. 511-521.

369. Communication orale, dont nous le remercions vivement. Voir Christina Seidl, Beiträge zur Wiener und niederösterreichischen Tafelmalerei der zweiten Hälfte des 15. Jahrhunderts (thèse, Vienne, 1987), ill. 224; ead., « Wiedergefundene Predellenflügel des spätgotischen Hochaltars von Maria Laach », dans Österreichische Zeitschrift für Kunst und Denkmalpflege, t. 47, 1993, p. 14-27, p. 19, ill. 21; ead., « Die Predellenflügel des spätgotischen Hochaltars in Maria Laach am Jauerling », dans Ars sacra : Kunstschätze des Mittelalters aus dem Salzburg Museum, éd. Peter Husty, Peter Laub, Salzbourg, 2010, p. 69-80.

370. Vente par Hugo Ruef, Munich, 1983; H. Sieveking, Der Meister..., p. 189 et n. 766 , attribue la charte au Maître des rinceaux des panneaux de Sunthaym (Klosterneuburg, Stiftsbibl., CCl 130). Il a aussi décoré l'antiphonaire de Stainz (Graz, Universitätsbibl., Cod. 2); C. Beier, Die illuminierten Handschriften..., t. I, p. 395-398 (n 122), et t. II, ill. 808-812. 
Il faut renoncer à poursuivre l'étude $a u x I^{\mathrm{e}}$ siècle. Un règlement de pêche de 1506 servira à clore ce parcours dans une tradition qui pourtant s'est perpétuée au-delà, et avec abondance, au moins dans les lettres d'armoiries et les lettres diffamatoires. La lettre patente, manifestement destinée à la ville de Vienne, par laquelle l'empereur Maximilien I ${ }^{\mathrm{er}}$ réglait la pêche dans le Danube, est accompagnée, au-dessous, des « portraits » des poissons concernés (ill. 55) : c'est une œuvre de très grande qualité, digne d'être comparée, dans la même période, aux études d'après nature d'Albrecht Dürer comme à l'extrême naturalisme de l'école de Gand-Bruges ${ }^{371}$.

$$
* *
$$

Le décor des chartes ne répond habituellement à aucune exigence diplomatique et juridique, à deux exceptions près : les lettres d'armoiries, surtout les plus anciennes, où l'image supplée au blasonnement; et les lettres diffamatoires illustrées, où le texte et l'image sont indissociables. Au-delà, l'enluminure fait partie des caractères externes destinés à conférer une apparence particulière, solennelle, remarquable et mémorable, à un document dont le contenu, lui, est plutôt conventionnel; le décor concourt ainsi au même effet que les dimensions souvent imposantes du parchemin ${ }^{372}$ ou l'écriture formelle, textualis formata ou bâtarde.

Toute typologie d'après les caractères internes doit considérer les auteurs et la nature des actes. Sur le premier point, l'Europe centrale se distingue au sein de la chrétienté. En Angleterre et en France, un rôle prédominant revient à la chancellerie royale : en Angleterre dans la longue durée, et en France particulièrement au temps de Charles V. Dans nos régions, en revanche, les auteurs de chartes enluminées ne constituent nullement un groupe homogène, et la chancellerie impériale ou royale n'est au premier plan que sous Louis de Bavière (dans un contexte d'opposition politique avec la Curie) et pour la genèse des lettres d'armoiries. Quant au contenu, on confectionnait des chartes enluminées plus spécialement pour certains

371. 24 février 1506; Vienne, Stadt- und Landesarchiv, Hauptarchiv Urk. 6015; Die Donau : 1000 Jahre Österreich, eine Reise (expos., Vienne, Schottenstift,), éd. Günter Düriegl, Vienne, 1996, n 8.16; Heinrich Berg, « Die Fischereiordnung Maximilians I. für die Donau und ihre Nebenflüsse, 1506 Februar 24 », dans Wiener Geschichtsblätter, 1993, p. 117-118; Geschichte der Bildenden Kunst..., t. III [n. 265], p. 562-563 (nº 301, par Fritz Koreny); Richard C. Hoffmann, Christoph Sonnlechner, «Vom Archivobjekt zum Umweltschutz : Maximilians Patent über das Fischereiwesen von 1506 », dans Studien zur Wiener Geschichte, Jahrbuch des Vereins für Geschichte der Stadt Wien t. 62-63, 2006-2007, p. 79-133; reprod. avec notice par M. Roland, [en ligne :] monasterium.net.

372. Une forte proportion des chartes présentées ici varient entre $40 \times 60 \mathrm{~cm}$ et $60 \times 80 \mathrm{~cm}$. Ainsi, on utilise des peaux entières, aux bordures parfois non rognées (et la lettre de fondation d’Amédée VI de Savoie [n. 316] est coupée en gardant le triangle du cou). Ces dimensions ne sont pas justifiées par la longueur du texte; au contraire, dans les indulgences d'Avignon, le grand format permet une écriture de très gros module. 
types d'actes : aux lettres d'indulgence, lettres d'armoiries et lettres diffamatoires, s'ajoutent occasionnellement contrats de mariage, règlements constitutifs de confréries religieuses et autres actes de fondation.

L'aspect publicitaire, qui joue manifestement un rôle fondamental, doit être envisagé de manière nuancée. La publicité est inhérente au système des indulgences, puisqu'il s'agit d'attirer le plus grand nombre de visites et de contributions financières; les actes portent même la trace matérielle de leur possible exposition par suspension. La publicité est non moins propre aux lettres diffamatoires. Tous les autres types de chartes visent à une publicité plus limitée. Le choix d'un décor luxueux revenait en premier lieu au bénéficiaire, qui en payait les frais et conservait ensuite sa charte par devers lui. C'était lui aussi qui savait à qui il la montrerait, qui il comptait impressionner. Le décor pouvait s'adresser aux membres d'un groupe plus ou moins clos (couvent, confrérie, communauté de bourgeois ou famille), mais aussi leur servir à en imposer à l'extérieur. Ce n'est que dans de rares cas, dans la charte dotale de Théophano ou chez Louis de Bavière ou Albert VI d'Autriche, que l'auteur de l'acte lui-même semble vouloir par le décor affirmer son prestige.

$\mathrm{Au}$ sein de la tradition massive des indulgences issues de la Curie et des lettres d'armoiries, plus ou moins soignées, certains exemples tranchent par des choix plus originaux à l'initiative du bénéficiaire. Ceux-ci montrent assez que de tels documents, même produits en masse, gardaient une portée locale et une valeur identitaire certaines.

L'analyse iconographique confirme la part du destinataire dans la mise au point de l'acte. La représentation d'un écu dans les lettres d'armoiries ou des patrons d'une église dans les lettres d'indulgence définit des archétypes. La figuration de l'auteur remettant au bénéficiaire la charte elle-même ou l'objet du privilège y ajoute l'évocation d'un événement honorifique et mémorable. Et au-delà on note bien des choix graphiques plus personnels, sortant souvent du lot par leur qualité artistique.

Afin de stimuler les recherches sur les chartes enluminées, il importe que diplomatistes, archivistes et historiens accordent à la configuration visuelle des chartes l'importance qui est la sienne, et s'efforcent en particulier de mettre au jour nombre de documents encore inconnus; c'est aussi le but que poursuit la base de données alimentée par nous sur le sujet.

Nous espérons enfin que ce premier essai de synthèse permettra de nourrir la discussion sur un matériau considérable et encore trop peu connu, concernant l'acte comme médium, autrement dit l'articulation entre la valeur juridique des actes, leur élaboration artistique et leur pouvoir de communication. Les chartes enluminées offrent ainsi l'occasion de croiser deux traditions de recherche que tout semble séparer, la diplomatique et l'histoire de l'art, pour les ouvrir ensemble à des questions nouvelles.

\section{Martin Roland. Andreas ZaJic.}



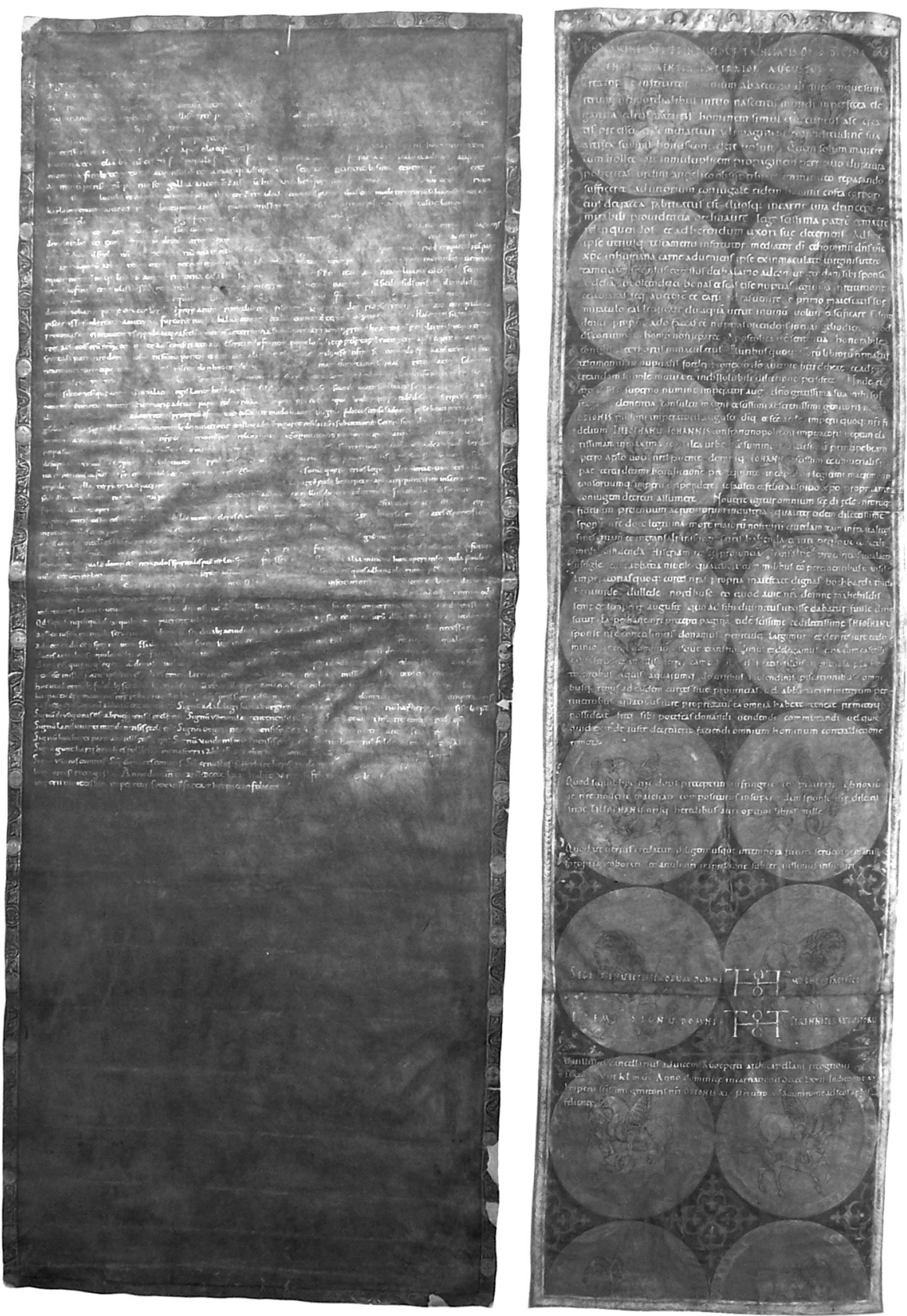

ILL. 1. $a$. Confirmation des privilèges de l'Église romaine, dite Ottonianum, 13 février 962 (Arch. Vat., Arm. 1, Caps. III, n. 1; D O.I. 235). - b. Charte dotale de Théophano, 14 avril 972 (Wolfenbüttel, Niedersächs. Staatsarchiv, 6 Urk. 11; D O.II. 21). Phot. : Kaiserin Theophanu..., t. II, p. 136. 


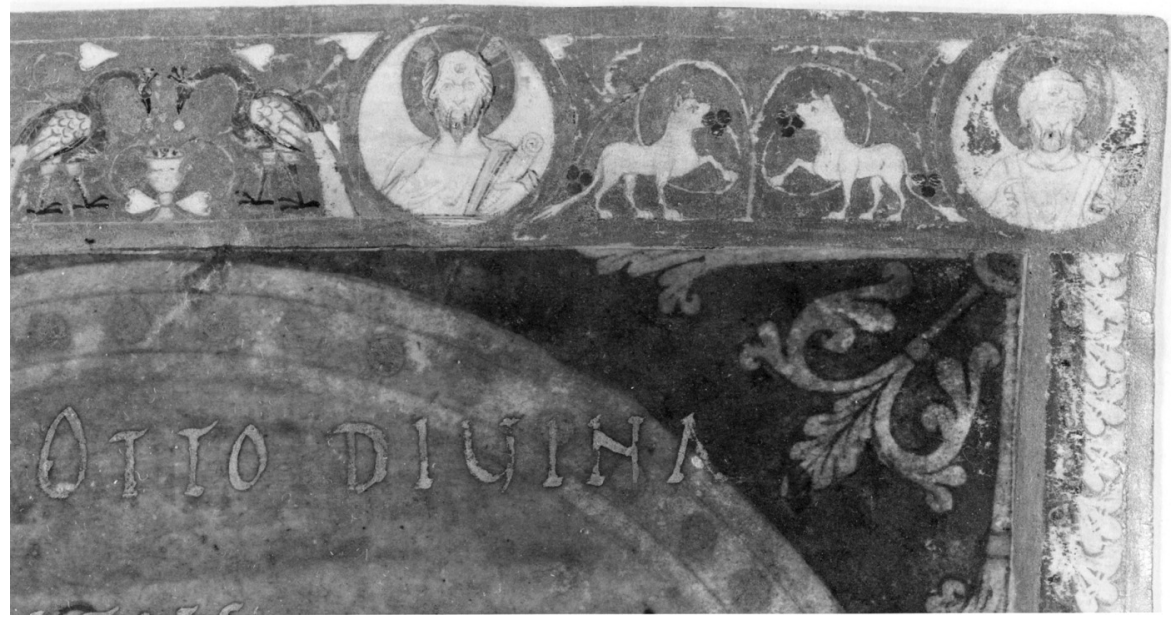

ILL. 2. Détail de l'ill. $1 b$ : bordure supérieure.
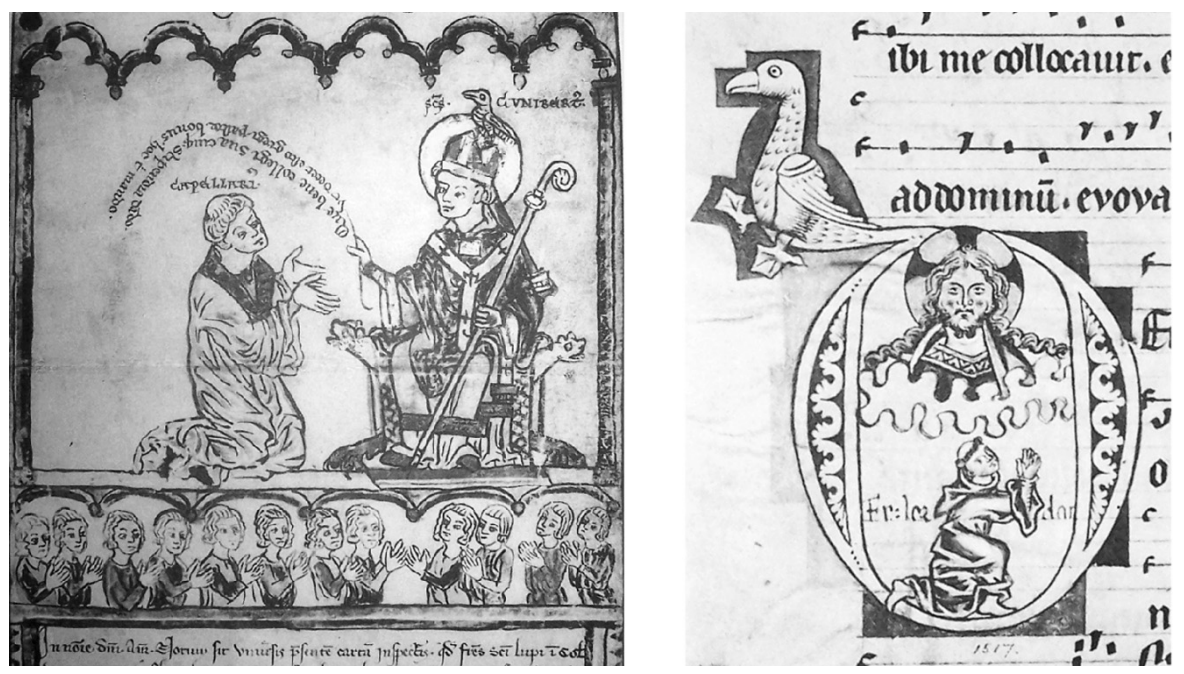

ILL. 3. a. Charte de la confrérie Saint-Loup de Cologne, 1247-1248 (Cologne, Hist. Archiv der Stadt Köln, U 3/184). Phot. : Ornamenta ecclesiae..., p. 19. - b. Fragment d'un antiphonaire, Rhénanie, v. 1250 (Londres, Victoria \& Albert Mus., n. 1517). Phot. : H. Swarzenski, Die lateinischen..., Planches, ill. 253. 

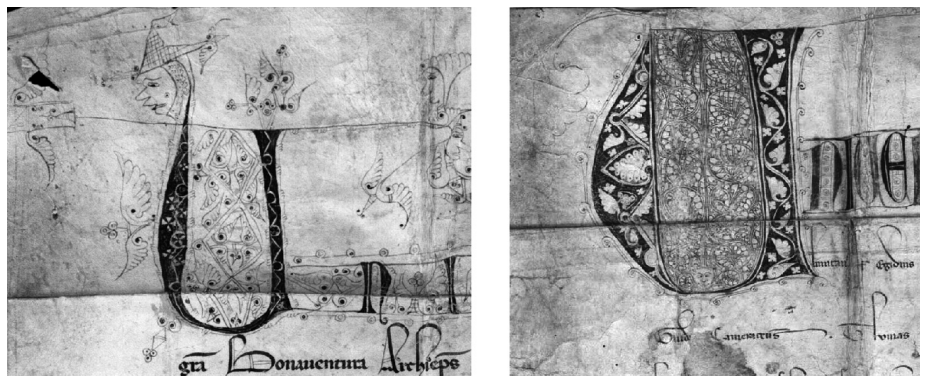

ILL. 4. Lettres d'indulgence collectives : $a .1296 ; b .1297$ (Vienne, Schotten, Stiftsarchiv, 01 Urk. 1296; 01.Urk. 1297). Phot. : monasterium.net.

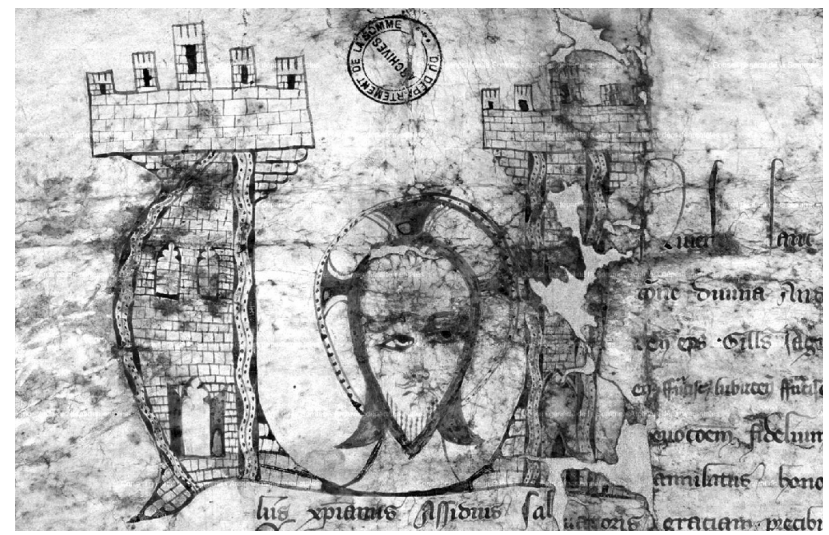

ILL. 5. Lettre d'indulgence collective pour Saint-Martin de Picquigny, 11 mai 1323 (Amiens, Arch. dép. Somme, 18 G SC 13). Phot. : archives.somme.fr.
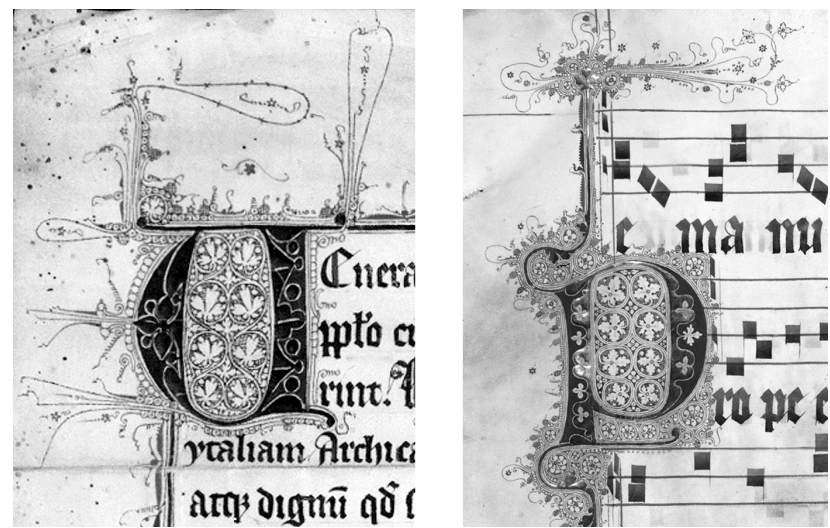

ILL. 6. $a$. Lettre d'indulgence de l'archevêque de Cologne, 28 décembre 1307 (Florence, Arch. di Stato, Diplomatico, S. Pier Maggiore). Phot. : www.archiviodistato.firenze.it - b. Graduel de Wettingen, Cologne, après 1334 (Aargau, Aargauer Kantonsbibl., MsWettFm 1). Phot. : e-codices.ch. 
ILL. 7. Lettre d'indulgence de l'évêque de Liège, 23 mai 1315

(Florence, Arch. di Stato, Diplomatico, S. Croce).

Phot. : A. Grunzweig,

«Une lettre... ».

ILL. 8. (haut) $a-b$. Détails de l'ill. 7. (bas) c. Cérémonial de Gand, 1322 (Gand, Universiteitsbibl., ms. 233). Phot. : F. Masai, M. Wittek et al., Manuscrits datés conservés en Belgique, t. I, Bruxelles-Gand, 1968, pl. 105.

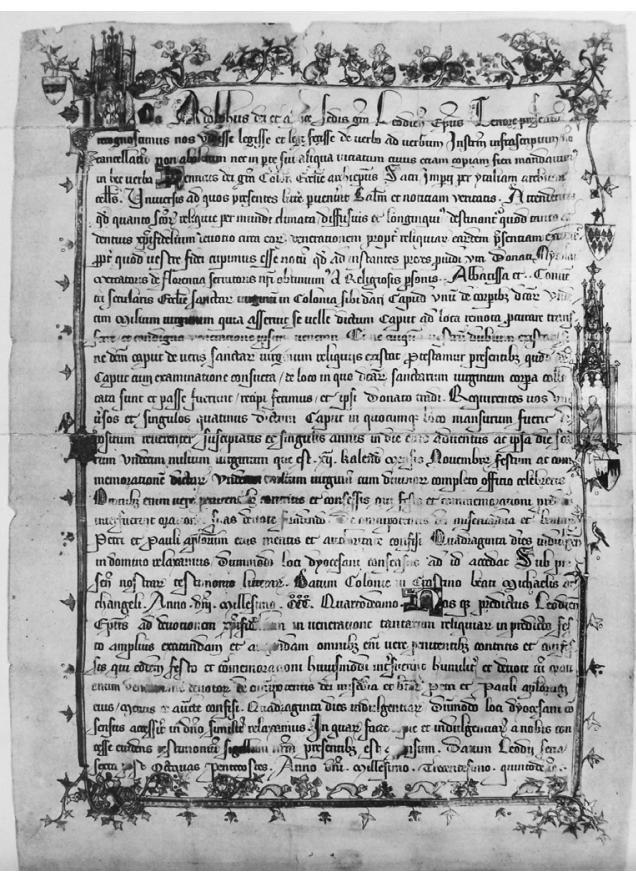

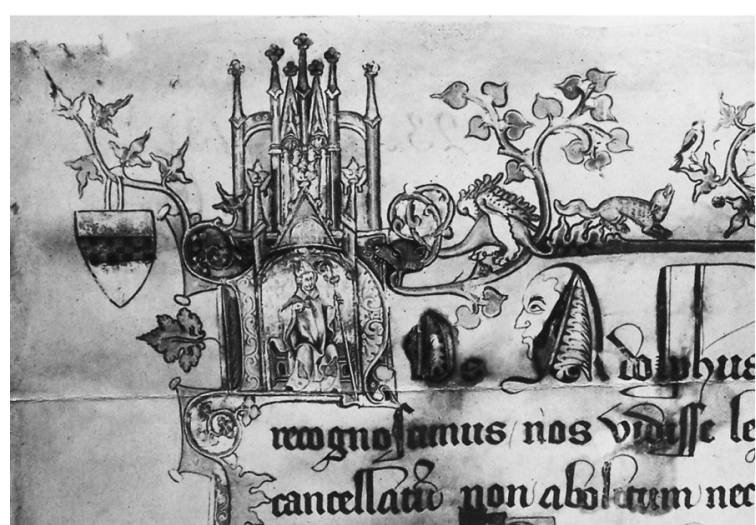

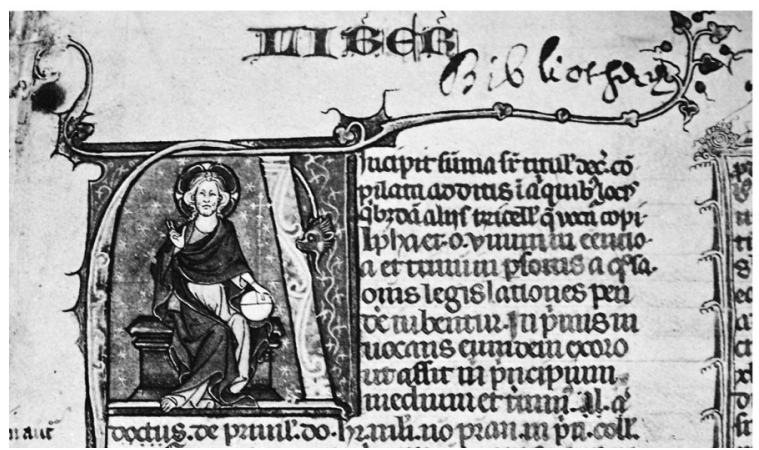

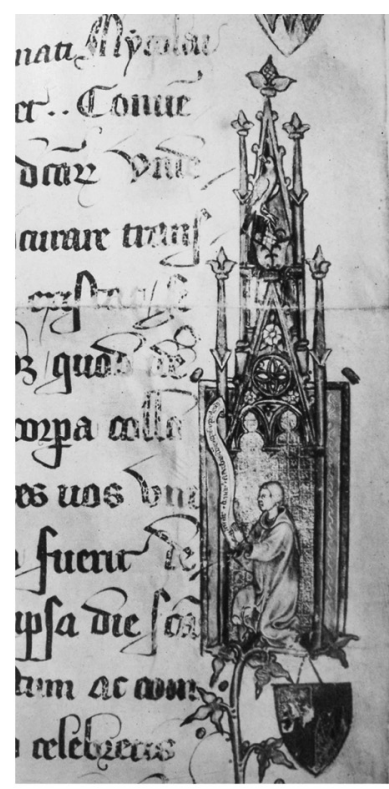



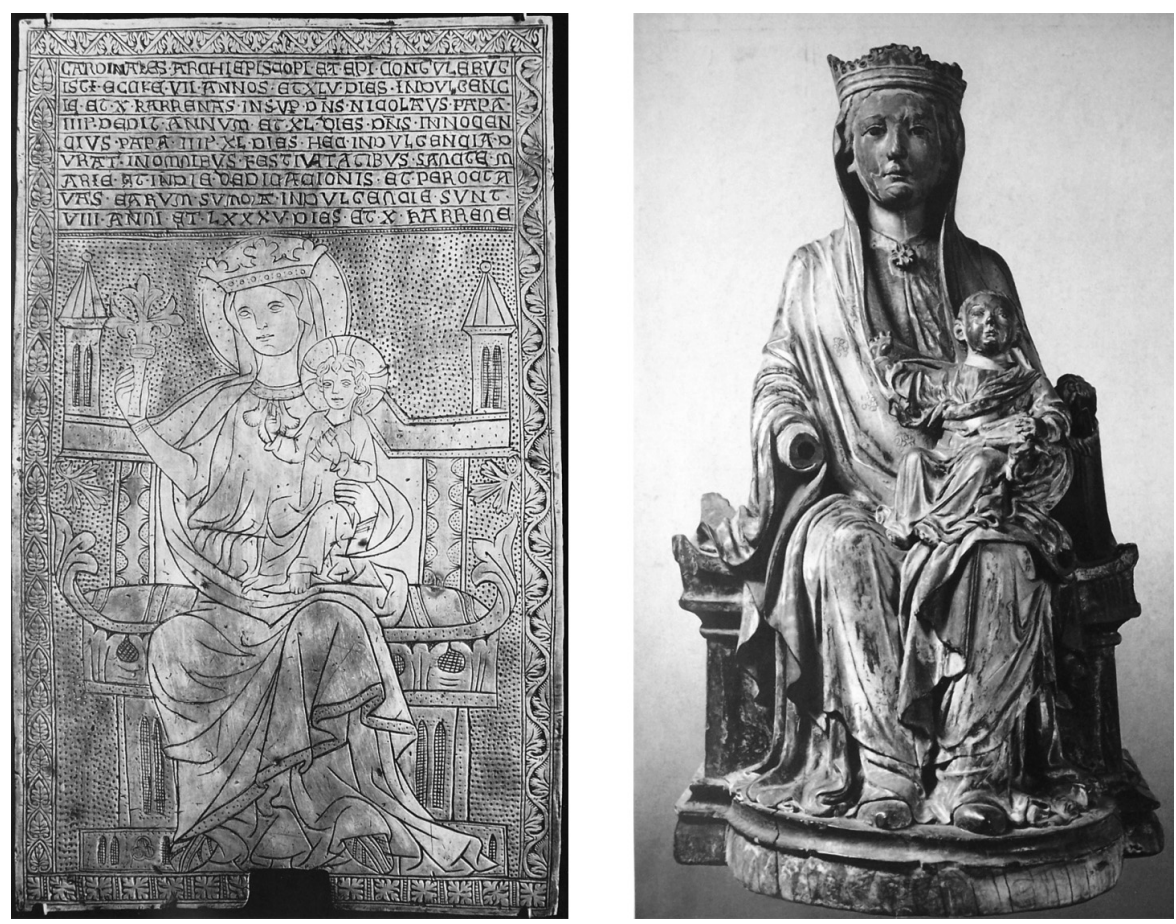

ILL. 9. $a$. Tablette d'indulgence de Halberstadt (Halberstadt, Domschatz, inv. 32). Phot. : H. Fuhrmann, Die Inschriften..., pl. XX, ill. 40. - b. Vierge de Halberstadt.
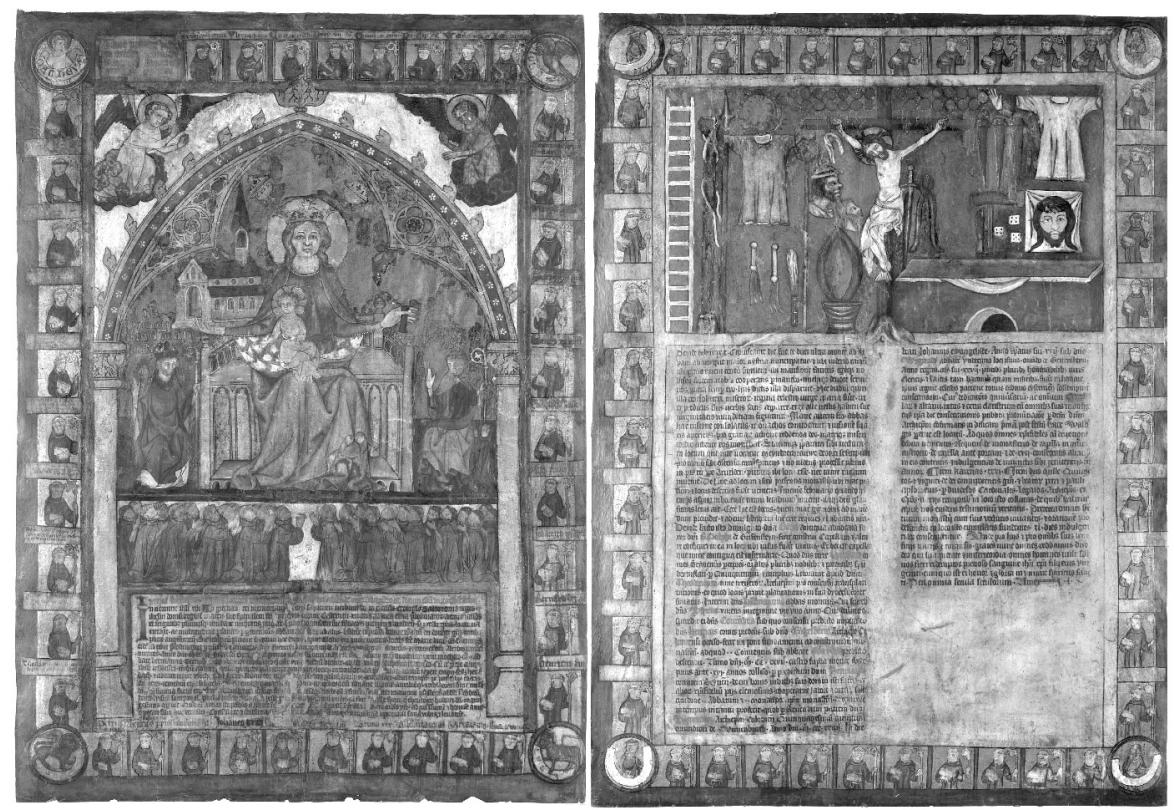

ILl. 10. Panneaux de Marienstatt, v. 1324 (Bonn, Rheinisches Landesmuseum, inv. 790). 


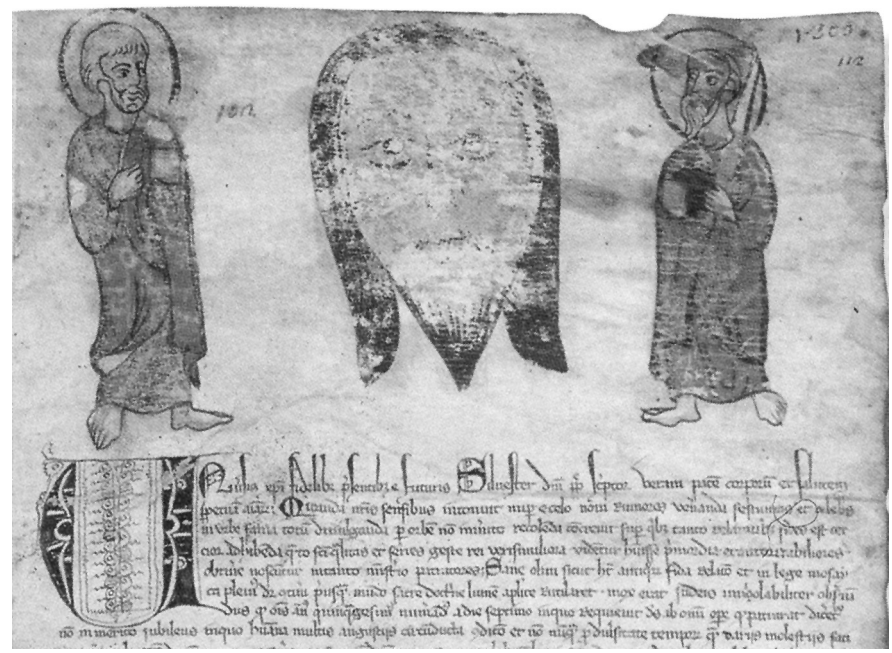

ILL. 11. Lettre dite de Sylvestre, 1300 (Cortone, Bibl. del Comune e dell'Accad. etrusca, cod. 101, fol. 6). Phot. : Il volto...
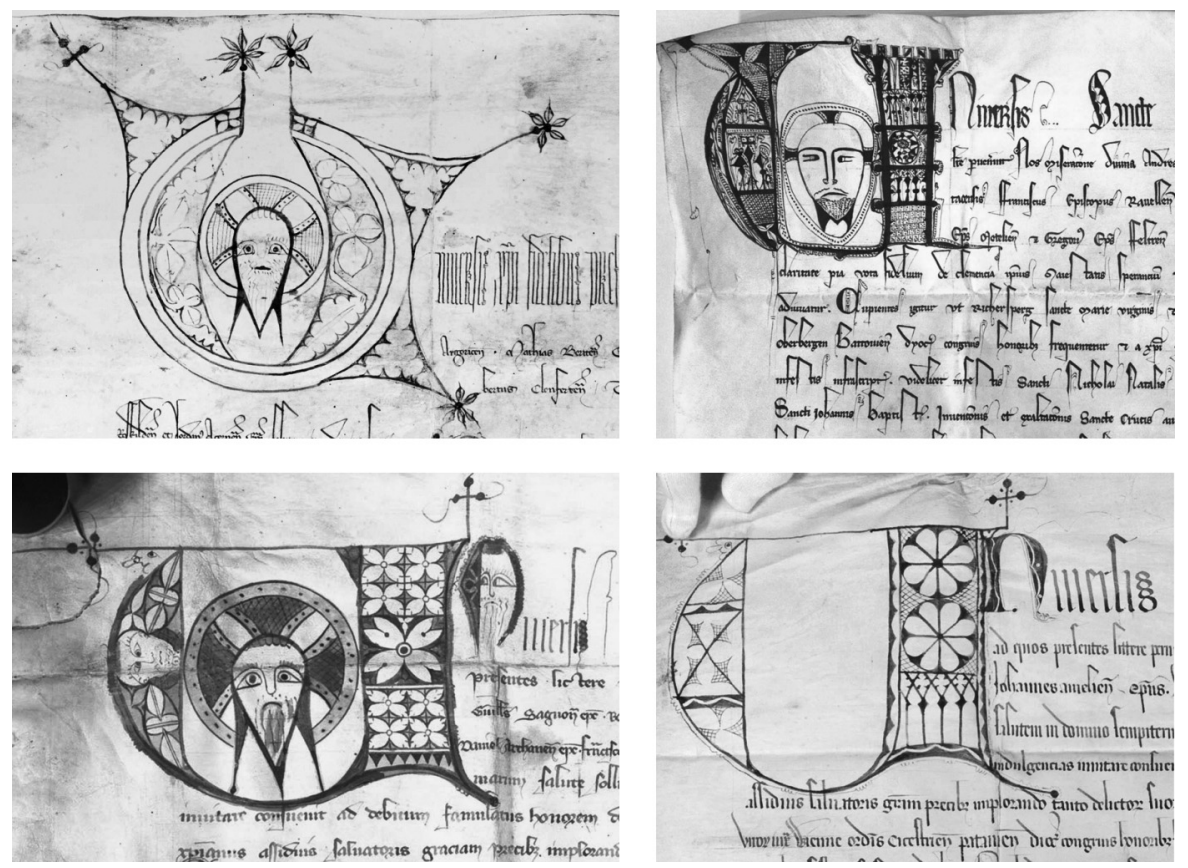

ILL. 12. Lettres d'indulgence collectives pour : (haut) $a$. les Cisterciennes de Maria Saal à Staré Brno, 8 décembre 1325 (Brno, Moravský zemský archiv, E 9, sub dato); $b$. les chanoines réguliers de Reichersberg, 3 avril 1326 (Reichersberg, Stiftsarchiv); - (bas) c. la chapelle d'Otto Haimo à Vienne, 30 septembre 1327 (Vienne, Stadt- und Landesarchiv, Urkunde 101); - $d$. les Cisterciens de Heiligenkreuz, 10 avril 1328 (Heiligenkreuz, Stiftsarchiv). Phot. : monasterium.net. 


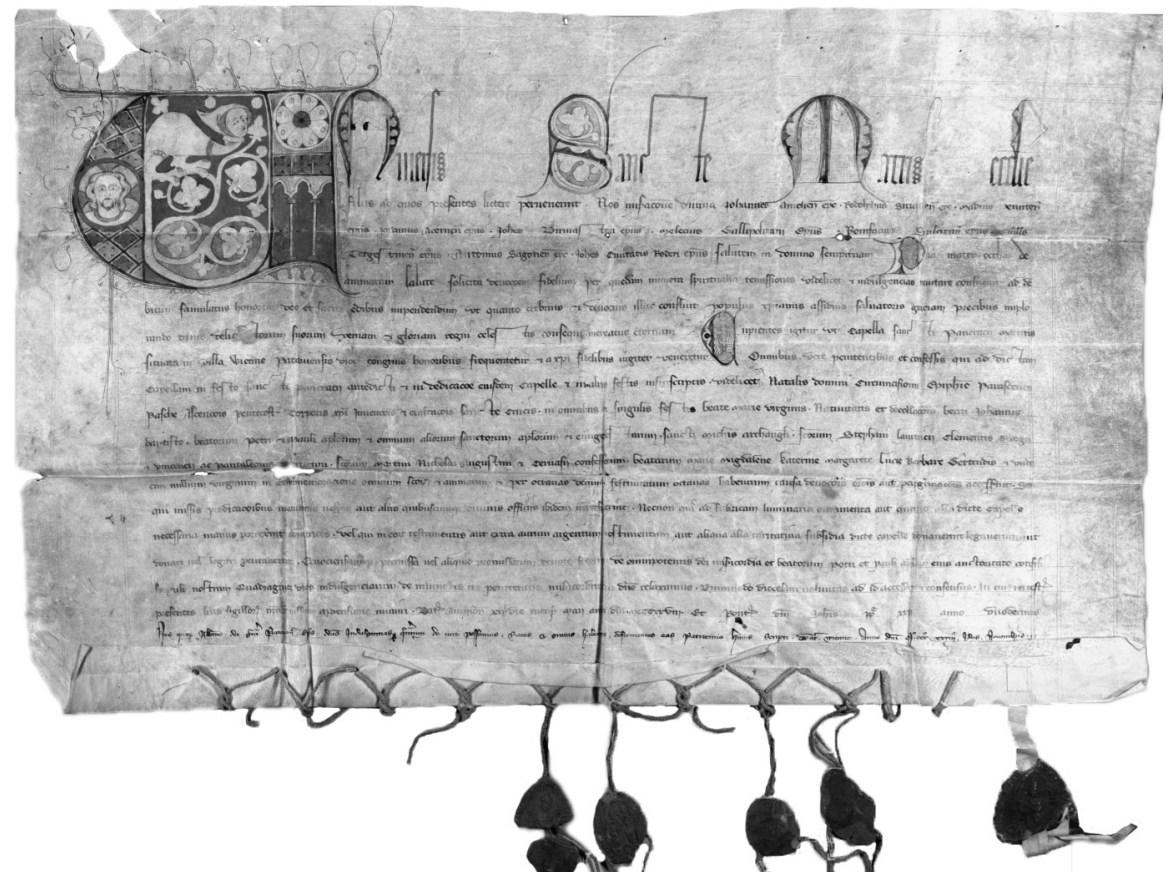

ILL. 13. Lettre d'indulgence collective pour la chapelle Saint-Pancrace de la Hofburg, Vienne, 12 mai 1328 (Vienne, Schotten, Stiftsarchiv, 01.Urk. 1328_05_12). Phot. : monasterium. net.
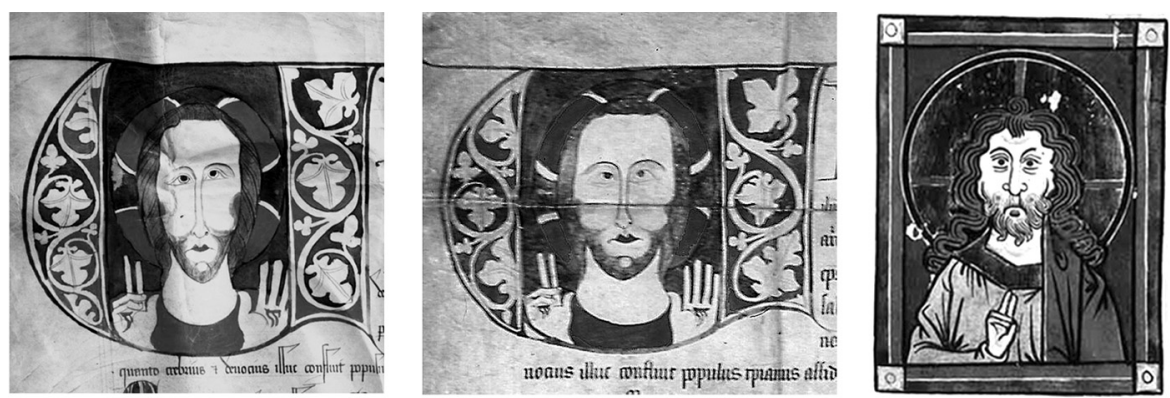

ILL. 14. Lettres d'indulgence collectives pour : $a$. la chapelle des Saints-Barthélemy-et-Zénon au château de Reifenstein, 6 avril 1330 (Vienne, Archiv des Deutschen Ordens, $\mathrm{n}^{\mathrm{0}}$ 1562). Phot. : monasterium.net; $-b$. l'abbaye de Mönchengladbach et sa chapelle des Saints-Étienneet-Benoît, 10 avril 1330 (Nordrheinwestfäl. Landesarchiv, Abteilung Rheinland [Düsseldorf], Mönchengladbach, Urk. 102). Phot. orig. - $c$. Livre de prières de la reine Élisabeth, Ratisbonne, fin $\mathrm{du} \mathrm{XIII}^{\mathrm{e}}$ s., fol. 8 (Vienne, Minoritenkonvent, Alserstraße). Phot. : tethys.

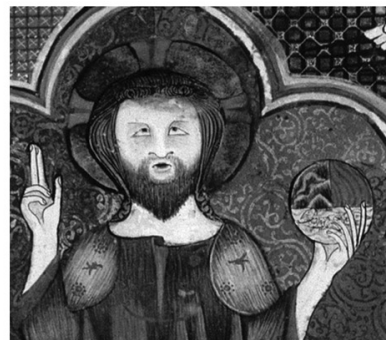
imareal.oeaw.ac.at/realonline. $-d$. Missel à l'usage de Vienne : Christ trônant (Bibl. mun., ms. 526, fol. 110v). Phot. orig. 


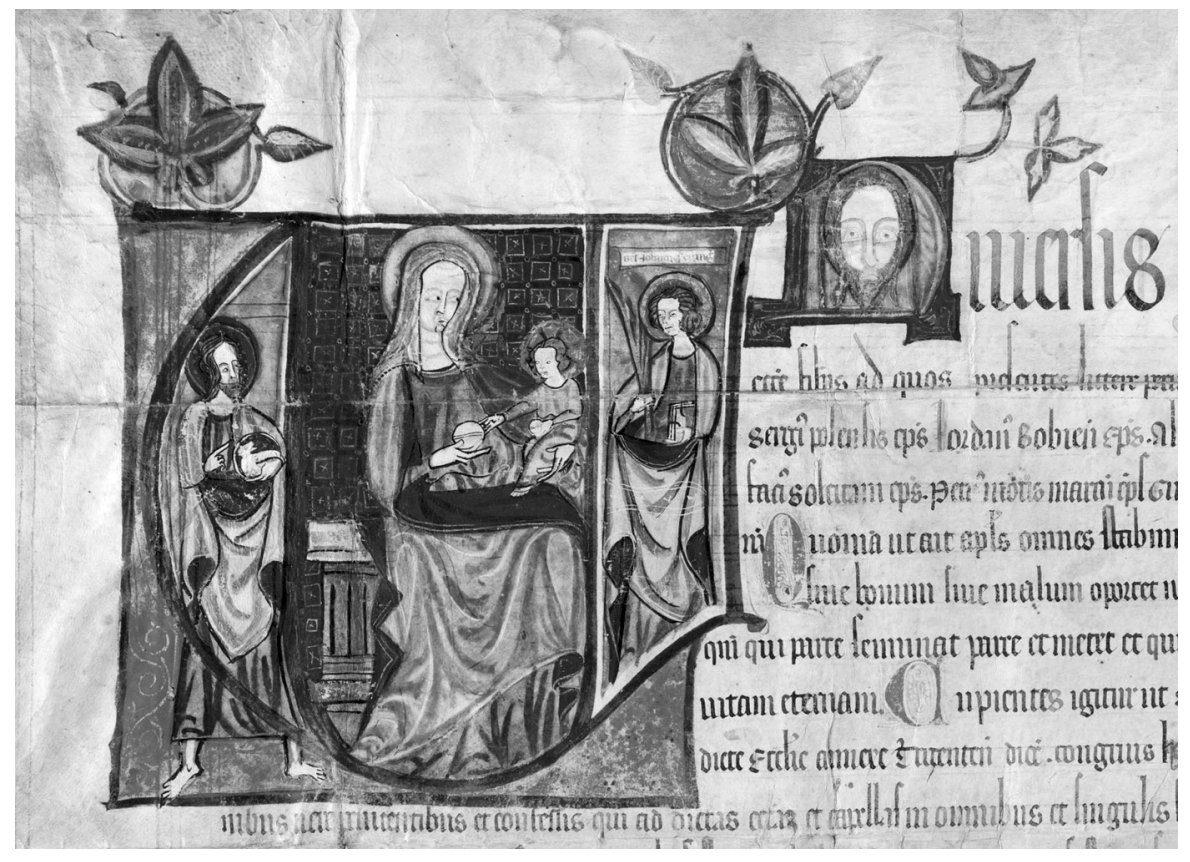

ILL. 15. Lettre d'indulgence collective pour l'église paroissiale de Cembra, 15 septembre 1331 (Trento, Arch. di Stato, PAT, busta 4, no 1). Phot. orig.

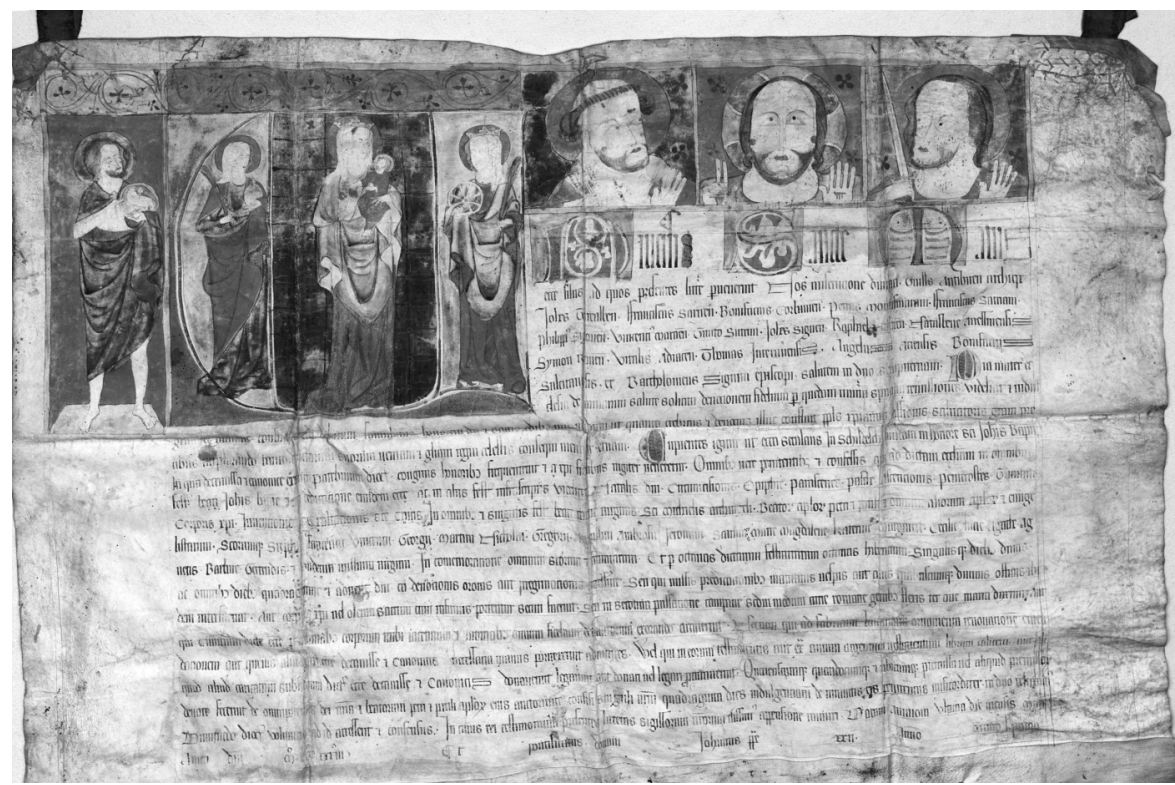

ILL. 16. Lettre d'indulgence collective pour l'abbaye de Schildesche, 31 mai 1333 (Nordrheinwestfäl. Landesarchiv, Abteilung Westfalen, 1.4.3.2, Stift Schildesche, Urk. no 70a). Phot. orig. 


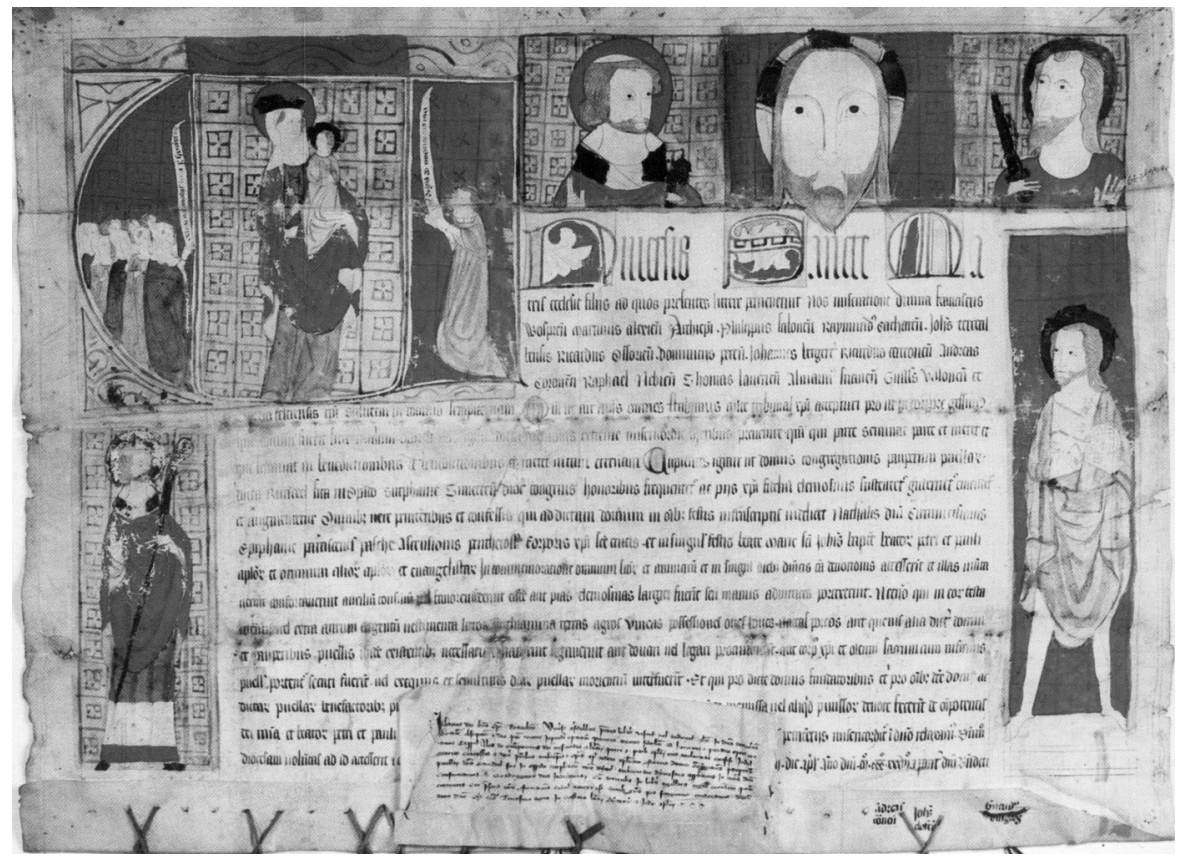

ILL. 17. Lettre d'indulgence collective pour le couvent féminin de Het Rondeel à Zutphen, 8 avril 1336; Zutphen, Stadarchief, Archief van het convent Rondeel, inv. 6. Phot. : Das goldene Zeitalter des Herzogtums Geldern, Geldern, 2001, p. 206.
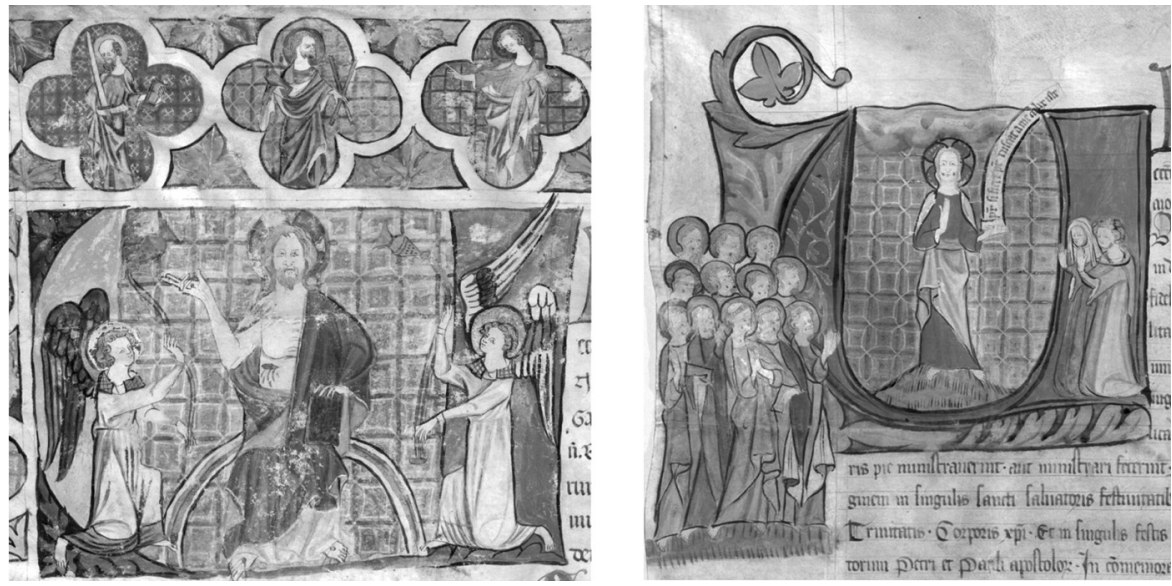

ILL. 18. a. Lettre d'indulgence collective pour Fröndenberg, 2 janvier 1342 : Christ trônant (Nordrheinwestfäl. Landesarchiv, Abteilung Westfalen, 1.4.1.2, Stift Fröndenberg, Urk. $\mathrm{n}^{\mathrm{o}}$ 162). Phot. : Krone und Schleier.... - b. Lettre d'indulgence collective pour le relief du Christ au Mont des Oliviers, cimetière de Saint-Étienne à Vienne, 22 janvier 1343 (Vienne, Diözesanarchiv). Phot. : monasterium.net. 


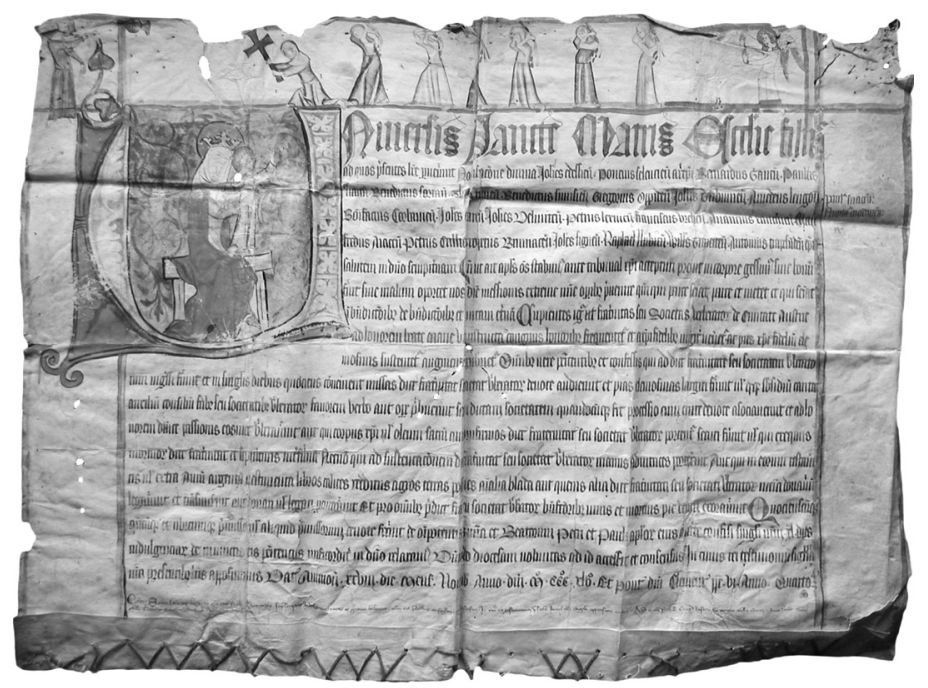

ILL. 19. Lettre d'indulgence collective pour les « battuti » de Cividale, 28 novembre 1345 (Udine, Bibl. civica Vincenzo Joppi, Fondo principale, 1228/III, n. 16). Phot. orig.

ILL. 20. $a$. Lettre d'indulgence collective pour les moniales de Saint-Laurent de Vienne, 6 septembre 1353 (Vienne, Haus-, Hof- und Staatsarchiv, Allgem. Urkundenreihe, sub dato). Phot. : monasterium.net. $-b$. Bible historiale : Salomon et la reine de Saba, Vienne (?), 1448 (Vienne, Österr. Nationalbibl., Cod. 2773, fol. 151v). Phot. orig.
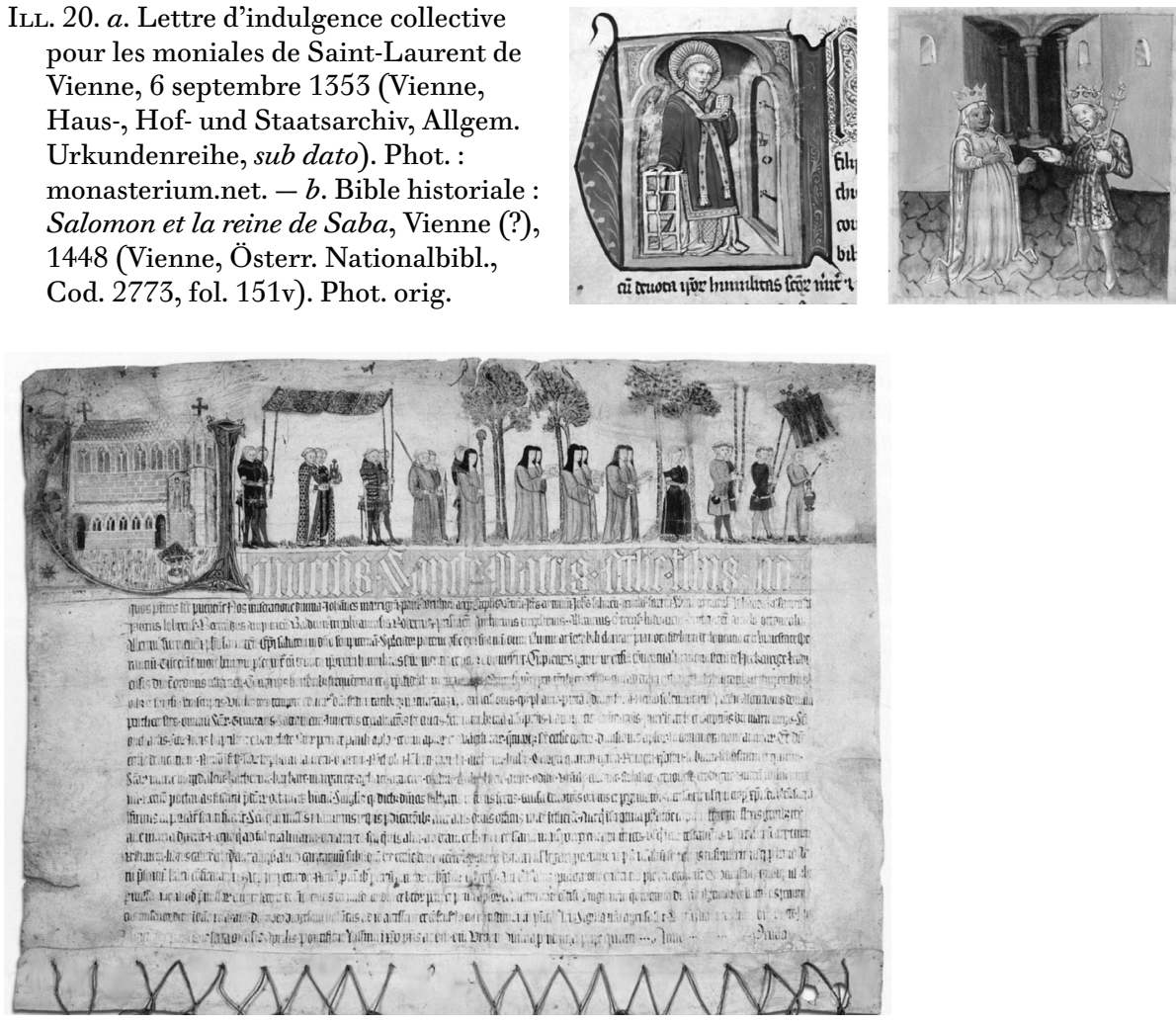

ILL. 21. Lettre d'indulgence collective pour les Cisterciennes de Herkenrode, 6 avril 1363 (Sint-Truiden, Provinciaal Museum voor religieuze Kunst, inv. KPL/sd/251). Phot. orig. 


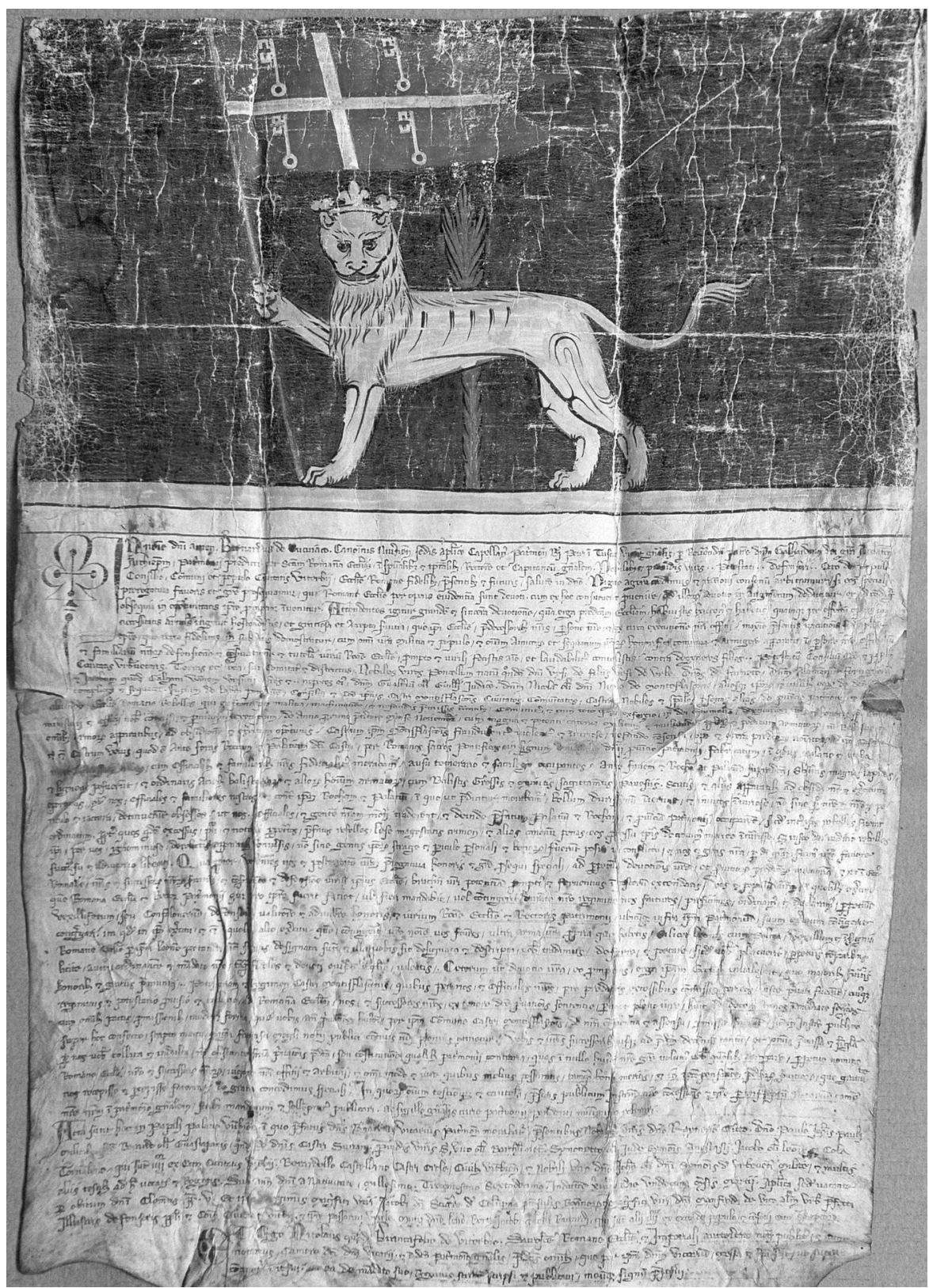

ILL. 22. Lettre d'armoiries de Bernard de Coucy, vicaire général du pape en Tuscie, pour la ville de Viterbe, 11 mars 1316 (Viterbe, Bibl. comunale degli Ardenti, serie Pergamene sciolte, $\mathrm{n}^{\circ}$ 220, collocazione 364). Phot. orig. 


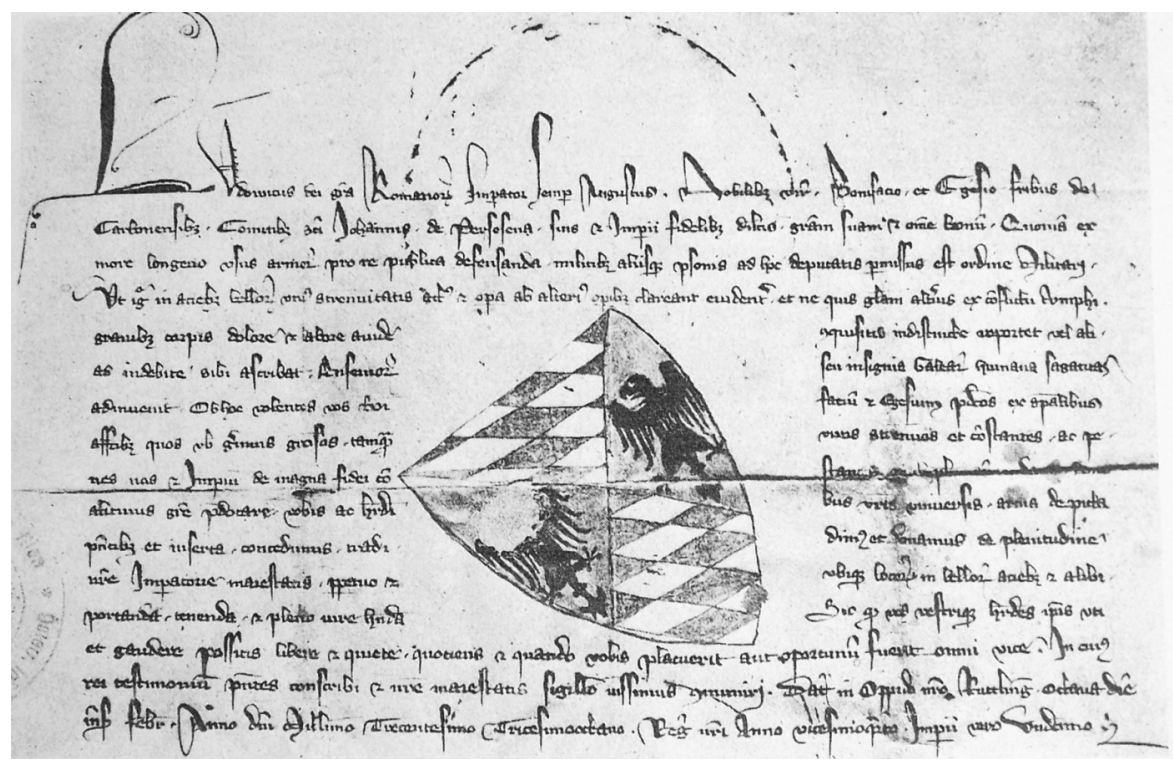

ILL. 23. Lettre d'armoiries de Louis de Bavière pour Bonifatius et Egesius de Carbonensibus, 8 février 1338 (Bologne, Bibl. comunale dell'Archiginnasio, mss. Gozzadini 74/a). Phot. : F. Bock, « Der älteste... ».

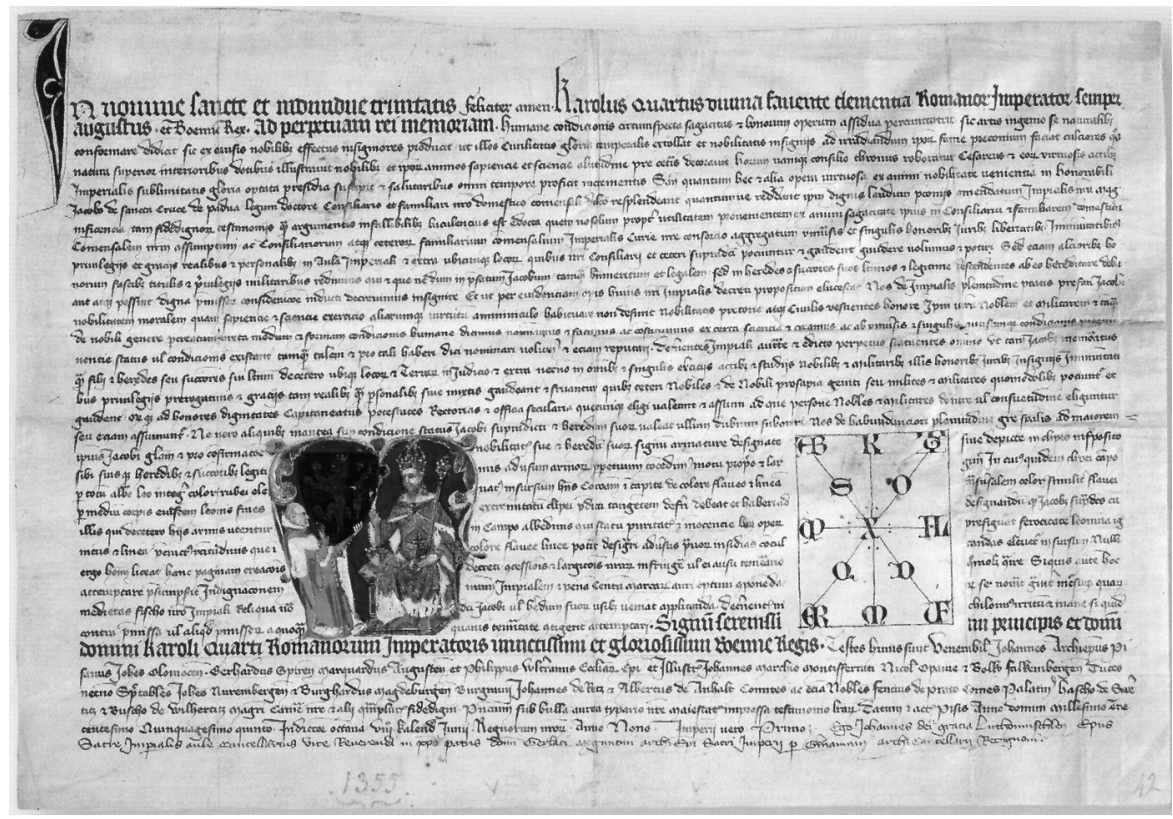

ILl. 24. Lettre d'armoiries de Charles IV pour Giacomo Santacroce, 25 mai 1355 (Venise, Fondazione Giorgio Cini, inv. 2042). Phot. : Heiliges römisches Reich... 

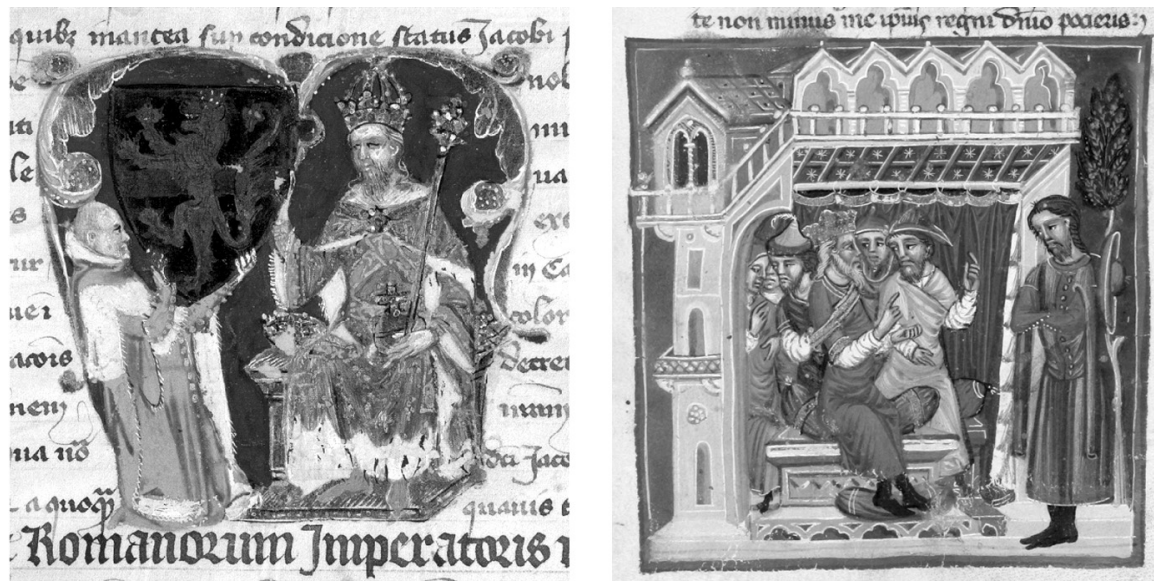

ILL. 25. a. Détail de l'ill. 24. - b. Guido de Columnis, Historia destructionis Troiae (Cologny, Fondation Martin Bodmer, cod. Bodmer 78, fol. 2). Phot. : e-codices.ch.

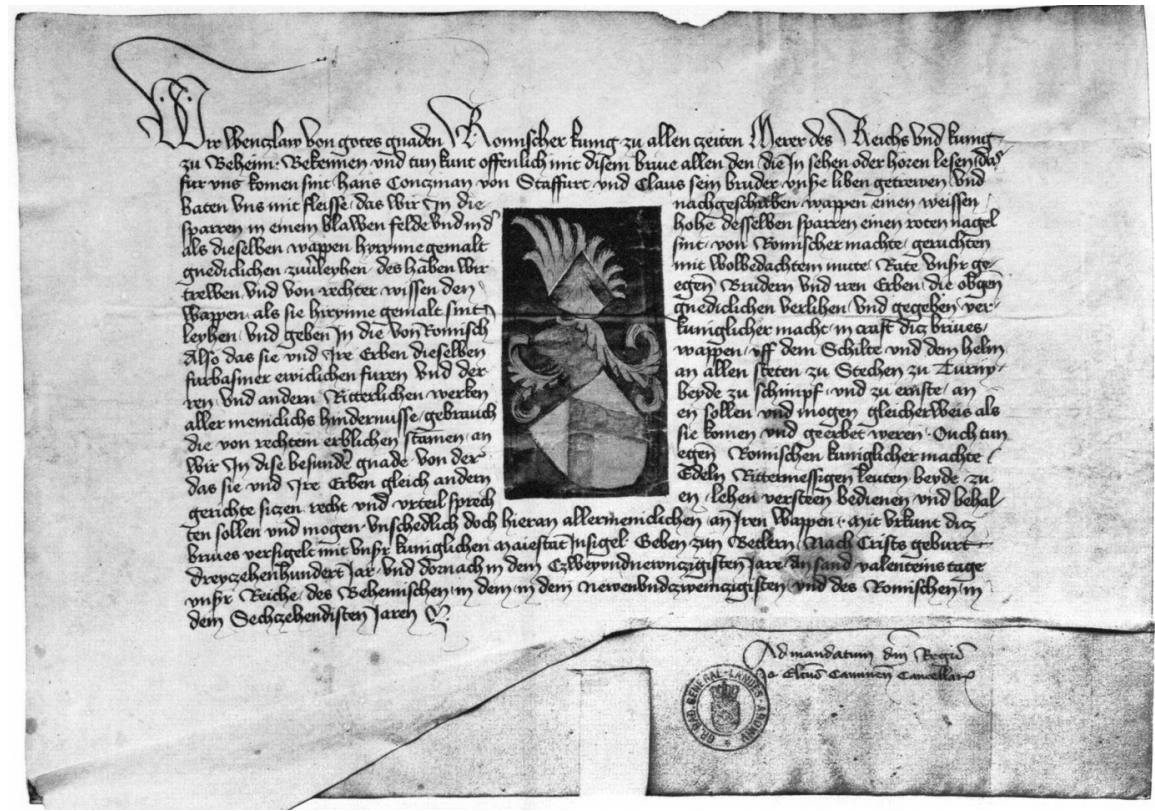

ILL. 26. Lettre d'armoiries du roi Wenceslas pour Hans et Claus Conczman de Staffurt, 14. février 1392 (Karlsruhe, Landesarchiv Baden-Württemberg, Generallandesarchiv Karlsruhe, D 426). Phot. : H. v. Sybel, T. Sickel, Kaiserurkunden... 


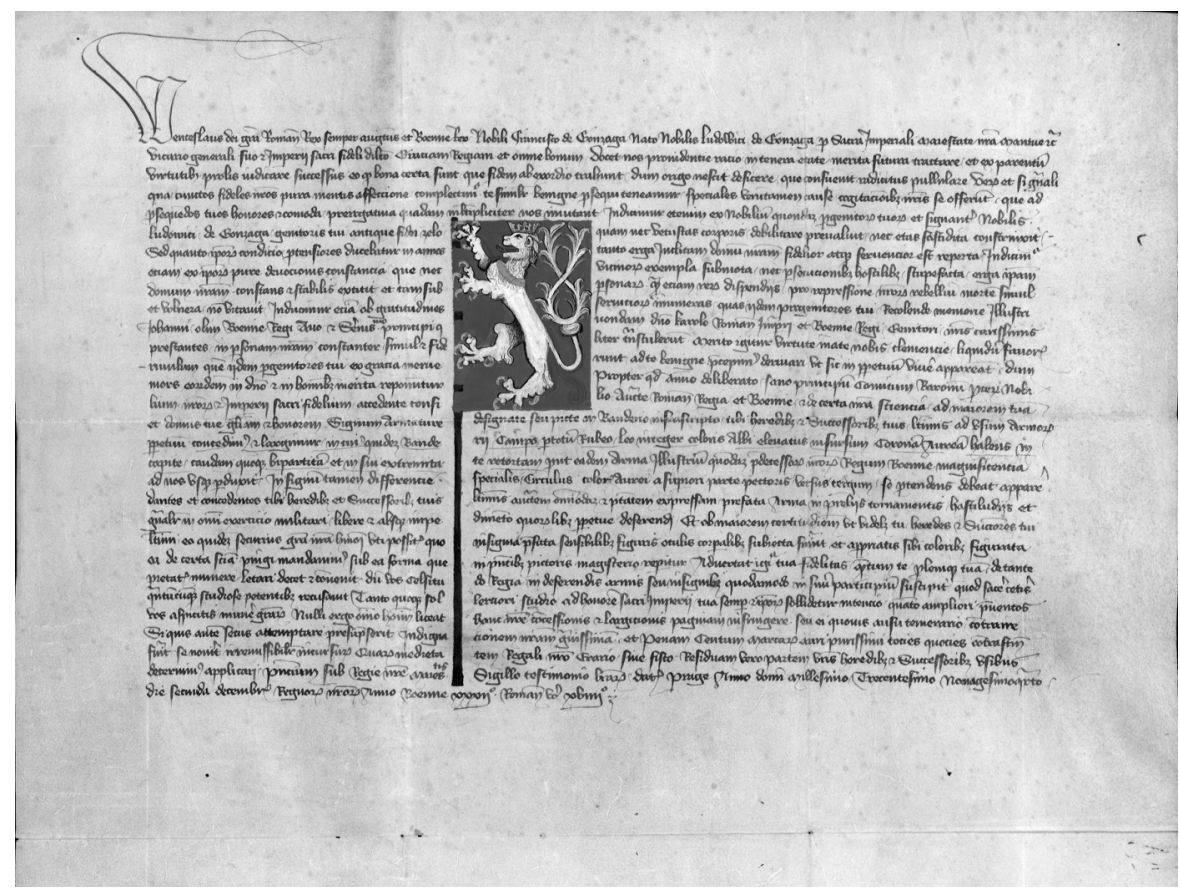

ILL. 27. Lettre d'armoiries du roi Wenceslas pour François (I ${ }^{e r}$ ) Gonzague, 2 décembre 1394 (Mantoue, Arch. di Stato, Arch. Gonzaga, busta 384). Phot. orig.

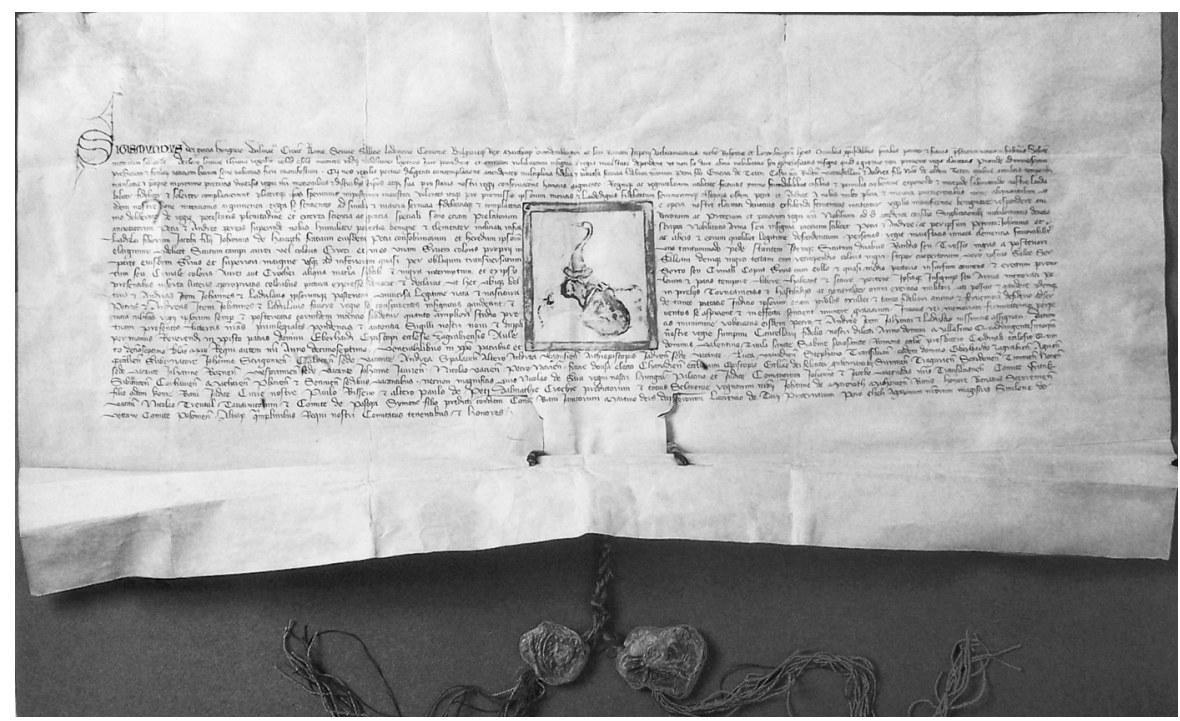

ILl. 28. Lettre d'armoiries de Sigismond de Hongrie pour Péter et András Tétényi et la famille Haraszti, 15 avril 1405 (Budapest, Magyar Országos Levéltár, DL 64.122). Phot. : Z. Jékely, « Die Rolle... », p. 299. 


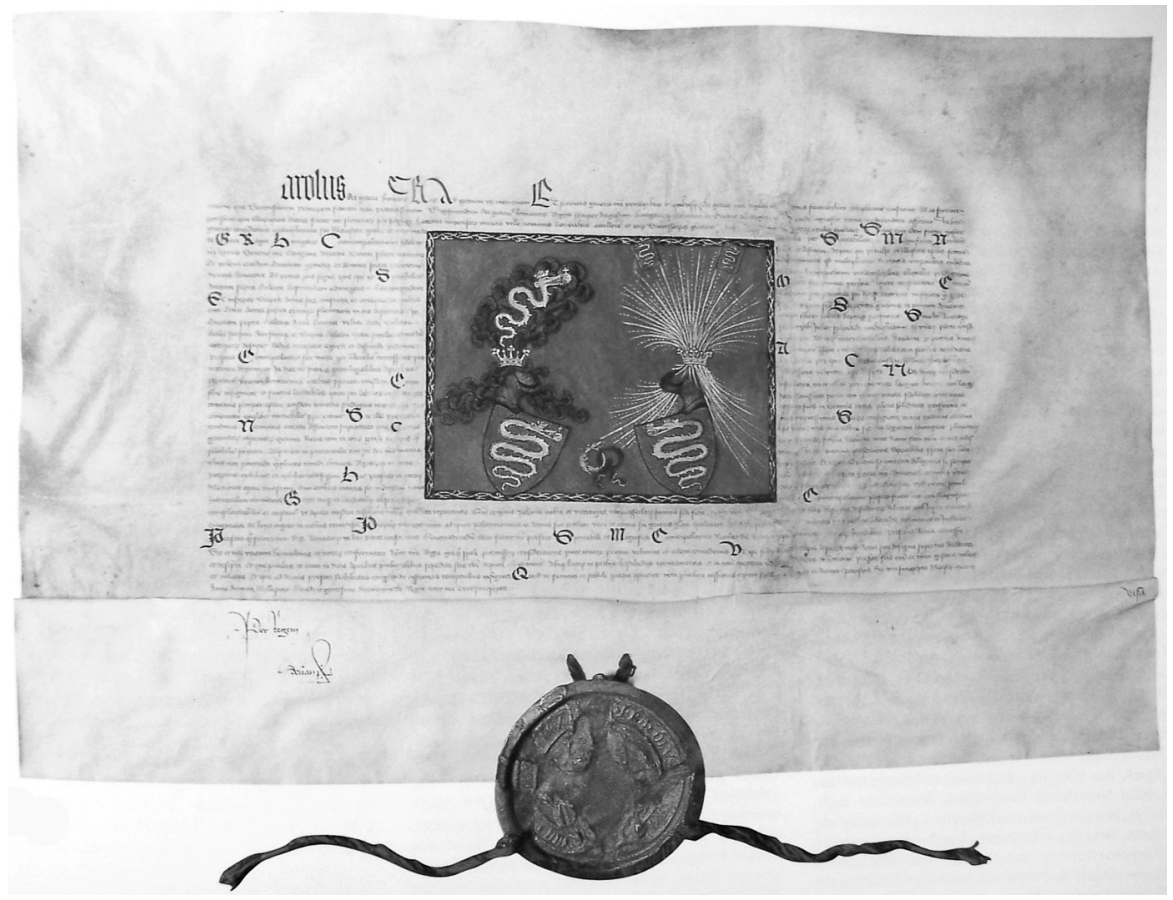

ILL. 29. Lettre d'armoiries de Charles VI de France pour Nicolas (II) Garai, palatin de Hongrie, 26 mars 1416 (Bratislava, Slovenský Národný Archív, Archív rodu Zay z Uhrovca, fasc. C, n ${ }^{\circ}$ 8). Phot. : Sigismundus...
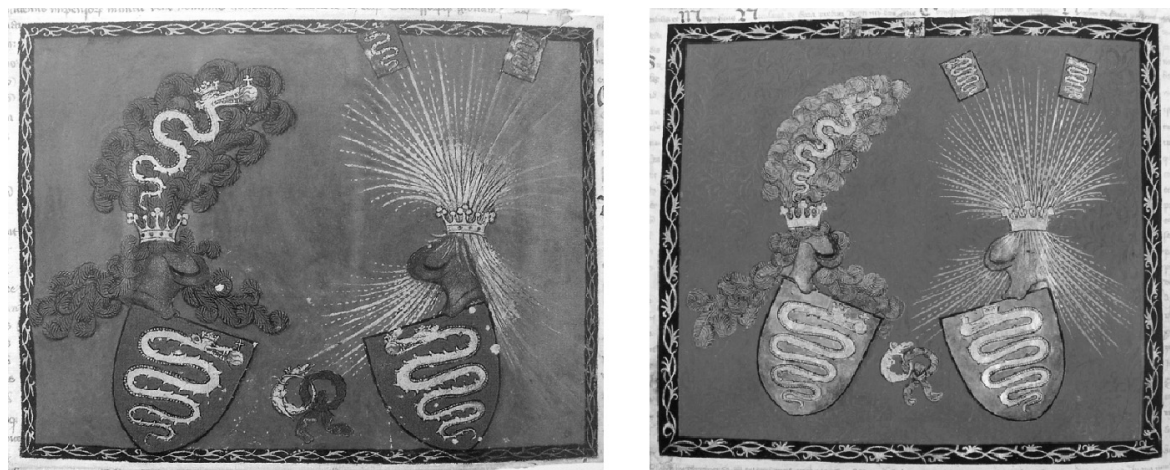

ILL. 30. $a$. Détail de l'ill. 29. - b. Lettre d'armoiries de Sigismond de Hongrie pour Nicolas (II) Garai, palatin de Hongrie, 26 mars 1416 (Bratislava, Slovenský Národný Archív, Archív rodu Zay z Uhrovca, fasc. C, nº 8). Phot. : Sigismundus... 


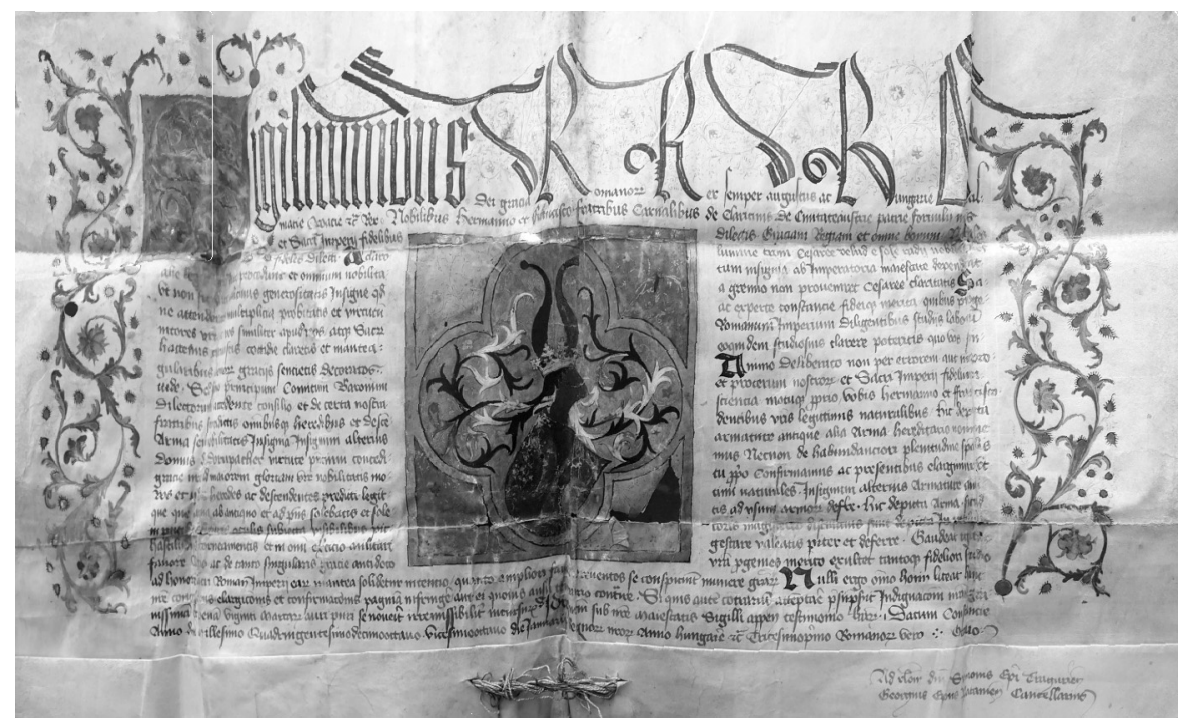

ILL. 31. Lettre d'armoiries de Sigismond de Hongrie pour Ermanno et Francesco de' Claricini, 28 janvier 1418 (Brno, Moravská Galerie, inv. č. 20272). Phot. orig.

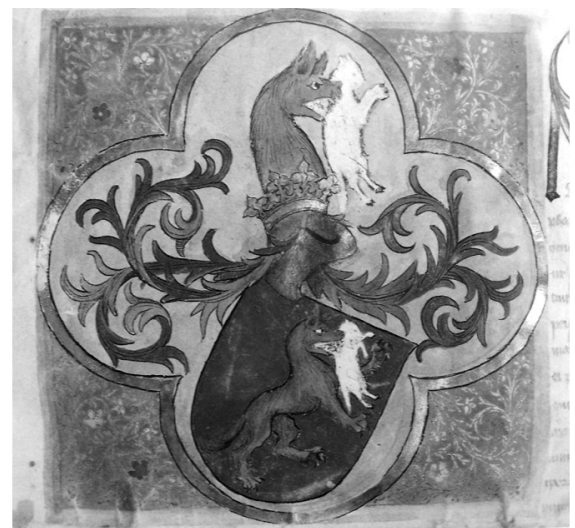

ILL. 32. $a$. Lettre d'armoiries de Sigismond de Hongrie pour la famille Suki, 29 mars 1418 (Cluj, Archiva Istorica a Filialei Din Cluj a Academici RR).

Phot. : Z. Jékely, « Die Rolle... ». $-b$. Initiale à rinceaux, Vienne, v. 1440 (Vienne, Österr. Nationalbibl., cod. 1544, fol. 1). Phot. orig.

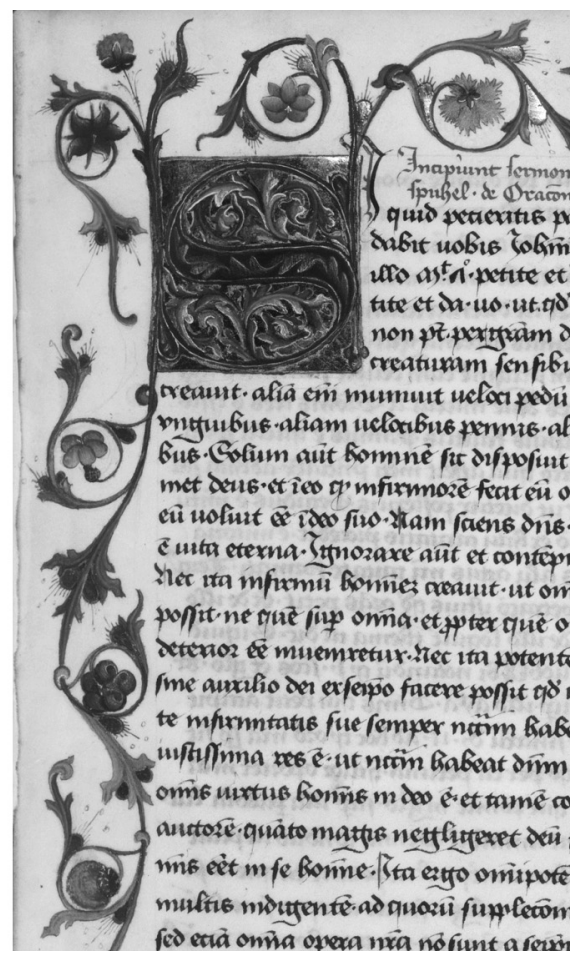



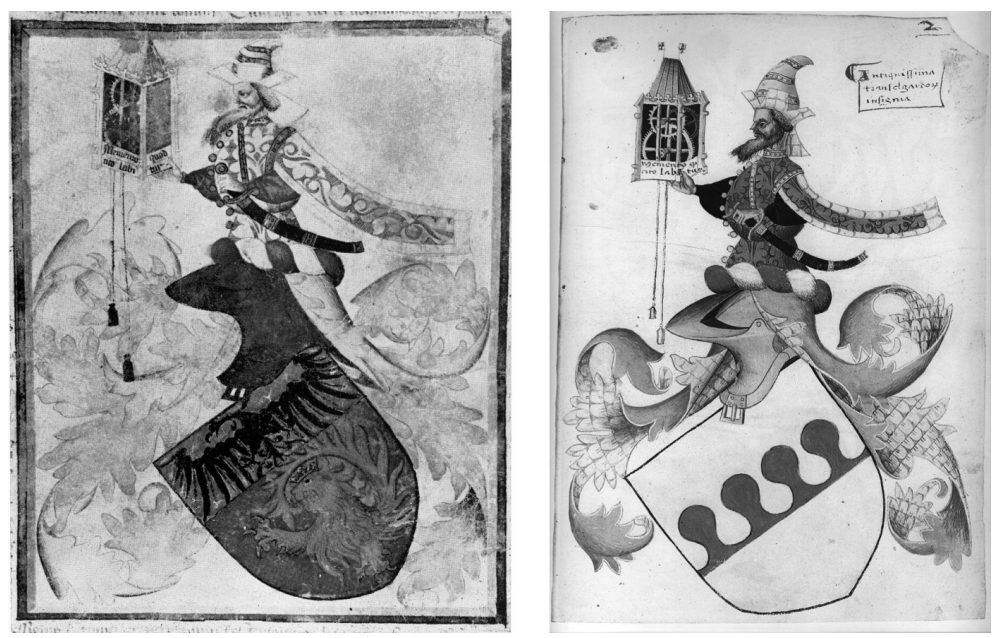

ILL. 33. $a$. Lettre de noblesse et d'armoiries du comte palatin Giovan Francesco Capodilista pour Manfredo Dal Cortivo, 19 juillet 1435 : armoiries (Padoue, Bibl. civica, BP 1641/III). Phot. : Il gotico nelle Alpi... - b. Codex Capodilista : armoiries des Transelgardi (Padoue, Bibl. civica, BP 954, fol. 2). Phot. : De viris..., p. 33 et fac-sim.

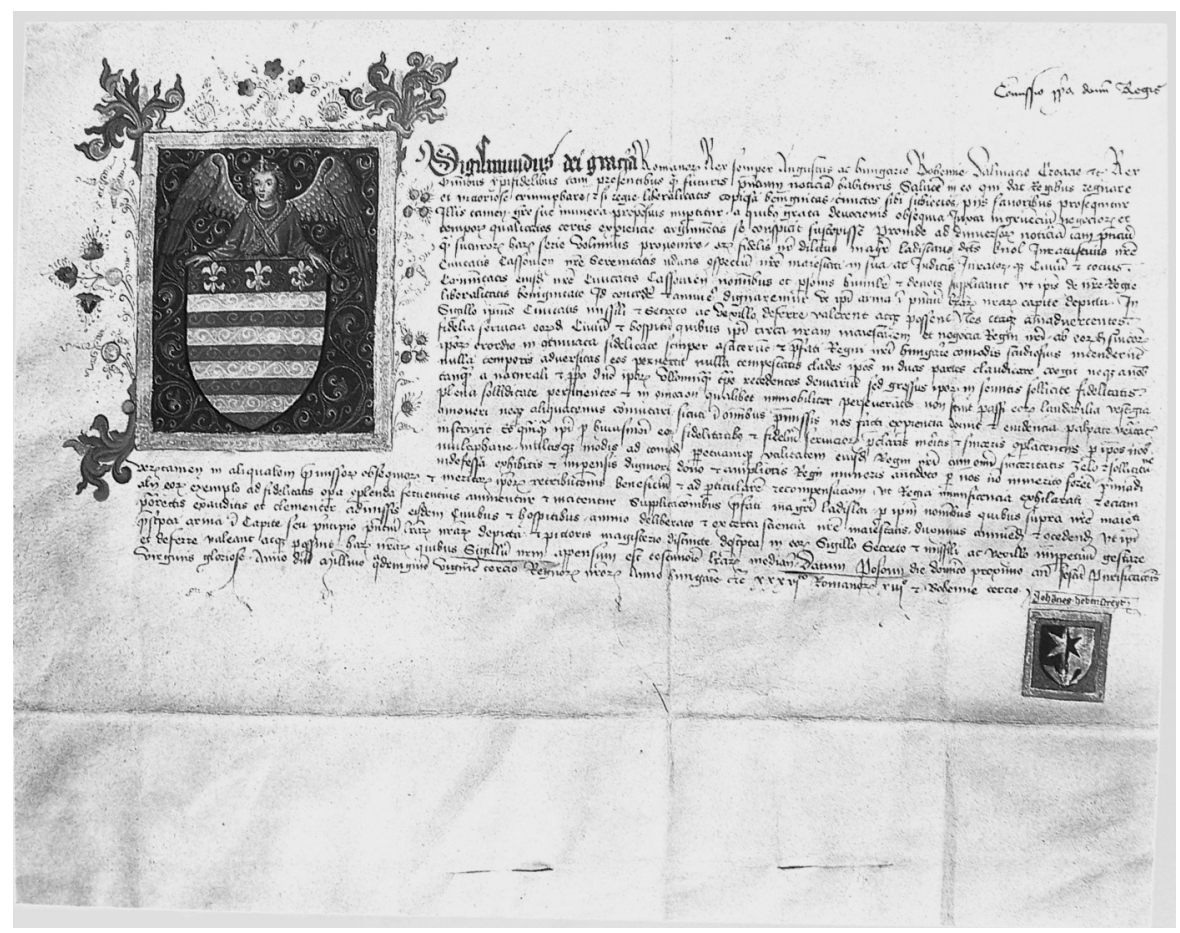

ILL. 34. Lettre d'armoiries de Sigismond de Hongrie pour la ville de Kaschau (Košice), 31 janvier 1423 (Košice, Archív mesta, Insignia, nº 2). Phot. : Gotika... 


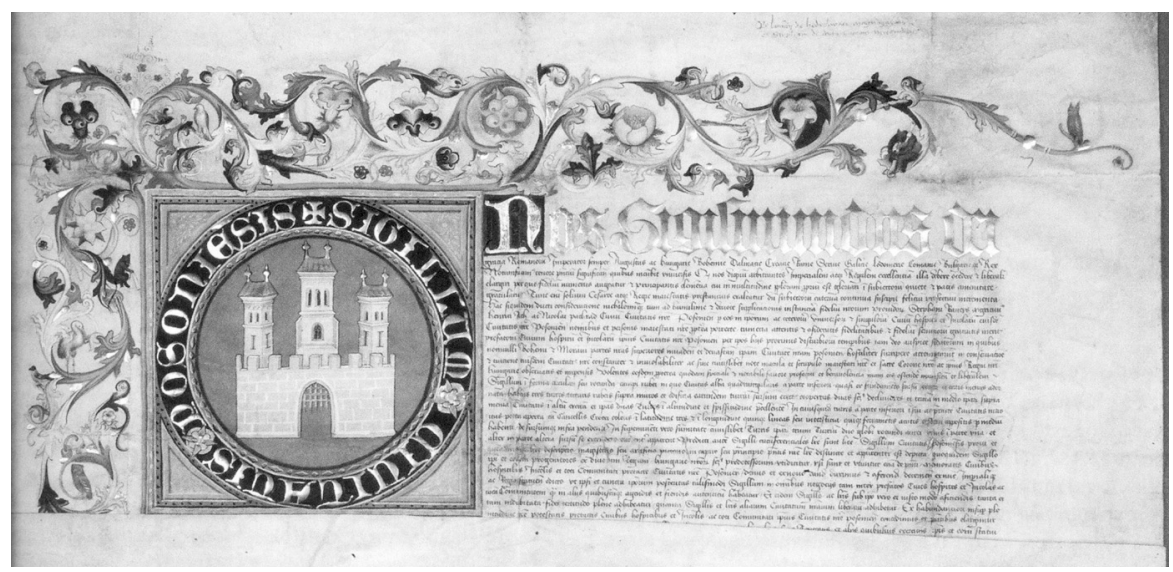

ILL. 35. Lettre d'armoiries de Sigismond de Hongrie pour Presbourg (Bratislava), 8 juillet 1436 (Bratislava, Archív mesta, Sign. 1435). Phot. : Gotika...
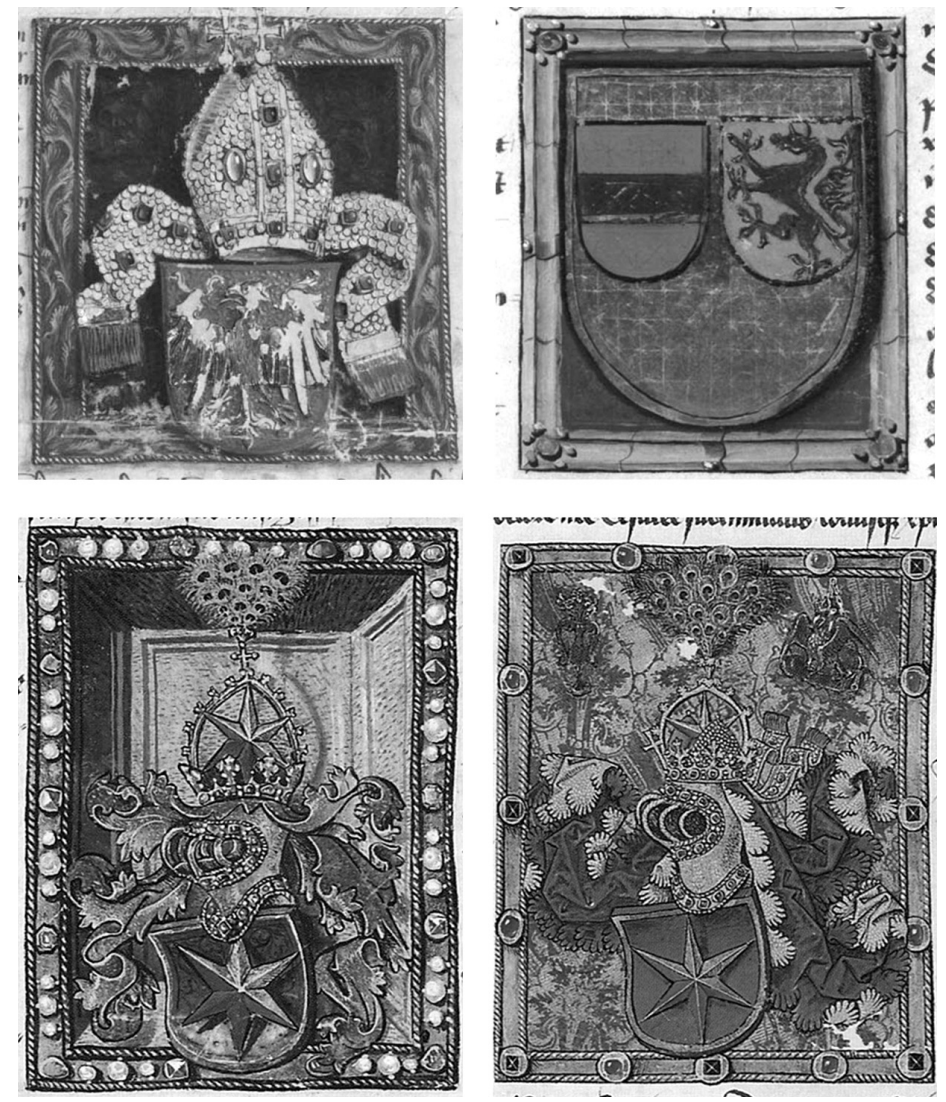

ILl. 36. Lettres d'armoiries par le Maître de la Handregistratur : (haut) a. 1446; - b. 1453; - (bas) c. $1459 ;-d .1459$. Phot. : monasterium.net. 


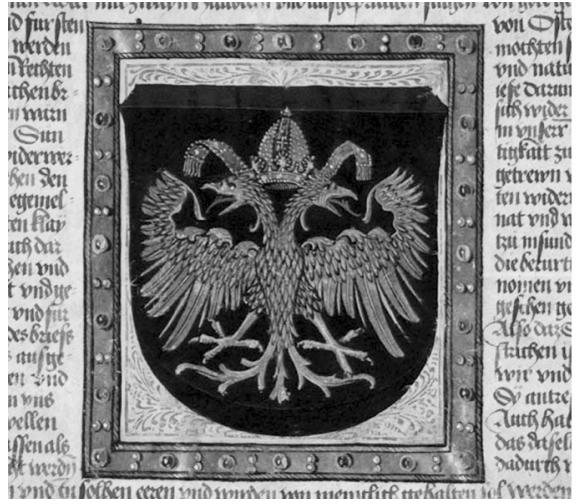

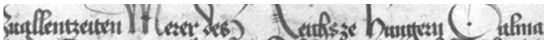

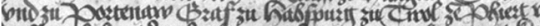

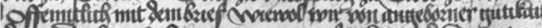
8)

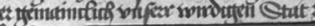

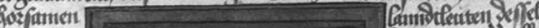

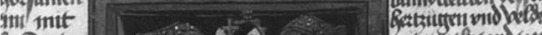

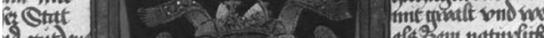

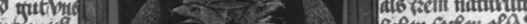

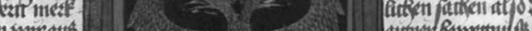
11 wirettib ande?t tif w walum trezanfet Oon auth tukenipui mertirtiajs 3 semiso minget mitem ant gef idar (n)

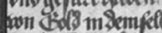

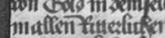

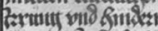
X Kink

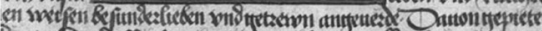

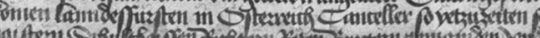

ILL. 37. Lettres d'armoiries de Frédéric III pour : $a$. Krems (par le Maître de la Handregistratur), $1^{\mathrm{er}}$ avril $1463 ;-b$. Vienne, 26 septembre 1461. Phot. : monasterium.net.
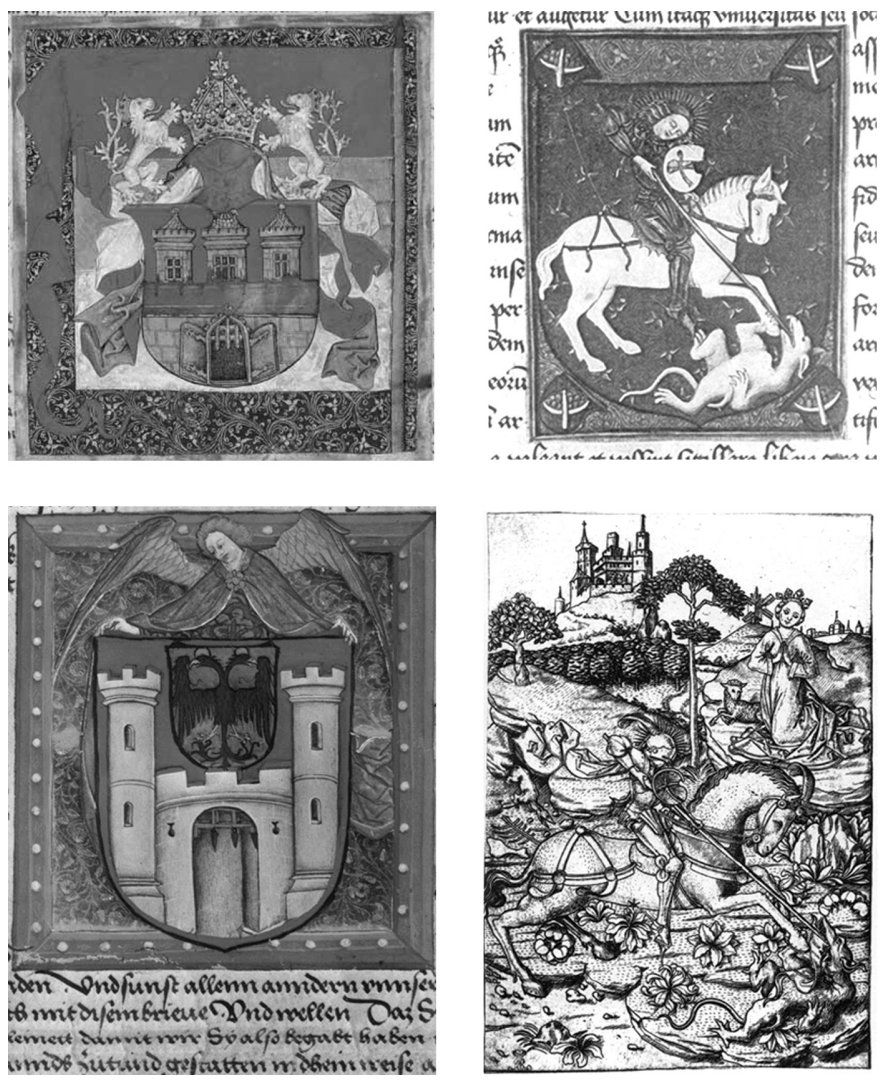

ILl. 38. (Haut) Lettres d'armoiries par le Maître du Friedrichsbrevier : a. 1475. Phot. orig. - b. 1473. Phot. : D. Radocsay, «Wiener Wappenbriefe... » - (Bas) $c$. Lettre d'armoiries par Ulrich Schreier, 1481. Phot. : M. Roland, « Buchmalerei »... - d. Maître E. S., Saint Georges, gravure. Phot. : H. Appuhn, Meister E. S.... 

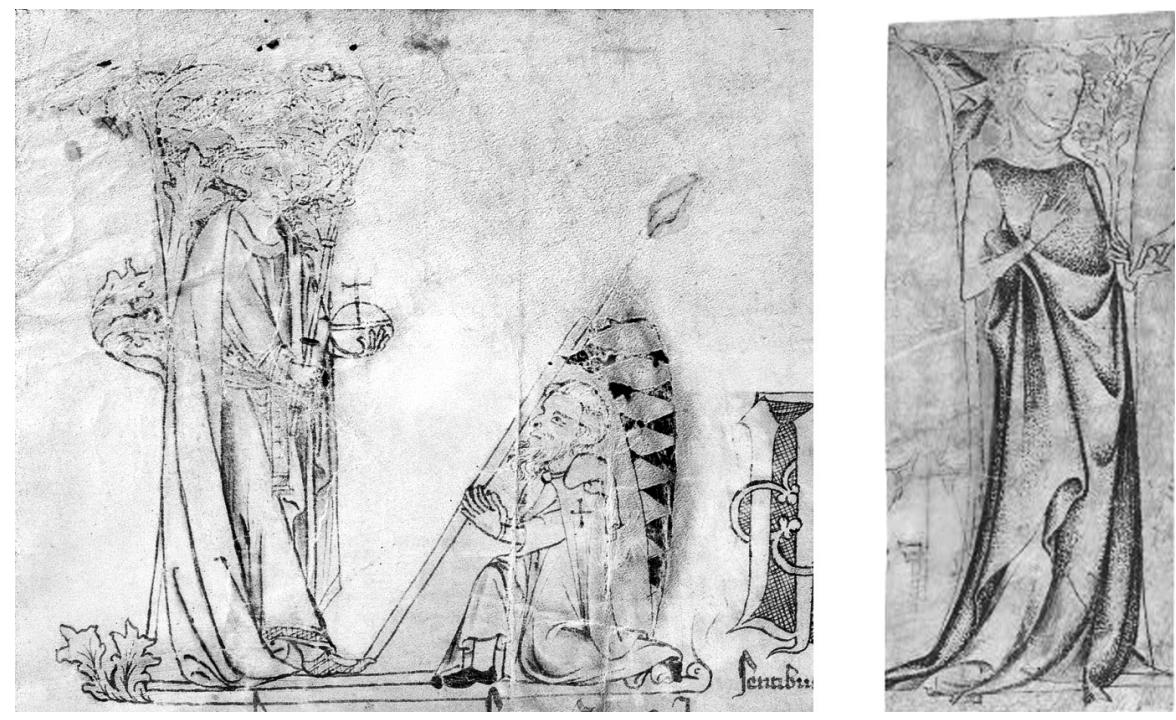

ILL. 39. $a$. Charte de Louis de Bavière pour l'ordre Teutonique, 15 novembre 1337 : initiale historiée de Léonard de Munich. Phot. : hv.spk-berlin.de. $-b$. Washington, Nat. Gall. of Art, inv. 1971.19.1. Phot. : images.nga.gov.

ILL. 40. Lettre de Louis de Bavière élevant Berthold VII de Henneberg-Schleusingen au rang de prince d'Empire, $1^{\text {er }}$ janvier 1330

(Thüringisches Staatsarchiv, Gemeinschaftl. Hennebergisches Archiv, Urkunde 220).

Phot. : C. Wrede, Leonhard....
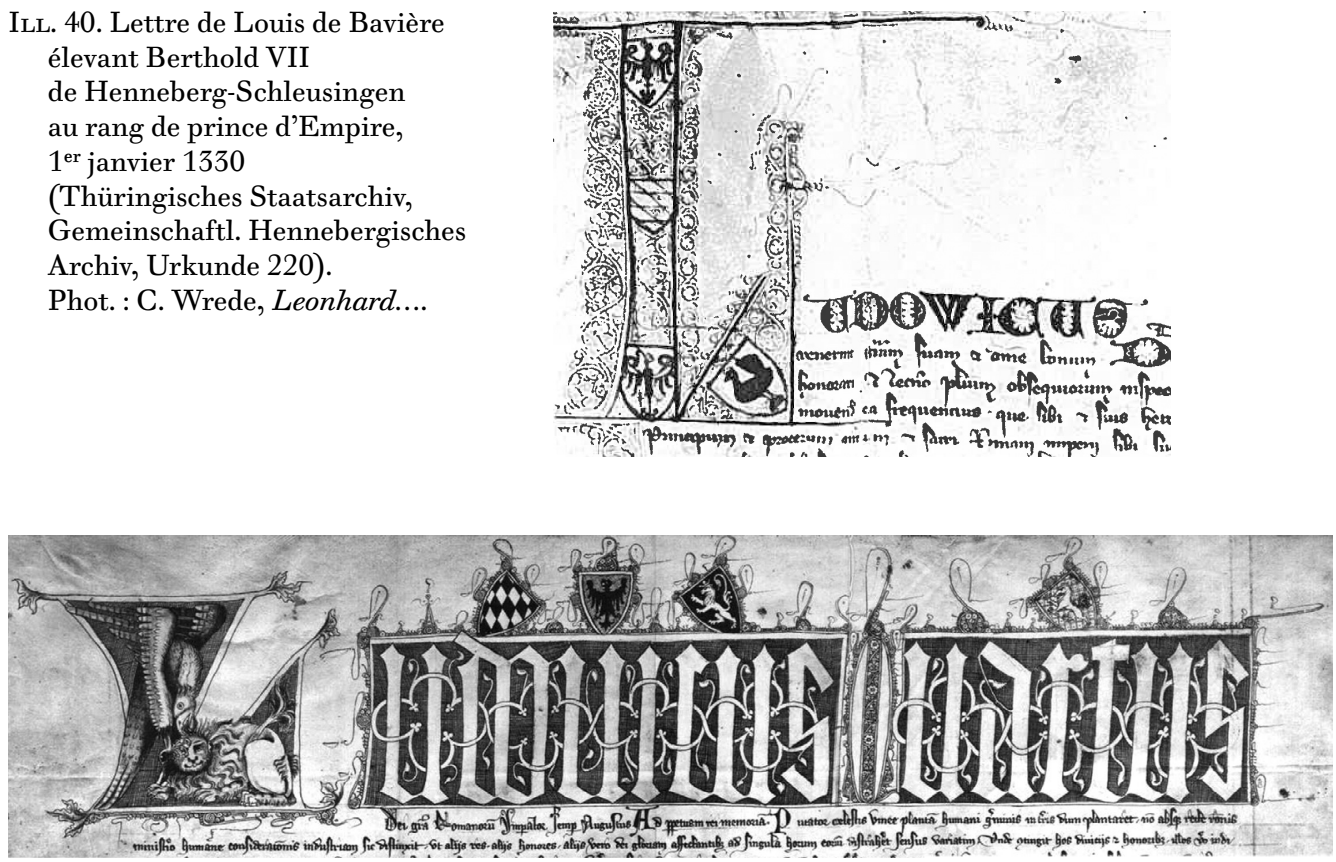

ILL. 41. Charte de Louis de Bavière pour l'hôpital du Saint-Esprit auprès de Saint-Sebald de Nuremberg, 24 février 1341 (Munich, Bayerisches Hauptstaatsarchiv, Kaiserselekt 784). Phot. : H. v. Sybel, T. Sickel, Kaiserurkunden... 

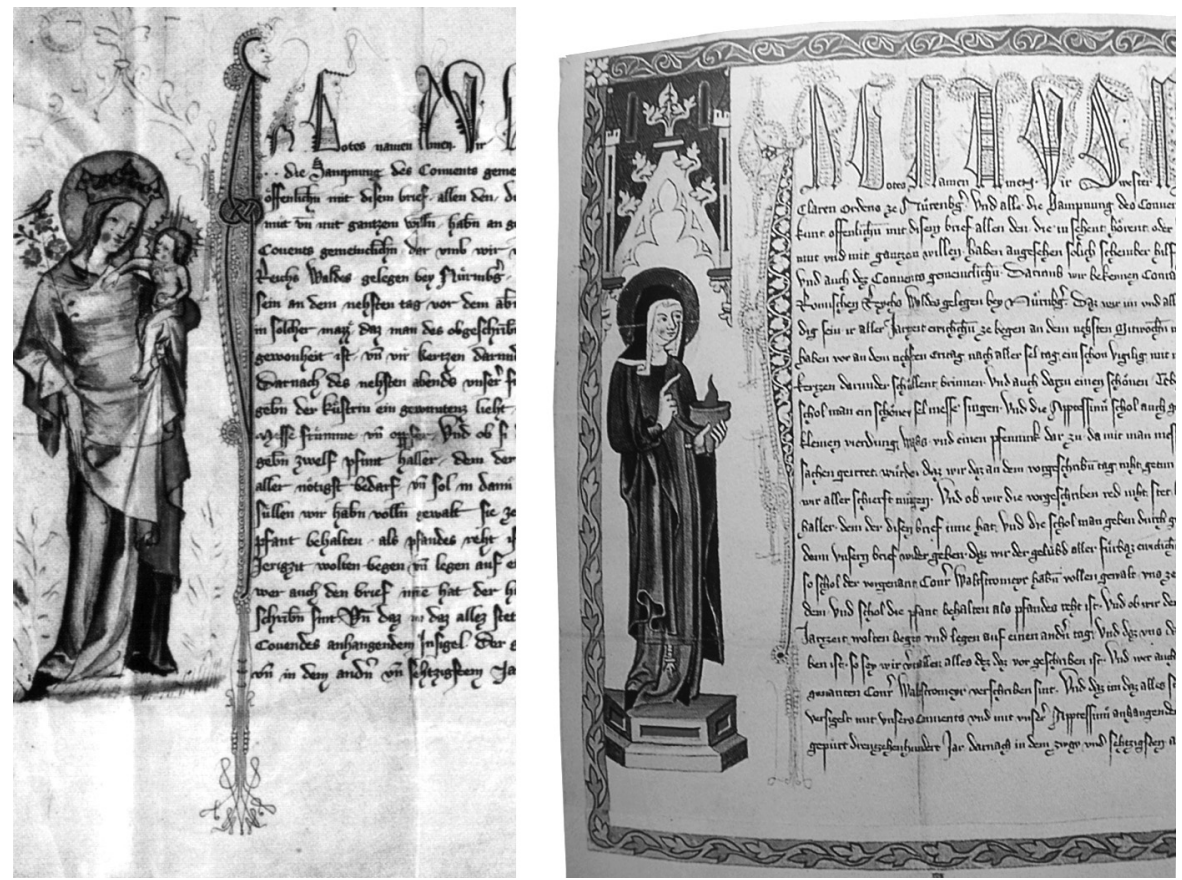

ILL. 42. Contre-lettres pour Konrad Waldstromer : $a$. du couvent Sainte-Catherine de Nuremberg, 23 juillet $1362-b$. du couvent Sainte-Claire de Nuremberg, 8 août 1362 (Nuremberg, Stadtarchiv, Reichsstadt Nürnberg, Urk. 1118, Faszikel 154). Phot.: Krone und Schleier...

ILL. 43. Acte notarié de Johannes de Cespite, 24 ou 25 avril 1360 (Bâle, Staatsarchiv des Kantons Basel Stadt, Klosterarchiv Domstift, Urk. 119). Phot. orig.

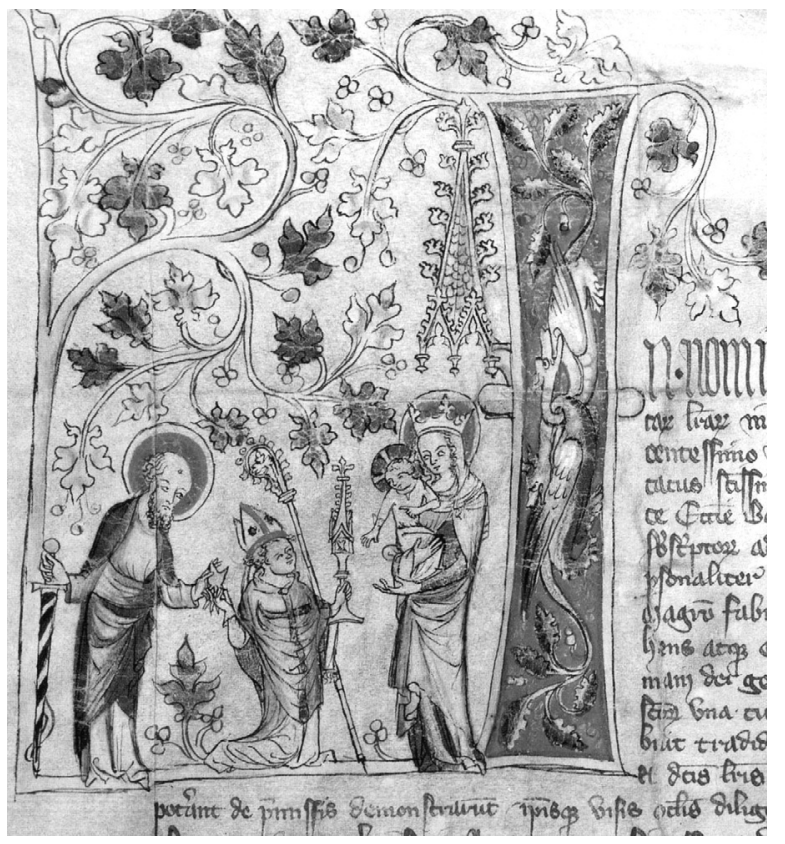




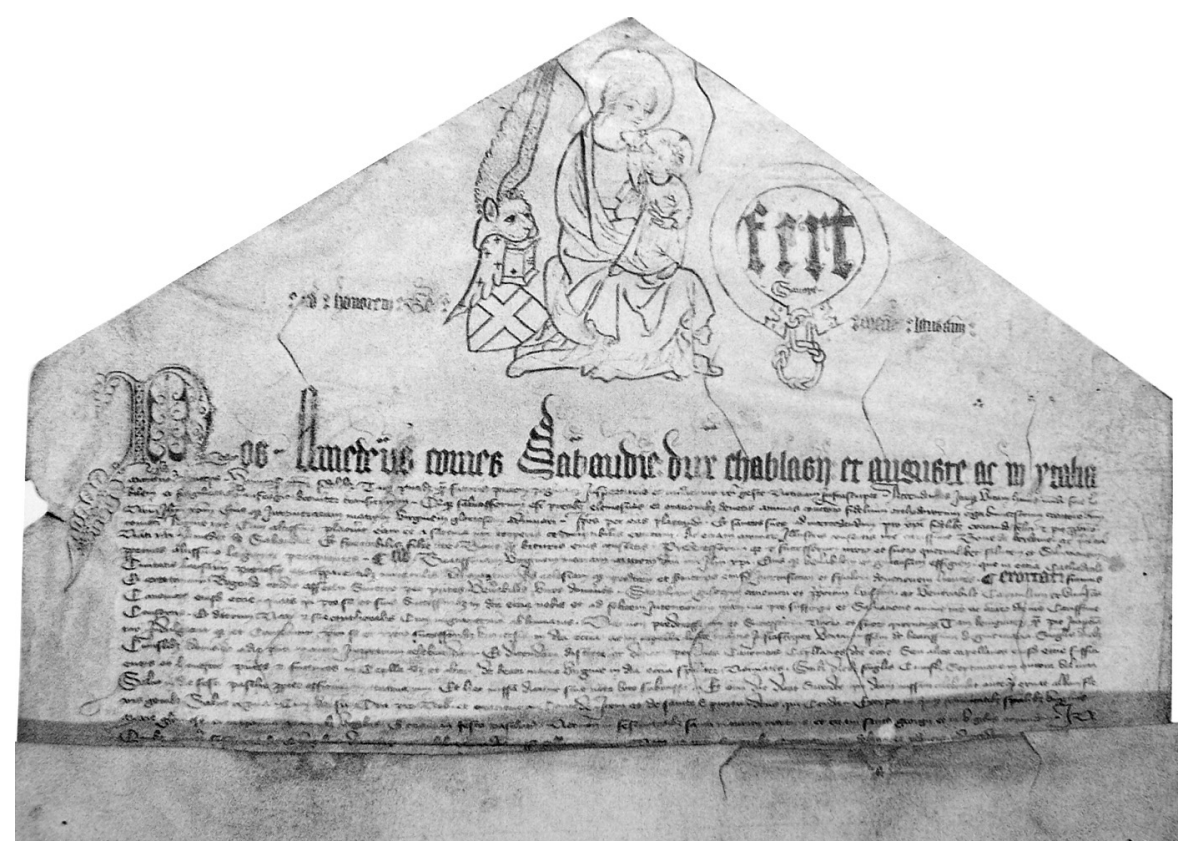

ILL. 44. Fondation d'une messe par Amédée VI de Savoie dans la chapelle Notre-Dame de la cathédrale de Lausanne, 29 janvier 1382 (Turin, Arch. di Stato, Corte, Materie ecclesiastiche, Arcivescovadi e vescovadi stranieri, Vescovado di Losanna, mazzo 1, fasc. 5). Phot. : Il gotico nelle Alpi...

ILL. 45. Fragment d'une kétouba, 1391-1392 (Vienne, Österr. Nationalbibl., Cod. Hebr. 218). Phot. : M. Keil, Gemeinde und Kultur...

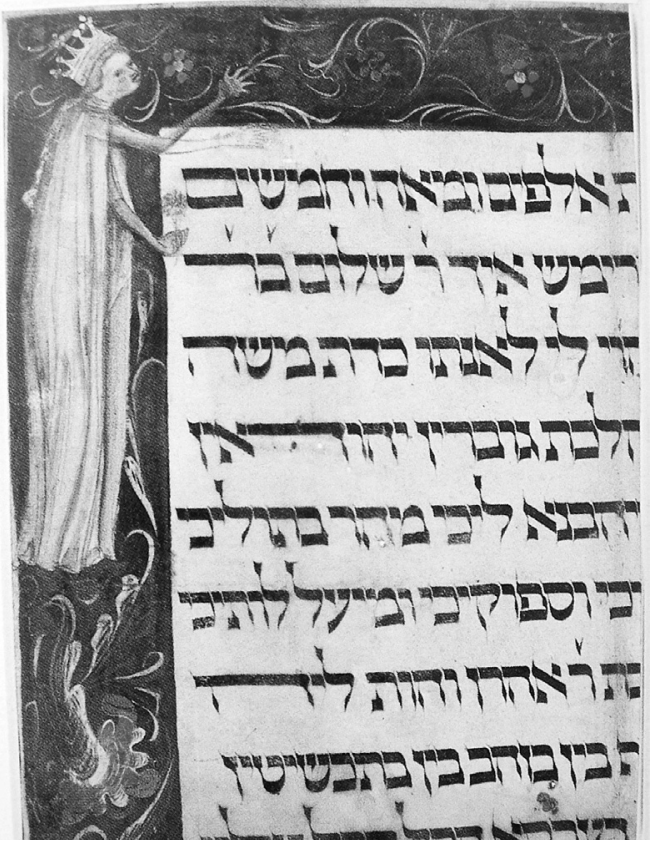



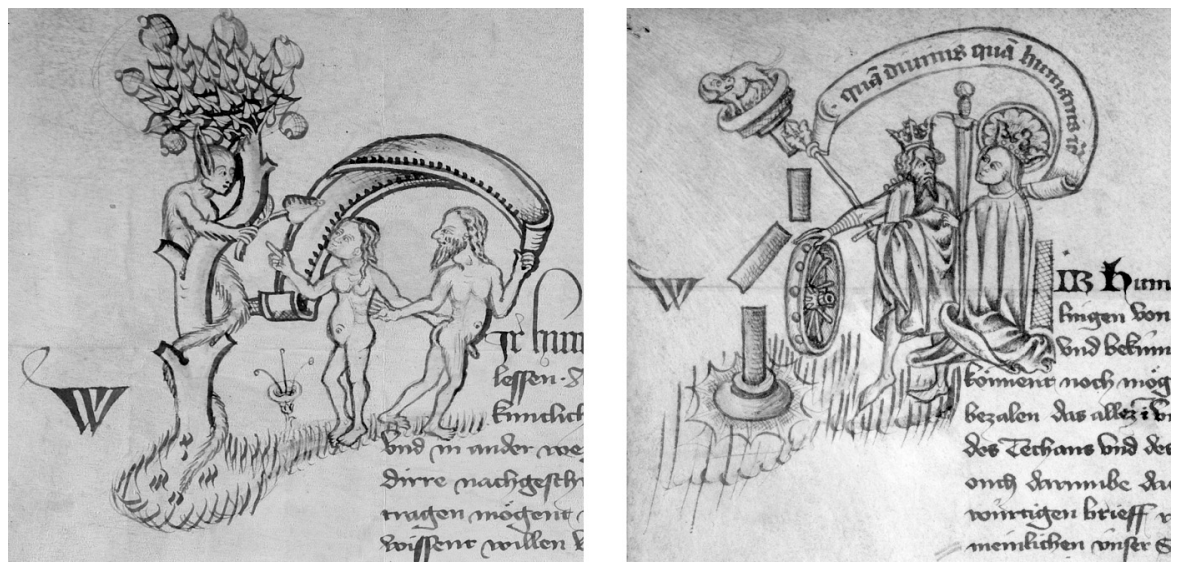

ILL. 46. $a-b$. Vente à la ville de Bâle, par l'évêque Humbert de Neuenburg et le chapitre cathédral, des châteaux et villes de Waldenburg, Homburg et Liestal, 26 juillet 1400 : initiales (Liestal, Staatsarchiv Basel-Landschaft, Altes Archiv, Urk. 179; Bâle, Staatsarchiv Basel Stadt, Städtische Urk. 788a). Phot. orig.

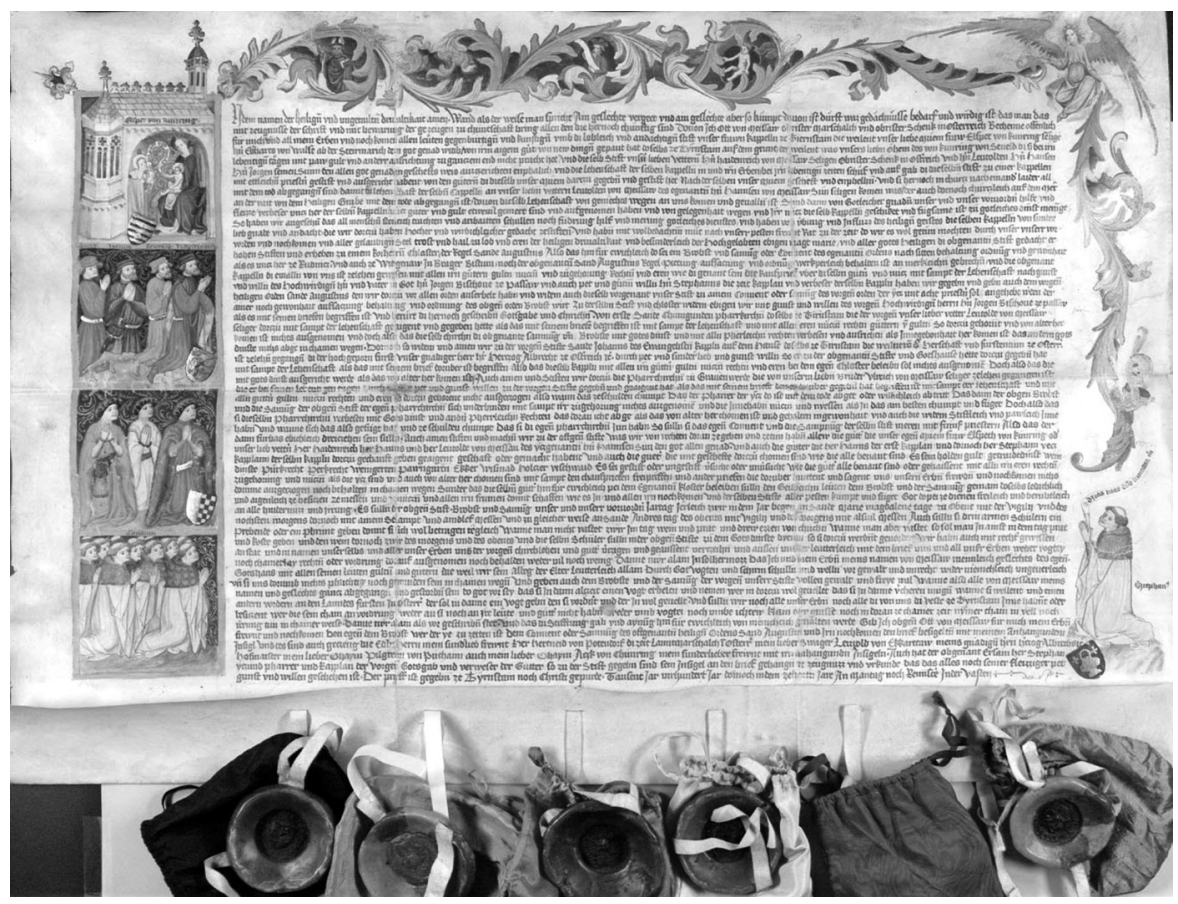

ILl. 47. Fondation du couvent d'Augustins de Dürnstein, 17 février 1410 (Herzogenburg, Stiftsarchiv, D. n. 147). Phot. : monasterium.net 


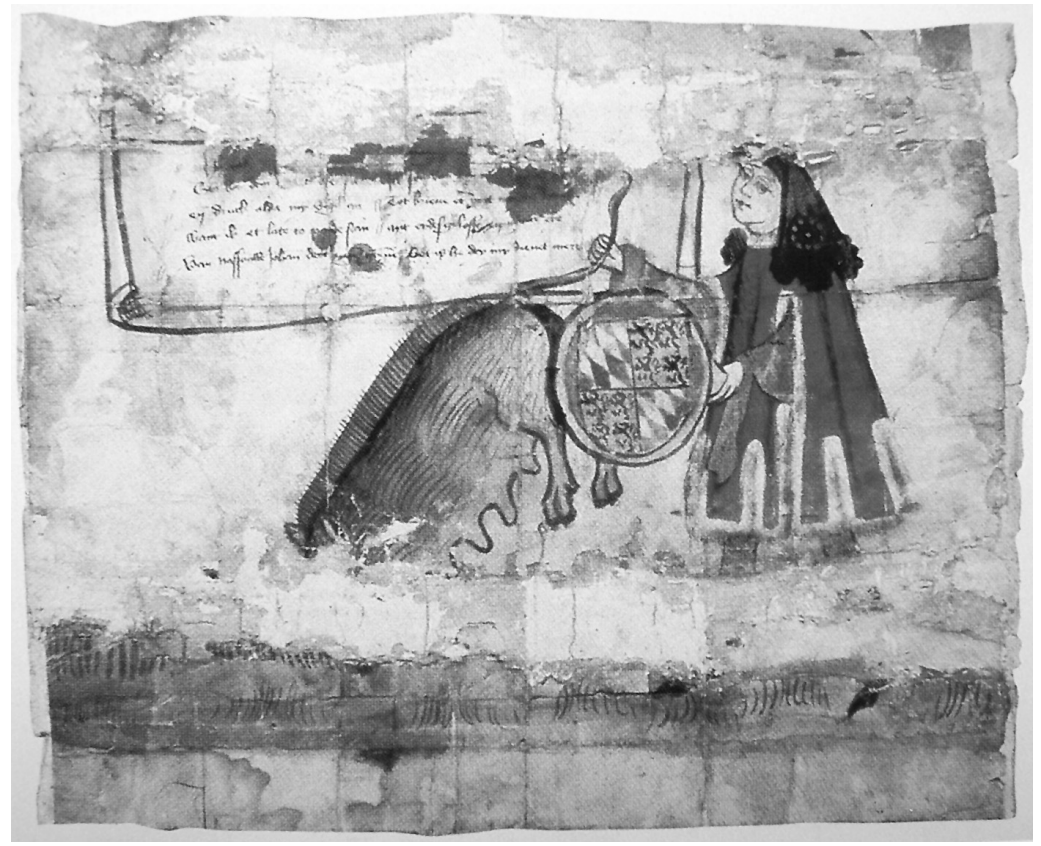

ILL. 48. Lettre diffamatoire du comte Jean III de Nassau-Dillenburg contre le duc Jean de Bavière, comte de Hollande, v. 1420 (Wiesbaden, Hess. Hauptstaatsarchiv, Abt. 170, $\mathrm{n}^{\circ}$ 1026). Phot. : M. Lentz, Konflikt...

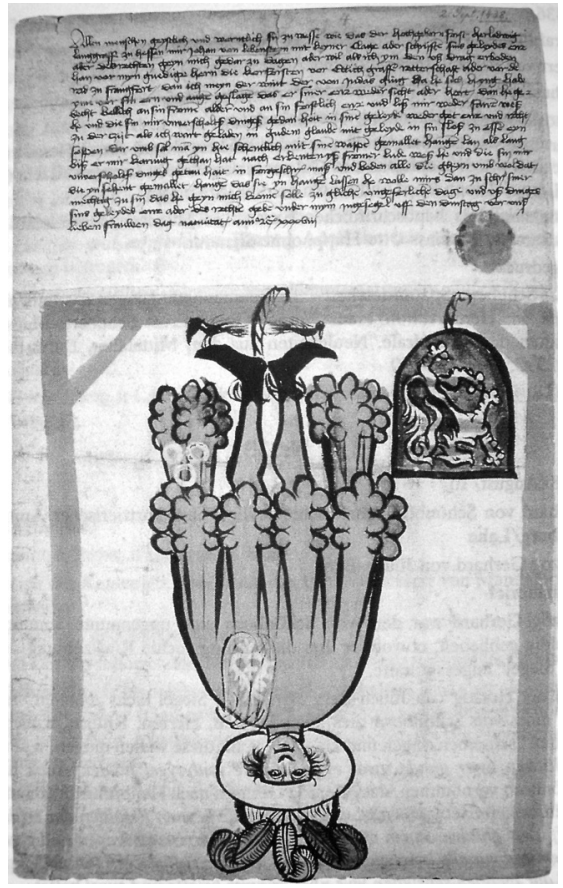

ILL. 49. Lettre diffamatoire du chevalier Jean de Löwenstein contre le landgrave Louis I ${ }^{\text {er }}$ de Hesse, 2 septembre 1438 (Francfort, Institut für Stadtgeschichte [Stadtarchiv], Reichssachen I, no 3605). Phot. : Lentz, Konflikt...

\section{(Page suivante :)}

ILL. 50. Lettre diffamatoire du comte Bernard de Moers (Meurs), 20 novembre 1493 (Zutphen, Regionaal Archif Zutphen, Municipal archif Zutphen, inv. 2386). Phot. : www.regionaalarchiefzutphen.nl.

ILL. 51. Gravures infamantes :

$a$. Nicolas d'Abensberg et ses armes pendus à l'envers, 1461. Phot. The illustrated Bartsch... - b. Le sceau armorié de Heinz de Gut(t)enberg souillé par une vache, v. 1490. Phot. : F. Eisermann, Verzeichnis... 

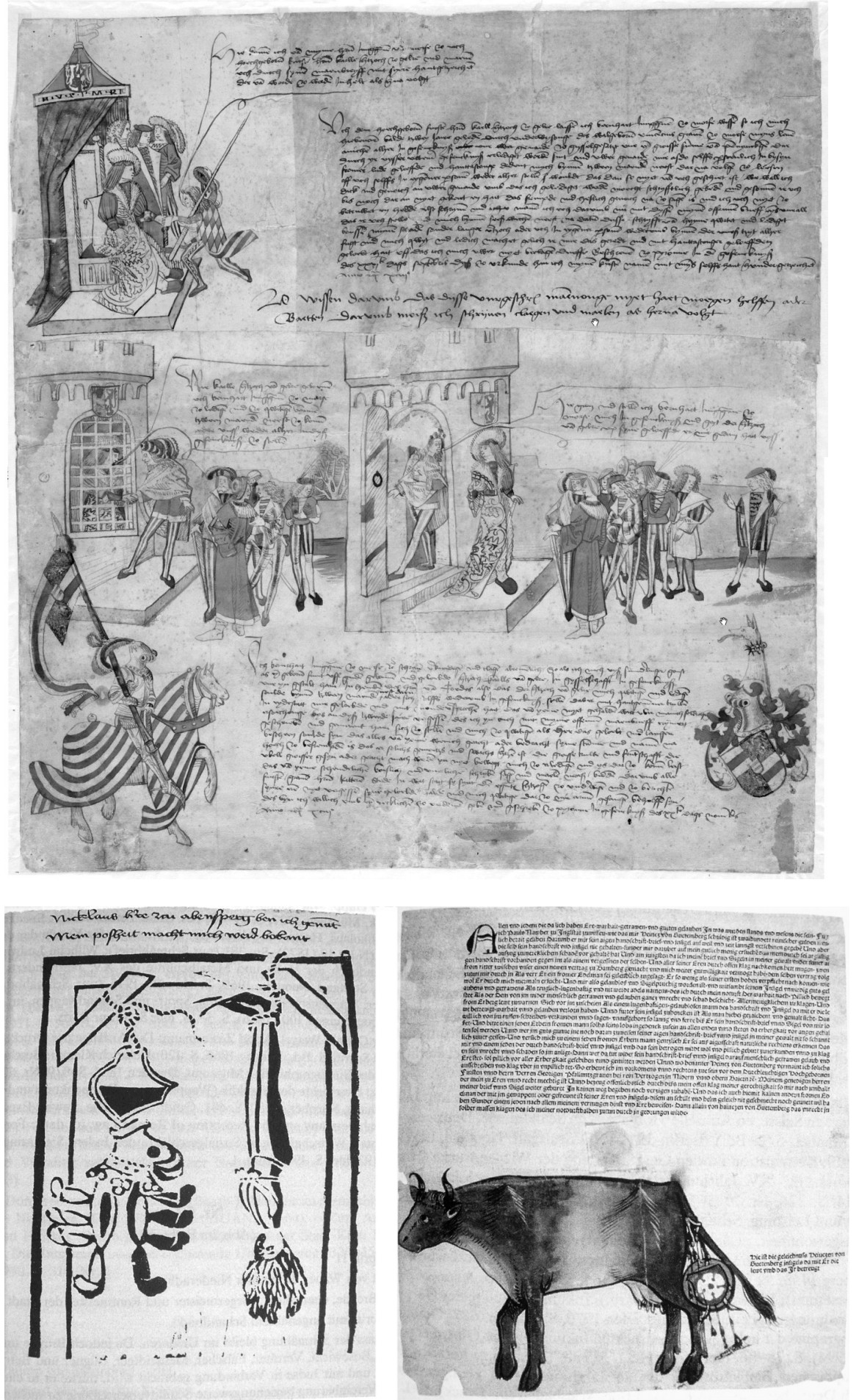

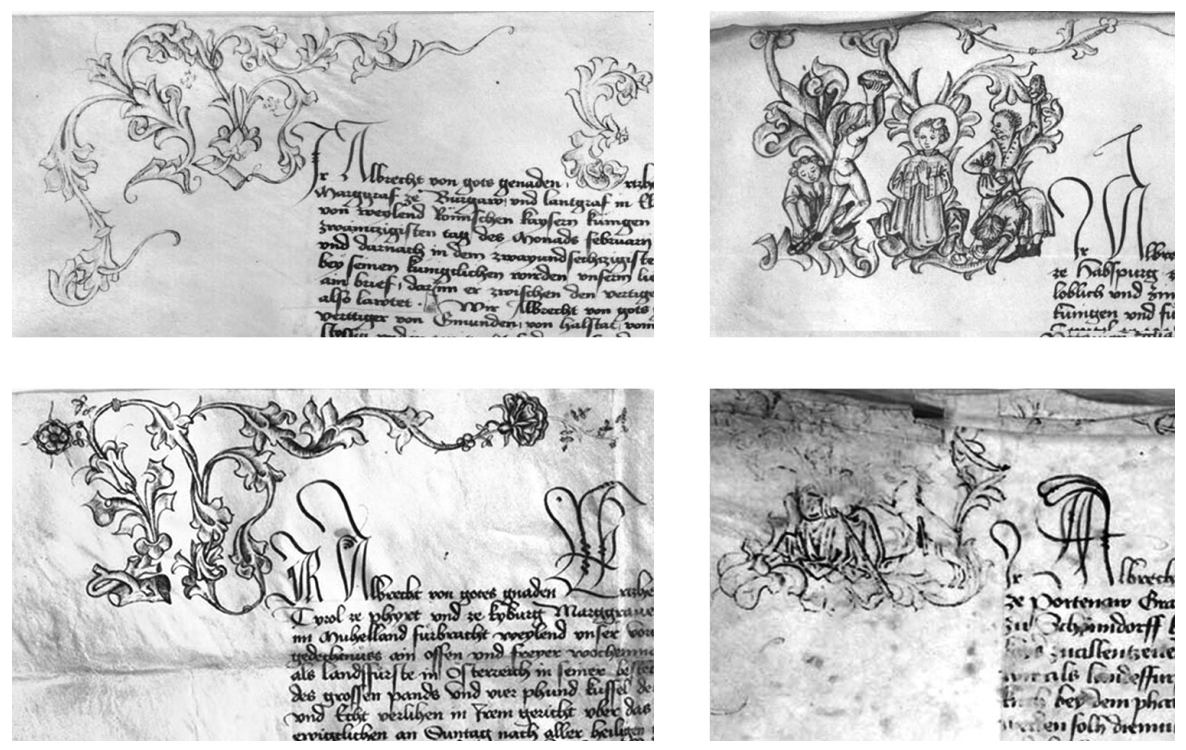

ILL. 52. Confirmations des privilèges de quatre maisons religieuses par l'archiduc Albert VI d'Autriche $: a$. Lambach; $b$. Passau; $c$. Schlägl; $d$. Vöcklabruck, 1458-1460. Phot. : monasterium.net.
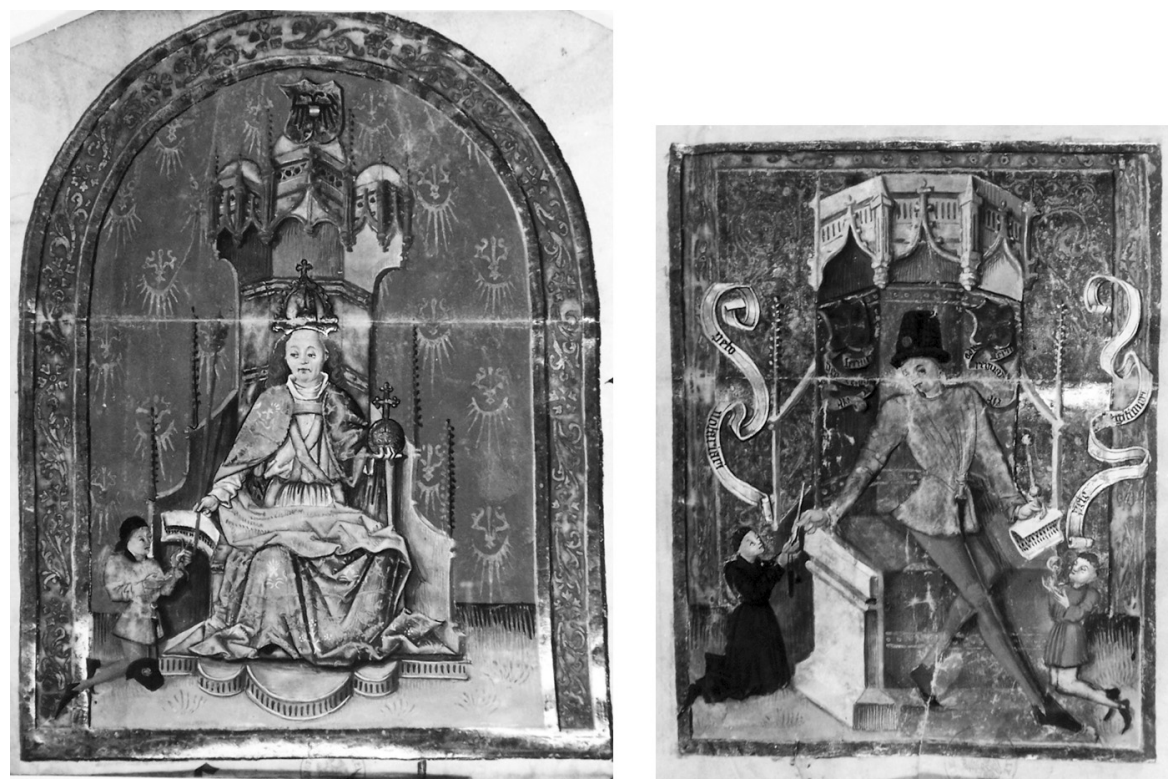

ILL. 53. $a-b$. Acte notarié de Raoul Goullette ou Houllette, copie d'une charte de Frédéric III du 11 juin 1465, nommant Gérard du Champ de Liège comte palatin impérial : détails (Paris, Bibl. nat. France, ms. Clairambault 1052, fol. 20). Phot. : coll. Gerhard Schmidt. 


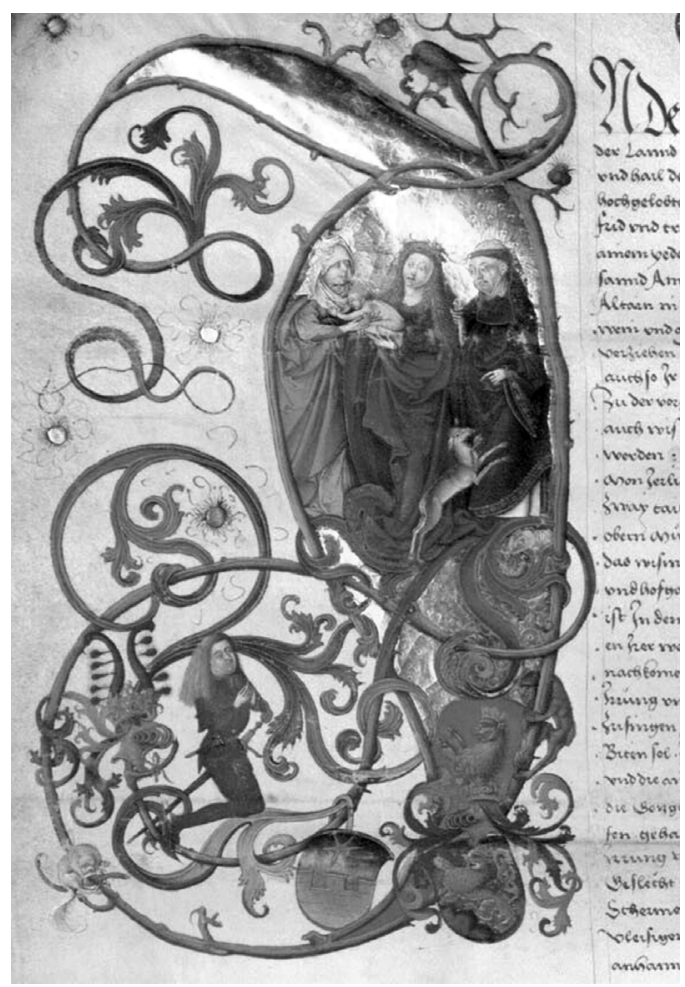

ILL. 54. Lettre de fondation de Gaspard de Roggendorf pour l'église paroissiale de Pöggstall, 11 novembre 1494 (St. Pölten,

Diözesanarchiv, sub dato). Phot. : monasterium.net.

\section{ILL. 55. Lettre patente} de Maximilien I ${ }^{e r}$ réglant la pêcherie dans le Danube et ses affluents, 24 février 1506 (Vienne, Stadt- und Landesarchiv, Hauptarchiv, Urk. 6015). Phot. : monasterium.net.

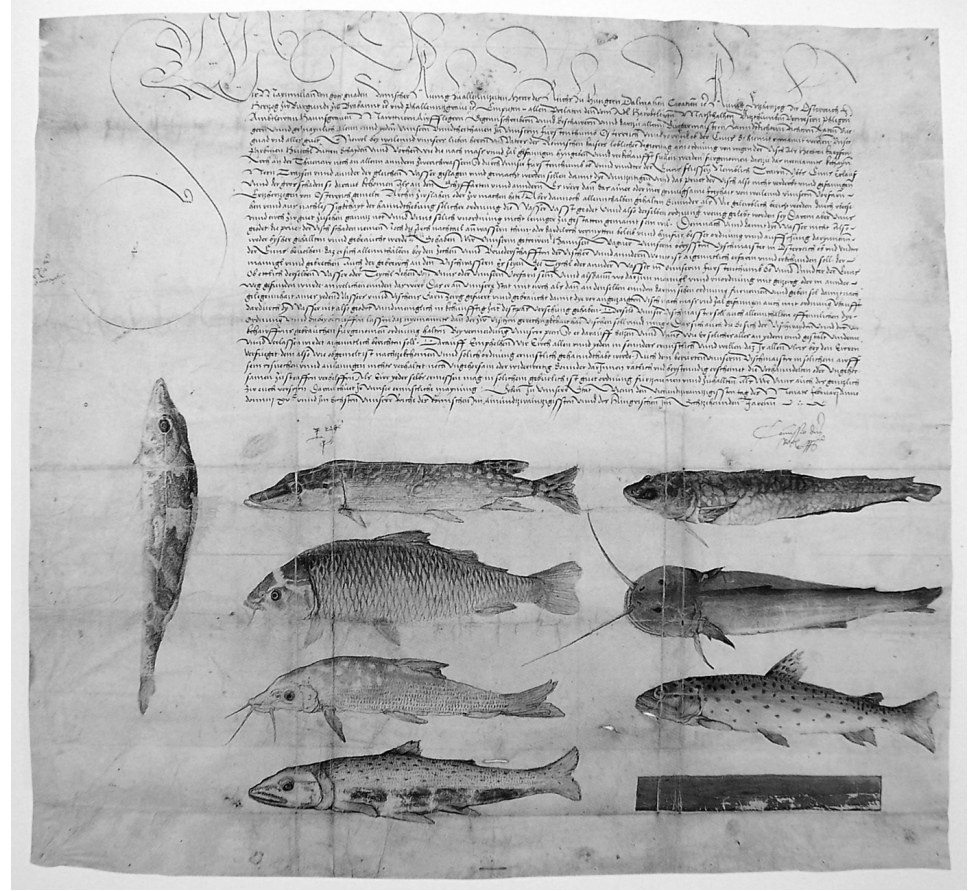

